UC-NRLF

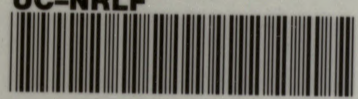

В 3091336 

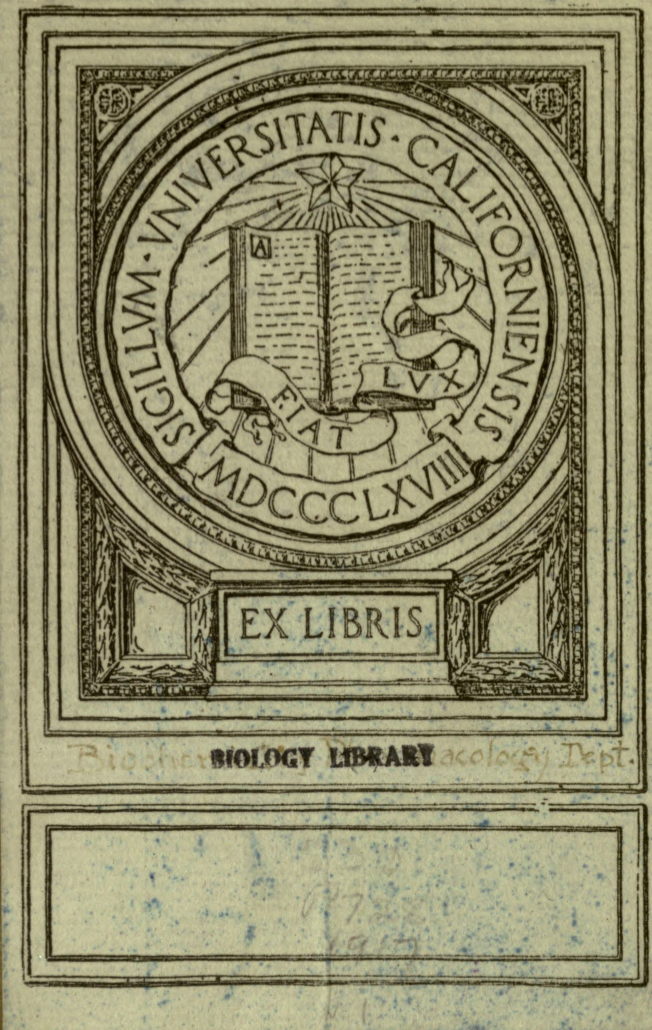


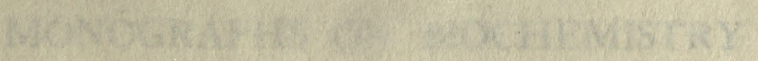

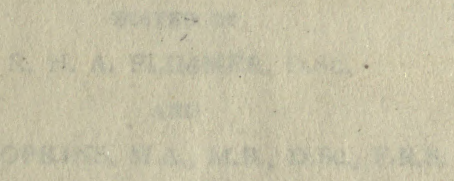





\section{MONOGRAPHS ON BIOCHEMISTRY}

\section{EDITED BY}
R. H. A. PLIMMER, D.SC.

AND

F. G. HOPKINS, M.A., M.B., D.Sc., F.R.S. 


\section{MONOGRAPHS ON BIOCHEMISTRY.}

ROYal 8vo.

$\checkmark$ THE NATURE OF ENZYME ACTION. By W. M. BAyliss, D.Sc., F.R.S. Third Edition. 5s. 6d. net.

$\checkmark$ THE CHEMICAL CONSTITUTION OF THE PROTEINS. By R. H. A. Plimmer, D.Sc.

Third Edition, Part I.-Analysis.

Second Edition, Part II.-Synthesis, etc. 4s. net.

THE VEGETABLE PROTEINS. By Thomas B. OsBorne, Ph.D. New Impression. 4s. net.

THE SIMPLE CARBOHYDRATES AND THE GLUCOSIDES. By E. FrankLand ARmstrong, D.Sc., Ph.D. Second Edition. 5s. 6d. net.

$\checkmark$ THE FATS. By J. B. Leathes, F.R.S., M.A., M.B., F.R.C.S.

ALCOHOLIC FERMENTATION. By A. Harden, Ph.D., D.Sc., F.R.S. Second Edition. 4s. 6d. net.

THE PHYSIOLOGY OF PROTEIN METABOLISM. By E. P. CathCaRT, M.D., D.Sc. 4s. 6d. net.

SOIL CONDITIONS AND PLANT GROWTH. By E. J. Russell, D.Sc., F.R.S. Third Edition. 6s. 6d. net.

OXIDATIONS AND REDUCTIONS IN THE ANIMAL BODY. By H. D. DAKIN, D.Sc., F.R.S. 4s. net.

THE SIMPLER NATURAL BASES. By G. BARger, M.A., D.Sc. 6s. 6d. net.

NUCLEIC ACIDS. THEIR CHEMICAL PROPERTIES AND PHYSIOLOGICAL CONDUCT. By Walter Jones, Ph.D. 4s. net.

THE RESPIRATORY EXCHANGE OF ANIMALS AND MAN. By August Krogh, Ph.D. 6s. 6d. net.

The following are in preparation :-

THE DEVELOPMENT AND PRESENT POSITION OF BIOLOGICAL CHEMISTRY. By F. Gowland Hopkins, M.A., M.B., D.Sc., F.R.S.

THE POLYSACCHARIDES. By ARTHUR R. LiNG, F.I.C.

COLLOIDS. By W. B. HARDY, M.A., F.R.S.

PHYSICAL METHODS, USED IN BIOLOGICAL CHEMISTRY. By S. G. Walpole, D.Sc.

PROTAMINES AND HISTONES. By A. Kossel, $\mathrm{Ph}$.D.

LECITHIN AND ALLIED SUBSTANCES. By H. MACLEAN, M.D., D.Sc.

THE ORNAMENTAL PLANT PIGMENTS. By A. G. PERKIN, F.R.S.

CHLOROPHYLL AND HAMOGLOBIN. By $\mathrm{H}$. J. PAGE, B.Sc.

LONGMANS, GREEN AND CO.,

LONDON, NEW YORK, BOMBAY, CALCUTTA, AND MADRAS. 
T H E

\section{CHEMICAL CONSTITUTION \\ oF}

\section{THE PROTEINS}

BY

R. H. A. PLIMMER, D.Sc.

UNIVERSITY READER IN PHYSIOLOGICAL CHEMISTRY, UNIVERSITY COLLEGE, LONDON

IN THREE PARTS

PART I

ANALYSIS

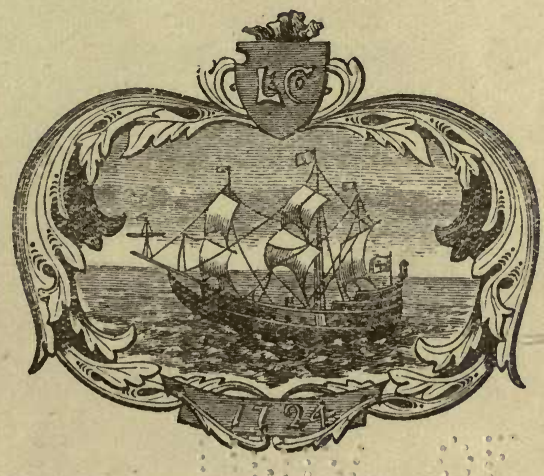

WIFH. DIAGRAMS

\section{THIRD EDITION}

LONGMANS, GREEN AND CO. 39 PATERNOSTER ROW, LONDON FO'URTH AVENUE \& 30TH STREET, NEW YORK BOMBAY, CALCUTTA, AND MADRAS 



\section{Dedicateo}

Tо

\section{EMIL FISCHER}

THE MASTER OF

ORGANIC CHEMISTRY IN ITS RELATION TO BIOLOGY 



\section{GENERAL PREFACE.}

THE subject of Physiological Chemistry, or Biochemistry, is enlarging its borders to such an extent at the present time, that no single text-book upon the subject, without being cumbrous, can adequately deal with it as a whole, so as to give both a general and detailed account of its present position. It is, moreover, difficult, in the case of the larger text-books, to keep abreast of so rapidly growing a science by means of new editions, and such volumes are therefore issued when much of their contents has become obsolete.

For this reason, an attempt is being made to place this branch of science in a more accessible position by issuing a series of monographs upon the various chapters of the subject, each independent of and yet dependent upon the others, so that from time to time, as new material and the demand therefor necessitate, a new edition of each monograph can be issued without re-issuing the whole series. In this way, both the expenses of publication and the expense to the purchaser will be diminished, and by a moderate outlay it will be possible to obtain a full account of any particular subject as nearly current as possible.

The editors of these monographs have kept two objects in view : firstly, that each author should be himself working at the subject with which he deals; and, secondly, that a Bibliography, as complete as possible, should be included, in order to avoid cross-references, which are apt to be wrongly cited, and in order that each monograph may yield full and independent information of the work which has been done upon the subject.

It has been decided as a general scheme that the volumes first issued shall deal with the pure chemistry of physiological 
products and with certain general aspects of the subject. Subsequent monographs will be devoted to such questions as the chemistry of special tissues and particular aspects of metabolism. So the series, if continued, will proceed from physiological chemistry to what may be now more properly termed chemical physiology. This will depend upon the success which the first series achieves, and upon the divisions of the subject which may be of interest at the time.

R. H. A. P.

F. G. H. 


\section{PREFACE TO THIRD EDITION.}

WORK upon the chemistry of the proteins is always in progress, and a large amount of new matter has required incorporation in this edition. At the same time a thorough revision has been made, and the former omission of references in the text to the papers quoted in the bibliography has been remedied.

The new matter in this edition is mainly connected with the analysis of proteins. It has therefore been thought advantageous to divide this part of the monograph into two: Part I. Analysis. Part II. The Amino Acids. New or improved analytical methods are constantly being devised, whilst the description of the amino acids is a more definite part of the subject matter.

The division into two parts will be a saving of labour to author, publisher and printer, and the expense to the purchaser will be lessened. The editors mentioned these considerations at the time the monographs were first issued.

R. H. A. P.

April, r.9r7. 



\section{CONTENTS OF PART I.}

\section{INTRODUCTION}

I. HydROLYSIS - - - - - - - - - - 9

II. The Isolation and Estimation of the Units - - - - 15

A. The Mono-amino Acids - - - - - - - 17

Tyrosine - - - - - - - - - - - - 17

(I) Isolation and Gravimetric Estimation - - - - $\quad$ I7

(2) Colorimetric Estimation - - - - - - 20

(3) Estimation by Bromination - - - - - - 22

Cystine - - - - - - - - - - - 24

(I) Isolation and Gravimetric Estimation - _ _ - $\quad 24$

(2) Separation of Cystine and Tyrosine - - - - 25

TRYPTOPHAN - - - - - - - - - 27

(1) Isolation and Gravimetric Estimation - - _ - 27

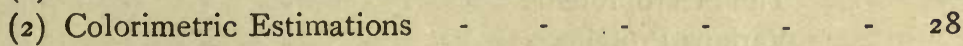

(3) Estimation by Bromination - - - - - - 32

The other Mono-Amino Acids - - $\quad$ - $\quad$ - $\quad 33$

(r) Isolation of Glutamic Acid as Hydrochloride - - 33

(ra) Isolation of Glutamic Acid as Zinc Salt _ - - 34

(Ib) Isolation of Glutamic and Aspartic Acids as Silver Salts 34

(Ic) Isolation of Glutamic and Aspartic Acids as Calcium Salts 34

(2) Esterification - - - - - - - - 35

(3) Isolation of Glycine as Ester Hydrochloride - - $\quad 36$

(4) Extraction of the Esters of the Amino Acids - - - 37

(5) Fractional Distillation of the Esters in Vacuo - - 40

(6) The Isolation of the Individual Mono-amino Acids - 42

(a) Proline - - - - - _ - - - 43

(b) Glycine, Alanine, Valine, Leucine, and Isoleucine - - 44

i. Separation of Valine from Leucine and Isoleucine - $\quad 45$

ii. Valine - - - _ - _ - - 46

iii. Leucine and Isoleucine -

iv. Separation of Valine and Alanine - - _ - - $\quad 48$

v. Separation of Glycine and Alanine - - - - - $\quad$ - $5 \mathrm{I}$

(c) Phenylalanine - + - + - + +52 
(d) Aspartic Acid - - - - - - - - - 52

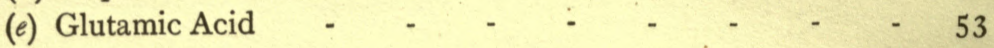

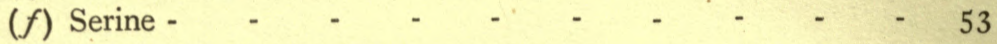

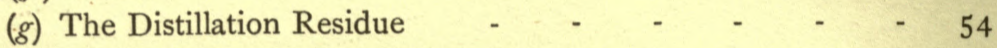

(h) The Isolation of Oxyproline - - $\quad-\quad$ - $\quad-\quad-54$

B. The Di-Amino Acids - - - - - - - - $\quad$ - 55

I. Hydrolysis and Estimation of Protein - - - $\quad$ - 55

II. Removal of Sulphuric Acid. Estimation of Ammonia and Humin Nitrogen - - $\quad$ - $\quad$ - $\quad$ - $\quad$ - 55

III. Precipitation of Arginine and Histidine - - . $\quad 5^{6}$

IV. Estimation and Isolation of Histidine - - - $\quad$ - 57

V. Estimation and Isolation of Arginine - - - $\quad$ - 59

VI. Estimation and Isolation of Lysine - - - - - 60

Colorimetric Estimation of Histidine - - - - - 6I

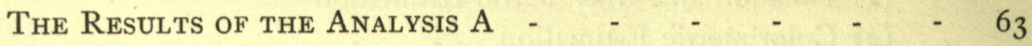

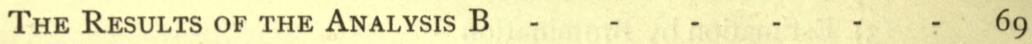

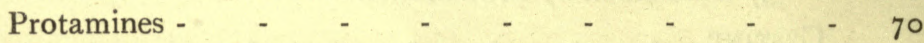

Histones - - - - - - - - - 72

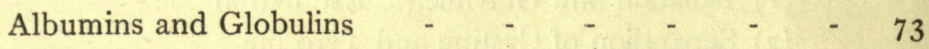

The Vegetable Proteins - $\quad$ - $\quad$ - $\quad$ - $\quad$ - $\quad$ - 74

Phosphoproteins - - - - - - - - - - $\quad$ - 76

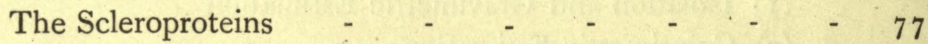

Various Proteins - - - - - - - - - - - $8 \mathrm{I}$

Derivatives of Proteins - _ - - _ - - - - 82

Analysis of Proteins by the Distribution of the Various

KindS OF Nitrogen - $\quad$ - $\quad$ - $\quad$ - $\quad$ - $\quad$ - $\quad$ - 85

A. Distribution of the Nitrogen in Three Groups - $\quad$ - 87

B. Distribution of the Nitrogen in Seven Groups - $\quad$ - 89

I. Estimation of Amino Nitrogen - - - - $\quad$ - 89

II. Estimation of the Different Groups of Amino Acids - 97

Analytical Data - $\quad$ - $\quad$ - $\quad$ - $\quad$ - $\quad$ - $\quad$ -

I. Composition of Proteins in Amino Acids - - - III

II. Distribution of Nitrogen in Three Groups - - - I3I

III. Distribution of Nitrogen in Seven Groups - _ - - I32 $^{2}$

IV. Distribution of Nitrogen in Seven Groups, in Foodstuffs I 34

V. Effect of Carbohydrate on the Distribution of Nitrogen in

- Seven Groups - - - $\quad$ - $\quad$ - $\quad$ - $\quad$ - $\quad$ - $\quad$ - 135

TABLE : Milligrams of Amino Nitrogen corresponding to I c.c.

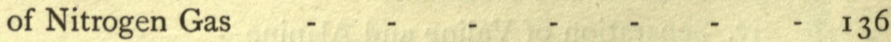

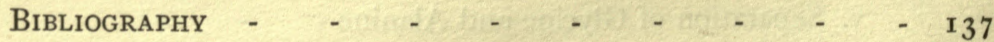

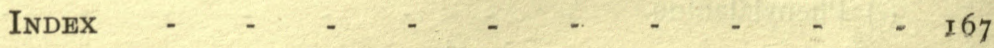




\title{
THE CHEMICAL CONSTITUTION OF THE PROTEINS.
}

\author{
PART I. \\ INTRODUCTION.
}

THE proteins, of which we know some forty or fifty natural ones occurring in both animals and plants, are divided according to their origin, solubility, coagulability on heating and other physical characteristics into the following groups:-

I. Protamines, e.g., salmine, sturine, clupeine, scombrine, cyclopterine, cyprinine.

II. Histones, e.g., thymus histone, Lota histone, Gadus histone, histone from blood corpuscles.

III. Albumins, e.g., ovalbumin, conalbumin, serum albumin, various vegetable albumins.

IV. Globulins, e.g., serum globulin, fibrinogen and its derivative fibrin, myosinogen and its derivative myosin occurring in the muscles of animals ; legumin, conglutin, amandin occurring in plants, and some crystalline vegetable globulins, e.g., edestin, excelsin.

V. Glutelins, e.g., glutenin in wheat, oryzenin in rice, soluble in very dilute alkali.

VI. Gliadins, e.g., wheat-gliadin, hordein, zein, occurring in cereals and soluble in $70-80$ per cent. alcohol.

VII. Phosphoproteins, e.g., caseinogen, vitellin, ichthulin.

VIII. Scleroproteins, e.g., keratin from hair, horn, feathers, eggmembrane. Collagen, gelatin, elastin. Silk-fibroin, silkgelatin.

IX. Conjugated Proteins :-

(a) Nucleoproteins : nucleic acid in combination with protein, generally I., II., III.

(b) Chromoproteins : chromogenic substance in combination with protein, e.g., hæmoglobin.

PT. I. 
(c) Giucoproteins sarbohydrate in combination with protein, e.g., mucin, ovomucoid.

X. Derivatives of Proteins :-

(a) Metaproteins, e.g., acid-albumin, alkali-globulin.

(b) Proteoses, e.g., caseose, albumose, globulose.

(c) Peptones, e.g., fibrinpeptone.

(d) Polypeptides, e.g., glycyl-alanine, leucyl-glutamic acid, a tetrapeptide ( 2 glycine $+\mathrm{I}$ alanine $+\mathrm{I}$ tyrosine).

Except the protamines, the histones, and the derivatives of the proteins, all the proteins contain carbon, hydrogen, nitrogen, sulphur and oxygen, and they possess the following elementary composition :-

C 5. I-55 per cent.

$\begin{array}{lrl}\mathrm{H} & 7 & \\ \mathrm{~N} & 15-19 & \\ \mathrm{~S} 0 & 0.4-2 \cdot 5 & \\ \mathrm{O} & 20-30 & \end{array}$

from which a formula such as

$$
\mathrm{C}_{726} \mathrm{H}_{1174} \mathrm{~N}_{194} \mathrm{~S}_{3} \mathrm{O}_{214}
$$

which is that of globin, the basis of hæmoglobin, can be calculated.

The phosphoproteins and the nucleoproteins contain also the element phosphorus; in the former, probably combined directly with one of the constituents of the protein molecule ; in the latter, combined with a pyrimidine or purine base or a carbohydrate ; these substances, together with phosphorus, constitute nucleic acid.

Investigations upon their chemical constitution have been carried on now for nearly a century, but it is only since I90I that, by the work of Emil Fischer and his pupils, any clear view has really been obtained of their actual constitution. The main result of these investigations is that the protein molecule is built up of a number of amino acids, belonging to four different series, and of which the following have been definitely determined:-

A. Monoaminomonocarboxylic acids.

I. Glycine, $\mathrm{C}_{2} \mathrm{H}_{5} \mathrm{NO}_{2}$, or amino-acetic acid.

$\mathrm{CH}_{2} \cdot\left(\mathrm{NH}_{2}\right) \cdot \mathrm{COOH}$

2. Alanine, $\mathrm{C}_{3} \mathrm{H}_{7} \mathrm{NO}_{2}$, or $\alpha$-aminopropionic acid.

$\mathrm{CH}_{3} \cdot \mathrm{CH}\left(\mathrm{NH}_{2}\right) \cdot \mathrm{COOH}$

3. Valine, $\mathrm{C}_{5} \mathrm{H}_{11} \mathrm{NO}_{2}$, or $\alpha$-aminoisovalerianic acid.<smiles>CC(C)C(N)C(=O)O</smiles> 
4. Leucine, $\mathrm{C}_{6} \mathrm{H}_{13} \mathrm{NO}_{3}$, or $\alpha$-aminoisocaproic acid.

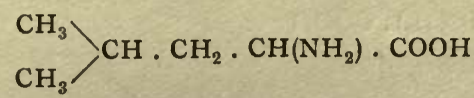

5. Isoleucine, $\mathrm{C}_{6} \mathrm{H}_{13} \mathrm{NO}_{2}$, or $\alpha$-amino- $\beta$-methyl- $\beta$-ethyl-propionic acid.

$\mathrm{CH}_{3}$

$\mathrm{C}_{2} \mathrm{H}_{5}$

$\mathrm{CH} \cdot \mathrm{CH}\left(\mathrm{NH}_{2}\right) \cdot \mathrm{COOH}$

6. Phenylalanine, $\mathrm{C}_{9} \mathrm{H}_{11} \mathrm{NO}_{2}$, or $\beta$-phenyl-a-aminopropionic acid.

$$
\mathrm{C}_{6} \mathrm{H}_{5} \cdot \mathrm{CH}_{2} \cdot \mathrm{CH}\left(\mathrm{NH}_{2}\right) \cdot \mathrm{COOH}
$$

7. Tyrosine, $\mathrm{C}_{9} \mathrm{H}_{11} \mathrm{NO}_{3}$, or $\beta$-parahydroxyphenyl-a-aminopropionic acid.

$$
\mathrm{HO} \cdot \mathrm{C}_{6} \mathrm{H}_{4} \cdot \mathrm{CH}_{2} \cdot \mathrm{CH}\left(\mathrm{NH}_{2}\right) \cdot \mathrm{COOH}
$$

8. Serine, $\mathrm{C}_{3} \mathrm{H}_{7} \mathrm{NO}_{3}$, or $\beta$-hydroxy- $\alpha$-aminopropionic acid.

$$
\mathrm{CH}_{2}(\mathrm{OH}) \cdot \mathrm{CH}\left(\mathrm{NH}_{2}\right) \cdot \mathrm{COOH}
$$

9. Cystine, $\mathrm{C}_{6} \mathrm{H}_{12} \mathrm{~N}_{2} \mathrm{O}_{4} \mathrm{~S}_{2}$, or dicysteine, or di-( $\beta$-thio- $\alpha$-aminopropionic acid). HOOC. CH $\left(\mathrm{NH}_{2}\right) \cdot \mathrm{CH}_{2} \cdot \mathrm{S}-\mathrm{S} \cdot \mathrm{CH}_{2} \cdot \mathrm{CH}\left(\mathrm{NH}_{2}\right) \cdot \mathrm{COOH}$

\section{B. Monoaminodicarboxylic acids.}

ro. Aspartic acid, $\mathrm{C}_{4} \mathrm{H}_{7} \mathrm{NO}_{4}$, or aminosuccinic acid.

$\mathrm{HOOC} \cdot \mathrm{CH}_{2} \cdot \mathrm{CH}\left(\mathrm{NH}_{2}\right) \cdot \mathrm{COOH}$

II. Glutamic acid, $\mathrm{C}_{5} \mathrm{H}_{9} \mathrm{NO}_{4}$, or $\alpha$-aminoglutaric acid.

$\mathrm{HOOC} \cdot \mathrm{CH}_{2} \cdot \mathrm{CH}_{2} \cdot \mathrm{CH}\left(\mathrm{NH}_{3}\right) \cdot \mathrm{COOH}$

C. Diaminomonocarboxylic acids.

12. Arginine, $\mathrm{C}_{6} \mathrm{H}_{14} \mathrm{~N}_{4} \mathrm{O}_{2}$, or $\alpha$-amino- $\delta$-guanidinevalerianic acid.

$$
\mathrm{HN}=\mathrm{C} / \mathrm{NH}_{\mathrm{NH}} \cdot \mathrm{CH}_{2} \cdot \mathrm{CH}_{2} \cdot \mathrm{CH}_{2} \cdot \mathrm{CH}\left(\mathrm{NH}_{2}\right) \mathrm{COOH}
$$

13. Lysine, $\mathrm{C}_{6} \mathrm{H}_{14} \mathrm{~N}_{2} \mathrm{O}_{2}$, or $\alpha$, $\epsilon$-diaminocaproic acid.

$$
\mathrm{H}_{2} \mathrm{~N} \cdot \mathrm{CH}_{2} \cdot \mathrm{CH}_{2} \cdot \mathrm{CH}_{2} \cdot \mathrm{CH}_{2} \cdot \mathrm{CH}\left(\mathrm{NH}_{2}\right) \cdot \mathrm{COOH}
$$

\section{Heterocyclic compounds.}

14. Histidine, $\mathrm{C}_{6} \mathrm{H}_{9} \mathrm{~N}_{3} \mathrm{O}_{2}$, or $\beta$-imidazole- $\alpha$-aminopropionic acid.

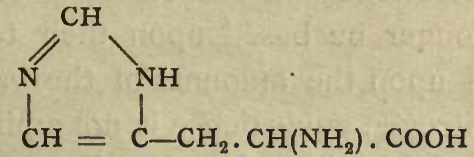

15. Proline, $\mathrm{C}_{5} \mathrm{H}_{2} \mathrm{NO}_{2}$, or $\alpha$-pyrrolidine carboxylic acid.

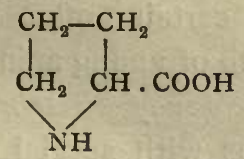

I6. Oxyproline, $\mathrm{C}_{5} \mathrm{H}_{9} \mathrm{NO}_{3}$, or $\gamma$-hydroxy- $\alpha$-pyrrolidine carboxylic acid.<smiles>O=C(O)C1CC(O)CN1</smiles> 
17. Tryptophan, $\mathrm{C}_{11} \mathrm{H}_{12} \mathrm{~N}_{2} \mathrm{O}_{2}$, or $\beta$-indole- $\alpha$-aminopropionic acid.<smiles>NC(CC1[CH]NCC1)C(=O)O</smiles>

E. Ammonia.

These seventeen amino acids, together with ammonia, which is present in the form of acid amide groups, are the basis of the composition of the protein molecule. They are generally referred to as "Bau-steine," the bricks, or foundation stones; but as the English translation of the German word is not entirely expressive of its meaning, it is preferable to use the term unit or element for these compounds in their relation to the proteins.

Most proteins contain all these amino acids or units in various proportions, but some proteins, such as gelatin, contain only fourteen or fifteen, and some, such as salmine, are built up of three or four units, these units being di-amino acids and histidine. Full data of the proportions, so far as is known, are given in the tables on pp. I II-I30, and further reference to details is made on pp. $63-84$.

Our purely chemical knowledge of the proteins has led to a greater knowledge of the digestion of proteins. Proteins are completely converted into their constituent units in the alimentary canal of animals; in this form they reach the bloodstream and circulate to the various organs of the body: Each organ rebuilds its tissue from the circulating amino acids, as well as giving rise to them during its catabolism. In plants, too, protein is transferred from one region to another in the form of amino acids. We think of and work with proteins in terms of amino acids. All considerations and deductions as to the dietetic value of proteins can no longer be based upon their total nitrogen content, but must be based upon the amounts of the various amino acids in their molecule. Nitrogen equivalence is not amino acid equivalence. Proteins devoid of certain units are of no value for the maintenance of life; proteins deficient in certain amino acids are of little or of no value for ensuring the growth of young animals. These particulars are given in Cathcart's Physiology of Protein Metabolism, second edition. The analysis of proteins with special reference to those units of metabolic value is therefore of the greatest importance.

The long list of amino acids is sufficient evidence of the complexity of the protein molecule; and, as yet, it seems to be incomplete, for several other products have been described :- 
I. Aminobutyric Acid.-The presence of aminobutyric acid, which would complete the series of monoaminomonocarboxylic acids, was assumed by Schützenberger [1879]. A small amount of a substance of the empirical formula $\mathrm{C}_{4} \mathrm{H}_{9} \mathrm{NO}_{2}$ was isolated by Foreman [ 1913,2 ] from the products of hydrolysis of caseinogen. Foreman considered it to be $a$-aminoisobutyric acid, but his evidence is not quite sufficient for the identification of the product. Abderhalden [Abderhalden and Weil, 1913,3$]$ subsequently stated that an amino acid of this composition had been obtained from a great number of proteins but that its constitution was not established.

2. Norleucine or a-amino-n-caproic Acid.-In addition to the two isomers, leucine and isoleucine, of the empirical formula $\mathrm{C}_{6} \mathrm{H}_{13} \mathrm{NO}_{2}$, another isomer, norleucine, has been shown to be present in the protein of the nervous tissue of the brain [Abderhalden and Weil, 1912, 2; I 9 I $3,1,2,3]$. It is apparently identical with glycoleucine described by Thudichum [I90I]. This unit is most likely present in other proteins also. Further evidence of its more general occurrence is given by the results of Skraup and Witt [1907], who obtained $n$-valerianic acid, which can only arise from a normal caproic acid, by the action of alkaline hypobromite on caseinogen and of Heckel [1908], who by the same method obtained $n$-valerianic acid from the leucine fraction of amino acids prepared fròm caseinogen; also of Samec [1908], who obtained $n$-caproic acid by the reduction of the leucine fraction of amino acids prepared from elastin.

3. Skraup [1904] added several new units to the list. Two of these, diaminoadipic acid and diaminoglutaric acid, were subsequently $[1905,2]$ shown to be alanine and a mixture of glycine and alanine. The other compounds were hydroxyaminosuccinic acid, $\mathrm{C}_{4} \mathrm{H}_{7} \mathrm{NO}_{5}$, dihydroxydiaminosuberic acid, $\mathrm{C}_{8} \mathrm{H}_{16} \mathrm{~N}_{2} \mathrm{O}_{6}$, caseanic acid, $\mathrm{C}_{9} \mathrm{H}_{16} \mathrm{O}_{7} \mathrm{~N}_{2}$, and caseinic acid, $\mathrm{C}_{12} \mathrm{H}_{16} \mathrm{O}_{5} \mathrm{~N}_{2}$. These substances were not found by Skraup $[1905, I]$ in gelatin, but another compound, $\mathrm{C}_{12} \mathrm{H}_{25} \mathrm{~N}_{5} \mathrm{O}_{10}$, was obtained.

Adensamer and Hoernes [1905], who used the same method as Skraup, could only isolate small quantities of caseanic and caseinic acids from egg-albumin. All these substances are most probably mixtures. Caseinic acid resembled in many ways the substance diaminotrioxydodecanic acid.

4. The two substances, Hydroxyaminosuberic acid, $\mathrm{C}_{8} \mathrm{H}_{15} \mathrm{O}_{5} \mathrm{~N}$, and hydroxydiaminosebacic acid, $\mathrm{C}_{10} \mathrm{H}_{20} \mathrm{O}_{5} \mathrm{~N}_{2}$, described by Wohlgemuth [1904, 1905] in the protein of the liver are, like the above, probably mixtures. 
5. Diaminotrioxydodecanic acid, $\mathrm{C}_{12} \mathrm{H}_{26} \mathrm{O}_{5} \mathrm{~N}_{2}$, was isolated by Fischer and Abderhalden [1904] from some tyrosine prepared from caseinogen. Other workers have subsequently searched for this compound, but have never isolated it. Abderhalden and Weil [1912, 2] stated that it had been obtained in very varying yields, which made it appear probable that it was a secondary product of hydrolysis and that its constitution appeared to be different to that implied by its name.

6. A substance of the formula $\mathrm{C}_{11} \mathrm{H}_{15} \mathrm{O}_{5} \mathrm{~N}$ was isolated by Torquati [1913, I, 2] from the seedlings and green pods of the vetch, Vicia Faba. This compound was investigated by Guggenheim [1913], who ascertained that its elementary composition corresponded more closely to the formula $\mathrm{C}_{9} \mathrm{H}_{11} \mathrm{O}_{4} \mathrm{~N}$, and that its constitution was 3,4 , dihydroxyphenylalanine,

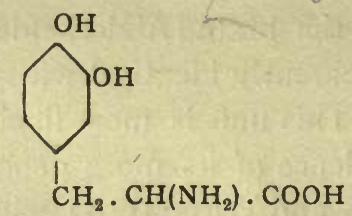

In properties it resembled the synthetical dl-dihydroxyphenylalanine described by Funk [19II] and also by Stephen and Weizmann [19I4]. Like adrenaline this substance possesses a pyrocatechin nucleus. (See Barger's Simpler Natural Bases.)

7. Gortner [19II] mentions the presence in wool of an aromatic phenolic compound, which gives Millon's reaction but is not tyrosine. If it should prove to be dihydroxyphenylalanine, this compound may prove also to be present in other proteins and to be a unit of general occurrence.

8. Abderhalden and Kempe $[1907,1]$, in preparing tryptophan by the tryptic digestion of caseinogen, observed the presence of another compound of the formula $\mathrm{C}_{11} \mathrm{H}_{12} \mathrm{~N}_{2} \mathrm{O}_{3}$. It was found more frequently when the digestion was prolonged and the subsequent preparation was slow ; it seems to be an oxidation product of tryptophan. It does not give the usual reactions for tryptophan and is converted by hydrochloric acid into a quinoline derivative. It is known as oxytryptophan.

9. 3,5-Diiodotyrosine is present in the protein contained in corals and other sea-animals : it is formed when proteins are treated with the halogen: it is not included in the above list since it is of such rare occurrence and presumably a derivative of tyrosine.

10. Glucosamine.-The presence of glucosamine in the protein molecule is a disputed question; there is no doubt that a carbohydrate 
containing nitrogen is contained in the glucoproteins in their prosthetic group, but it is doubtful if it be present in the protein part of the molecule, although a carbohydrate has been obtained from carefully purified proteins containing no prosthetic group, such as crystallised egg-albumin and serum-albumin. The fact that the yield of carbohydrate from such a protein becomes smaller the more often it is recrystallised, suggests that the presumably pure protein still contained an impurity; this impurity would be a glucoprotein, which is found in both egg white and serum from which the crystallised proteins are separated, and this would give rise to the carbohydrate. Glucosamine is therefore excluded from the above list.

The composition of the protein molecule has been determined by the method of hydrolysis. As the result of hydrolysis a complex mixture of all, or nearly all, the previously mentioned units is obtained. These have been isolated by various methods based upon the fractional crystallisation of the compounds themselves, or of their copper, silver and other salts. Only when one or more of the amino acids occurred in somewhat large amounts was their isolation and characterisation effected; their amount seldom reached a value higher than 20 per cent. of the total quantity, and the remainder was represented by uncrystallisable syrups of unknown nature. The products, termed leuceines, acids of the series $\mathrm{C}_{n} \mathrm{H}_{2 n-1} \mathrm{NO}_{2}$, and glucoproteines, acids of the series $\mathrm{C}_{n} \mathrm{H}_{2 n} \mathrm{~N}_{2} \mathrm{O}_{4}$, in gelatin, glucoproteines- $a$ and tyroleucine in albumin, described by Schützenberger [1879] and by Lepierre [1903] have been shown by Hugounenq and Morel [1906, 1907] and Galimard, Lacomme and Morel [1906] to be mixtures of now definitely known substances.

A great advance was made when Drechsel discovered that the protein molecule contained di-amino acids as well as mono-amino acids, and to Kossel and Kutscher we owe our chief knowledge concerning their isolation and estimation. Emil Fischer, in 1901, by his study of the amino acids and their derivatives, introduced a new method of isolating and separating the mono-amino acids, which depended upon the fractional distillation in vacuo of their esters, and which is now commonly known as the ester method. This method, though not yet really quantitative, has enabled us to obtain a knowledge of some 70 per cent. of the total products resulting by hydrolysis, and it has shown us that phenylalanine, serine and alanine, which were only known to occur in a few, are present in all proteins, and that phenylalanine in its distribution is the principal aromatic constituent, for it often 
exceeds in amount that of tyrosine and occurs when this latter is absent. Further, it has demonstrated the presence of two new compounds, proline and oxyproline.

New units have thus been discovered with each improvement in, and development of, the methods of analysis of the proteins. The exact constitution of these units had also to be determined. This portion of the subject has been attended with entire success; we now know the chemical constitution of every clearly defined unit in the protein molecule. Except glycine, all the amino acids contained in proteins are optically active and this property must also be considered.

The final problem in the chemical constitution of the proteinsthe synthesis-remains. This problem is still in its infancy. After numerous attempts by the earlier investigators its foundation was laid by Emil Fischer, who has synthesised a compound which, if it had been found in nature, would have been described as a protein. The difficulties in this part of the subject are very considerable. Not only is the amino acid required, but also its natural optical isomer is required. Many of the amino acids can only be readily obtained by decomposition of the protein, and, even if they be prepared by synthesis, much time and expense is involved. The proper conjunction of the amino acids is then necessary; the results of analysis give no clue as to whether the arrangement is $a, b, c, d, e$ or $b, c, d, a, e$, or $d, e, b, a, c$, etc. Some idea of the arrangement of the units in the protein molecule has been obtained by the isolation of several polypeptides, as the combinations together of the amino acids are termed, from proteins. Their isolation is so difficult that there must be many years of incessant labour before a real natural protein will be actually produced in the laboratory.

The study of the Chemical Constitution of the Proteins can therefore be divided into three sections :-

I. The Chemical Composition of the Protein Molecule. Analysis. II. The Chemical Constitution of the Units. The Amino Acids. III. The Synthesis of the Proteins. The Polypeptides. 


\section{HYDROLYSIS.}

The complex problem of the composition of the protein molecule has been solved by the method of hydrolysis, though other methods such as fusion with alkali, oxidation with permanganate, chromic acid, etc., action of halogens have been employed. Hydrolysis has been effected by (I) boiling with acids, (2) boiling with alkalies, (3) the action of the various proteoclastic enzymes which occur in animals and plants. Proteins were first hydrolysed by acids in 1820 by Braconnot, who used dilute sulphuric acid; between 1850 and 1875 hydrochloric acid was most frequently used as the hydrolysing agent by Ritthausen, Hlasiwetz and Habermann, and others; from 1870 to 1880 Schuitzenberger employed baryta water under pressure. The action of vegetable enzymes on proteins was studied chiefly by Schulze and his co-workers, that of animal enzymes by Kühne, Kossel, Kutscher, Drechsel, and numerous other investigators.

\section{(a) Hydrolysis with Hydrochloric Acid.}

\section{(i) Concentrated Acid.}

Hydrolysis of proteins by boiling with concentrated hydrochloric acid for several hours produces a dark brown solution of the products. Hlasiwetz and Habermann [1871, 1873] carried out the hydrolysis in the presence of stannous chloride in order that the solution should remain colourless. This addition is not necessary, as was shown by Cohn [ $1896-97]$ and was not made by E. Fischer in his researches.

The hydrolysis of protein is usually carried out by heating it with three times its quantity of concentrated hydrochloric acid of specific gravity I.19. The protein is placed in a round flask and covered with the acid; on shaking and warming slightly it gradually passes into solution. The solution, which at first may become violet in colour, gradually turns brown; it is then boiled under a reflux condenser for six to twenty-four hours, depending on the particular protein. The solution has finally a dark brown colour and during the hydrolysis a portion of the hydrochloric acid is evolved as gas. It is filtered from humin substances (secondary products arising from carbohydrate and tryptophan and other units, see p. $6_{5}$ ) and fatty material by passage through a Buchner funnel covered with linen, and these are well washed with water. The products are isolated from this solution. 


\section{(ii) Dilute Acid.}

Hydrolysis may be equally well affected by boiling the protein with from 10-20 parts of 20 per cent. hydrochloric acid for twentyfour to forty-eight hours. [Van Slyke, I 9 I I 4.]

Henriques and Gjaldbäk [1910] have found that complete hydrolysis is produced by heating the protein with $3 \mathrm{~N}$ hydrochloric acid in an autoclave at $150^{\circ}$ for one and a half hours. These observers made no statement as to the quantity of acid they used. Their experiments were confirmed by Van Slyke $[1912,2]$ who hydrolysed I 5 grams of protein with 50 c.c. of $3 \mathrm{~N}$ acid, i.e., with thirty-three times the quantity. Van Slyke showed further that complete hydrolysis was effected either by heating at $100^{\circ}$ for forty-eight hours with 20 per cent. acid or at $150^{\circ}$ with $3 \mathrm{~N}$ acid. Henriques and Gjaldbäk [1910] found that the hydrolysis of egg albumin was not complete by heating for twelve hours with concentrated acid, but was complete on heating at $150^{\circ}$ for 1.5 hours in an autoclave with $3 \mathrm{~N}$ acid. There was no advantage in heating at $150^{\circ}$ for a longer period of time; at $180^{\circ}$ in an autoclave decomposition of the amino acids occurred with the formation of ammonia.

\section{(iii) Alcoholic Hydrochloric Acid.}

Proteins are also hydrolysed by boiling with alcohol saturated with hydrogen chloride. Pribram [I9II] first drew attention to this fact, showing that hydrolysis occurred with carefully dried protein and carefully dried reagents ; the hydrolysis was more complete if the alcohol contained 3-5 per cent. of water. Similar results were previously published by. Pfannl [1910]. They are not in accordance with those of Abderhalden and Hanslian [1912], who showed that no appreciable hydrolysis took place if moisture was carefully excluded during all operations. Weizmann and Agashe [1913] have isolated small quantities of amino acids, but consider that the main result of hydrolysis with alcoholic hydrochloric acid is the formation of complex products intermediate between protein and amino acid. Herzig and Landsteiner [1914] estimated the amount of esterification in the case of serum proteins which were heated with various strengths of alcoholic hydrochloric acid. Their results also show that hydrolysis of the protein takes place, but only to a small extent. 


\section{(b) Hydrolysis with Sulphuric Acid.}

The protein is hydrolysed by boiling for fifteen to twenty-four hours with six times its quantity of $25-33$ per cent. sulphuric acid, or with a mixture of three times its weight of concentrated sulphuric acid and six times its weight of water under a reflux condenser. Generally, the mixture is heated for one to one and a half hours on a water-bath until frothing has ceased and then in an oilbath at $105^{\circ}$ for the necessary length of time.

\section{(c) Comparison of the Hydrolysis with Hydrochloric and Sulphuric Acids.}

Several observers have maintained that the results obtained by hydrolysing with concentrated hydrochloric acid and with 25-33 per cent. sulphuric acid are different, but investigations by Abderhalden and Funk [1907] and by Skraup and Türk [1909] have proved that complete hydrolysis is effected by both acids, if the boiling be continued for a sufficiently long time.

\section{(d) Hydrolysis with Hydrofluoric Acid.}

Hugounenq and Morel [1908; 1909, I ; 1909, 2], who have employed hydrofluoric acid, found that the results depend on the strength of the acid; the stronger the acid the greater is the amount of complex polypeptides. Many hours' boiling with dilute acid are required to effect complete hydrolysis.

\section{(e) Hydrolysis with Alkalies.}

Proteins are not generally hydrolysed by boiling with alkali. Alkali hydrolysis is only used for special purposes. The amino acids produced are completely racemised, whereas acids cause only partial racemisation. Arginine is destroyed by boiling with alkali and converted into ornithine and ammonia. Cystine is also decomposed by boiling with alkali.

\section{(f) Comparison of the Hydrolysis with Acids and Alkalies.}

Abderhalden, Medigreceanu and Pincussohn [1909] compared the hydrolysis by acids and alkalies. Alkalies produce the most complete hydrolysis. Abderhalden and Brahm [1909] found that a body, formed from silk, and resistant to hydrolysis by acid, could only be completely hydrolysed by alkali. 


\section{I2 THE CHEMICAL CONSTITUTION OF THE PROTEINS}

\section{$(g)$ Determination of the Completion of Hydrolysis.}

The completion of the hydrolysis has usually been ascertained by performing the biuret test on the solution and on any residue remaining when the time of hydrolysis is completed. Further hydrolysis is required if the biuret test is positive. Many proteins are hydrolysed with great slowness and, as has been pointed out by Osborne and Jones [1910, 3], boiling with acids for a much longer time than stated above is necessary; in the case of caseinogen, Osborne and Guest [19II] found that hydrolysis with concentrated hydrochloric acid was only complete after three to five days.

The biuret test is not altogether a satisfactory way of determining the completion of hydrolysis. It is necessary to determine whether an increase of ammonia and amino nitrogen occurs on a further period of six or eight hours' boiling. This increase can be estimated either by Van Slyke's amino nitrogen method or by Sörensen's method of titration with formalin.

\section{(i) Van Slyke's Amino Nitrogen Method.}

The hydrolysis is carried out in a tared flask under a reflux condenser; after six or eight hours the heating is discontinued. A portion of 1 or 2 c.c. is removed with a pipette and diluted to ro c.c. The amino nitrogen is estimated in this solution as described on pp. 89-96; the reaction is allowed to proceed for five minutes in the stationary apparatus and subsequently shaken for one minute. The flask in which the hydrolysis is carried out is weighed, and the boiling continued for another six or eight hours. The flask is again weighed to ascertain if the solution has become more concentrated; water may be added to replace the loss or a correction made for the decrease in volume. The hydrolysis is continued until the amino nitrogen is constant.

\section{(ii) Sörensen's Titration Method with Formalin.}

Sörensen [1907] proved that amino acids could be accurately estimated in solution by titration with alkali after they had been treated with neutralised formalin. The reaction of the amino acid with formalin results in the formation of a methylene compound, the neutral amino acid becoming a free carboxylic acid :-

$$
\begin{aligned}
& \mathrm{CH}_{2} \cdot \mathrm{NH}_{2} \\
& \mathrm{COOH}
\end{aligned}
$$


Some modification of the method is necessary for the titration of amino acids when they are present in dark brown solutions such as result from the hydrolysis of proteins. Sörensen and Jessen-Hansen [1907] have given the following procedure: The reaction of the solution must be approximately decinormal ; 25 c.c. of such a solution is used and placed in a 50 c.c. measuring flask. If the solution is not of this concentration in acid, 20 c.c. are taken and treated with ${ }_{5} \mathrm{~N}$ hydrochloric acid or sodium hydrate as required to produce the proper acidity. In the case of a solid substance I-3 grams are dissolved in 25 c.c. of $\cdot \mathrm{I} \mathrm{N}$ hydrochloric acid. Four c.c. of $2 \mathrm{~N}$ barium chloride solution (244 grams per litre) are added and then gradually about 20 c.c. of $33 \mathrm{~N}$ silver nitrate solution ( 56.7 grams per litre), which is best dropped into the solution from a small measuring cylinder. After each addition of silver nitrate the mixture is frequently and thoroughly shaken. The foam settles on standing for a short time and the flask is then filled with water free from carbon dioxide; if great accuracy is required four drops more of water are put in to allow for the volume of the silver chloride. The solution is filtered through an $\mathrm{I} I \mathrm{~cm}$. filter paper, taking care to bring as much as possible of the precipitate upon the filter. The filtrate, which is at first cloudy, is again poured carefully on the filter. The filtrate is now quite clear, and 15 or 30 c.c. are titrated with formalin using phenolphthalein as indicator. The reagents required are ( $\mathrm{I}$ ) a solution of 0.5 gram of phenolphthalein in 50 c.c. alcohol +50 c.c. water; (2) a neutral formalin solution which must be prepared fresh for every series of experiments. It is prepared by adding I c.c. of phenolphthalein solution to 50 c.c. of commercial formalin (30-40 per cent.) and adding $\cdot 2 \mathrm{~N}$ baryta or sodium hydrate solution until it has a faint pink colour. In order to be sure of the end point in the titration a control colour is prepared in the same volume of liquid as is used in the actual experiment. E.g., Io c.c. of the formalin solution are added to 20 c.c. of boiled distilled water : 5 c.c. of $\cdot 2 \mathrm{~N}$ baryta or sodium hydrate are added and the solution titrated with $2 \mathrm{~N}$ hydrochloric acid, which is dropped in until the solution has a faint pink colour. A drop of $\cdot 2 \mathrm{~N}$ baryta or soda is added to produce a distinct red colour. Twenty c.c. of the solution ${ }^{1}$ to be estimated are treated with ro c.c. of the formalin solution and then with $\cdot 2 \mathrm{~N}$ baryta or soda until there is a red colour; a few more c.c. of alkali are added. The solution is titrated with $2 \mathrm{~N}$ hydrochloric acid until the colour is paler

${ }^{1}$ Henriques and Gjaldbäk [19Io] neutralise the solution to litmus before titrating in the presence of formalin. 


\section{I4 THE CHEMICAL CONSTITUTION OF THE PROTEINS}

than that of the control and finally $\cdot 2 \mathrm{~N}$ alkali is added until the colour matches that of the control. To the control solution two drops of $\cdot 2 \mathrm{~N}$ alkali are now added so as to produce a deep red colour, and alkali is added to the solution until it attains the same deep red colour. The difference between the alkali and acid used in the solution and in the control (from $0-0.2$ c.c.) gives the titration figure.

\section{(h) Hydrolysis with Enzymes.}

Hydrolysis by the action of proteoclastic enzymes is never complete. The earlier investigators always observed that a complex body-antipeptone-resistant to the further action of trypsin was formed. Fischer and Abderhalden [1903, I, 2] have confirmed this observation and have found that the resistant body contains all the phenylalanine and proline present in the protein molecule; even by the combined action of pepsin and trypsin, although phenylalanine and proline are formed under these conditions, a body resistant to hydrolysis by trypsin still remained. Almost complete hydrolysis may be effected by trypsin and the enzymes in the small intestine if a sufficiently long time be given for the digestion.

Henriques and Gjaldbäk [1910] estimated the amount of unhydrolysed protein, and found that in a prolonged digestion some 5-10 per cent. of the amino nitrogen still remained in combination.

Hydrolysis by enzymes, though of use in the discovery of new units in the protein molecule, is not serviceable for a complete analysis of the decomposition products. 


\section{THE ISOLATION AND ESTIMATION OF THE UNITS.}

The units composing the protein molecule belong to four different classes of organic compounds, but are divided into two main groups for the purpose of isolation and estimation:-

A. The mono-amino acids, including proline and oxyproline.

Tyrosine and cystine differ from the other mono-amino acids by their extremely slight solubility in neutral aqueous solutions. They are therefore easily obtained after hydrolysis by acids by neutralising and concentrating the solution, when they crystallise out.

B. The di-amino acids, including histidine. The three compounds in this group were formerly called the hexone bases on account of their basic properties and the fact that each of them contains six carbon atoms.

The remaining unit, tryptophan, is almost completely destroyed by hydrolysis by acids; it is usually isolated after hydrolysis by trypsin.

Ammonia (amide nitrogen) is estimated by hydrolysing the protein with concentrated hydrochloric acid, removing the great excess of acid by evaporation under reduced pressure, adding excess of magnesia, distilling off the ammonia in vacuo and collecting it in excess of standard acid. This operation is usually carried out in the determination of the distribution of the total nitrogen amongst the two main groups (p. 97). The estimation of ammonia is frequently combined with the estimation of the di-amino acids (p. 55).

The separation and estimation of the two main groups of amino acids is generally not carried out in one experiment, but only when the amount of protein available is small, as very different quantities of material are required. Thus, the di-amino acids can be determined in 25-50 grams of protein with considerable accuracy, whereas the mono-amino acids can only be determined with fair accuracy when 250-500 grams of protein can be used. The two processes, of which the details are given under the two sections, may be combined as follows :-

The protein is hydrolysed by boiling for fifteen to twenty-four hours with six times its quantity of 25-30 per cent. sulphuric acid. The solution is neutralised with baryta and the filtrate and washings from the barium sulphate are evaporated down to a small volume. Tyrosine (and cystine) crystallise out. The filtrate is diluted with water and sulphuric acid added till the content of acid is 5 per cent. The 


\section{I6 THE CHEMICAL CONSTITUTION OF THE PROTEINS}

di-amino acids are then precipitated with phosphotungstic acid (pp. 6o, 98); from this precipitate they are obtained by decomposition with baryta and separated by means of their silver compounds as described in section B (p. 55). The filtrate is freed from phosphotungstic acid and sulphuric acid with baryta, excess of which is removed with carbon dioxide and sulphuric acid, and then treated for the other mono-amino acids as described in section A (p. 33).

On the whole it is not advisable to combine the two processes, since the phosphotungstic acid precipitation does not effect a perfect separation of the two groups and considerable loss occurs. 


\section{A. The Mono-amino Acids.}

\section{Tyrosine.}

\section{(I) Isolation and Gravimetric Estimation.}

Hydrolysis by sulphuric acid possesses one great advantage over that by hydrochloric acid, as it can be subsequently completely and easily removed by baryta.

The protein is hydrolysed by boiling with five to six times its quantity of 25 per cent. sulphuric acid for twelve to fifteen hours; the solution, after filtration, is diluted with twice its volume of water and neutralised with barium carbonate, or a strong solution of baryta, the excess of which is then quantitatively removed by dilute sulphuric acid. The solution, together with the water used in thoroughly washing the precipitate of barium sulphate, is then evaporated down, until the compound crystallises out. It is filtered off, the filtrate is concentrated, and further crops of crystals are removed until the mother liquor no longer gives Millon's reaction for tyrosine. The amount of cystine in most proteins is so small that the product generally consists only of tyrosine. It is purified by recrystallisation from water, decolorisation of the solution being effected by charcoal. The yield of tyrosine so obtained is the measure of its amount in the protein.

On account of the insolubility of tyrosine and the difficulty of filtering and completely washing the barium sulphate precipitate in order to abstract from it the whole of the tyrosine, Abderhalden and Teruuchi [1906], in the case of silk, hydrolysed the protein with hydrochloric acid, the greater part of which was then removed by evaporating several times in vacuo after diluting the concentrated solution with water; the remainder of the hydrochloric acid was then estimated in a small aliquot portion, and the main bulk neutralised with the calculated amount of caustic soda. The týrosine then crystallised out and was purified by recrystallisation from water.

Abderhalden [1912] shortened the process by hydrolysing the silk by boiling for three hours with three times its quantity of concentrated hydrochloric acid, evaporating the solution to dryness repeatedly in vacuo to remove the hydrochloric acid, dissolving the residue in water and passing in ammonia gas, or dissolving in ammonia, again evaporating in vacuo to dryness and treating the residue with cold water.

PT. I. 
Tyrosine remained. It is better to dissolve the residue in hot water, decolorise with charcoal, and allow the tyrosine to crystallise out.

When large quantities of protein are under investigation, the removal of the hydrochloric acid, after evaporation in vacuo, is effected by treating the solution with cuprous oxide until it is green in colour, filtering off and washing the cuprous chloride, and removing dissolved copper by hydrogen sulphide. A current of air is then passed through the solution to remove the hydrogen sulphide, and the remainder of the hydrochloric acid is either neutralised with the calculated quantity of soda or is removed by treating with silver carbonate. The solution on concentration deposits the tyrosine.

Levene and van Slyke $[1908,2]$ prefer the use of hydrochloric acid to that of sulphuric acid for separating tyrosine on account of the difficulty of completely extracting it from the barium sulphate precipitate and of obtaining it in a state of purity. Their procedure is the following: The protein is hydrolysed with concentrated hydrochloric acid; the solution is concentrated and saturated with gaseous hydrochloric acid. Glutamic acid hydrochloride separates out. The filtrate and washings from this precipitate are concentrated in vacuo to remove the greater part of the hydrochloric acid. The solution is then diluted to 7 litres (for 400 grams protein) and boiled with lead oxide till its reaction is alkaline. ${ }^{1}$ The lead oxide is prepared by precipitation with baryta, washed by decantation and preserved in the form of a paste. The precipitate of lead oxychloride is filtered off when the solution has cooled. It retains the resinous matters and a nearly colourless filtrate results. The remainder of the chlorine, which is estimated in an aliquot portion, is removed by means of the calculated quantity of silver sulphate, the excess of lead by adding sulphuric acid and passing in hydrogen sulphide, and of sulphuric acid by baryta. On concentrating the solution to one-seventh almost pure tyrosine separates out; it is filtered off, washed, dried and weighed. A portion of the other amino acids can be obtained by further concentration, and treated for leucine and valine (see p. 45). The di-amino acids are then precipitated (pp. 60, 98) and the filtrate is treated for the other monoamino acids.

If the solution be highly concentrated a mixture of tyrosine and leucine may separate out. This mixture may be separated by treating with glacial acetic acid. Leucine is soluble, tyrosine is insoluble [Habermann and Ehrenfeld, 1902].

${ }^{1}$ Levene and Van Slyke [19ro] state that excess of lead oxide should be avoided so as to prevent the formation of the insoluble lead salt of tyrosine. 
The data for tyrosine by the gravimetric method by various workers are in some cases quite concordant, but there are instances in which the data are very different, e.g., A bderhalden and Langstein [1910] give 4.6 per cent. for the amount of tyrosine in caseinogen, whereas Osborne and Guest [I9II] were only able to isolate 3.4 per cent. The same quantity was obtained by Totani [19r6]. Totani was able to isolate up to $4 . I$ per cent. by the further treatment of the liquid with mercuric sulphate. Osborne and Clapp $[1907,8]$ have emphasised the fact that from zein it is extremely difficult to crystallise the whole of the tyrosine, and Abderhalden and Fuchs [1913] also make a similar statement. They state further that better yields are obtained by evaporating the solutions in vacuo, which prevents access of acid and alkali vapour which keeps the tyrosine in solution and prevents it from crystallising. Sometimes the basic di-amino acids such as lysine form a combination with tyrosine preventing crystallisation. It may be generally considered that all these data are minimal.

In order to obtain tyrosine E. K. Marshall, jun. [1913], pointed out that it was made more quickly and with less manipulation if it were prepared by the tryptic digestion of caseinogen. Pig's pancreas was finely minced, mixed with an equal weight of water, and allowed to stand in the presence of chloroform for two days, whereupon the mixture was incubated at $37^{\circ}$ for twenty-four hours, cooled and filtered. IOO-I 50 grams of caseinogen are added per litre of filtrate, the solution is made slightly alkaline with ammonia and digested at $37^{\circ}$ for three to seven days. Tyrosine separates out and is filtered off after cooling. The solid matter is extracted with 1000,500 , and 250 c.c. of boiling water and these extracts are evaporated to 250 c.c. The tyrosine which crystallises out is obtained quite pure by one recrystallisation. The yield is given as 5 grams from 100 grams of caseinogen and $I \cdot 2$ grams from $I$ litre of pancreas extract.

This method of preparation of tyrosine has been used for many years by the author by digesting caseinogen dissolved in alkali with various preparations of trypsin. The yields were never so high as the 3.8 per cent. obtained by Marshall; on the average about 2.5 per cent. 


\section{(2) Colorimetric Estimation.}

Folin and Denis $[1912,2]$ introduced a method for the quantitative estimation of tyrosine in proteins depending upon the blue colour which tyrosine gives with a phosphotungstic-phosphomolybdic reagent [1912, I].

The estimation is carried out as follows :-

A weighed quantity - about I gram-of dried protein is hydrolysed by boiling under a reflux condenser for twelve hours with 25 c.c. of 20 per cent. hydrochloric acid. The solution is transferred to a 100 c.c. measuring flask and made up to volume. One or two c.c. of this solution are placed in a 100 c.c. flask, 5 c.c. of the reagent ${ }^{1}$ are added, and after five minutes 25 c.c. of a saturated solution of sodium carbonate. The volume is made up to 100 c.c. with water. At the same time 5 c.c. $\left(=\mathrm{I} \mathrm{mgm}\right.$.) of a standard tyrosine solution ${ }^{2}$ are placed in another 100 c.c. measuring flask and treated in the same way. The maximum blue colour develops in half an hour. After this time the colours of the two solutions are matched in a Duboscq colorimeter, the standard being set at $20 \mathrm{~mm}$. The solutions, if not clear, are filtered before making the comparisons.

Folin and Denis' results, compared with the gravimetric data, were :-

\begin{tabular}{|c|c|c|c|c|c|c|}
\hline & $\begin{array}{l}\text { Colori- } \\
\text { metric, } \\
\text { per cent. }\end{array}$ & $\begin{array}{l}\text { Gravi. } \\
\text { metric, } \\
\text { per cent. }\end{array}$ & & & $\begin{array}{l}\text { Colori- } \\
\text { metric, } \\
\text { per cent. }\end{array}$ & $\begin{array}{l}\text { Gravi- } \\
\text { metric, } \\
\text { per cent. }\end{array}$ \\
\hline Wool (sheep) & & $2 \cdot 4$ & Caseinogen & . & $6 \cdot 5$ & 4.5 \\
\hline Hair & $4 \cdot 3$ & $3^{\circ} 0$ & Vitellin ${ }^{\circ}$. & . & $5 \cdot 2$ & $3 \cdot 4$ \\
\hline Horr & 6.5 & $4^{\cdot 6}$ & Conalbumin & . & $4 \cdot 9$ & \\
\hline Gelatin & trace & - & Ovalbumin & . & $5 \circ$ & $r \cdot 8$ \\
\hline Ovomucoid & $5 \cdot 4$ & - & Lactalbumin & & 4.9 & 0.9 \\
\hline Globulin (flax seed) & $3 \cdot 3$ & - & Globulin (castor & an) & & - \\
\hline (soy bean): & 4.0 & $r \cdot 9$ & n (cow pea) & & $4 \cdot 6$ & $2 \cdot 3$ \\
\hline (white bean) & $4 \cdot 5$ & $2 \cdot 2$ & nin (pea). & & $4 \cdot 5$ & $2 \cdot 8$ \\
\hline in (squash seed) & 4.9 & $r_{4}$ & laize) & . & $6 \cdot 5$ & - \\
\hline n (hazel nut) & $4^{\circ} \mathrm{o}$ & - & Zein (maize) & & $5 \cdot 5$ & $3 \cdot 6$ \\
\hline np seed) & $5 \cdot 2$ & $2 \cdot I$ & Hordein (barley) & • & $4 \% 7$ & $1 \cdot 7$ \\
\hline mond) & 47 & $I \cdot I$ & Gliadin (wheat). & . & $3 \cdot 3$ & $2 \cdot 4$ \\
\hline ulin (cotton seed) & 4.7 & $2 \cdot 3$ & Glutenin (wheat) & & $5 \cdot 8$ & $4 \cdot 3$ \\
\hline
\end{tabular}

In all cases the values by the colorimetric method are higher than those by the gravimetric. These higher values for tyrosine were shown by Folin and Denis not to be due to the reaction taking place with

${ }^{1}$ Ioo grams of sodium tungstate, 20 grams of phosphomolybdic acid and 50 c.c. of 85 per cent. phosphoric acid are added to 750 c.c. of water. The solution is boiled for two hours under a reflux condenser, cooled and diluted to rooo c.c. 2 c.c. of this reagent will give the maximum colour with $\mathrm{x}$ mgm. of tyrosine.

${ }^{2}$ Pure tyrosine dissolved in $\cdot \mathrm{rN} \mathrm{HCl}$ so that 5 c.c. contain $\mathrm{I}$ mgm. of tyrosine. 
other amino acids, all of which were tested except tryptophan, oxytryptophan and oxyproline, nor to the formation of phenols during hydrolysis. They therefore concluded that, in the absence of any amino acid at present unknown, these values more correctly represent the amounts of tyrosine in proteins than the gravimetric values.

Abderhalden and Fuchs [1913] subsequently maintained that the values for tyrosine by the gravimetric method were more exact than those by the colorimetric method. They showed that tyrosine added to gelatin could be almost entirely recovered from the mixture of the products of hydrolysis, and that a reaction was given by oxytryptophan and by tryptophan. These reactions are not of a similar colour intensity as the reaction with tyrosine.

Folin and Denis [1913] conceded that their figures may be a little too high, but do not consider that the presence of tryptophan, though it may react after boiling with acids, will cause the great differences observed especially as the higher results are of a similar magnitude with caseinogen and with zein.

Abderhalden [1913] stated that oxyproline gave a blue colour reaction with the reagent, but seeing that gelatin with 3 per cent. of oxyproline only shows a trace of colour and that other proteins probably contain still smaller amounts of oxyproline, the error due to oxyproline, together with that due to oxytryptophan and tryptophan, is not sufficient to account for the differences. We must therefore conclude that the data by the colorimetric method more nearly represent the actual amount of tyrosine in proteins than the data by the gravimetric method. 


\section{(3) Estimation by Bromination.}

It was shown by J. H. Millar [1903] that tyrosine was readily brominated and converted into dibromotyrosine, and that the amount of tyrosine in a simple mixture of amino acids could be accurately estimated by means of this reaction.

A. J. Brown and E. T. Millar [1906] using this reaction showed that the tyrine in proteins was completely liberated at a very early stage in the hydrolysis by trypsin. Their data gave the tyrosine content of edestin as $4^{.06}$ per cent., a figure which is considerably higher than that obtained by direct isolation ( $2 \cdot 1$ per cent.). They made no estimations of tyrosine in other proteins.

Plimmer and Eaves [1913] studied this reaction more closely with a view to the estimation of tyrosine in proteins. It was not found possible to apply the reaction to the products of hydrolysis of proteins by acids, since tryptophan, though almost entirely decomposed by boiling with acids, gave rise to products which absorbed bromine, but if the hydrolysis of the protein were effected by the action of trypsin, and if the amount of bromine absorbed were determined after about six hours, values for tyrosine were obtained which agreed closely with those by the gravimetric method. If the amount of bromine absorbed was determined after twenty-four to twenty-eight hours' hydrolysis, the values for tyrosine were very similar to those by the colorimetric method of Folin and Denis.

The procedure was to digest a known weight of protein in faintly alkaline solution with trypsin, to remove measured volumes of the digest after the stated period, and to treat this volume with a 5 per cent. solution of phosphotungstic acid in 5 per cent. sulphuric acid to remove histidine, which absorbs bromine. A measured volume of the filtrate was treated with a known volume of $2 \mathrm{~N}$ sodium bromate solution and IO-20 c.c. of 20 per cent. sodium bromide solution. After half an hour the excess of bromine was determined by titration with thiosulphate solution, using starch and sodium iodide as indicator. At the same time the same volume of trypsin solution was digested by itself and treated in a similar way so as to deduct the amount of tyrosine in this solution.

The values of tyrosine by bromination are given in the following table and are compared with the gravimetric and colorimetric:- 


\begin{tabular}{|c|c|c|c|c|c|c|c|}
\hline & & & & $\begin{array}{c}\text { Bromination after } \\
6 \text { hours' digestion, } \\
\text { per cent. }\end{array}$ & $\begin{array}{l}\text { Gravimetric, } \\
\text { per cent. }\end{array}$ & $\begin{array}{l}\text { Bromination after } \\
24-28 \text { hours' } \\
\text { digestion. }\end{array}$ & $\begin{array}{l}\text { Colorimetric, } \\
\text { per cent. }\end{array}$ \\
\hline \multicolumn{4}{|c|}{ Caseinogen } & $5 \cdot 3$ & $4 \cdot 5$ & $6 \cdot 3$ & $6 \cdot 5$ \\
\hline "Peptone & Ro & he' & & $10 \cdot 2$ & - & 10.2 & - \\
\hline Silk fibroin & & . & . & $9^{\cdot} 5^{1}$ & 9 to 10.5 & - & - \\
\hline Conglutin & . & . & . & $I \cdot 3$ & $2 \cdot I$ & $3 \cdot x$ & - \\
\hline Legumin & . & & - & $2 \cdot 7$ & $2 \cdot 8$ & $4^{\prime 2}$ & 4.5 \\
\hline Edestin & . & & & $I \cdot 7$ & $2 \cdot I$ & $3 \cdot 6^{2}$ & $5 \cdot 2$ \\
\hline Vignin & & . & & $3 \cdot 4$ & $2 \cdot 3$ & $6 \cdot 0$ & $4^{\cdot 6}$ \\
\hline Globulin (s & $q u$ & h s & & $3 \cdot 2$ & $3 \cdot 1$ & $5 \cdot 8$ & 4.9 \\
\hline Amandin & . & · & . & $2 \cdot 9$ & $I \cdot I$ & $5 \cdot I$ & 47 \\
\hline Glycinin & • & . & - & $I \cdot I$ & I.9 & 35 & $4^{\circ} 0$ \\
\hline Excelsin & - & - & & 2.5 & $3 \cdot x$ & $4 \cdot 6$ & - \\
\hline
\end{tabular}

1 By acid hydrolysis.

$25^{\circ} 2$ after forty-eight hours.

The bromination method thus does not decide whether the gravimetric value or the colorimetric value represents the tyrosine content of protein the more accurately and consequently is of little value for determining the tyrosine content of proteins. It may prove of use to ascertain the amount of tyrosine in the impure tyrosine which is isolated from proteins, if this impure tyrosine is shown to be free from tryptophan. The gravimetric values may then be found to be higher than those given by the various workers, who have usually only weighed pure recrystallised tyrosine. 


\section{Cystine.}

\section{(I) Isolation and Gravimetric Estimation.}

With few exceptions cystine has not been isolated from the products of hydrolysis of proteins other than the keratins, and in these cases usually mixed with tyrosine from which it required separation. Mörner [1901-2], who first isolated cystine from the products of hydrolysis, heated the protein-hair, keratin from horn, egg-shells, etc. - with five times its quantity of 13 per cent. hydrochloric acid under a reflux condenser on a water-bath for six to seven days. The solution was then decolorised with charcoal and evaporated in vacuo, and the residue dissolved in 60-70 per cent, alcohol. On neutralisation with soda a mixture of cystine and tyrosine separated out.

Embden [1900] hydrolysed horn by boiling under a reflux with three times its quantity of concentrated hydrochloric acid. The liquid was neutralised to amphoteric reaction and allowed to stand for not more than twenty-four hours. The black pigment (melanin) was filtered off and the filtrate after acidifying was boiled with charcoal. The pale yellow filtrate gave on standing in a cool place a large precipitate of tyrosine and cystine. Further quantities were obtained in the same way on concentrating the mother liquor.

Some alterations in this procedure were made by Friedmann [1902]. The hydrolysed protein was nearly neutralised with a concentrated solution of caustic soda, decolorised by boiling with large amounts of charcoal, and allowed to cool. Cystine and tyrosine crystallised out.

A simple method of preparing cystine from wool was described by Folin [1910]. The wool is boiled with concentrated hydrochloric acid in the proportion of 100 grams of wool to 200 c.c. of acid for three to five hours. The hot solution is then neutralised to congo red by adding sodium acetate in the form of crystals. Almost the whole of the cystine separates out on standing. After several hours the precipitate is dissolved in 3-5 per cent. hydrochloric acid, the solution is boiled with charcoal, and the hot colourless solution is neutralised as before by adding a hot concentrated solution of sodium acetate. Cystine separates out in the characteristic hexagonal plates as the solution cools. No data of the yield were given.

The mother liquor on dilution and on standing deposits tyrosine. This is most readily purified by dissolving in hydrochloric acid, decolorising the solution with charcoal, and then neutralising exactly with ammonia, when almost pure tyrosine separates out. 


\section{(2) Separation of Cystine and Tyrosine.}

The mixture of cystine and tyrosine was separated by Mörner by fractional crystallisation from ammonia; if much tyrosine was present it separated out first, but if cystine exceeded tyrosine in quantity this compound crystallised out first; the remainder was only separated with difficulty.

The method adopted by Embden and followed by Friedmann was the solution of the tyrosine from the mixture, suspended in water, by the addition of very dilute nitric acid. The separation could be checked by microscopic observation of the crystals, the needle-shaped crystals of tyrosine dissolving whilst the plates of cystine remained. After washing free from acid with water, the cystine was recrystallised from ammonia.

Separation of the mixture was effected by Abderhalden [1903] and by Abderhalden and Pregl [1905, 2] by dissolving in ammonia and adding glacial acetic acid keeping the reaction alkaline; tyrosine was precipitated: on acidifying with glacial acetic acid the cystine separated.

The separation of cystine from hydrolysed Bence-Jones protein by Hopkins and Savory [19II] was carried out by precipitation of a tryptic digest with mercuric sulphate in acid solution (see under tryptophan). Before the second precipitation the solution was concentrated after removal of the acid; cystine crystallised out.

The precipitation of cystine by mercuric sulphate in 5 per cent. sulphuric acid solution in which the mercury compound of tyrosine is soluble was used by Osborne and Clapp in the cases of squash seed globulin $[1907,6]$, and wheat gliadin [1906] respectively.

Winterstein [I90I] showed that cystine was precipitated by phosphotungstic acid, but the observation seems to have been overlooked. Cystine and tyrosine can be separated by means of this reagent. The mixture is dissolved in $\mathbf{5}$ per cent. sulphuric acid and treated with excess of phosphotungstic acid solution. Cystine phosphotungstate generally separates out in a crystalline condition. From this precipitate the cystine can be obtained by the usual method (see under di-amino acids), but a large excess of baryta must be avoided as cystine is readily decomposed by alkalies. Cystine crystallises out on neutralising the filtrate from the barium phosphotungstate. Winterstein decomposed the phosphotungstate with hydrochloric acid. The precipitate is made into a paste with water, placed in a separating 
funnel and treated with small quantities of concentrated hydrochloric acid. Ether is added and the mixture well shaken. At first an emulsion is formed, but on adding more ether and acid and thoroughly shaking a clear ethereal solution of phosphotungstic acid settles to the bottom; if this does not occur, decomposition is not complete and more acid must be added and the shaking repeated. The middle layer containing the cystine hydrochloride is separated; the other layers are treated once more in the same way and the middle layers are combined. Ether is removed from the acid solution by warming on the waterbath and the cystine is separated by exactly neutralising with soda.

The separation of cystine and tyrosine has been examined by Plimmer [1913]. Neither the phosphotungstic acid method nor the mercuric sulphate method was found to be satisfactory, as loss of both substances occurred. In the case of phosphotungstic acid some tyrosine was carried down with the precipitate and was only removed by prolonged washing, and some of the cystine was decomposed in recovering it from its phosphotungstate. In the case of mercuric sulphate, the cystine is not completely precipitated. A quantitative separation of the two compounds was effected by means of absolute alcohol saturated with hydrogen chloride. Tyrosine is converted into its ethyl ester hydrochloride; cystine is not acted upon. The mixture of the two compounds is covered with the alcoholic hydrochloric acid and warmed upon the water-bath to dissolve the tyrosine. An equal volume of absolute alcohol is now added to precipitate any cystine which may dissolve. The undissolved cystine is filtered off and washed with absolute alcohol till it is free from acid and recrystallised from ammonia in the usual way. The filtrate containing the tyrosine ester is diluted with two volumes of water and boiled for eight hours, water being added when necessary. The ester is thus hydrolysed and on neutralising the tyrosine is precipitated.

The usefulness of this method is shown by the treatment of presumably pure tyrosine prepared from wool by Folin's method for obtaining cystine; one specimen of 5 grams contained 0.05 gram of cystine, another specimen of 4 grams yielded 0.2 gram of cystine. 


\section{Tryptophan.}

\section{(I) Isolation and Gravimetric Estimation.}

Tryptophan is not obtained by the hydrolysis of proteins by acids owing to its decomposition and is prepared by the action of trypsin. By the method of Hopkins and Cole [190I, 2] the protein is digested in alkaline solution by trypsin, until the solution gives a maximal coloration when tested with bromine water; the solution is acidified, boiled and filtered. The clear solution (better after concentrating in vacuo and filtering off tyrosine, which crystallises out) is acidified with sulphuric acid until it contains 5 per cent., and then 10 per cent. mercuric sulphate in 5 per cent. sulphuric acid solution is added as long as a precipitate, which contains tryptophan, cystine and tyrosine, is formed. The yellow precipitate is freed from tyrosine by washing with 5 per cent. sulphuric acid in which the tyrosine compound is soluble, that is, until the washings no longer react with Millon's reagent. The precipitate is decomposed by sulphuretted hydrogen, and the solution containing cystine and tryptophan after removing the hydrogen sulphide is again acidified with sulphuric acid to 5 per cent. and fractionally precipitated with the mercuric sulphate reagent. The cystine is thrown down first, filtered off, and then the tryptophan is precipitated. The precipitate is again decomposed by hydrogen sulphide, and the solution, freed from sulphuric acid, is evaporated down, alcohol being continually added to hasten the evaporation and prevent decomposition of the tryptophan, which crystallises out. It is purified by recrystallisation from water. The yield represents its amount in the protein.

Neuberg and Popowsky [1907] introduced a few alterations in the procedure, such as evaporation to one quarter and filtration from tyrosine before precipitating with mercuric sulphate; in decomposing the precipitate with hydrogen sulphide they make the solution faintly alkaline with baryta and treat with the gas for twenty-four hours, warming several times. The removal of sulphuric acid in the last operation is carried out with lead carbonate in ammoniacal solution, the lead being subsequently removed with hydrogen sulphide.

Abderhalden and Kempe [1907, I] made very little alteration in the procedure of Hopkins and Cole beyond evaporation of the solutions in vacuo and removal of hydrogen sulphide with a current of carbon dioxide. The yield of tryptophan obtained by these workers $(0.53$ per cent.) is less than the yield mentioned by Hopkins and Cole in the case of caseinogen ( $I^{\prime} 5$ per cent.). Usually about $I$ per cent. is obtained from caseinogen. 


\section{(2) Colorimetric Estimations.}

Attempts have been made by several investigators to estimate the amount of tryptophan in proteins by colorimetric methods.

I. Levene and Rouiller [1906-07] suggested a procedure depending upon the bromine absorption of tryptophan. The protein was digested by trypsin and the tryptophan precipitated by mercuric sulphate as described above. This precipitate was decomposed by hydrogen sulphide in I-2 per cent. sulphuric acid solution and the filtrate from the mercuric sulphide made up to a definite volume. To $15^{\circ}$ c.c. of this solution 2 c.c. of amyl alcohol were added and then gradually bromine water with vigorous shaking. The end point was reached when the purple colour of the amyl alcohol disappeared and became yellow.

The absorption of bromine is influenced by the presence of tyrosine and cystine, which are precipitated by mercuric sulphate with tryptophan. The amount of tyrosine thrown down is negligible, if the mercuric sulphate reagent is added only as long as the solution gives a reaction for tryptophan with bromine water and if the precipitate is washed until the washings give no reaction for tyrosine. A correction is made for the absorption by cystine, the amount of cystine in the solution being determined by a sulphur estimation. The bromine water used is standardised against solutions of tryptophan and cystine.

Up to the present no values of the amount of tryptophan in proteins have appeared, the further work of these authors [1907] being concerned with the hydrolysis of the protein by baryta and the nature of the bromine derivatives of tryptophan. They found that tryptophan was not completely separated from protein by the hydrolysis with baryta unless the hydrolysis was prolonged and that under these conditions the colour reaction was not satisfactory. By a short hydrolysis polypeptides containing tryptophan are present, which also absorb bromine and affect the estimation. At the stage when a violet colour is produced by bromine water they consider that a mixture of monoand dibromo-tryptophan is present and that the dibromide is present when excess of bromine has been added.

2. Proteins containing tryptophan give a reddish-violet to blue colour reaction with glyoxylic acid and sulphuric acid-the Adamkiewicz-Hopkins reaction. It is positive for a concentration of tryptophan of $I$ in 100,000. This reaction has been made use of by Fasal [1912] for estimating tryptophan in proteins and is carried out in the follow- 
ing way: Solutions of tryptophan of a concentration of $\mathrm{I}$ in 1000 , $I$ in $2000, I$ in 3000 and so on up to I in 10,000 are prepared and also $I$ in 20,000 up to $I$ in 50,000 . To I c.c. of these solutions in test tubes of equal size and bore are added 2 c.c. of glyoxylic acid solution $^{1}$ and 6 c.c. of concentrated sulphuric acid. A series of coloured solutions from deep blue to red-violet result. A known weight (about 0.1 gram) of previously purified and dried protein is placed in another test tube and treated with 2 c.c. of glyoxylic acid and 6 c.c. of concentrated sulphuric acid. The colour so produced is compared with the other colours. The one showing the closest comparison is then matched with the one from the protein in a Duboscq colorimeter, the cups of which are entirely made of glass. Readings are taken from both above and below in the usual manner. Usually the comparison was made with the tryptophan solution I in 4000 , i.e., I c.c. $=0.00025$ gram tryptophan. If the colorimeter readings were for example $22:$ I 8 (standard) the protein contains $1 \cdot 23$ times as much tryptophan as the solution, i.e., O.I gram protein contains $0.00025 \times 1.23$ gram tryptophan or 0.3 per cent.

In most cases the colours could be matched fairly well, but in some cases the comparison was difficult owing to brown shades in the protein solution. This could be sometimes overcome by taking different amounts of protein. In these cases Fasal [1913] found that a comparison was possible if the colours were compared in the apparatus with colour filters described by Sörensen. ${ }^{2}$ Numerous estimations were made by Fasal; they are given in the following table in which the figures are the percentage of tryptophan:-

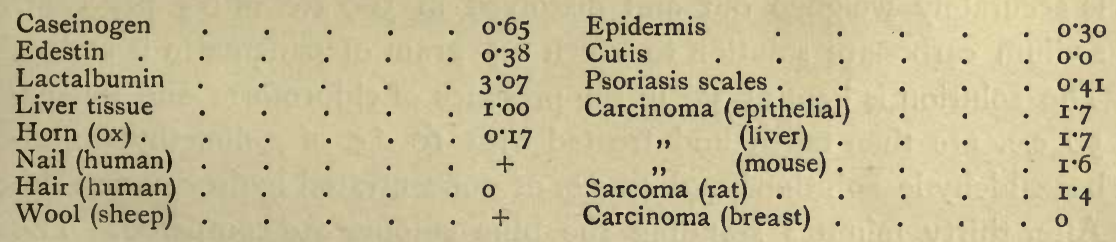

The different kinds of keratin, for which the method was particularly devised on account of their insolubility by pepsin and trypsin, show very striking differences. The value for caseinogen is higher than that found by the gravimetric method by Abderhalden and Kempe, but lower than that found by Hopkins and Cole. The large amalgam.

${ }^{1}$ Prepared by reducing a saturated aqueous oxalic acid solution with 3 per cent. sodium

${ }^{2}$ Biochemische Zeitschrift, 1909, 2x, 201. 
amount of tryptophan in lactalbumin is most noticeable. Greater amounts of tryptophan were present in carcinoma than in the normal tissue, but tryptophan was absent in carcinoma of the breast.

3. Tryptophan is decomposed by putrefactive bacteria with the formation of indole. An investigation by Herzfeld [1913, I] into the formation of indole by the action of alkali (the highest yields being given by boiling with $\mathrm{I} 000$ c.c. of 9 per cent. caustic soda and I gram of copper sulphate), showed that the estimation of tryptophan under these conditions was not practicable. Sanders and May [19I2-I3] have also tried to estimate tryptophan by the formation of indole. The pancreatic digest of protein was inoculated with fæcal bacteria, distilled, and the indole in the distillate treated with nitrous acid. At the same time an indole solution was treated in a similar way and the colours compared. Caseinogen gave an amount of indole corresponding to I 6 per cent. of tryptophan.

4. Herzfeld $[1913,2]$ determined the tryptophan content of several proteins by the colorimetric and spectrophotometric comparison of the colour given by tryptophan with $p$-dimethylaminobenzaldehyde and concentrated hydrochloric acid. A blue colour is given by this reagent with one part of tryptophan in $\mathrm{r}, 000,000$. As a standard colour a solution of I gram of ignited copper sulphate dissolved in 100 c.c. of water is used, I c.c. of this solution being treated with 20 c.c. of ammonia and diluted to roo c.c. This blue solution has the same colour as 0.0001 gram of tryptophan in its reaction with p-dimethylaminobenzaldehyde and hydrochloric acid. The two are carefully compared before use. About I gram of the purified and dried protein is accurately weighed out and dissolved in 500 c.c. of 0.5 per cent. sodium carbonate solution to which 0.5 gram of pancreatin is added. The solution is kept at $37^{\circ}$ in the presence of chloroform and xylene. 50 c.c. are then taken and treated with ro c.c. of $p$-dimethylaminobenzaldehyde solution ${ }^{1}$ and 40 c.c. of concentrated hydrochloric acid. After thirty minutes' standing the blue colours are compared. The tryptophan content of the pancreatin is also determined and the amount deducted from the digest of protein with pancreatin. The colorimetric values agreed closely with the spectrophotometric.

The tryptophan content of several proteins was determined :water.

120 grams $p$-dimethylaminobenzaldehyde dissolved in 500 c.c. conc. $\mathrm{HCl}$ and 500 c.c. 


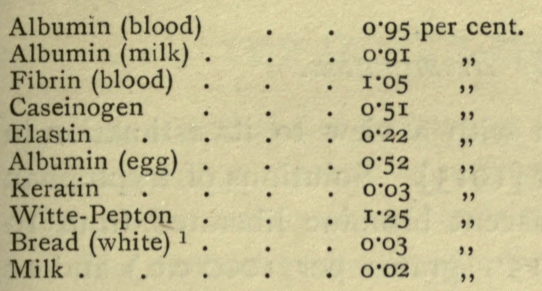

${ }^{1} 69^{\circ} 9$ per cent. dry substance.

These values are not in agreement with those found by Fasal in the cases of milk albumin, caseinogen, edestin and keratin (horn).

In all cases the time of digestion of the protein was presumably twenty-four hours, and in this time the whole of the tryptophan is not likely to be liberated from the protein. A maximal colour reaction for tryptophan with bromine water as stated by Hopkins and Cole is only obtained after several days, and the rate of digestion of proteins is not likely to be the same; keratin is not dissolved by trypsin and hence the low value:

The tryptophan content of the kidneys in normal and pathological conditions has been determined by this method by Kurchin [19I4]; normal kidneys contained slightly more than pathological. 


\section{(3) Estimation by Bromination.}

The bromination of tryptophan with a view to its estimation in solution has been studied by Homer [1915]. Solutions of tryptophan were treated with excess of $(a)$ nascent bromine liberated from ro c.c. of a sodium bromate solution ( $15 \cdot 1$ grams per 1000 c.c.) and 10 c.c. of sodium bromide solution ( $5 \mathrm{I}^{\circ} 5$ grams per 1000 c.c.) by 5 c.c. of concentrated hydrochloric acid; $(b)$ saturated bromine water. After varying periods of time, from thirty minutes to eight hours, the excess was titrated with $\cdot$ I $\mathrm{N}$ thiosulphate solution after adding potassium iodide. Under these conditions try'ptophan was found to absorb eight atoms of bromine. The first reaction is identical with that used by Plimmer and Eaves in their estimation of tyrosine; these workers found that tryptophan absorbed six atoms of bromine.

In carrying out the estimation in proteins the protein was hydrolysed by boiling 100 grams with 350 grams barium hydrate dissolved in 2500 c.c. of water for 20 to 120 hours. In the absence of metallic salts tryptophan was found to be stable to the action of baryta (see above, 3). The baryta was removed with sulphuric acid and the solution acidified to 5 per cent. On the addition of the mercuric sulphate reagent the tryptophan is precipitated. The precipitate was filtered off after forty-eight hours and washed until free from tyrosine; it was then suspended in 2 per cent. sulphuric acid and decomposed with hydrogen sulphide. The filtrate from the mercuric sulphide was freed from hydrogen sulphide and treated with phosphotungstic acid to remove polypeptides. The filtrate containing the tryptophan was treated with baryta to remove phosphotungstic acid, and with sulphuric acid to remove baryta, and made up to a definite volume (usually r 000 c.c.). 50 c.c. of this solution were treated with sodium bromate and bromide solutions, and at the same time a tryptophan solution was treated in the same way. The excess of bromine was titrated with - IN thiosulphate. From the bromine absorption of the tryptophan the amount of tryptophan in the solution was calculated and hence the amount in the protein.

The tryptophan content of caseinogen was determined in this way and was found to be from 0.99-I.59 per cent. No other determinations were made. 


\section{THE OTHER MONO-AMINO ACIDS.}

The isolation and estimation of these units is usually not carried out separately, except occasionally for glutamic acid and glycine. The process is one which yields the mono-amino acids in sequence.

The method generally adopted in isolating the other mono-amino acids is that first employed by E. Fischer [190I]. It has been modified in certain details by his pupils, particularly Abderhalden [1910] and other workers have contributed to its improvement.

Hydrolysis is more conveniently effected by concentrated hydrochloric acid than by dilute sulphuric acid, and is carried out as mentioned on p. 9.

\section{(I) Isolation of Glutamic Acid as Hydrochloride.}

The method of isolation of glutamic acid as hydrochloride was introduced by Hlasiwetz and Habermann [1 873].

The solution of amino acids in 25 per cent. hydrochloric acid is concentrated in vacuo to a half or a third of the original volume, and glutamic acid, if present in any large amount, is removed as its hydrochloride by saturating the solution with dry gaseous hydrochloric acid. After allowing to stand at $0^{\circ}$ for some days, glutamic acid hydrochloride crystallises out. This occurs in the case of caseinogen and certain vegetable proteins, which contain from 10-40 per cent. of this amino acid. The glutamic acid hydrochloride is filtered off after adding an equal volume of ice-cold alcohol, washed with alcoholic hydrochloric acid, redissolved in water, and boiled with baryta to remove ammonia. The barium is removed with sulphuric acid and the glutamic acid is again precipitated as hydrochloride by saturating the solution with gaseous hydrogen chloride. It is usually quite pure. The mother liquor on further concentration may give further crops of glutamic acid hydrochloride. These are treated in the same way as the first crop. The whole of the glutamic acid in the protein is not always precipitated as hydrochloride; the remainder is then isolated later. The precipitation of glutamic acid hydrochloride is, however, so nearly complete that the yield is considered quantitative. Many comparative determinations of the glutamic acid content of various proteins have been made by Abderhalden and his co-workers, and a series of values in numerous vegetable proteins and a few animal proteins have been published by Osborne and Gilbert [1906]. Abderhalden

PT. I. 


\section{[1912] states that glutamic acid is most rapidly obtained from the} hydrochloride by dissolving in water, passing in ammonia, evaporating to dryness, and recrystallising from water. The remaining glutamic acid is obtained from the mother liquor by adding alcohol.

\section{(Ia) Isolation of Glutamic Acid as Zinc Salt.}

In view of the sometimes incomplete separation of glutamic acid as hydrochloride, especially in the cases of the proteins containing less than ro per cent. of this unit and in view of its incomplete isolation as ester at a later stage, the observation of Kutscher [1903] that glutamic acid forms a very insoluble zinc salt might be made use of to isolate it. The mixture of amino acids, after removal of the greater part of the hydrochloric acid by evaporation in vacuo, is diluted with water and boiled with excess of zinc oxide and allowed to cool. The precipitate consisting of the excess of zinc oxide and zinc glutamate is dissolved in hot dilute acetic acid and treated with hydrogen sulphide. The filtrate on evaporation yields glutamic acid.

A disadvantage of this method is the fact that leucine also forms a zinc salt which is soluble with difficulty. The separation of glutamic acid and leucine may be effected by the method of Osborne and Liddle [19ro, 2], i.e., neutralising the acidity of the glutamic acid and crystallising out the leucine. The glutamic acid is then obtained on acidifying and crystallising, or as hydrochloride.

\section{(Ib) Isolation of Glutamic and Aspartic Acids as Silver Salts.}

Glutamic acid and aspartic acid form silver salts which are not easily soluble in water [Habermann, 1875]. Siegfried [189I] was able to isolate aspartic acid as silver salt and Kutscher [r903] has shown that the solubility of the silver salts of these amino acids in water is very slight. Kutscher devised a method for isolating these units depending upon the insolubility of the silver salts. The mixture of amino acids after hydrolysis with sulphuric acid and removal of the di-amino acids, or similarly after hydrolysis with hydrochloric and removal of di-amino acids, is evaporated in vacuo to remove as much as possible of the hydrochloric acid; its removal is completed as silver chloride. The solution is treated with silver nitrate or better another soluble silver salt and baryta water carefully added, avoiding excess which decomposes the silver salts. This may be tested by withdrawing a drop of the solution and placing it in contact with a drop of ammoniacal silver nitrate; a turbidity indicates that more baryta is required. The silver salts are decomposed and the mixture is separated, either by preparing glutamic acid hydrochloride, or by preparing the zinc salts; the zinc salt of aspartic acid is easily soluble in water.

\section{(IC) Isolation of Glutamic and Aspartic Acids as Calcium Salts.}

Foreman $\left[\mathrm{IgI}_{4}, \mathrm{I}\right]$ has found that the calcium salts of these dibasic amino acids are insoluble in alcohol and has described a method for isolating them based upon this property.

The hydrochloric acid solution is evaporated to a syrup in vacuo; the syrup is dissolved in 200-400 c.c. of water per 20-40 grams of protein and 0.5 gram of slaked calcium oxide per gram of protein is added. The mixture is shaken well and filtered from excess of lime and humin substances. The filtrate is evaporated in vacuo at $40-45^{\circ}$ to a volume of 3.5-4 c.c. per gram of protein; ammonia is thus removed. The temperature at which evaporation is carried out should not exceed $45^{\circ}$ so as to prevent the transformation of glutamic acid into pyrrolidone carboxylic acid. Rectified spirit is now added in small quantities at a time with vigorous shaking so as to prevent clumping of the pre- 
cipitate; alcohol is added so long as precipitation occurs, about I litre being required. The precipitate is filtered off and washed thoroughly with alcohol. If a small precipitate forms as the wash alcohol comes in contact with the filtrate, it is neglected: it does not contain glutamic acid and aspartic acid, but may consist of the calcium salt of tyrosine. The precipitate is dissolved in about 300 c.c. of water and treated with oxalic acid to remove the calcium completely. The filtrate from calcium oxalate is treated with silver sulphate solution to remove traces of chloride and pigmented substance; the pigmented substance dissolves if the solution be heated, but is removed later. Excess of silver is removed from the solution with hydrogen sulphide and the volume reduced to about one half. By now adding a solution containing 5-Io grams of phosphotungstic acid the colouring matter is precipitated, and the excess of this reagent is thrown down by baryta, which is added until the blue colour, if formed, disappears ; excess of baryta is removed by sulphuric acid and the filtrate evaporated to about 50 c.c. The solution is transferred to a weighed dish with a stirring rod, further evaporated to 20 or 25 c.c. for 40 grams of protein and allowed to cool. The acids crystallise out, are stirred and dried further in a desiccator over calcium chloride.

The mass does not consist of a mixture of the pure amino acids; it is therefore stirred up with cold glacial acetic acid; the insoluble residue is filtered off, again stirred with glacial acetic acid, filtered off and washed; the residue is dried and weighed. The acetic acid solution dries in vacuo over potash to a gum which contains pyrrolidone carboxylic acid, which may be estimated by determining the amino nitrogen before and after hydrolysis with concentrated hydrochloric acid.

The residue of glutamic acid and aspartic acid is separated by preparing the copper salts and crystallising out copper aspartate. The glutamic 'acid is isolated from the filtrate as hydrochloride; or glutamic acid may be isolated first as hydrochloride and the aspartic acid from the filtrate. By determining the carbon content of the mixture of the acids, the proportion of aspartic acid in the mixture is given by multiplying the yield by

the remainder is glutamic acid.

$$
\frac{40.82 \text { - per cent. of carbon }}{40 \cdot 82-36.09}
$$

The method has only been carried out with caseinogen; the yield of aspartic acid was $r \cdot 8$ per cent. and of glutamic acid about $\mathbf{r} 6.2$ per cent. On adding the amount of glutamic acid corresponding to the amino nitrogen determination of the pyrrolidone carboxylic acid the yield was $2 r^{\circ} 8$ in one experiment and $24^{\circ} \mathrm{I}$ in another. This is considerably higher than the yield of 15.6 by the hydrochloride method; the yield of glutamic acid actually isolated was in good agreement with the above.

\section{(2) Esterification.}

The filtrate from the glutamic acid hydrochloride, to which the mother liquors from the recrystallisations are added, is concentrated in vacuo at a low temperature to a thick syrup; this is dissolved in absolute alcohol ( 3 litres to I kilo. protein), and the amino acids are esterified by saturating the alcohol with dry gaseous hydrochloric acid at the ordinary temperature and then warming on the water-bath for half an hour. In the process of esterification a large amount of water is formed, which prevents its completion; the alcohol is therefore evaporated off in vacuo at a temperature below $50^{\circ}$ and the resulting syrup again dissolved in absolute alcohol and saturated with 
dry gaseous hydrochloric acid. In some cases it may be necessary to repeat this operation once more.

The esterification, according to Osborne and Jones [1910, 2], is more advantageously effected by the method of Phelps and Tillotson. The concentrated solution of amino acid hydrochlorides is dissolved in alcoholic hydrochloric acid and zinc chloride is added as a catalyst. The solution is maintained at a temperature of $100^{\circ}$ and the vapours of absolute alcohol containing some hydrochloric acid are passed into the solution. The water arising during the process is removed by the alcohol vapours as fast as it is formed, and complete esterification results in a shorter time.

Since the completion of the esterification of the amino acids necessitates at least two evaporations and two treatments with absolute alcohol and hydrogen chloride, Foreman [rgr 3 and unpublished ${ }^{1}$ ] proposed that the esterification be effected with the dry lead or copper salts of the amino acids. The solution of amino acids is evaporated in vacuo and steam is passed into the remainder to remove hydrochloric acid as completely as possible. It is diluted to about 2000 c.c. (with 320 grams protein) and heated with Ioo grams of precipitated lead hydroxide. The undissolved matter, which is dark in colour and contains humin, is filtered off. The filtrate is boiled for forty-five minutes with $400-500$ grams of litharge. It is best to treat first with precipitated lead hydroxide, as under these conditions the humin separates in a flocculent state. The excess of litharge is filtered off and washed, and the solution is evaporated to about 500 c.c. On cooling it sets to a semi-solid mass, but it is stirred up on a water-bath until it becomes too viscous and dried in a steam oven. The dry mass, so obtained, can be powdered, but this is not necessary. The lead salts are suspended in about $\mathbf{r}_{500}$ c.c. of absolute alcohol and dry hydrogen chloride passed in until the liquid is saturated. The solution is allowed to cool and again saturated with hydrogen chloride. The lead chloride is filtered off and washed with absolute alcohol; the filtrate and washings are evaporated to half their volume at $40^{\circ}$ and $15 \mathrm{~mm}$. The excess of hydrochloric acid is removed by slowly adding at $0^{\circ}$ alcohol saturated with dry ammonia until the liquid is only faintly acid, thus avoiding liberation of the esters from their salts. The ammonium chloride, thus formed, is filtered off and washed with absolute alcohol and the alcohol evaporated off in vacuo at $40^{\circ}$ and $15 \mathrm{~mm}$. (the further treatment is described on p. 40 ).

\section{(3) Isolation of Glycine as Ester Hydrochloride.}

At this stage, glycine, if it occurs in the protein, e.g., in gelatin, in any considerable amount, is separated as glycine ester hydrochloride by concentrating in vacuo at $40^{\circ}$ to two-thirds and seeding the solution with a crystal of this compound and allowing to stand for twentyfour hours at $0^{\circ}$. The precipitate is filtered off while the liquid is kept cold and is washed with ice-cold alcohol ; the mother liquor, on further concentration in vacuo and saturation again with hydrochloric acid, may give another crop of glycine ester hydrochloride, which is treated

${ }^{1}$ Mr. Foreman has kindly informed me of the full details of his process, which gives as good, or even better, yields than the direct esterification process. 
in same way. The glycine ester hydrochloride is dried in vacuo over lime and sulphuric acid, and is purified by recrystallisation from absolute alcohol, charcoal being used to decolorise the solution. Almost the whole of the glycine may be isolated in this way [Fischer, 1902].

The filtrate containing the esters of the hydrochlorides of the other amino acids and the filtrate from the recrystallised glycine ester hydrochloride are combined and concentrated to a syrup in vacuo at $40^{\circ}$, the process of esterification is best repeated again, and any further quantities of glycine ester hydrochloride separated.

\section{(4) Extraction of the Esters of the Amino Acids.}

The esters are liberated from their hydrochlorides in the solution which has been concentrated in vacuo at $40^{\circ}$ to a syrup by one of the following methods:-

(a) About one-third to one-half the volume of water is added to dissolve the syrup, and, if I kilo. of protein has been used, the solution is divided into two or four portions for convenience and to ensure the subsequent thorough cooling; to each portion two or three volumes of ether are added, and the mixture is thoroughly cooled in a freezing mixture of ice and salt; strong caustic soda (33 per cent.) is now added till the free hydrochloric acid is neutralised; this can be tested by adding a small quantity of a saturated solution of potassium carbonate. The feebly basic esters of aspartic and glutamic acids, which are very sensitive to free alkali, are thus liberated and are dissolved by the ether, which is quickly poured off and replenished by a fresh quantity. Caustic soda and solid potassium carbonate added in small portions at a time set free the other esters from their hydrochlorides; these are dissolved by the ether, which is frequently renewed throughout the process and thoroughly mixed with the mass of salt and potassium carbonate; sufficient caustic soda must be added to combine with the whole of the hydrochloric acid, and as much potassium carbonate as is necessary to form finally a pasty mass in order that the esters, which are very easily soluble in water, are salted out and dissolved by the ether. A large amount of ether is required for this extraction, which is continued until the ether separates in a colourless state, and an essential condition is that, throughout the process of extraction the various portions be kept thoroughly cold by shaking in the freezing mixture.

The several ethereal extracts are each dried by shaking for about five minutes with potassium carbonate; they are then combined to- 
gether and allowed to stand for twelve hours with anhydrous sodium sulphate.

The ether is next evaporated off, preferably in small quantities at a time and in vacuo at the ordinary temperature; in this way the lower boiling esters do not distil with the ether and the danger of decomposing them by a higher temperature is avoided. A brown oil, consisting of the esters of the amino acids, results ; this is fractionally distilled in vacuo.

A considerable amount of the lower boiling esters nevertheless distils with the ether, especially those of alanine and glycine. Leucine ester has also been found in the distillate. They are recovered by shaking out the ether with dilute hydrochloric acid and evaporating the acid aqueous solution to dryness, when they remain as amino acid hydrochlorides. The glycine is separated as ester hydrochloride and the alanine, and leucine if present, are separated as esters by fractional distillation in vacuo (see p. 40). They may also be obtained by evaporating their solution with water, removing the hydrochloric acid with lead oxide and silver carbonate, the excess of these by hydrogen sulphide and fractional crystallisation. Leucine, if present, separates out first, and subsequently the alanine. A mixture of small quantities of glycine and alanine generally remains which is too small for further separation; it may be treated with picric acid (see p. $5 \mathrm{I}$ ).

By this method of extracting the esters from their hydrochlorides, neither that of tyrosine, which remains behind combined with alkali, nor those of the di-amino acids, which are soluble with difficulty in ether, are obtained. This is adrantageous for the subsequent process of separation, but the method has the disadvantage that the whole quantity of esters is not taken up by the ether. Extraction with chloroform after ether increases the amount of ester; it separates the pasty mass of potassium carbonate into particles which can be washed with the solvent; this extract contains the ester of tyrosine.

The main loss seems to be caused by the destruction of the esters by the alkali. In order to avoid this loss, the mass of carbonate is treated with excess of hydrochloric acid and evaporated down, the potassium chloride being filtered off as it separates out; the residue is extracted with alcohol and the above process of esterification is repeated. It is simpler to suspend the mass of carbonate in absolute alcohol and to saturate the solution with gaseous hydrochloric acid. The salts remain insoluble and are filtered off and the alcoholic solution is treated as has been described. 
(b) In order to separate the amino acids as completely as possible, Fischer introduced another method of liberating the esters from their hydrochlorides, i.e., treatment with sodium ethylate. The hydrochloric acid is removed as completely as possible by evaporation in vacuo and the mixture of ester hydrochlorides is dissolved in five times its quantity of absolute alcohol. The amount of chlorine is estimated in a small portion of this, and to the remainder the calculated quantity of sodium dissolved in absolute alcohol and freshly prepared, so as to make a 3 per cent. solution, is added. The sodium chloride formed is filtered off. Its separation is greatly facilitated by the addition of ether and cooling to $0^{\circ}$. The alcohol is removed by evaporation in vacuo. A small quantity of the lower boiling esters of the amino acids passes into the distillate with the alcohol, but is recovered by acidifying with hydrochloric acid and evaporating when the amino acid hydrochlorides are obtained. A dark-brown oil again results, which is fractionally distilled in vacuo.

Although this method prevents loss by the action of alkali, the yield of the higher boiling fractions is not so great on account of the more complex nature of the mixture of esters. The residue which does not distil contains the tyrosine, the di-amino acids, and other substances.

(c) Instead of employing caustic soda and potassium carbonate for the liberation and salting out of the esters, Levene [1905] proposed the use of barium oxide, for which he claims the following advantages:-

(i) On account of its small solubility in water, a large excess of alkali which causes saponification of the esters is avoided.

(ii) In neutralising the free acid the rise in temperature is less than with caustic soda.

(iii) When the second esterification is required it is more easily removed.

The procedure described by Levene and Van Slyke $[1909,2]$ is as follows :-

The concentrated solution of the ester hydrochlorides is poured into a porcelain or enamelled vessel of capacity of I litre for every I25I 50 grams protein, and the flask is washed out with ice-cold baryta solution. The vessel is placed in a freezing mixture. When the contents are cold excess of crystallised baryta is added, and the mixture is thoroughly stirred with a wooden or porcelain spatula. The peculiar sticky mass in a few minutes becomes liquid and the solution becomes alkaline in reaction. Several volumes of ether are then poured over 
the solution. The ether is then poured off and a fresh quantity added. More baryta is added and the stirring continued. The ether is replenished and more baryta added several times. During the process the mixture becomes cloudy and pasty, but finally a light dry mass of baryta is left.

The ethereal solutions are treated as described in the (a) method.

For the second esterification process the residue is stirred up several times with water, filtered through asbestos, and washed with water till no more organic matter is extracted. Most of the baryta remains undissolved. The solution is freed from that which has dissolved by the equivalent quantity of sulphuric acid, acidified with hydrochloric acid, and esterified in the usual manner.

(d) Pribram [1910] found that the esters may be liberated very conveniently by the action of ammonia. His preliminary experiment with glycine gave a yield of 69 per cent. and an equally good yield of esters was obtained from gelatin. Abderhalden has also found this method very serviceable.

The concentrated solution of ester hydrochlorides is mixed with ether and surrounded with a freezing mixture. Ammonia, dried by passing through three towers of caustic soda and lime, is then passed into the solution. The ammonium chloride which is formed is filtered off and washed with absolute alcohol. The ether is distilled off and the esters fractionally distilled in vacuo.

(e) Zelinsky, Annenkoff and Kulikoff [IIII] suggested a still simpler procedure for obtaining the esters. The concentrated solution of the ester hydrochlorides is mixed with lead oxide ( 200 grams to roo grams protein) and the mass is directly distilled in vacuo. Abderhalden and Weil [rgr2, 3] do not recommend this method on account of the great loss which occurs during extraction.

(f) Foreman (see p. 36) dissolves the syrup of ester hydrochlorides in rooo-I500 c.c. of dry chloroform and filters from ammonium chloride. $300-35^{\circ}$ grams of anhydrous baryta are added in small quantities at a time and the mixture well shaken after each addition. The liquid is tested with silver nitrate and nitric acid and if a precipitate forms it is allowed to stand until this no longer occurs. The excess of baryta is filtered off and washed with dry chloroform, the chloroform is evaporated off in vacuo and the residue dissolved in ether ; only a gum-like substance remains undissolved. The ether is removed by distillation in vacuo and the residue of ester distilled in vacuo. The baryta was found to contain some amino acids; it was decomposed with sulphuric acid and the solution treated with lead hydroxide in the same way as the original solution.

\section{(5) Fractional Distillation of the Esters in Vacuo.}

The fractional distillation of the brown oil, which is obtained by either of these methods, is carried out firstly at a pressure of IO-I 2 $\mathrm{mm}$. produced by a water pump, and then at a pressure of $0.5 \mathrm{~mm}$. 
produced by a Geryck vacuum pump, as described by Fischer and Harries [1902]. In order to preserve the high vacuum in this process liquid air is used for condensing the alcohol vapour arising from the decomposition of the esters; carbonic acid has been used by other investigators, and Levene and Van Slyke [1908, I] employed sulphuric acid, contained in cotton wool and cooled by a freezing mixture, as an absorbent for this purpose. A small quantity of ester also passes over with the alcohol; this cannot be recovered if Levene and Van Slyke's modification be used. The accompanying figure shows the arrangement for the distillation at low pressure. At $10-12 \mathrm{~mm}$. pressure the receiver should be cooled in a freezing mixture.

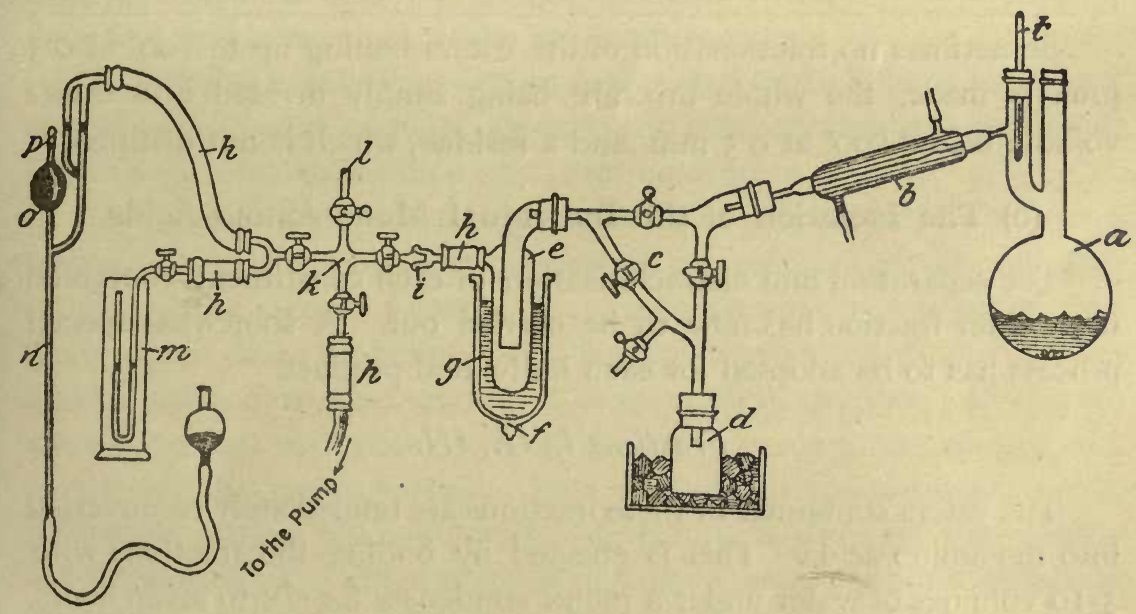

FIG. I.

From Berichte der Deutschen Chemischen Gesellschaft, 35, 2160.

The temperatures at which the various fractions are collected are those of the vapours of the esters at $10 \mathrm{~mm}$. pressure, and those of the water-bath at $100^{\circ}$ and of an oil-bath, which replaces the waterbath for the higher temperatures up to $160^{\circ}$, at $0.5 \mathrm{~mm}$. pressure.

Formerly the lower boiling fractions were again distilled in vacuo so as to obtain a further fractionation, but each fraction, even then, did not generally contain a single ester of an amino acid. A second fractionation is therefore no longer carried out.

In the case of the higher boiling fractions a second fractionation is not necessary, since the esters contained in them can be separated by their varying solubility in water, ether and petroleum ether. Accord- 
ing to Osborne and Jones $[1910,2]$ the distillation of the esters boiling above $110^{\circ}$ can be dispensed with. An equally good separation of this residual mixture can be effected if it be carried out in the same way as is described for the esters after they have been distilled.

The following table shows the fractions which are usually collected, and the amino acid esters which they may contain :-

\begin{tabular}{|c|c|c|}
\hline Temperature. & Pressure. & Esters of \\
\hline $\begin{array}{l}\text { Fraction I. To } 60^{\circ} \text { (vapour) } \\
\text { "II. } 60-90^{\circ} \text { (vapour), } 100^{\circ} \text { (water-bath) } \\
\text { " III. 100 (water-bath) } \\
" \text { IV. 100-160 (oil-bath). }\end{array}$ & $\begin{array}{l}\text { ro } \mathrm{mm} \text {. } \\
\text { Io } \mathrm{mm} \text {. } \\
0.5 \mathrm{~mm} \text {. } \\
0.5 \mathrm{~mm} \text {. }\end{array}$ & $\begin{array}{l}\text { Glycine, alanine, leucine, } \\
\text { proline. } \\
\text { Valine, leucine, proline. } \\
\text { Leucine, proline. } \\
\text { Phenylalanine, glutamic acid, } \\
\text { aspartic acid, serine. }\end{array}$ \\
\hline
\end{tabular}

Sometimes no fractionation of the esters boiling up to $100^{\circ}$ at 0.5 $\mathrm{mm}$. is made, the whole mixture being simply divided into esters volatile below $100^{\circ}$ at $0.5 \mathrm{~mm}$. and a residue, which is not distilled.

\section{(6) The Isolation of the Individual Mono-Amino Acids.}

The separation and characterisation of each constituent contained in an ester fraction has now to be carried out. A somewhat special process has to be adopted for each individual product.

\section{Fractions I., II., III.}

The esters contained in these fractions are immediately reconverted into the amino acids. This is effected by boiling the fractions with 5-IO volumes of water under a reflux condenser for six to seven hours, until the alkaline reaction has disappeared.

If leucine be present in considerable amount, as may be the case in fraction III., the solution on cooling may deposit crystals of this substance. These are filtered off, washed with water, dried and weighed. Identification of the product is carried out as described below.

The three solutions are then evaporated to dryness in vacuo in weighed flasks and the amount of residue ascertained for each fraction.

Levene and Van Slyke $[1908,2]$ have found that leucine ester, like phenylalanine ester, is readily dissolved by ether from water. The ester fractions may therefore, before hydrolysis, be mixed with 3 volumes of water and extracted with ether, and the ether extract washed three times with water. The aqueous solution is then saponified by boiling and the extract, after removal of the ether, is treated in the same way. 


\section{(a) Proline.}

Proline is the only product contained in these fractions which is soluble in alcohol; it is also much more easily soluble in water than the other products.

The dry residues are therefore extracted several times with boiling absolute alcohol ; these extracts on cooling frequently become turbid, and on standing deposit other amino acids which, though insoluble in alcohol, are dissolved when proline is present. They are filtered off and returned to the portion insoluble in alcohol.

The combined alcoholic extracts of the three fractions are again evaporated to dryness in vacuo and the residue is treated several times with cold absolute alcohol. A considerable amount is undissolved; as before this is returned to the insoluble portion.

The alcoholic solution is again evaporated to dryness in vacuo and extracted with cold absolute alcohol, and this operation is continued until all the insoluble amino acids are removed.

The final alcoholic solution is evaporated to dryness and the residue weighed. As thus obtained, the proline is a mixture of the optically active and the racemic forms. These are separated by conversion into their copper salts by boiling with freshly precipitated copper oxide. The resulting dark-blue solution is evaporated to dryness, and the residue is treated with absolute alcohol which dissolves the copper salt of the optically active proline. This solution on concentration yields the greater part of the compound in a crystalline state, but the remainder is amorphous. The copper salt of the racemic proline, which is insoluble in alcohol, is purified by crystallisation from water.

The identity of the compounds is established by a determination of the water of crystallisation and of the copper. The racemic copper salt contains 2 molecules of water of crystallisation, and in this state it is dark blue in colour; in the anhydrous state its colour is violet. Further characterisation is obtained by preparing proline from it. The copper salt is dissolved in water and decomposed with hydrogen sulphide. The filtrate is concentrated to a small volume and precipitated with alcohol. The product, crystallised from alcohol, is obtained in flat needles. $l$-proline has a sweet taste, melts at $206-209^{\circ}$ and has a rotation of $[a]_{20}^{\mathrm{D}}=-774^{\circ}$. The phenylhydantoin of $l$-proline is the most suitable derivative for still further characterisation.

The amount of proline in the protein is given by the yield of the two copper salts obtained in a pure state. The actual proline content 


\section{THE CHEMICAL CONSTITUTION OF THE PROTEINS}

of the protein is considerably larger than the figures given in the tables (pp. I I I-I 30). Abderhalden and Kautzsch [1912] consider that the yields of both forms of proline should be always separately given. The yield if it be based on the yield of copper salts is not a proper value.

The real proline content can be accurately determined, as Van Slyke [I9I I, 3] has shown by his nitrous acid method (p. 89), by a determination of the total and amino-nitrogen of the product soluble in absolute alcohol. The alcoholic solution is made up to a definite volume and aliquot portions are taken for these estimations. The difference gives the amount of nitrogen present as proline from which the amount of proline can be calculated. In the case of caseinogen the proline content was found to be 6.7 per cent., a figure which is twice that found by Abderhalden. It agrees with that found by Engeland by his method of methylation (p. 69). Abderhalden and Kautzsch [1912] believe that the proline content determined by the Van Slyke method is not accurate, as the solution may contain other nitrogenous products which do not evolve nitrogen on treatment with nitrous acid.

\section{(b) Glycine, Alanine, Valine, Leucine, and Isoleucine.}

These five amino acids are present together in varying proportions in the residues which are insoluble in absolute alcohol. Their separation is only effected with great difficulty, and the procedure depends very largely upon which amino acids are present in the several fractions.

In each case the residue is dissolved in water and, if necessary, the solution is decolorised by boiling with charcoal. The aqueous solutions are concentrated and fractionally crystallised; the final mother liquor is evaporated to dryness. Each fraction is dried and weighed. Indications of the constituents of each fraction may be obtained:-

I. By elementary analysis of the carbon, hydrogen and nitrogen content.

2. By determining the melting-point; the substance must be rapidly heated. Glycine melts at $240^{\circ}$, alanine about $297^{\circ}$, leucine about $300^{\circ}$, and valine about $315^{\circ}$.

3. By the taste. Glycine and alanine have a sweet taste; valine is less sweet and it leaves a bitter after-taste; leucine is insipid and slightly bitter.

The following fractions may be obtained by the fractional crys- 
tallisation of the amino acids obtained from the esters after removal of the proline :-

I. Valine + leucines.

2. Valine + alanine.

3. Alanine. This is purified by recrystallisation from dilute alcohol.

4. Alanine + glycine.

If the esters be separated by distillation into three fractions, the residues from fraction I. will contain chiefly glycine and alanine; from fraction II. valine, leucine and isoleucine; from fraction III. leucine and isoleucine.

\section{i. Separation of Valine from Leucine and Isoleucine.}

These three compounds are the most difficult to separate from each other. Their separation has really only been accomplished by chance.

In those cases where the isolation of the individual substance has succeeded it has been effected by the fractional crystallisation of the amino acids themselves and of their copper salts and by the different solubility of the compounds in methyl alcohol. Valine is soluble in methyl alcohol, isoleucine is insoluble in the cold solvent, but soluble in the hot. On cooling the solution, however, the presence of valine prevents its separation. The copper salt of leucine is very insoluble, but the mixed copper salts are relatively soluble. Leucine and isoleucine were first separated by F. Ehrlich [1904] by the different solubility of their copper salts in methyl alcohol; that of leucine is insoluble. The separation is most tedious and not at all satisfactory.

In order to give us more information about the constituents of this fraction, Levene and Van Slyke [1909, I, 2] worked out a method which depends upon the precipitation of leucine and isoleucine as their lead salts from ammoniacal solution and the subsequent separation of these two amino acids by means of the different solubility of their copper salts in methyl alcohol. The details are as follows :-

The mixture is carefully analysed and the amount of leucine + isoleucine is calculated from the carbon content:-

Leucine and isoleucine contain $54^{.92}$ per cent. C.
Valine contains $. \quad \cdot 5 \mathrm{I}^{\cdot 24}, "$ difference $=3.68$ per cent.
$\frac{\text { Per cent. carbon }-5 \mathrm{r}^{\cdot 24}}{3^{\cdot 68}}=$ per cent. of leucine isomers in the mixture.

The mixture is pulverised and suspended in 7 parts of water and the water is raised to the boiling-point: for each gram of substance I. 5 c.c. of concentrated ammonia solution is then added. The flask 
is stoppered and shaken so as to dissolve the amino acids ; if necessary the solution may be again heated.

4 c.c. of I.I M lead acetate solution (sp. gr. I.254 at $20^{\circ}$ ) for each gram of leucine and isoleucine are slowly added to the hot solution, which is thoroughly stirred during the addition. The solution is then cooled in ice-water and after one to two hours is filtered through a Buchner funnel, or a Gooch crucible, according to the amount of precipitate. The solid matter is pressed down so as to remove the mother liquor as completely as possible, and it is washed firstly with 90 per cent. alcohol, then with ether, and dried in vacuo over sulphuric acid.

It is curious that the presence of valine facilitates the separation of the lead salts of the leucine isomers.

If the proportion of isomers: valine be less than $2:$ I the precipitation is not so complete. In these cases less lead acetate solution (3.7 c.c.) should be taken and the filtrate concentrated in vacuo till the percentage of valine reaches 10 . Ammonia is again added and the precipitate treated as before. It is preferable to treat the filtrate once more in the above manner after the valine has been separated.

\section{ii. Valine.}

The filtrate is freed from lead by means of hydrogen sulphide, and the solution, filtered from lead sulphide, is evaporated to dryness. The dry residue is treated with an alcohol-ether mixture $(3: I)$ to extract acetic acid and ammonium acetate. The small amount of valine which dissolves is recovered by again evaporating to dryness and extracting with alcohol and ether.

Pure valine generally remains; it is identified by recrystallisation from water, elementary analysis, and rotation in 20 per cent. hydrochloric acid of $[a]_{20}^{\mathrm{D}}=+28 \cdot 8^{\circ}$; a rotation of $26-28^{\circ}$ is generally found as racemisation occurs in the process.

If analysis shows leucine to be present the above treatment must be repeated. 


\section{iii. Leucine and Isoleucine.}

The purity of the lead salt, as obtained above, is tested by analysis. This is performed by dissolving about 0.3 gram in 5 c.c. of normal nitric acid in a 100 c.c. beaker and precipitating the lead with 5 c.c. of normal sulphuric acid followed by 50 c.c. of absolute alcohol. The lead sulphate, which settles rapidly in a granular form, is collected after about fifteen minutes in a Gooch crucible and washed with 95 per cent. alcohol acidified with sulphuric acid. The crucible is placed in another crucible, heated gently until the alcohol is driven off, and then with the full heat of the Bunsen burner for ten minutes.

If the lead content be too high, due to contamination with the lead salt of valine, the mixture is purified by dissolving it, after thorough pulverisation, in 5 parts of hot water $+\frac{1}{4}$ part of glacial acetic acid and reprecipitating by adding 0.5 c.c. of concentrated ammonia solution for every gram of salt. The precipitate is collected and treated as above under the conditions where the amount of valine present is small.

The last portions of the mixed leucines are recovered by repeating the entire process.

The mixed lead salts are dissolved in 15-20 parts of hot water + $\frac{1}{4}$ part of glacial acetic acid, and hydrogen sulphide is passed into the solution. The filtrate from the lead sulphide is evaporated in vacuo to dryness, and the residue is washed with a mixture of equal parts of alcohol and ether to remove acetic acid.

Since these isomers have been shown not to be racemised by heating with acids, the composition of the mixture can be ascertained by determining the rotation in 20 per cent. hydrochloric acid:-

$$
\begin{aligned}
& \left.\begin{array}{c}
d \text {-isoleucine has }[\alpha]_{20}^{\mathrm{D}}=+374^{\circ} \\
l \text {-leucine } "[\alpha]^{\mathrm{D}}=+15 \cdot 6^{\circ}
\end{array}\right\} \text { difference }=21 \cdot 8^{\circ} \\
& \text { hence percentage of } d \text {-isoleucine }=100 \times \frac{a-15 \cdot 6}{21 \cdot 8} \\
& " \quad \quad l \text {-leucine }=100 \times \frac{37 \cdot 4-\alpha}{2 I^{\circ} \cdot 8} .
\end{aligned}
$$

From the weight of the mixed amino acids and these data the amount of each isomer can be calculated.

The mixed isomers are converted into their copper salts by boiling with excess of copper oxide, which is thoroughly boiled out with water to remove the last traces of the copper salt of leucine which is pale blue in colour and very insoluble.

The solution of the copper salts is evaporated to dryness in vacuo. 
The dry and finely pulverised copper salts are then shaken in a shaking machine with 94 per cent. methyl alcohol. The insoluble copper salt of leucine is filtered off and washed with solvent. The soluble copper salt of isoleucine may be contaminated with some of the copper salt of leucine. It is therefore decomposed with hydrogen sulphide, reconverted into copper salt and again extracted with methyl alcohol. Both the leucine and isoleucine are obtained in the usual way from the copper salt and recrystallised from water.

They are identified by elementary analysis, rotation and estimation of copper in their copper salts.

\section{iv. Separation of Valine and Alanine.}

Levene and Van Slyke [1913] described a method for separating these two amino acids. It depends (I) upon the greater insolubility of alanine phosphotungstate than valine phosphotungstate in a solution containing ro per cent. of sulphuric acid and 20 per cent. of phosphotungstic acid; (2) the greater insolubility of valine in 80 per cent. acetone. Alanine combines with 14 parts of phosphotungstic acid. The solubility of alanine phosphotungstate in the above solution is 0.15 gram per 100 c.c.; that of valine phosphotungstate is I. 2 gram. A mixture of the two compounds can be separated by crystallisation from this solution. Glycine behaves like alanine; its phosphotungstate has the solubility of 0.2 gram per 100 c.c. If leucine be present in the mixture it must be first separated as lead salt (above).

In carrying out the separation the mixture should preferably contain not more than 50 per cent. of valine, and in precipitating the alanine the volume of liquid should be as small as possible. There are two alternatives: $(a)$ if the alanine phosphotungstate is not recrystallised, the volume should be 100 c.c. for every gram of valine present; $(b)$ if the alanine phosphotungstate be recrystallised, the volume need only be $30-40$ c.c. per gram of valine; one recrystallisation from the same volume yields pure alanine phosphotungstate.

The most satisfactory separation is conducted by dissolving the mixture of valine and alanine in a hot sulphuric acid solution containing 10 grams per 100 c.c. in the proportion of $30-40$ c.c. per gram of valine present. This amount is given by an elementary analysis of the mixture. Phosphotungstic acid ${ }^{1}$ in the ratio of $14: 1$ according

${ }^{1}$ The phosphotungstic acid is purified by Winterstein's method by dissolving in a small volume of water and extracting with ether. An oily solution heavier than water 
to the maximum amount of alanine in the mixture and I gram excess for every 5 c.c. of solution is dissolved in the hot solution. A greater excess does not interfere with the separation, but it requires removal subsequently. The solution is kept at $0^{\circ}$, or in ice water in an ice box for at least twenty-four hours. ${ }^{1}$ The alanine phosphotungstate separates in large transparent crystals forming a solid layer on the bottom and sides of the vessel. The supernatant solution is decanted and the crystals are redissolved in the same volume of ro per cent. sulphuric acid as that originally used, I gram of phosphotungstic acid per 4 or 5 c.c. of liquid are added, and the solution kept at $0^{\circ}$ for twenty-four hours. The alanine phosphotungstate is filtered off by suction and washed with ro per cent. sulphuric acid containing 20 per cent. of phosphotungstic acid.

The alanine in the phosphotungstate is determined and recovered by dissolving the salt in hot water in which it gives a somewhat turbid solution and making up to a known volume containing 50-100 $\mathrm{mgm}$. of alanine per Io c.c. The nitrogen in this solution is estimated by Van Slyke's method (p. 89) using Io c.c., or 2 c.c. if the micro-apparatus be used. It can also be estimated by Kjeldahl's method, but this is not so convenient on account of the violent bumping caused by the separation of tungstic acid. This estimation gives a more accurate value for the alanine than its isolation, as loss occurs during the removal of the phosphotungstic acid; the actual amount isolated is from $90-95$ per cent. of that found by the nitrogen estimation. A correction for the solubility of alanine phosphotungstate - I 5 gram in 100 c.c. solution-can be applied.

The remainder of the solution is washed into a beaker, heated to boiling, and treated with excess of pure 20 per cent. lead acetate solution ${ }^{2}$ excess of lead acetate is ascertained by removing a drop and testing with dilute sulphuric acid. Lead sulphate and phosphotungstate are filtered off and thoroughly washed. The filtrate and washings are concentrated to about 50 c.c. per gram of alanine, an equal volume of 95 per cent. alcohol added, and the mixture heated on the water-bath for about one hour. This removes the remainder of the

results. It is washed several times with water and the ether removed on the water-bath. The product is not hygroscopic and forms a colourless solution. It should leave no residue after precipitation with pure lead acetate and evaporation of the filtrate.

${ }^{1}$ Working at room temperature, about 75 per cent. of the alanine is precipitated if one half of the volumes given are used.

${ }^{2}$ This should leave no residue after removal of the lead with hydrogen sulphide and evaporating to dryness.

PT. I. 


\section{O THE CHEMICAL CONSTITUTION OF THE PROTEINS}

lead sulphate. The excess of lead is removed with hydrogen sulphide, the lead sulphide washed with water containing hydrogen sulphide and the liquid is evaporated in vacuo to a small volume. It is transferred to a Jena glass dish, evaporated until all liquid disappears and the alanine dried by placing in a vacuum desiccator over sulphuric acid and caustic potash. The substance becomes discoloured if it be dried on the water-bath. The product is nearly ash-free alanine, but it may contain glycine, if glycine was present in the original mixture. The rest of the alanine in the mixture is obtained after isolating the valine.

The phosphotungstic acid filtrates and washings containing the valine is made up to a known volume and the amount of valine estimated by a nitrogen determination by Van Slyke's method, using Io per cent. sulphuric acid instead of water in a blank determination. The reagents are removed with lead acetate as described above under alanine, and the solution evaporated till valine begins to crystallise; 2-3 volumes of 80 per cent. acetone are added and the mixture washed into a flask with 80 per cent. acetone; the flask is stoppered to prevent evaporation of the acetone and allowed to stand for twelve hours. Valine crystallises out; it is filtered off and washed with 80 per cent. acetone. Its yield is $80-85$ per cent. of the amount found in the mixture by analysis.

The filtrate is evaporated to dryness and the above separation repeated. It is then practically quantitative. 


\section{v. Separation of Glycine and Alanine.}

There are two methods of separating these compounds:-

(a) By reconverting the mixture into esters, separating the glycine as ester hydrochloride, and distilling the alanine ester, which is then decomposed by boiling with water and the alanine obtained by crystallisation.

(b) By precipitating the glycine as picrate [Levene, 1906; Levene and Van Slyke, 1912].

Glycine picrate, which was first described by Levene, was shown by Levene and Van Slyke to have the composition of 2 molecules of glycine and I molecule of picric acid. The pure compound on heating softens at $200^{\circ}$ and melts at $202^{\circ}$; it is soluble to the extent of 0.35 gram ( $=14$ gram glycine) in 20 c.c. of water. In preparing it, it is not advisable to use a large excess of picric acid, as this increases the solubility of the picrate though the solubility is lessened in the presence of alanine.

The separation of glycine and alanine is effected by dissolving the mixture in 3-4 parts of hot water and then adding an amount of picric acid exceeding that required to combine with the glycine ( $\mathrm{I} \cdot 5$ grams per I gram glycine) but not exceeding the amount required to combine with the whole of the amino nitrogen in the mixture if this be calculated as glycine. The solution is cooled to $0^{\circ}$; glycine picrate crystallises out completely in about one hour. It is filtered off and washed with a small quantity of water, followed by 95 per cent. alcohol. Its purity is controlled by a melting-point determination and amino nitrogen content. The filtrate is acidified with a known excess of normal sulphuric acid and freed from picric acid by shaking out with the ether. The sulphuric acid is removed by adding an equivalent of standard baryta solution and the filtrate from the barium sulphate is evaporated to dryness. The residue consists of alanine, generally of over 90 per cent. purity, the impurity being glycine. Pure alanine results on recrystallisation and a separation of the remainder can be effected by repeating the process.

Glycine is identified by the melting-point and analysis of its ester hydrochloride and picrate; its amount in the protein is given by the yield.

Alanine is identified by elementary analysis and its rotation in hydrochloric acid solution. The amount in the protein is also given by the yield. 


\section{Fraction IV. or Non-distilled Higher Boiling Esters.}

\section{(c) Phenylalanine.}

The ester of phenylalanine differs from the esters of aspartic acid, glutamic acid and serine, which are present with it in this fraction, by being only slightly soluble in water.

The mixed esters are dissolved in 5 volumes of water. If a large amount of phenylalanine be present, it may separate in the form of oily drops. The aqueous solution is extracted with an equal volume of ether. The ether extract is then washed several times with water to remove the last traces of any of the other esters which may have been dissolved by the ether. The ether is removed by distillation and the ester is hydrolysed by evaporation with concentrated hydrochloric acid. The resulting phenylalanine hydrochloride is purified by crystallisation from hydrochloric acid, and can be identified by an estimation of its content in chlorine.

The free amino acid is obtained from the hydrochloride by treating with sodium acetate, or ammonia, and precipitating from hot aqueous solution with alcohol. A determination of the melting-point of $283^{\circ}$ and rotation of $[a]_{20}^{\mathrm{D}}=-35^{\circ} \mathrm{I}^{\circ}$ in aqueous solution characterises the compound.

\section{(d) Aspartic Acid.}

The esters in the aqueous solution from which the phenylalanine ester has been extracted with ether are saponified by boiling with baryta; the solution of baryta is prepared by dissolving twice the quantity of barium hydrate to that of ester in sufficient hot water, filtering and allowing to cool. The clear solution is poured off from the crystals and to it is added the solution of esters. Hydrolysis is then effected by heating for two hours on the water-bath. The solution is allowed to stand for several days to allow the barium salt of racemic aspartic acid to crystallise out.

The barium aspartate is decomposed with sulphuric acid, the barium sulphate filtered off, and the excess of sulphuric acid quantitatively removed with baryta. Pure aspartic acid crystallises out from the solution on evaporation. It is identified by analysis and by the analysis of its copper salt.

The remainder of the aspartic acid is isolated after removal of glutamic acid as hydrochloride (e) as follows :-

The solution is evaporated in vacuo to remove as much hydrochloric 
acid as possible. The residue is dissolved in water and boiled with yellow lead oxide until a test portion of the cold solution no longer gives a reaction for chlorine. ${ }^{1}$ The filtered solution is freed from lead by hydrogen sulphide and the filtrate from lead sulphide is evaporated to a small volume, when aspartic acid crystallises out. The mother liquor contains principally serine, but more aspartic acid and other products are also present.

Note.-Osborne and Liddle $[1910,2]$ have observed that an intermediate fraction between fractions III. and IV. containing aspartic ester and leucine ester and possibly also phenylalanine ester may distil. The separation of leucine and aspartic acid (or glutamic acid) is impossible by fractional crystallisation. The fraction should be treated as described and the leucine separated from the aspartic acid by neutralising with soda and crystallising. Leucine results. On acidifying the filtrate and again crystallising the aspartic acid is obtained.

\section{(e) Glutamic Acid.}

The filtrate from the barium aspartate is exactly freed from barium by sulphuric acid and the solution is evaporated to dryness in vacuo. The residue is dissolved in water, the solution decolorised, if necessary, by boiling with charcoal and the glutamic acid is precipitated as hydrochloride by passing in dry gaseous hydrogen chloride. A further quantity of glutamic acid hydrochloride may be obtained from the mother liquor by concentration and similar treatment. Practically the whole of the glutamic acid present in the protein is thus obtained as hydrochloride. The larger portion is separated directly, before the mixture of amino acids is esterified.

Glutamic acid is obtained from the hydrochloride by treatment with the calculated quantity of caustic soda to combine with the hydrochloric acid and by crystallisation from water, in which it is soluble, when pure, with some difficulty. Elementary analysis of the free acid, or of its hydrochloride, determines its identity and its weight gives the amount in the protein.

\section{(f) Serine.}

It is most difficult to isolate serine and obtain it in a pure state. The solution from which the active aspartic acid has crystallised out is neutralised, if acid, with caustic soda and concentrated. Serine crystallises out in crusts of monoclinic crystals, and is identified by its melting-point of $240^{\circ}$ and elementary analysis.

${ }^{1}$ Levene and Van Slyke [IgIo] point out that, if excess of lead oxide be used, the insoluble lead salt of aspartic acid is formed with consequent loss of this amino acid. 
Its $\beta$-naphthalene sulphonyl-derivative,

$$
\mathrm{C}_{10} \mathrm{H}_{7} \mathrm{SO}_{2} \mathrm{Cl}+\mathrm{H}_{2} \mathrm{~N} \cdot \mathrm{CH} \backslash{ }_{\mathrm{COOH}}^{\mathrm{CH}_{2} \mathrm{OH}}=\mathrm{HCl}+\mathrm{C}_{10} \mathrm{H}_{7} \mathrm{SO}_{2} \cdot \mathrm{NH} \cdot \mathrm{CH}\left\langle\begin{array}{l}
\mathrm{CH}_{2} \mathrm{OH} \\
\mathrm{COOH}
\end{array}\right.
$$

which is prepared by shaking in alkaline solution with $\beta$-naphthalene sulphonyl-chloride, serves for the isolation of the remainder from the filtrate. This compound is very suitable for its characterisation. (M.P. $=214^{\circ}$ corr.)

(g) The Distillation Residue.

If the higher boiling esters are distilled a dark reddish-brown and thick syrupy residue remains in the distilling flask and sometimes crystals are observed clinging to the walls of the vessel. The mass consists chiefly of the anhydrides of the amino acids. Leucinimide may be extracted by boiling it with ethyl acetate. The residue is generally so small in amount that it is not further examined, but if this be necessary the mass is boiled with baryta for sixteen hours, the baryta removed and the process of separation repeated.

\section{(h) The Isolation of Oxyproline.}

Only in a few cases has this compound been isolated from the products of hydrolysis of proteins, since its separation is extremely laborious. Its ester is not extracted by ether, and it consequently remains behind in the mass of carbonate; if its isolation be required a second esterification is generally not performed.

The mass of carbonate is treated as previously described (p. 38). The aqueous solution is evaporated in vacuo to remove hydrochloric acid as completely as possible. The organic matter is dissolved in water so that its content is about I per cent.; sulphuric acid is added and the di-amino acids are precipitated with phosphotungstic acid (see p. 60). The excess of reagents are removed from the filtrate with baryta, the solution is concentrated in vacuo to a small volume and hydrochloric acid is removed with silver sulphate. The silver and sulphuric acid are precipitated in the usual way, the solution is evaporated in vacuo to a small volume and allowed to stand in a desiccator over sulphuric acid. Oxyproline slowly crystallises out.

Oxyproline is more easy to obtain when the esters have been separated with sodium ethylate. It is then present in the distillation residue; this is treated in a similar way. It is identified by its melting-point of $270^{\circ}$, rotation of $[a]_{20}^{D}--81^{\circ} 04^{\circ}$ in aqueous solution and by conversion into its $\beta$-naphthalene sulphonyl-derivative. 


\section{B. The Di-Amino Acids.}

The isolation and estimation of the three compounds-arginine, histidine, lysine-are carried out by the method described by Kossel and Kutscher [1900-I] which was slightly modified by Kossel and Patten [1903]. Further modifications and improvements have been added by Steudel [1903], Kossel and Pringle [1906] and Osborne, Leavenworth and Brautlecht [1908]. The method is based upon the earlier work of Drechsel, Hedin, and Kossel, and depends upon the precipitation of arginine and histidine as their silver salts, their separation by difference in solubility in water and in strongly alkaline solution, and the precipitation of lysine from the filtrate by phosphotungstic acid, and then by picric acid.

The method has been described in full by Weiss [1907] and by Steudel [ 1 IO $]$ and is carried out as follows :-

\section{Hydrolysis and Estimation of Protein.}

About 25-50 grams of protein are hydrolysed by boiling with dilute sulphuric as stated on p. II. The exact amount of protein is then estimated by making the volume up to I litre with water and determining the nitrogen in 5 or ro c.c. by Kjeldahl's method; from this figure the amount of protein can be calculated, if the amount of nitrogen in it be known.

\section{Removal of Sulphuric Acid. Estimation of Ammonia and Humin Nitrogen.}

The acid solution is heated to boiling and treated with a hot concentrated solution of baryta until the reaction is only faintly acid and almost the whole of the sulphuric acid is precipitated as barium sulphate, which is filtered off by suction and thoroughly washed with boiling water, by stirring up and raising to the boiling-point. This should be repeated twice or until the filtrate gives no precipitate with phosphotungstic acid. The filtrate and washings are evaporated down best in vacuo at $70^{\circ}$ and again made up to I litre. A determination of the nitrogen in 5 or 10 c.c. of this solution gives by difference the amount of nitrogen contained in the melanin, which is carried down by the barium sulphate. It is known as "humin nitrogen I."

In this liquid two determinations are made of the amount of 


\section{THE CHEMICAL CONSTITUTION OF THE PROTEINS}

nitrogen present as ammonia, by distilling portions of 100 c.c. with magnesium oxide.

The ammonia is removed from the remainder by evaporating with magnesia, or better barium carbonate, on the water-bath.

The two portions, freed from ammonia, are combined, and made alkaline with baryta, or barium carbonate.

The separate solutions are now combined, the precipitate of barium carbonate and barium sulphate is filtered off and washed by boiling with water three times; the excess of barium is removed from the filtrate by dilute sulphuric acid and the precipitate again filtered off and washed out. Filtrate and washings are combined together, evaporated down and made up to I litre and a Kjeldahl nitrogen determination again made. Allowing for the nitrogen given off as ammonia, the difference between this and the previous estimation gives the humin nitrogen II. contained in the alkaline barium magnesia precipitate.

\section{Precipitation of Arginine and Histidine.}

The solution, which now contains a small quantity of sulphuric acid, is placed in a 5 litre flask, and treated with a hot saturated solution of silver sulphate, ${ }^{1}$ which is slowly added, until the solution contains sufficient to give a yellow-brown, not a white or pale yellow precipitate, on removing a drop and testing it with baryta water in a watch-glass. If, during the process, there be any undissolved silver sulphate at the bottom of the flask, it is dissolved by adding more water before a fresh quantity is added, in order that a yellow-brown precipitate be given in the test drop with baryta. As soon as sufficient silver is present to combine with all the arginine and histidine, the solution is allowed to cool to $40^{\circ}$ and is saturated with finely powdered baryta, i.e., until some remains undissolved after repeated shaking. The precipitate, which is thus formed and which consists of the silver salts of arginine and histidine, is filtered off and stirred up together with the filter paper in a mortar with baryta, when it is again filtered off and washed with baryta water. The lysine in the filtrate is separated according to VI.

The precipitate of the silver salts of arginine and histidine is suspended in water containing sulphuric acid and decomposed with hydrogen sulphide. The filtrate from the silver sulphide and barium

\footnotetext{
${ }^{1}$ Osborne prefers to use silver nitrate.
} 
sulphate, which is thoroughly extracted in the usual manner with boiling water, is evaporated down to remove the hydrogen sulphide and again made up to I litre; a Kjeldahl nitrogen determination in 20 c.c. now gives the amount of nitrogen in the substances precipitated by silver and baryta.

\section{Estimation and Isolation of Histidine.}

(a) The solution is freed from sulphuric acid by neutralising to litmus with baryta and adding barium nitrate as long as a precipitate is formed; the barium sulphate is filtered off and washed.

The solution is concentrated to 300 c.c., acidified with nitric acid, if necessary, and treated with silver nitrate, as before, till a test drop gives a yellow-brown colour with baryta; when this occurs it is exactly neutralised to litmus with baryta and 5 c.c. of a cold saturated solution of baryta are added. If I c c.c. of the filtered solution when tested with a drop of baryta give a precipitate which indicates that the silver salt of histidine is not completely thrown down, 2 c.c. of saturated baryta solution are added to the main bulk, and this test is repeated until a test portion remains clear. The precipitate of the silver salt of histidine is then filtered off.

Instead of adding excess of baryta, Kossel and Pringle direct that a suspension of barium carbonate be added to the neutral solution, the solution warmed on the water-bath and then raised to the boilingpoint. After cooling, the histidine silver salt is filtered off and washed with baryta till free from nitric acid. The filtrate and washings are treated as in V. for arginine.

The precipitate of the silver salt of histidine is suspended and heated in water to which sulphuric acid is added until the reaction is acid and decomposed with hydrogen sulphide. Excess of hydrogen sulphide is removed by boiling and the silver sulphide is filtered off and washed. The solution and washings are concentrated and made up to 250 c.c. A nitrogen estimation in $20-25$ c.c. by Kjeldahl's method gives the amount of histidine.

The histidine is isolated from the remainder of the solution as hydrochloride or as picrolonate :-

I. As Hydrochloride. - The solution is made alkaline with baryta, the barium sulphate formed is filtered off, excess of baryta is removed by carbon dioxide, and the whole is evaporated to dryness. The residue is extracted with boiling water and to the solution, filtered from barium carbonate, hydrochloric acid is added. Histidine dichloride, 


\section{THE CHEMICAL CONSTITUTION OF THE PROTEINS}

$\mathrm{C}_{6} \mathrm{H}_{9} \mathrm{~N}_{3} \mathrm{O}_{2} .2 \mathrm{HCl}$, is obtained on evaporating down. The yield is $75-8 \mathrm{o}$ per cent. of the histidine estimated by the Kjeldahl determination.

2. As Picrolonate. - The excess of sulphuric acid is removed by treating the hot solution with excess of baryta, and excess of the latter is removed by carbon dioxide; it is evaporated down and filtered from barium sulphate and carbonate, which are thoroughly washed. The filtrate and washings are evaporated to about ro c.c., if necessary after the addition of a drop of sulphuric acid to remove the last traces of barium. The necessary quantity of picrolonic acid (calculated from the above Kjeldahl determination and dissolved in a small quantity of alcohol) is added; the precipitate of histidine picrolonate is filtered off after three days, washed with water, dried and weighed. The amount of histidine can be calculated from the formula $\mathrm{C}_{6} \mathrm{H}_{8} \mathrm{~N}_{3} \mathrm{O}_{2} \cdot \mathrm{C}_{10} \mathrm{H}_{8} \mathrm{~N}_{4} \mathrm{O}_{5}$; it corresponds very closely with the amount calculated from the Kjeldahl estimation.

(b) Osborne, Leavenworth and Brautlecht find that it is better to remove the greater portion of the histidine by precipitation with mercuric sulphate. The solution is concentrated to about 250 c.c., sulphuric acid is added till the solution contains 5 per cent. of this acid, and it is treated with a slight excess of mercuric sulphate solution. The precipitate of histidine mercury sulphate is allowed to stand for twelve to twenty-four hours when it is filtered off, washed with 5 per cent. sulphuric acid, suspended in water and decomposed with hydrogen sulphide. The filtrate and washings from the mercuric sulphide which contain the histidine are neutralised with baryta and barium nitrate added until barium sulphate is no longer precipitated. The barium sulphate is filtered off and thoroughly washed. The histidine is then thrown down as silver compound and estimated as under $(a)$. The filtrate from the mercury precipitate is freed from mercury, neutralised and treated as described under (a) so as to throw down the small quantity of histidine not precipitated by mercuric sulphate. 


\section{Estimation and Isolation of Arginine.}

The filtrate containing the arginine is saturated with baryta; the precipitate of the silver salt of arginine, so obtained, is filtered off, and precipitate and filter paper are stirred up in a mortar with baryta, filtered off, and the process repeated till the precipitate is free from nitric acid. It is then suspended in water containing a slight excess of sulphuric acid and decomposed with hydrogen sulphide. The filtrate and washings from the precipitate of silver sulphide and barium sulphate are evaporated down and made up to 500 c.c., or I litre. The amount of arginine is estimated from the amount of nitrogen determined in $25-50$ c.c. of this solution by Kjeldahl's method.

The arginine is isolated from the remainder of the solution as nitrate, copper nitrate double salt, or as picrolonate.

I. As Nitrate. - The solution is freed from sulphuric acid by baryta, the excess of which is removed by carbon dioxide, and evaporated down. The last traces of baryta are then removed with a drop of sulphuric acid, the solution is neutralised with nitric acid and evaporated to dryness. Arginine nitrate, $\mathrm{C}_{6} \mathrm{H}_{14} \mathrm{~N}_{4} \mathrm{O}_{2} \cdot \mathrm{HNO}_{3}+\frac{1}{2} \mathrm{H}_{2} \mathrm{O}$ is obtained as a dry white crystalline mass. The double salt with copper nitrate is then prepared from the nitrate by boiling with copper oxide; a yield of $85-90$ per cent. is obtained.

2. As Picrolonate. - The solution is freed from sulphuric acid as described above, and evaporated down to about 10 c.c. The necessary quantity of picrolonic acid (calculated from the nitrogen determination and dissolved in a small volume of hot alcohol) is then added; the yellow crystals of picrolonate are filtered off after a few days, washed with a small quantity of water, and dried at $110^{\circ}$. The yield of arginine calculated from the picrolonate, $\mathrm{C}_{6} \mathrm{H}_{14} \mathrm{~N}_{4} \mathrm{O}_{2} \cdot \mathrm{C}_{10} \mathrm{H}_{8} \mathrm{~N}_{4} \mathrm{O}_{5}$, which loses its one molecule of water of crystallisation at $110^{\circ}$, is almost quantitative, since the picrolonate has the very slight solubility of I part in I 124 parts of water. 


\section{Estimation and Isolation of Lysine.}

The lysine is contained in the filtrate from the precipitate of the silver salts of arginine and histidine.

The solution is acidified with sulphuric acid and freed from silver by hydrogen sulphide; the filtrate and washings from the precipitate of silver sulphide and barium sulphate, which is treated in the usual manner, are evaporated down to 500 c.c. Sulphuric acid is then added until the content is 5 per cent., and the lysine is precipitated by not too large an excess of phosphotungstic acid. ${ }^{1}$ This is added until a portion of the clear liquid on the further addition of the reagent remains clear for ten seconds. After twenty-four hours the precipitate of lysine phosphotungstate is filtered off by suction and washed with 5 per cent. sulphuric acid by stirring up in a mortar. After making up the filtrate and washings to a definite volume an estimation of the substances not precipitated may be made in an aliquot part by the Kjeldahl method.

The lysine phosphotungstate is made into a uniform suspension with water and poured into boiling water. A hot saturated solution of baryta is added until the solution is strongly alkaline and contains excess of baryta. The precipitate of barium phosphotungstate, which is formed, is filtered off and boiled out several times with baryta and then with water. The alkaline solution is freed from baryta by means of carbon dioxide, concentrated, filtered, and evaporated on the waterbath nearly to dryness. Water is then added, the barium carbonate filtered off and washed, and the solution once more evaporated, after which it is made up to a definite volume and the lysine estimated in an aliquot portion by Kjeldahl's method.

The lysine is separated from the remainder of the solution as picrate. The solution is evaporated down in a porcelain basin to dryness, and a small quantity of alcohol is added to the sticky residue. It is then treated with a saturated solution of picric acid in alcohol until no further precipitation of picrate occurs. After twenty-four hours this precipitate is filtered off and washed with a small quantity of absolute alcohol; it is then recrystallised by solution in boiling water, filtering if necessary, and evaporating to a small volume, when lysine picrate, $\mathrm{C}_{6} \mathrm{H}_{4} \mathrm{~N}_{2} \mathrm{O}_{2} \cdot \mathrm{C}_{6} \mathrm{H}_{2}\left(\mathrm{NO}_{2}\right)_{3} \mathrm{OH}$, crystallises in needles on

${ }^{1}$ Schulze and Winterstein [1902] found that phenylalanine under certain conditions is precipitated by phosphotungstic acid and they have been able to isolate phenylalanine in this way. 
cooling; these are filtered off, washed with alcohol, dried, and weighed.

The last portions of the lysine in the mother liquor from the picrate can be obtained by acidifying with sulphuric acid, extracting the picric acid with ether, precipitating as phosphotungstate, and repeating the above process for obtaining lysine picrate.

\section{Colorimetric Estimation of Histidine.}

Weiss and Ssobolew [1913] attempted to estimate histidine colorimetrically by its reaction with diazobenzene sulphonic acid. With pure solutions of histidine their attempts were successful; the estimation was apparently not so successful in solutions containing other amino acids, as no data were given. In all cases, tyrosine which gives a very similar reaction, must be absent from the solution.

In performing the reaction a fresh solution of diazobenzene sulphonic acid is necessary. The authors prepared a standard reagent made up by mixing I part of solution A with 2 parts of solution $B$.

The composition of these is:-

$\mathrm{A}=4$ grams of sulphanilic acid, 40 c.c. concentrated hydrochloric acid, water to 400 c.c. At room temperature solution takes place in twenty-four hours.

$\mathrm{B}=0.5$ per cent. solution of sodium nitrite in water.

The solution is made alkaline with a ro per cent. solution of anhydrous sodium carbonate.

A standard solution of $\mathrm{I}$ in 10,000 of histidine monochloride is also required.

The standard colour for comparison is made by thoroughly mixing I. 5 c.c. of the diazo reagent $(\mathrm{I} A+2 \mathrm{~B})$ with Io c.c. of the standard histidine solution and adding 3 c.c. of the soda solution. The colour produced is in five to ten minutes of a pure red shade, optimal, and stable.

The unknown solution is successively diluted say $\mathrm{I}$ in 5 , I in 20 , $\mathrm{I}$ in $40, \mathrm{I}$ in 80 , I in 160 . To 10 c.c. are added $\mathrm{I} \cdot 5$ c.c. of diazo reagent and 3 c.c. of soda as above. ${ }^{1}$

The dilution at which a colour corresponding with the standard colour is noted. As soon as the colour intensity decreases, the optimal dilution is passed. For example the matching of colours may be between $I$ in 80 and $I$ in 160 . Intermediate dilutions of $I$ in 100 and

${ }^{1}$ No colour appears with very concentrated solutions of histidine, so that absence of colour does not imply absence of histidine, unless no colour appears on further dilution. 


\section{2}

\section{THE CHEMICAL CONSTITUTION OF THE PROTEINS}

I in 120 are made until there is the best matching of the colours. Finally, a stage will be reached at which I in IOO may be the best match and $\mathrm{I}$ in IOI will give a colour which is slightly less intense. The final matching may be performed in a Duboscq colorimeter.

With solutions containing other amino acids, just as with concentrated solutions of histidine, no colour appears unless more reagent is added. This is due to the combination of other amino acids with the reagent. In order therefore to estimate histidine under these conditions more reagent is necessary and in order to avoid excess, which interferes by producing a dirty-green colour, a fixed volume of 20 c.c. was decided upon. This volume allows of an alteration of the amount of diazo reagent of from $\mathrm{I} \cdot 5$ to 7 c.c., e.g., IO c.c. solution +4.5 c.c. reagent +3 c.c. soda $+2 \cdot 5$ c.c. water. The standard was also diluted to 20 c.c. with 5.5 c.c. water. Two variables are thus introduced in effecting an estimation ( $a$ ) the necessary dilution of the histidine solution, $(b)$ the necessary amount of reagent.

The first testing is carried out with the reagent $k$, a series being prepared represented as $k^{7}, k^{6 \cdot 5}, k^{6} \ldots k^{2}, k^{1 \cdot 5}$, where the index denotes the amount of reagent. Testing is then done with dilutions of the solutions, the series being represented by $\frac{k^{5}}{4}, \frac{k^{4}}{5}$ etc., where the denominator denotes the dilution. In practice all the preliminary experiments are not necessary, since as soon as the quantity of reagent is found, those trials with amounts greater than this quantity can be omitted. With greater dilution generally less reagent is required. The series experimentally tested may be for example-

I. $k^{7}, k^{6.5}, k^{5}$. . . $k^{3}, k^{2.5}, k^{2}, k^{1.5}$ optimal reaction with $k^{5}$.

II.

$$
\frac{k^{5}}{2}, \frac{k^{4 \cdot 5}}{2}, \frac{k^{4}}{2} \ldots \frac{k^{2 \cdot 5}}{2}, \frac{k^{2}}{2}, \frac{k^{1 \cdot 5}}{2} \quad, \quad \text { ", } \frac{k^{4}}{2} \text {. }
$$

III. $\frac{k^{4}}{3}, \frac{k^{3 \cdot 5}}{3}, \frac{k^{3}}{3}, \frac{k^{2 \cdot 5}}{3}, \frac{k^{2}}{3}, \frac{k^{1 \cdot 5}}{3}$

IV.

$$
\frac{k^{3 \cdot 5}}{4}, \frac{k^{3}}{4}, \frac{k^{2 \cdot 5}}{4}, \frac{k^{2}}{4}, \frac{k^{1 \cdot 5}}{4}
$$

V.

$$
\frac{k^{3}}{5}, \frac{k^{2 \cdot 5}}{5}, \frac{k^{2}}{5}, \frac{k^{1 \cdot 5}}{5} \text {. All colours below standard. }
$$

The estimation is then made with the solution represented by $\frac{k^{3}}{4}$,i.e., with a dilution of $I$ in 4 and with 3 c.c. of reagent. 


\section{THE RESULTS OF THE ANALYSIS.}

A.

Inspection of the results of analysis, which are tabulated on pages I I I-I 30 , shows that there is a considerable deficit in the sum of the units composing the protein molecule.

The best analyses are those of the protamines, of the silk-fibroin of spider's silk, and the gliadin of wheat; in these, some 80-90 per cent. of the protein is accounted for; in most cases, the sum of the figures only reaches 50-70 per cent. and in the other cases complete analyses do not exist. The deficiencies are due almost entirely to losses incurred in isolating and purifying the amino acids.

A careful inquiry where the loss occurs has been made by Osborne in conjunction with Leavenworth and Brautlecht [1908] and in conjunction with Jones [1910, I, 3], and by Abderhalden [1910], Abderhalden and Weil [191 1, 2; 1912, I], who have estimated the nitrogen at each stage in the process for isolating the mono-amino acids.

Osborne, Leavenworth and Brautlecht have proved that the loss does not fall upon the di-amino acids. They are convinced that the method for their isolation and estimation is extremely satisfactory, for they have been able to recover from $80-90$ per cent. of the di-amino acids in a pure state. They consider that no other di-amino acid than the three hexone bases is present in most proteins; Fischer and Abderhalden's diaminotrioxydodecanic acid in caseinogen may be an exception; this protein seems to be the most complex in the number of units which it contains.

The loss therefore occurs in the isolation and estimation of the mono-amino acids. Fischer pointed out, when he first described his ester method, that the values were not to be regarded as quantitative. The fact that all the figures given are those of the amount of the pure dry compound isolated is sufficient evidence that the total quantity of products is not accounted for.

The sources of loss in the several steps of the long process have received special attention from Osborne and Jones [1910, I, 3], who are confirmed in their observations by Abderhalden and Weil [I9II, 2; I $912, \mathrm{I}]$.

I. Hydrolysis.-In many cases the hydrolysis of the proteins may not have been complete. Some proteins are very difficult to bring into solution in the concentrated hydrochloric acid, and portions may 


\section{THE CHEMICAL CONSTITUTION OF THE PROTEINS}

adhere to the sides of the flask and may therefore not be hydrolysed. Even if there be apparent total solution a small amount may escape hydrolysis by becoming enclosed in the "humin "which is formed to a greater or lesser extent. The insoluble material should be filtered off, washed, and tested with the biuret reaction. The absence of the biuret reaction is not an absolute criterion that hydrolysis is complete, for many polypeptides do not show it and are very resistant to hydrolysis. The residue, if large, should therefore be hydrolysed again. Complete hydrolysis should be tested for by Van Slyke's amino-nitrogen method (p. 89). Osborne has found that hydrolysis is sometimes only complete after boiling for two to five days.

Henriques and Gjaldbäk [1910] made an examination, by the formal titration method of Sörensen, of the completeness of hydrolysis of proteins by the action of enzymes and by boiling with acids. Hydrolysis by enzymes was seldom complete, but complete hydrolysis was effected by boiling for twelve hours with 20 per cent. hydrochloric acid, except in the case of certain proteins. They found that complete hydrolysis occurred on heating the protein with $3 \mathrm{~N}$ hydrochloric acid for one and a half hours in an autoclave at $150^{\circ}$. The completion of hydrolysis could only be ascertained by testing the solution for increase of amino groups whilst at the same time the amount of ammonia must be minimal, i.e., arising only from amide groups and not by deamination of the amino acids. Andersen and Roed-Müller [I 1 I 5] on account of the fact that more ammonia is slowly formed in a prolonged hydrolysis are inclined to attribute its origin to uramido groups in the protein molecule. The rate of evolution of ammonia was found by Skraup and Hardt-Stremayr [1908] to be rapid at first and quite slow subsequently, the greater part being evolved at the beginning of the hydrolysis. Van Slyke [1912,2] maintained that the maximum amino nitrogen was evolved whether the hydrolysis was effected in an autoclave at $150^{\circ}$ or by boiling at $100^{\circ}$ for forty-eight hours; there was less tendency for deamination at $100^{\circ}$ than at $150^{\circ}$.

Pittom [1914] also found that ammonia is rapidly liberated in the early stages of hydrolysis. Amino-nitrogen is liberated in the same way during hydrolysis by acid, or by enzymes. Caseinogen differs from egg-albumin in its hydrolysis. More amino acids are formed from caseinogen than from egg-albumin in the earlier stages; the reverse holds good at later stages; at a still later stage the rate of amino acid formation is the same as in the early stage. There seems to be a definite point at which complex polypeptides are broken down into simpler 
compounds. Some of the simpler polypeptides are not precipitated by phosphotungstic acid.

Sulphur-containing substances and sometimes sulphur have been found in the reflux condenser, and the smell of iodoform has been noticed in the hydrolysis of spongin.

2. Formation of Humin.-Nearly all proteins on hydrolysis yield an insoluble brownish-black residue, humin or melanin. Humins are formed by boiling carbohydrates with concentrated mineral acids, and if nitrogenous matter be present, the humin contains nitrogen. Samuely [1902] suggested that the humin formed from proteins was due to a secondary reaction between amino acids and carbohydrates, and obtained melanins containing nitrogen on boiling various amino acids with hydrochloric acid in the presence of carbohydrate. Maillard [1912] similarly obtained melanin-like substances on heating glucose and other carbohydrates with glycine and alanine; the reaction was most rapid with xylose and arabinose, and alanine was the most reactive of the amino acids. These products were shown by Maillard [1913] to yield cyclic bases on heating, and he suggested that cellulose and protein were the origin of the pyridine and allied bases found in coal-tar. Pyridine and other bases were obtained by Pictet and Chou [1916] by hydrolysing caseinogen in the presence of formaldehyde, and Maillard [1916] maintained that his results were substantially in agreement with those of Pictet and Chou. Gortner and Blish [1915], knowing that zein, which contains neither tryptophan nor carbohydrate and only a small quantity of histidine, gave very little humin, heated zein with acid in the presence of tryptophan and carbohydrate and obtained 86.6 per cent. of the nitrogen of the tryptophan in the form of humin; with histidine in the place of tryptophan 0.5 per cent. of its nitrogen was contained in the humin. Tryptophan thus is largely concerned in the formation of humin. Grindley and Slater [I9I5] found that other amino acids were concerned in the formation of humin. A detailed investigation upon the amino acids taking part in the formation of humin was made by Roxas [1916]. Alanine, leucine, phenylalanine and glutamic acid are not factors in humin formation; proline may be a factor under certain conditions in the formation of humin. Tryptophan gave up $7 \mathrm{I}$ per cent. of its nitrogen, tyrosine 15 , cystine $3 . \mathrm{I}$, arginine $2 \cdot 3$, lysine $2 \cdot 6$, histidine $I \cdot 8$. Generally, fructose and xylose were more reactive than glucose, and the three hexone bases reacted more readily in weak acid solutions than in strong. The amino nitrogen of arginine, histidine, and tryptophan was lost in the formation of humin; tyrosine and cystine did not react with loss of nitrogen.

PT. I. 


\section{THE CHEMICAL CONSTITUTION OF THE PROTEINS}

Roxas suggested that the mechanism of the reaction was :

(I) with histidine :-<smiles>CCNC(C(=O)O)N1CCC2CCCC21</smiles><smiles></smiles>

(2) with arginine :-

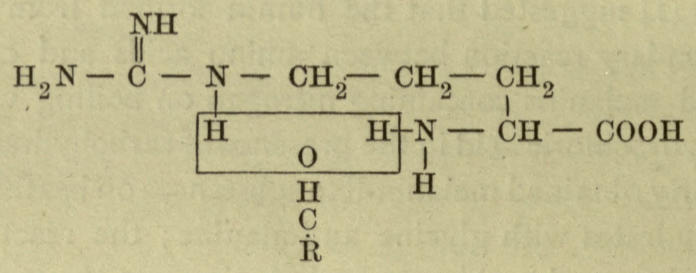

(3) with tryptophan:-

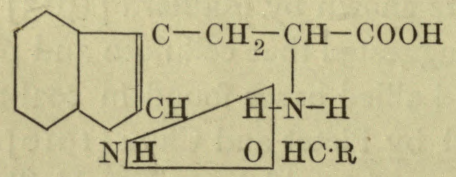

or

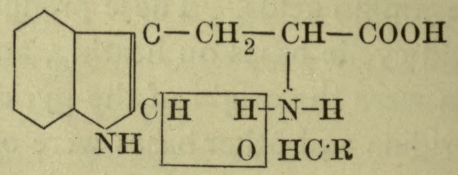

These possible condensation products can explain the formation of pyridine from melanin or humin :-<smiles>[R1]C1NC(C(=O)O)CC2(CC(C)C2)N1</smiles>

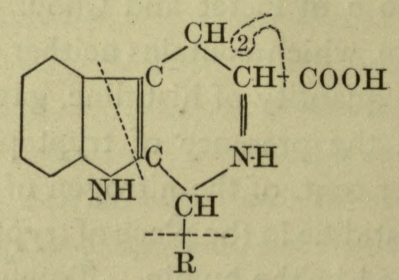

Gortner [1916] showed that the aldehydes, furfural, benzaldehyde and formaldehyde reacted on boiling with hydrochloric acid in a way similar to carbohydrates, and in presence of amino acids the humin nitrogen was large. The humin was mostly insoluble in acid except in the case of tryosine and formaldehyde. It appears that the reaction consists in the formation of furfural from carbohydrate and that humin arises by the condensation or decomposition of furfural together with nitrogen from amino acids if these be present in the solution.

The loss of products is considerably greater than the quantity of " humin," which generally amounts to I-2 per cent. of the protein. A loss, which cannot be estimated, is represented by the soluble brown pigment which colours the solution. 
3. Separation of Glutamic acid Hydrochloride.-The quantity of glutamic acid precipitated as hydrochloride never represents the total quantity present in the protein. The amount precipitated depends very largely on conditions. The precipitate usually contains ammonium chloride; this is removed by boiling with baryta, and if the baryta be removed with carbon dioxide the barium carbonate may contain barium glutamate, which is very insoluble, and consequently there is loss of this constituent. The remainder of the glutamic acid is recovered with the esters.

4. Esterification.-The loss in this process is not great, especially if it be repeated. Loss is chiefly due to hydrolysis of the esters when the water is removed by evaporation in vacuo. Phelps and Tillotson's method seems to be preferable.

5. Separation of Glycine Ester Hydrochloride.-The glycine is never completely isolated as ester hydrochloride; the remainder is obtained as ester.

6. Extraction of Esters.-Loss always occurs in this part of the process, but is covered when the process is repeated. The loss is largely mechanical and cannot be avoided. A small quantity of organic matter is retained by the sodium sulphate used for drying the esters.

7. Distillation of Esters.-(a) In distilling off the ether, especially if its volume be large, a considerable quantity of esters distils at the same time. Two receivers should be used and the esters extracted from the distillate.

(b) Decomposition of the esters occurs during the distillation, and a more or less large residue represents the loss. The products can be recovered, if necessary.

Abderhalden and Weil have found that in the process up to this stage 30 per cent. of glutamic acid, $40-45$ per cent. of aspartic acid, 37.5 per cent. of glycine, 30 per cent. of alanine, and 20 per cent. of leucine are lost; some of the glutamic acid is lost by conversion into pyrrolidone carboxylic acid. In the case of a mixture, of the glycine 50 per cent. was recovered, of the alanine 57 per cent., of the leucine 66 per cent., of the glutamic acid 58 per cent., and of the aspartic acid 40 per cent. The esters were liberated by treatment with caustic soda and sodium carbonate, alcoholic soda or ammonia. The best yields were obtained with alcoholic soda. The loss of higher boiling esters is greatly diminished if the distillation of fraction IV. be omitted. Osborne and Jones found that the separation of the esters in this fraction is not more troublesome than when they are distilled. 
8. Separation of the Individual Amino Acids.-The greatest loss occurs here as none of the methods of isolating the compounds are perfect.

(a) Proline.-The quantity extracted by alcohol is much greater than that obtained in a pure crystalline state and reckoned as proline. An estimation by Van Slyke's method may give the actual amount, though Abderhalden and Kautzsch think that this value is not really satisfactory. Abderhalden and Kautzsch [1912] regard the proline content determined gravimetrically as being very much below the actual amount.

(b) Valine, Leucine, Isoleucine.-The figures given represent the quantity of substance isolated in a pure state. The leucine figures in the tables are really those for leucine + isoleucine.

(c) Glycine and Alanine.-Nearly all the glycine can be obtained, but the actual amount of alanine is much greater.

(d) Glutamic Acid.-Probably the figures given for this amino acid most nearly approach the real content of the protein in this constituent.

(e) Aspartic Acid and Serine.-The figures are much too low, as the method of separation is extremely unsatisfactory.

9. Oxyproline.-The amount of this substance in the protein is greater than the quantities which have been isolated. Its method of isolation is so laborious that data are only available for a few proteins.

10. Tyrosine and Cystine.-The data for tyrosine most probably represent the content of the protein in this unit very closely.

The data for cystine are unsatisfactory; in many cases the data are calculated from the sulphur content of the protein; in the other cases they are those from pure isolated cystine. More satisfactory data are given by Van Slyke's amino method (p. 85).

I I. Tryptophan.-A large amount of protein is required for the isolation and estimation of tryptophan; it is on this account most probably that so few data exist. The isolation is easier the larger the quantity of material. Tryptophan might be isolated first in most cases and the remainder of the products isolated subsequently.

Osborne, allowing for all losses, calculates that from $4 \mathrm{I}-82$ per cent. can actually be recovered. In the cases of zein and gliadin 86 and 68 per cent. respectively are known; in the case of vignin only 5 per cent. more has to be accounted for. The losses from the esters are computed to be 50 per cent. of the alanine, serine, aspartic acid; 30 per cent. of the valine, proline, glutamic acid, phenylalanine; 20 per cent. of the leucine: only 50 per cent. of the cystine and tryptophan may be accounted for. 
Methylation of Amino Acids.

A method which may prove of some service in separating these various mixtures was described by Engeland [1909]. The amino acids are methylated in alkaline solution with methyl iodide and converted into their betaines :-

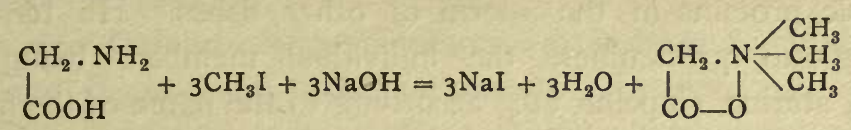

These products are separated by means of their double salts with mercuric chloride, gold chloride, and platinum chloride. In the case of caseinogen, Engeland isolated (I) 1-methyl-hygric acid, which is derived from proline; a yield corresponding to 6.7 per cent. of proline was obtained; (2) trimethyl leucine, (3) trimethyl valine, (4) betaine, (5) trimethyl-alanine. Subsequently, Engeland [1910] prepared the trimethyl derivative of phenylalanine and dimethyl glutamic acid, and [1914] isolated methyl-hygric acid from the products of hydrolysis of spongin. The procedure adopted was very laborious and seems to offer no advantages over the ester method. Its chief use may be in the separation of those mixtures which result by the ester method and for which the methods at present in use are not so satisfactory.

B.

The data in our possession show definitely that the various proteins are composed of the same units; in some cases certain are missing and in other cases one or more units are present in very much larger amount. These differences on the whole confirm our classification of the proteins on physical properties. No great differences are noticeable between the members of any single group except in the case of the scleroproteins. Although two proteins in any group may contain the same amount of any unit we cannot say that they are identical. Even if they contained the same amount of all the units they might still be different, for the arrangement of the units in the molecule may not be the same. The analytical data are given on pp. II I-I 30. The following brief particulars may be noted :- 


\section{Protamines.}

The first work upon this group of proteins was carried out by Miescher [1874], who described the basic substance-protaminepresent in the sperm of salmon. Piccard [1874] made similar investigations. Kossel extended the work of Miescher by examining the basic proteins in the sperm of other fishes. He termed the whole group protamines, the individual members being called salmine, sturine, clupeine, etc., according to the name of the fish from which they were prepared.

The first analyses of salmine and sturine [Kossel, 1896-97] were qualitative and showed the presence of arginine and histidine with quite small amounts of mono-amino acids. Lysine was found later in sturine [Kossel, I898], and it was thought that the protamines contained the three bases as their principal constituents, but Kossel [1898-99] with improved methods of analysis showed that arginine only was present in salmine and clupeine, whereas sturine contained all three hexone bases. Subsequent work by Kossel [1898-99, 1903], Morkowin [1899], Kossel and Dakin [1903-4, 1904, 1905] was devoted to the identification of the mono-amino acids. Quantitative analyses of the di-amino acids were made by Kossel and Kutscher [1900-I], and Kossel and Dakin [1904] published a complete analysis of salmine. Their result does not conform to that of Abderhalden [1904] and the difference is to be attributed to the material analysed; Abderhalden probably used salmine prepared from unripe sperm and not sufficiently purified; Kossel and Dakin used carefully purified salmine from ripe sperm.

A large number of protamines have been analysed by Kossel [1910, 1913] and the nature of the mono-amino acids determined in some of them by Kossel and Edlbacher [1913]. Some of these were previously investigated by Ulpiani [1902], by Dezani [1908], and by Taylor [1908-9]. Malenuick [1908] prepared sturine from the Russian sturgeon, but did not analyse its constituents. His method of preparation was criticised by Kossel [1910]. Kossel [1913] did not give the actual quantity of the units in these protamines, but determined the percentage of the total nitrogen present as argininenitrogen, histidine-nitrogen, mono-amino acid-nitrogen. The argininenitrogen on the average was about 80 per cent. of the total nitrogen, the mono-amino acid-nitrogen about ro per cent. Lysine was absent and histidine present only in percine.

The analyses show that the protamines are built up almost ex- 
clusively of di-amino acids, especially arginine, salmine containing over 80 per cent. Only small amounts of mono-amino acids are present in them. The mono-amino acids are alanine, aminovalerianic acid, serine, proline, tryptophan and tyrosine. It has not been determined whether the aminovalerianic acid is identical with valine from other proteins, though this is probable.

The chief features are the presence of arginine and the absence of lysine and histidine in salmine, clupeine, cyclopterine and other protamines. Sturine only contains arginine, histidine and lysine; cyprinine contains arginine and lysine; percine contains arginine and histidine. The general composition of the protamines seems to be $a_{2} m$ or $\left(a h l_{2} m\right.$ or $(a h)_{2} m$ where $a$ represents arginine, $h$ histidine, $l$ lysine, and $m$ mono-amino acid [Kossel, 1913].

As to the origin of the di-amino acids in the protamine of fish sperm the observations of Miescher suggested their formation from the muscular tissue of the fish. The salmon does not feed during its life in the river and loses weight at the expense of the increase in size of its roe. Kossel [1905] made calculations as to this possibility: the roe of a salmon contains 27 grams of protamine with 22.8 grams of arginine ; if the muscular tissue contain $7 \cdot 1$ per cent. of arginine, $32 \mathrm{I}$ grams of it would be required: more than this quantity of muscle is decomposed during the life of the salmon in the river, so that, as there is no evidence for its synthesis, its origin is by transference from the muscular tissue. Actual analyses of the protein of salmon muscle and salmon tissue have been made by Weiss [1907] and they confirm the calculations. In the transference of the arginine from the muscle to the roe it seems that it is rendered stable by combination with nucleic acid or some other grouping and thus transported, for under the ordinary conditions of decomposition of tissues arginine is itself decomposed. The transfer appears to occur not as the transfer of a single unit, but as the transfer of a complex containing several units. Such a complex is a histone which contains more mono-amino acid units than a protamine.

In general, Kossel regards the protamines as the simplest proteins, the more complex or ordinary proteins containing a protamine nucleus (i.e., of di-amino acids) to which is attached the mono-amino acid units, the histones being intermediate substances. This theory is supported by the results of analysis of other proteins, all of which contain arginine and other di-amino acids. The isolation from proteins of complexes containing only di-amino acids will be the only proof of a protamine nucleus in a protein molecule. 


\section{Histones.}

Histones are found in the unripe sperm of the salmon [Miescher, 1874], mackerel [Bang, I 899], and other fishes [Ehrström, I901]; also in the ripe sperm of the sea urchin [Matthews, 1897]. The first representative of the group was the histone, to which the name was first applied, prepared by Kossel [1883-84] from the red blood corpuscles of the goose. Lilienfeld [1894] prepared a similar substance from the thymus, and Schulz [1898] found that globin of hæmoglobin belonged to this group. Histones are characterised by being precipitated by ammonia in the presence of ammonium salts. Their other properties are described by Bang [1899]. They contain from I5.9119.79 per cent. of nitrogen.

Histones are supposed to be intermediate compounds between protamines and other proteins, and this supposition is confirmed by the results of analysis. They are distinguished from protamines in their smaller content of di-amino acids, namely, about 25 per cent. Only in the case of thymus-histone has an estimation been made of the mono-amino acids.

The protein constituent-globin-of hæmoglobin has always been regarded as a histone, but the presence of only 20 per cent. of di-amino acids is against this supposition. Further, the principal di-amino acid is histidine, whereas in the other histones it is arginine. It should be noted that hæmoglobin contains a considerably greater amount of histidine than the other proteins. The high content in histidine appears to be a peculiarity of the hæmoglobins; it may be connected with the origin of the red blood corpuscles from nucleated corpuscles since the glyoxaline ring contained in histidine is also contained in the purine bases, which are present in nucleic acid. Comparative data of the amount of histidine in the hæmoglobin of different animals by Abderhalden and Medigreceanu [1909] are at present only available for the red-blood corpuscles; those of the horse contain 5.3 per cent., of the hen 2.8 per cent., of the duck 2.5 per cent., of the goose 3.6 per cent.

An examination of the mono-amino acids in hæmoglobin was undertaken by Pröscher [1899] before Fischer had described his ester method. The analysis by Fischer and Abderhalden [1902] was repeated by Abderhalden [1903] whose data were considerably higher than those found by Fischer and Abderhalden; the mixture of amino acids was esterified three times. Abderhalden and Baumann [1907] analysed the hæmoglobin of dog's blood. 


\section{Albumins and Globulins.}

Albumins contain no glycine, whereas globulins contain this amino acid; they show no other striking differences. Their differentiation on physical grounds is thus scarcely borne out by analysis, and their interconversion, which has been described, may be possible.

The most recent results for crystallised egg-albumin by Osborne, Jones and Leavenworth [1909] confirm the earlier ones by Abderhalden and Pregl $[1905,2]$. They show that workers in different parts obtain very similar results with Fischer's ester method. The values by Hugounenq and Morel [1906] and by Hugounenq and Galimard [1906] are for coagulated egg-white.

Chapman and Petrie [1909] determined that egg-white contains 2.4 per cent. of arginine, 3.2 per cent. of lysine, and 0.7 per cent. of histidine, data which were required for experimental work on nutrition.

The comparative data by Abderhalden and Slavu [1909], both of serum albumin and serum globulin, with regard to their content in glycine, tyrosine and glutamic acid would incline one to believe that both the serum albumins and the serum globulins of different origin were of the same composition. They show no very great difference from fibrin.

The composition of lactalbumin has been determined by Abderhalden and Pribram [1907] and by Osborne, Van Slyke, Leavenworth and Vinograd [1915]. The very high lysine content of this protein accounts for its value in nutrition. It would appear that the globulin in milk contains glycine, a mixture of the coagulable proteins having been analysed by Abderhalden and Hunter [1906, I]. Abderhalden and Schittenhelm [1906] found I·3 per cent. of tyrosine and I per cent. of glutamic acid in the albumin of human milk.

Hopkins and Savory's thorough investigation of the Bence-Jones protein [I9II], in which they showed that its peculiar physical properties were due to the conditions under which it was examined, and that its chemical composition differed so distinctly from that of the proteoses, brings this protein into the class of coagulable proteins as a globulin. The Bence-Jones protein is characterised chemically by a high content of the aromatic amino acids; the combined values for phenylalanine and tyrosine are higher than those for any other blood or tissue protein. Both physically and chemically this protein seems to stand in a class by itself. Abderhalden and Rostoski [1905, 2] had previously analysed and examined this protein. Their figures are very similar to those of Hopkins and Savory. 


\section{THE CHEMICAL CONSTITUTION OF THE PROTEINS}

\section{The Vegetable Proteins.}

The vegetable proteins show no great difference from the animal proteins in regard to the number of amino acids which they contain in their molecule. The most noticeable features are their high content in glutamic acid and in arginine. Their ammonia content is also high. This is probably connected with the large amount of the dibasic glutamic acid and is in harmony with the occurrence of asparagine and glutamine in growing seedlings.

\section{Albumins.}

Only two vegetable albumins have so far been analysed, the legumelin of the pea and the leucosin of wheat. The resemblance in their composition extends not only to the general proportions of the amino acids, but also to the quantity isolated. Leucosin occurs in the embryo of wheat; it is not possible to locate legumelin in any particular part of the seed, but, from analogy, it may be supposed that both these proteins are constituents of the physiologically active tissues rather than a constituent of the reserve food-stuff for the embryo. Legumelin is quite different in composition from legumin and vicilin, two other proteins contained in the pea. These albumins show a resemblance in their composition to the animal albumins.

\section{Globulins.}

All the globulins, which can be prepared in a crystalline state, have a very similar composition. Excelsin contains the greatest amount of arginine and edestin of glutamic acid. These proteins form the best source of arginine. Their content in glutamic acid is about half the content of the gliadins in this amino acid. It is unfortunate that the analysis of edestin by Osborne and Liddle [1910, I] is incomplete. Their figures are higher than those of Abderhalden [1902, 1903] and they were unable to isolate oxyproline.

No great difference is to be noted between the crystalline globulins and the other vegetable globulins, except in the proportion of arginine which is distinctly less in most of the non-crystalline ones.

The legumins of the pea and vetch show no real difference in their physical properties and elementary composition, but the analysis shows that differences do exist, especially in the data for lysine and histidine. Analysis has also shown that vignin differs from the other legumins.

The vicilin of the pea contains less sulphur (O.I-O.2 per cent.) than 
any other protein; its analysis shows that it is distinct from legumin. It contains no glycine and more glutamic acid than legumin. A similar protein does not exist in the vetch.

Amandin contains 19 per cent. of nitrogen; the high content in arginine and ammonia serve to explain this high figure. The proteins of the peanut are rich in lysine, and in this respect are of great value for improving a diet containing protein which is deficient in this unit.

The high figure for valine in Foreman's analysis of the protein of linseed is remarkable.

\section{Gliadins and Glutelins.}

There is a very marked difference in the composition of the two proteins found in cereals. Those amino acids, which are absent in the alcohol-soluble protein, are present in the other protein, which is soluble in dilute alkali. The mixture (gluten) of these proteins in the grain, therefore, gives all the amino acids present in other proteins.

The gliadins are very like one another in composition. They are distinguished from other proteins by their high content in glutamic acid, proline and ammonia, their low content in arginine and histidine; lysine is absent from zein, but is present in wheat gliadin in very small amount. On account of the high content in proline and ammonia Osborne suggested the name of prolamines for this group; the group name-gliadins-has been preferred by the British workers.

Wheat-gliadin and rye-gliadin show no great differences, and it seems probable that they are the same protein. Zein of maize differs from them in containing no glycine and no tryptophan and also in containing more leucine and less glutamic acid. The high tyrosine content found by Kutscher does not seem to be correct. Kafir, largely grown in U.S.A., contains kafirin as its chief protein, which resembles zein, but contains lysine and tryptophan. Hordein contains more proline than any other protein.

Wheat-glutenin and the other glutelins seem to contain all the amino acids which have been isolated. The analysis of rice by the Japanese workers is for the whole grain and not for the isolated protein; they found that the husk of the grain also contained protein, and that the proportions of the constituent amino acids were different. Data for the di-amino acids in oryzenin have been published by Osborne, Van Slyke, Leavenworth and Vinograd [19I 5]. 


\section{THE CHEMICAL CONSTITUTION OF THE PROTEINS}

\section{Phosphoproteins.}

There is no striking peculiarity noticeable in the analyses of the phosphoproteins. If we disregard the small quantity of glycine found in caseinogen by some workers and in vitellin by Abderhalden and Hunter, who used the commercial product in their investigation, we must note the absence of this amino acid in the phosphoproteins. It is also absent from the albumins. Glycine is apparently, from the results obtained by numerous workers, the only amino acid which can be synthesised by the animal body from other products; if these phosphoproteins, especially vitellin, really contain no glycine a further proof is given of its synthesis by animals. Abderhalden and Kempe [1907,2] in their experiments on the synthesis of amino acids in the chick could not detect any differences in the amounts of glycine, tyrosine and glutamic acid at different periods of development.

\section{Caseinogen.}

Caseinogen has been hydrolysed more frequently than any other protein and was the protein first analysed by E. Fischer [190I] by the ester method. Fischer did not state the yields of the amino acids, but they were given later by Abderhalden [1905]. No data are given for isoleucine. Some samples of caseinogen seem to contain glycine; in others this unit is not found.

The analysis of caseinogen by Osborne and Guest [I9I I, I] is the most recent, and the data given are the highest which have been observed by them and other American workers. On account of the importance of this protein in nutrition it is very necessary to have as thorough an analysis as possible. The latest analysis has increased our knowledge of the constituent amino acids by about i 5 per cent. Some 30 per cent. of the protein still remains unaccounted for. Foreman's unpublished figures indicate that some of the amino acids are present in larger amounts than other workers have found.

The caseinogens of cow's, goat's, and human milk appear to have the same composition.

\section{Vitellin, etc.}

Vitellin, which has been analysed by four sets of investigators, has given very different results. The values of Hugouneng [1906] and of Levene and Alsberg [1906] do not correspond with the values of Abderhalden and Hunter [1906, 2] or of Osborne and Jones [1909, I]. The values by the latter workers are the most recent and are probably the most accurate.

The phosphoproteins in the eggs of fish (ichthulin) and the frog have been analysed by Hugounenq [1904] and by Galimard [1904]. 


\section{Scleroproteins.}

The scleroproteins, which in their physical properties comprise a heterogeneous collection of proteins, give on hydrolysis, as would be expected, results which support their classification.

\section{Silk.}

Of the proteins in this group those of silk have been most thoroughly investigated. Silk is a mixture of two proteins-silkfibroin and silk-gelatin; the latter is extracted from raw silk by boiling out with water under pressure when it loses 15-20 per cent. in weight; the insoluble portion which has the structure of the original silk forms the silk-fibroin.

Both silk-fibroin and silk-gelatin were analysed by Fischer and Skita [1901, 1902] when the ester method was first introduced. Silkfibroin is composed of practically only three amino acids, glycine, alanine and tyrosine, and is probably the simplest protein known. It contains more tyrosine than any other protein except that of the carapace of the tortoise and is the best source of tyrosine. Silk-fibroin differs very markedly in composition from silk-gelatin; this substance contains more serine than any other protein.

The composition of silk-fibroin and silk-gelatin from different sources is under investigation by Abderhalden and his pupils. The present data show that the composition of the various silk-fibroins is fairly similar, although many differences can be noted. The New Chwang, Schantung and Chefoo varieties are rather peculiar in leaving a somewhat large residue after hydrolysis, which seems to be connected with the food-stuff of the silk-worms. The New Chwang and Schantung worms are fed on oak leaves. The Canton and Bengal silks are most like the Italian; Indian Tussore silk contains a considerably smaller amount of glycine. African Tussore silk is like other Tussore silks and the silk of Bombyx mori from Africa resembled that of Bombyx mori from other countries. The silk of Anaphe had also a similar composition. In fact, the silk of caterpillars, spiders, and of Pinna nobilis have an almost identical composition, with tyrosine, glycine and alanine as the chief constituents [Abderhalden, I9II].

No striking differences are to be noted in the various silk-gelatins. The silk of other arthropods has also been examined. The silkfibroin from spider's silk, except for its high content in glutamic acid, 
closely resembles that of the silk-worm. The silks examined by Suzuki, Yoshimura and Inouye [1909] were distinctly different. The material spun by Oeceticus of the family Psychidæ in order to unite the bits of wood together with which it builds its house contained no tyrosine, but otherwise resembled silk-fibroin. The absence of tyrosine brings out a resemblance to ovokeratin.

\section{Origin of the Amino Acids in Silk.}

Abderhalden and Dean [1909] and Abderhalden and Weichardt [1909] have tried to ascertain whether the amino acids composing the silk are elaborated at the moment of spinning or whether they are selected out of the protein material by the spinning gland. Since the composition of the moth and cocoon together is about the same as the silk-worm, it seems most likely that the spinning gland selects the constituents in making the silk and does not synthesise them from other products.

Pigorini's experiments [1915] with Bombyx mori indicate that glycine is assimilated if it be added to the food in small quantities; in large quantities it had a toxic action, probably due to the formation of ammonia and other decomposition products. This fact supports the hypothesis that silk-formation is mainly a protective measure of the silk-worms, the object being to remove free amino acids from the organism.

Inouye [1912] showed that a great change in chemical composition of the animal takes place in the preparation of the cocoon by the caterpillar, but there is very little change between the pupa and the moth. No nitrogen is given off in the gaseous state, but fat is stored up in the pupa stage and consumed by the pupa and moth. In all stages the amount of mono-amino acids present is greater than that of di-amino acids ; mono-amino acids are found almost entirely in the cocoon. Protein is hydrolysed by a proteoclastic enzyme and its loss is balanced by the increase in amino acids, which are partially converted into ammonia. Inouye [1910] determined the amount of food (mulberry leaves) consumed by the silk-worm. I000 silk-worms ate 1 $2579^{\circ} 6$ grams of fresh leaves whose dry matter was 4056.6 grams ; I 324 grams or nearly 33 per cent. of the mulberry leaves were assimilated. The silk-worms were hatched on July I 2 th, attained maturity, 
and commenced to spin on August 6th. In other terms, a silk-worm during the period of its life as caterpillar, consumes 12.6 grams of fresh mulberry leaf or $4^{\circ} \circ$ grams of dry leaf, of which 1.3 grams is assimilated, in a period of twenty-five days. The amino acids in mulberry leaves have been estimated by Katayama [1916]. There is a marked difference in the proportions of the different units (see p. 123). Of the three chief constituents of silk, alanine is present in large amount in the mulberry leaf, but there is very little glycine; tyrosine is evidently present only in small amounts as no yield is mentioned. These data suggest that glycine may be synthesised de novo and that tyrosine arises from phenylalanine.

\section{Gelatin, Spongin, Elastin.}

Gelatin contains no tryptophan, cystine, or tyrosine, but it contains more glycine than any other protein, except elastin. It also contains a large amount of proline and oxyproline. Levene and Beatty's analysis [1906] was not made by the ester method. This protein appears to have no similarity to silk-gelatin, which contains so much serine.

Spongin resembles gelatin in its high content of glycine, but differs in its content of glutamic acid.

Elastin seems to be made up almost entirely of glycine and leucine; like gelatin, it contains no tyrosine, but it differs from gelatin in containing more phenylalanine. No di-amino acids could be isolated by Bergh [1898] and Hedin [1898], but a minute quantity of arginine was obtained by Kossel and Kutscher [1 898].

\section{Keratins.}

The keratins, except for certain of the proteins usually included in this sub-group, are remarkable for containing more cystine than any of the other proteins; in human hair cystine exists to the extent of about 14 per cent., in other keratins its amount varies from 2-8 per cent. Tyrosine is also present in fair quantities, and the amounts of leucine and of glutamic acid are high.

The amount of cystine isolated from the keratins is generally far below the actual quantity present. The cystine content has been ascertained by the determination of the total sulphur content of the hydrolysed protein and of the loosely-bound sulphur (see Part II.) [Mörner, 1901-2], or by the determination of the sulphur content of 
the cystine fraction dissolved in ammonia [Buchtala, 1907]. More cystine is present in the hair than in the horn of the same animal, as the following figures show:-

\begin{tabular}{|c|c|c|c|c|c|}
\hline \multicolumn{2}{|c|}{ Human hair } & \multicolumn{4}{|c|}{ I3.9 per cent. (Mörner) } \\
\hline ," & ," & $14^{\circ} \mathrm{O}$ & " & ", & (Buchtala) \\
\hline , & , & $13^{\circ} 0$ & ", & , & " \\
\hline " & ", & $14^{\circ} 5$ & $"$, & ", & $"$ \\
\hline$"$ & ". (white) & II 6 & $"$ & ", & " \\
\hline " & nails & $5^{\cdot 2}$ & $"$ & $"$ & " \\
\hline
\end{tabular}

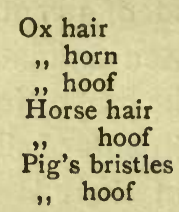

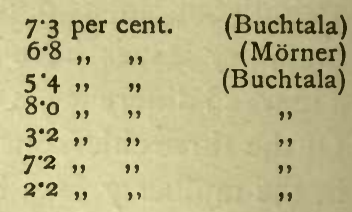

Human hair thus contains nearly double the amount of cystine that is found in the hair of other animals. White hair has less cystine than brown hair.

Horn and hair differ further in respect to their content in glycine and phenylalanine. Hair contains very little or no phenylalanine and from 3-4 per cent. of glycine (white hair 9 per cent.): horn contains very little glycine and from 2-3 per cent. of phenylalanine.

The keratins of sheep's wool and of goose feathers correspond in most respects with the keratin of hair.

Comparative analyses by Abderhalden and Fuchs [1908] show that the horn of older animals contains slightly less glutamic acid than that of younger: ox hoof one year old contained i 8 per cent., four years old I7; ox horn one year old 14, four years old 13 . The data for the horny material of the epidermis of a fish, a tortoise, a snake, an armadillo and an elephant form an interesting series in comparative physiological chemistry. The high tyrosine content of tortoise shell, armadillo scales and snake's scales is particularly noticeable and it is high also in whalebone and elephant hide. Tortoise shell has a high glycine content, like gelatin and elastin, and does not appear to contain glutamic acid. Tortoise shell has the highest tyrosine content of any protein.

The analysis of the egg-membrane of hen's eggs was made with material from 25,000 eggs; only a qualitative analysis with I 7 grams of the egg-membrane of the eggs of Testudo graeca was possible. No tyrosine is present in these proteins, but the egg-membrane of the eggs of Selachians contains tyrosine and only traces of cystine. Koilin, the horny material in birds' gizzards, has also a low cystine content. The egg-membranes and koilin are not considered by Hofmann and Pregl [1907] to belong to the sub-group of keratins. 


\section{Various Proteins.}

The only analyses which we possess of glucoproteins-pseudomucin and paramucin-were carried out before the ester method had become of general use. Otori [1904, I, 2] has given some analytical figures, but Pregl $[1908,2]$ with the small quantity of material available could only perform a qualitative analysis.

A large variety of proteins which cannot be included in any of the above groups have been examined, including micro-organisms and the muscle of Egyptian mummies.

The qualitative data given by Abderhalden and Rona [1905] for Aspergillus niger are of special interest, as this mould was grown on different nutrient solutions and in each case the same amino acids were synthesised. Emmerling [1909] found the usual amino acids in the phosphorescent infusoria ; Tamura [191 3, I, 2; 1914, I, 2] examined the amino acids in the bacilli of tubercle and diphtheria, Mycobacterium and a water bacillus; Omeliansky and Sieber [1913] analysed Azotobacter chroococcum. The protein of yeast has been investigated by Pringsheim [1913], Neuberg [1915], and Meisenheimer [1915]. The bacteria had a high content in phenylalanine, whilst the results for yeast are most variable.

The data for the muscle.of the Egyptian mummy are interesting as showing that the muscle substance is preserved from decomposition by the process of embalming. Autolysis of the muscle occurs, as amino acids could be extracted from the tissue by water.

The analysis of tumours by the ester method may perhaps throw some light on cancer. Several tumours have been analysed, and they all gave figures approximating to those in the table (p. I29). More useful information was published by Drummond [1 1 16], see pp. I09, I 33.

By analysing the membrane enveloping the fat particles of milk Abderhalden and Völtz [1909] have been able to show that the protein is not caseinogen, but that it is most probably a mixture of proteins, as is generally believed.

The analyses of chicken muscle, fish muscle, scallop muscle and ox muscle by Osborne and his associates are of extreme importance for the study of the nutritional value of these food-stuffs as compared with one another and with other, especially the vegetable, proteins. The several muscles show a very close resemblance to the vegetable globulins, but they contain less arginine and more lysine than these proteins. The high content in lysine is particularly noticeable; scallop muscle contains the least amount; in the other muscles it is about 7.5 per

PT. I. 
cent. Fish muscle contains the least amount of glutamic acid; the amounts in the other muscles are very close. The muscles are alike in respect of tyrosine, aspartic acid, arginine, lysine and histidine, and also phenylalanine, which is slightly more abundant in scallop muscle. Glycine is present in considerable amount in the free state in scallop muscle; otherwise, it is present only in ox muscle to any extent; since syntonin contains very little glycine, it is probably derived from the connective tissue in the ox muscle. It is curious that, as we pass from the lower forms of life to the higher, the amounts of glycine, alanine, leucine and proline increase.

The amount of protein in the nervous system seems to be small, as the total quantity of amino acid isolated by Abderhalden and Weil [191 2, 2; 1913, I] does not exceed Io per cent. Mention may again be made of the presence of norleucine amongst these amino acids.

The crystalline protein from the juice of Antiaris toxicaria examined by Kotake and Knoop [I9II] is a remarkable protein-probably a complex polypeptide-with 10.6 per cent. of cystine. Further data will no doubt decide the nature of this protein. Only a small quantity of material has been so far available.

\section{Derivatives of Proteins.}

Complete analyses of the proteoses-products intermediate between the proteins and amino acids-have been undertaken by Levene, and by Levene in conjunction with Van Slyke and Birchard, and by Skraup and his pupils.

In the case of the gelatoses and gelatin peptone, Levene [1902-3, 1904] found that the gelatoses contained 17-20 per cent. of glycine and gelatin peptone 17.4 per cent. as compared with 16.5 per cent. in gelatin itself. Skraup and Hummelberger [1908] gave the composition of gelatoses precipitated by half, two-thirds and complete saturation with ammonium sulphate and of gelatin peptone as follows:-

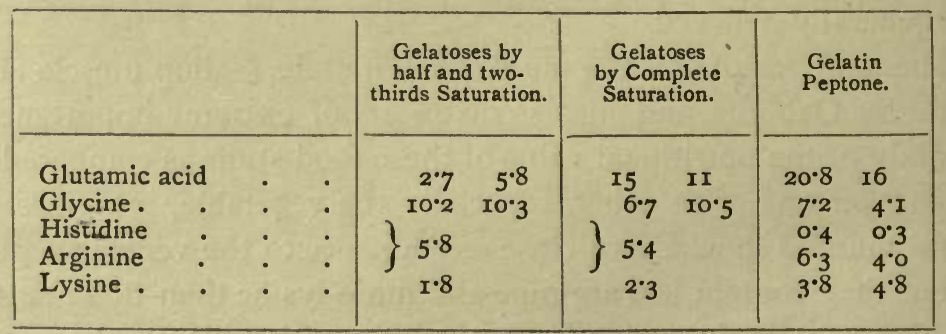

The gelatoses contain more glycine than gelatin which contains 9.6 per cent., but the peptone less. Levene found that amino acids 
were separated off in the production of peptone which accounts for the different figures for gelatin peptone.

The qualitative differences observed by the older workers, Kühne, Chittenden, Neumeister, and the analytical differences in the case of Witte's peptone observed by Pick have not been found. The generally accepted view that heteroalbumose contains more hexone bases than protoalbumose is not confirmed. We may note that heteroalbumose contains more glutamic acid than protoalbumose, and that it contains I per cent. more histidine.

Skraup and his pupils have made numerous analyses of various intermediate products. Skraup and Krause [1910, I, 2] analysed the derivatives of caseinogen. Proteose I. contained more glutamic acid and more tyrosine than caseinogen; proteose II. contained less glutamic acid but more tyrosine, and the peptone contained more glutamic acid and no tyrosine.

Skraup with Zwerger [1905] and with Witt [1906] examined the substances termed kyrins by Siegfried and came to the conclusion that they are mixtures. They found that gelatin-kyrin contained 50 per cent. of di-amino acids and casein-kyrin 80 per cent., the former being composed of I molecule of arginine, I molecule of histidine, I molecule of glutamic acid and 2 molecules of glycine, the latter of I molecule of arginine, 2 molecules of lysine and I molecule of glutamic acid.

Skraup with Lampel [1909], with Hummelberger [1909], and with Wöber [1909] gave the following data for the protein and for those products formed by the action of alkali, which were first prepared by Paal :-

\begin{tabular}{|c|c|c|c|c|c|c|c|c|}
\hline & Histidine. & Arginine. & Lysine. & Tyrosine. & Proline. & $\begin{array}{l}\text { Phenyl- } \\
\text { alanine. }\end{array}$ & $\begin{array}{l}\text { Glutamic } \\
\text { Acid. }\end{array}$ & $\begin{array}{l}\text { Other } \\
\text { Amino } \\
\text { Acids. }\end{array}$ \\
\hline $\begin{array}{l}\text { Serum globulin } \\
\text { Protalbic acid . } \\
\text { Lysalbic acid } \\
\text { Peptone. }\end{array}$ & $\begin{array}{l}I \cdot 7 \\
I \cdot 5 \\
I \cdot 7 \\
I \cdot 5\end{array}$ & $\begin{array}{l}3 \cdot 7 \\
0 \\
0 \\
0\end{array}$ & $\begin{array}{l}4 \cdot 3 \\
3 \cdot 9 \\
4 \cdot 4 \\
4 \cdot 4\end{array}$ & $\begin{array}{l}3 \cdot 1 \\
4 \cdot 4 \\
2 \cdot 5 \\
I \cdot 2\end{array}$ & $\begin{array}{l}3 \cdot 0 \\
3 \cdot 2 \\
2 \cdot 9 \\
2 \cdot 3\end{array}$ & $\begin{array}{l}3 \cdot 6 \\
1 \cdot 0 \\
2 \cdot 7 \\
1 \cdot 8\end{array}$ & $\frac{4 \cdot 4}{x \cdot 9}$ & $\begin{array}{l}18 \cdot 5 \\
20 \cdot 4 \\
21 \cdot 2 \\
13 \cdot 5\end{array}$ \\
\hline $\begin{array}{l}\text { Ovalbumin } \\
\text { Protalbic acid : } \\
\text { Lysalbic acid } \\
\text { Peptone . }\end{array}$ & $\begin{array}{l}r \cdot 5 \\
2 \cdot 3 \\
0 \cdot 3 \\
0 \cdot 6\end{array}$ & $\begin{array}{l}2 \cdot 9 \\
0 \cdot 4 \\
0 \cdot 2 \\
0 \cdot 3\end{array}$ & $\begin{array}{l}3 \cdot 9 \\
3 \cdot 3 \\
5^{\circ} 3 \\
4^{\circ} 0\end{array}$ & $\begin{array}{l}2 \cdot 4 \\
3 \cdot 4 \\
2 \cdot 6 \\
I \cdot 1\end{array}$ & $\begin{array}{l}I \cdot 5 \\
2 \cdot 0 \\
I \cdot 0 \\
0 \cdot 3\end{array}$ & $\begin{array}{r}5 \cdot 8 \\
12 \cdot 0 \\
5 \cdot 2 \\
2 \cdot 4\end{array}$ & $\begin{array}{l}3 \cdot 2 \\
1 \cdot 8 \\
1 \cdot 0 \\
1 \cdot 6\end{array}$ & $\begin{array}{r}7 \cdot 9 \\
\times 4^{\circ} \cdot 7 \\
7 \cdot 0 \\
3^{\circ} \cdot 2\end{array}$ \\
\hline $\begin{array}{l}\text { Edestin } \\
\text { Substance A } \\
\text { Substance B }\end{array}$ & $\begin{array}{l}2 \cdot 2 \\
2 \cdot 2 \\
3 \cdot 6\end{array}$ & $\begin{array}{r}14^{\cdot} \cdot 2 \\
5 \cdot 6 \\
13^{\circ} 0\end{array}$ & $\begin{array}{l}r \cdot 7 \\
0.8 \\
0.9\end{array}$ & $\begin{array}{l}2 \cdot 1 \\
I \cdot 4 \\
2 \cdot 1\end{array}$ & $\begin{array}{l}1 \cdot 7 \\
1 \cdot 7 \\
0.7\end{array}$ & $\begin{array}{l}2 \cdot 4 \\
0 \cdot 2 \\
0.4\end{array}$ & $\begin{array}{r}6 \cdot 3 \\
1 \cdot 5 \\
10 \cdot 9\end{array}$ & $\begin{array}{r}I x \cdot 1 \\
9 \cdot 4 \\
8 \cdot 5\end{array}$ \\
\hline
\end{tabular}




\section{THE CHEMICAL CONSTITUTION OF THE PROTEINS}

Even the elementary analyses of the substances differed according to Gupta [1909]:-

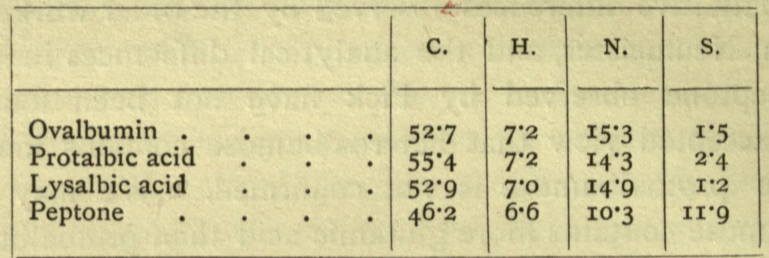

The analysis of plastein also does not answer the much discussed question whether it represents a synthetical product or a further product of digestion. The figures so nearly resemble those for Witte's peptone that one would be inclined to the view that plastein is still a mixture, which is precipitated under the conditions of the experiment.

In general, the analyses of the proteoses show that they contain all the amino acids originally present in the protein ; if a splitting of the large molecule had occurred in such a way that four or five amino acids only were present in each product, the synthetical problem would be easier; we have still no substantial clue as to the order in which the units are combined in the molecule (see Part III.).

Dennstedt and Hassler [1906] believe that in the formation of proteoses the process of oxidation occurs at the same time as hydrolysis. 


\section{ANALYSIS OF PROTEINS BY THE DISTRIBUTION OF THE VARIOUS KINDS OF NITROGEN.}

Since a complete analysis of a protein is still an impossibility, owing to the unsatisfactory methods for isolating and estimating the several mono-amino acids, the proteins cannot yet be differentiated by means of their chemical composition.

It has been proved by Osborne, Leavenworth and Brautlecht [1908] that the methods for estimating the ammonia content and the di-amino acid (the three hexone bases) content of a protein are almost perfect. We can therefore differentiate proteins by their content in these four products.

A further differentiation of the units composing the protein molecule into those containing amino groups and those containing nitrogen in heterocyclic combination was made by Van Slyke [19I0, I9II].

This subdivision is possible, since nitrous acid reacts only with amino groups with liberation of nitrogen :-

$$
\underset{\mathrm{COOH}}{\mathrm{CH}_{2} \cdot \mathrm{NH}_{2}}+\mathrm{HNO}_{2}=\underset{\mathrm{COOH}}{\mathrm{CH}_{2} \mathrm{OH}}+\mathrm{N}_{2}+\mathrm{H}_{2} \mathrm{O}
$$

the amount of nitrogen evolved being double that contained in the amino acid.

We can ascertain the following particulars :-

1. Amide nitrogen (ammonia).

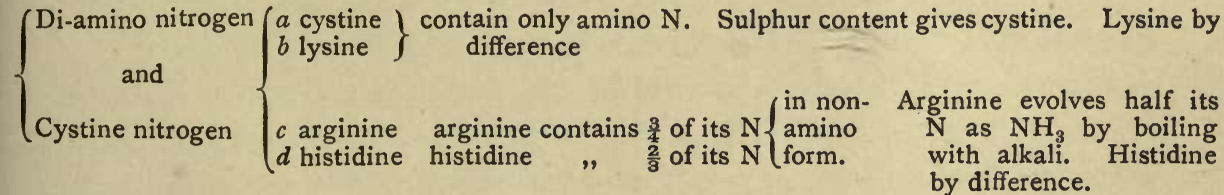
$\left\{\begin{aligned} \text { Mono-amino nitrogen } & \begin{array}{l}\text { glycine, phenylalanine, } \\ \text { alanine, tyrosine, } \\ \text { valine, } \\ \text { leucine, } \\ \text { isoleucine. }\end{array}\end{aligned}\right.$

Non-amino nitrogen $\begin{aligned} & \text { proline } \\ & b\left\{\begin{array}{l}\text { oxyproline } \\ \text { tryptophan }\left(\frac{1}{2}\right)\end{array}\right.\end{aligned}$

i.e., seven data out of the possible eighteen.

An eighth value is obtainable by determining the mono-aminodicarboxylic acid content as was shown by Andersen and Roed-Müller [1915]. This determination depends upon the fact that in a mixture of mono-amino acids, the mono-aminomonocarboxylic acids have a 
neutral reaction whereas the monoaminodicarboxylic acids have an acid reaction; by neutralising the solution the dicarboxylic acids react with I molecule of sodium hydroxide and on incineration leave an equivalent quantity of sodium carbonate, which can be titrated (see pp. 104-106). Only a few determinations have so far been made by Andersen and Roed-Müller, but they agree with the figure calculated from the amounts of aspartic and glutamic acids isolated from the products of hydrolysis :-

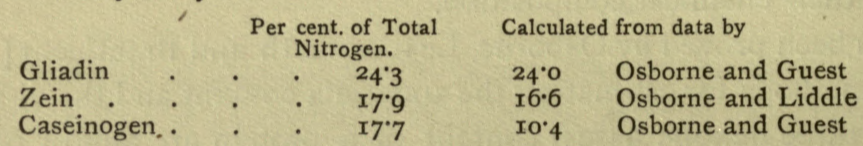

In the case of caseinogen the value is distinctly higher, but it may represent the amount of dicarboxylic acid in this protein more closely than the calculated figure, more especially as in this case the complete isolation of glutamic acid is more difficult than in vegetable proteins.

If we regard the data for tyrosine as almost accurate, we have still one more value of service for the chemical differentiation of the proteins. It is unfortunate that we cannot yet measure the tryptophan content of a protein, especially as this unit is so readily detected by means of its colour reactions. 


\section{A. DISTRIBUTION OF THE NITROGEN IN THREE GROUPS.}

The differentiation of proteins by the estimation of the various groups of the units was first attempted in Hofmeister's laboratory by Hausmann [1899, 1900], who estimated amide nitrogen, di-amino nitrogen and mono-amino nitrogen. The protein ( $\mathrm{I}$ gram) was hydrolysed with 20 c.c. of concentrated hydrochloric acid by boiling for five hours under a reflux condenser; the solution was diluted and distilled with excess of magnesia, and the ammonia, which was liberated, was collected in excess of standard acid; the solution was then acidified with acid and precipitated with phosphotungstic acid; after twenty-four hours the precipitate was filtered off, washed with phosphotungstic acid, dissolved in alkali and the nitrogen estimated in an aliquot portion by Kjeldahl's method; the filtrate was made up to a definite volume and nitrogen estimated in an aliquot portion.

Numerous objections to the accuracy of the data were raised. Henderson [ 1899 ] maintained that the amount of amide nitrogen varied according to the strength of the acid employed in the hydrolysis and the time of hydrolysis; Kutscher [1900], and also Chittenden and Eustis [1900], showed that the precipitation of the di-amino acids was not complete, and Schulze and Winterstein $[1901,2]$ found that certain mono-amino acids, e.g., phenylalanine, were precipitated by phosphotungstic acid under certain conditions. Hart [1901] preferred barium carbonate to magnesia for distilling off the ammonia.

Osborne and Harris [1903], Gümbel [1904], and also Rothera [1904], critically examined the various objections. The amount of amide nitrogen was not found to vary as Henderson stated; if similar conditions are always maintained in the precipitation with phosphotungstic acid most valuable comparative results can be obtained; the errors of incomplete precipitation of the di-amino acids and precipitation of mono-amino acids almost compensate each other.

Adopting Guimbel's suggestion of distilling off the ammonia in vacuo at $40^{\circ}$ and Osborne and Harris' procedure, the process may be carried out as follows:-

I. About I gram of protein is boiled with about roo c.c. of 20 per cent. hydrochloric acid in a 500 c.c. round bottom flask under a reflux condenser until the solution no longer gives the biuret reaction, usually from seven to ten hours. It is then evaporated in vacuo at 
$40^{\circ}$ to a volume of $2-3$ c.c. ; the greater portion of the hydrochloric acid is thus removed.

2. About 300 c.c. of water is then placed in the flask and a cream of magnesia, which has been freed from every trace of ammonia by long boiling, is added until in slight, but distinct, excess. The mixture is distilled in vacuo at $40^{\circ}$ and the distillate collected in excess of standard acid; about half the liquid should be distilled. Titration of the standard acid gives the amount of amide nitrogen.

3. The remainder of the solution is filtered through a nitrogen-free paper and the residue, thus collected, washed thoroughly with water. The nitrogen in this precipitate is estimated by Kjeldahl's method and is the "humin" nitrogen.

4. The filtered solution is concentrated to Ioo c.c. and cooled to $20^{\circ} ; 5$ grams of sulphuric acid and then 30 c.c. of a solution containing 20 grams of phosphotungstic acid and 5 grams of sulphuric acid per 100 c.c. are added.

5. The precipitate is filtered off after twenty-four hours and washed with a solution containing 2.5 grams of phosphotungstic acid and 5 grams of sulphuric acid per 100 c.c. The washing is effected by rinsing the precipitate from the filter into a beaker and returning to the paper three successive times, each portion of the wash solution being allowed to run out completely before the next is applied. About 200 c.c. of washings are generally obtained.

6. The precipitate is transferred to a 600 c.c. Jena glass flask and the nitrogen estimated in it by Kjeldahl's method, digesting it with 35 c.c. of concentrated sulphuric acid for seven or eight hours. Potassium permanganate crystals may be added three or four times. If the phosphotungstic acid precipitate be small, less sulphuric acid may be used, but sufficient must be taken to prevent bumping.

7. The remaining nitrogen, belonging to the mono-amino acids, is found by subtracting the sum of the nitrogen found in the preceding operations from the total nitrogen contained in the protein.

The data given in the table on page $\mathrm{I} 3 \mathrm{I}$ show that there are con. siderable differences in the amounts of the various kinds of nitrogen in proteins. 


\section{B. DISTRIBUTION OF THE NITROGEN IN SEVEN GROUPS.}

\section{Estimation of Amino Nitrogen.}

The action of nitrous acid upon amino acids and amides as a method for estimating these compounds was introduced by Sachsse and Kormann [1875]. These investigators employed an apparatus consisting of a small cylinder, furnished with a rubber stopper, through which two tap funnels and an exit tube for the evolved gas passed. Potassium nitrite was placed in the cylinder, dilute sulphuric acid in one of the tap funnels, and the solution of the substance $\left(0^{\circ} 6-I^{\circ} \circ \mathrm{gram}\right)$ in the other. The exit tube was placed under an eudiometer filled with ferrous sulphate solution to absorb the nitric oxide. Air was expelled from the apparatus by the decomposition of some of the nitrite with the acid. As soon as the expulsion was complete, the amide solution and more acid solution were allowed to enter into the cylinder and the gas collected. The ferrous sulphate solution freed the mixture from nitric oxide and more was added, if necessary. Carbon dioxide was then removed with potash and the remaining gas was measured.

This method was exhaustively tested in the Guinness Research laboratory by Horace Brown and J. H. Millar [rgo3]. They found that there were several serious sources of error in the original method before they could apply it to their own subject of investigation. These were due (I) to residual air contained in the apparatus, or in the liquids; $(2)$ to the difficulty of absorbing the excess of nitric oxide with ferrous sulphate. Carbon dioxide was used to remove the air and the evolved nitrogen, and difficulty was experienced in obtaining a steady and constant stream of this gas. Pure carbon dioxide was prepared by the action of 30 per cent. sulphuric acid on normal sodium carbonate solution. A constant evolution of gas was not obtained, when the two solutions were allowed to drop separately into a flask, owing to the supersaturation of the liquid with the gas. A steady stream of carbon dioxide was obtained by allowing the liquids to mix in a piece of wide glass tubing, which was drawn out at its lower extremity so that only a small aperture remained and closed at its upper end by a small cork through which tubes connected with reservoirs of acid and carbonate passed; two small apertures in its sides allowed for the escape of the gas. This wide tube was placed in the vessel used for the generation of the carbon dioxide. The mixture of acid and carbonate solutions accumulated to a height of about $3 \mathrm{~cm}$. in the tube, and then dropped into the flask, which could be emptied by an attached syphon tube. The carbon dioxide entered the apparatus through a special trap. Air contained in the apparatus was removed by a stream of carbon dioxide and steam, which was made to enter through this trap. All the solutions used were made with air-free water, charged with carbon dioxide; the same water was used for washing purposes.

The carbon dioxide was removed by the potash solution contained in a Lunge nitrometer, with which the exit tube of the apparatus was connected. The excess of nitric oxide was removed by means of oxygen, prepared by the electrolytic decomposition of water, and passed into the nitrometer, and the excess of oxygen by passing the gas in the nitrometer into a double Hempel pipette containing pyrogallol dissolved in 60 per cent. potash solution.

Allowing one to two hours for the reaction of the nitrous acid upon the amino acids, satisfactory results were obtained with glycine, alanine, phenylalanine, leucine, aspartic acid, glutamic acid and asparagine. The results with tyrosine were not satisfactory, but they found that it reacted quantitatively after bromination.

The estimation of the amino nitrogen was originally performed by Van Slyke [1910, I, 2; 191 I, 1, 2, 4] in an apparatus very similar to that used by Sachsse and Kormann and by Horace Brown and Millar. 
The whole apparatus was filled with nitric oxide, and this gas was used for washing the evolved nitrogen into the eudiometer; the excess of nitric oxide was then removed with permanganate contained in a Hempel pipette.

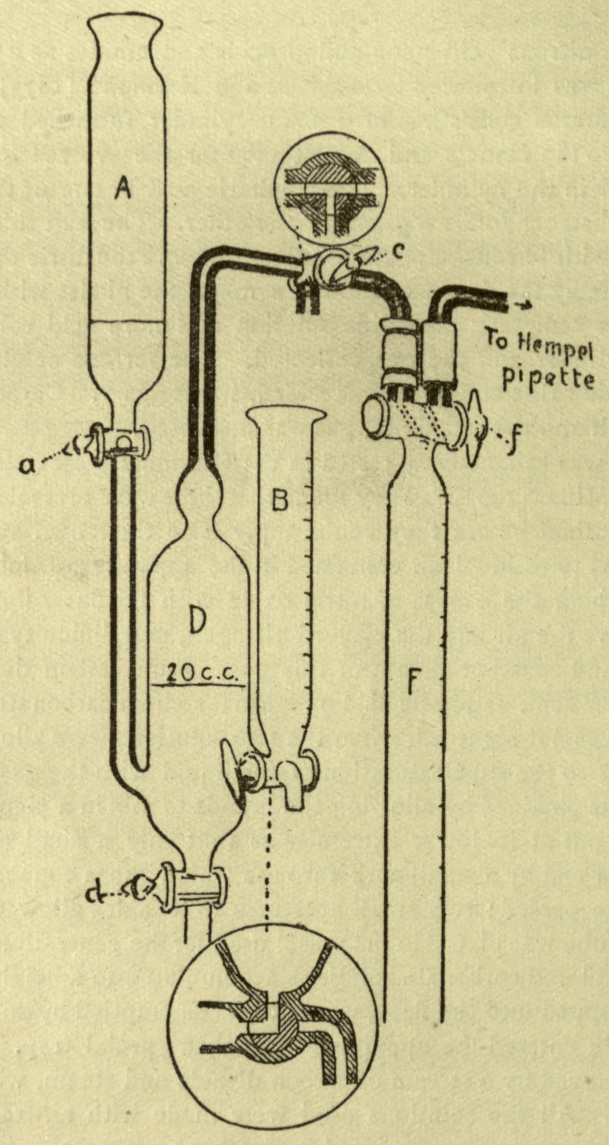

FIG. 2.

From J. Biol. Chem., I912, 12, 278.

A modified form of apparatus was devised by Klein [I9I I] and this form of apparatus, greatly improved, was adopted by Van Slyke [191 2, I ]. It has entirely displaced the older form of apparatus, and is shown in figs. 2 and 3 , the latter figure showing all the parts of the apparatus assembled for use upon a fixed stand. The parts are more frequently assembled on a stand which is movable.

The apparatus consists of the deaminising bulb $\mathrm{D}$ of $40-45$ c.c. capacity for the interaction of the nitrous acid and the solution of the amino substance. It has a mark at 20 c.c. Connected with this vessel, are 
A, a vessel of 35 c.c. capacity with a mark at 7 c.c. and tap $a$ for introducing solution into $\mathrm{D}$, or receiving solution from $\mathrm{D}$.

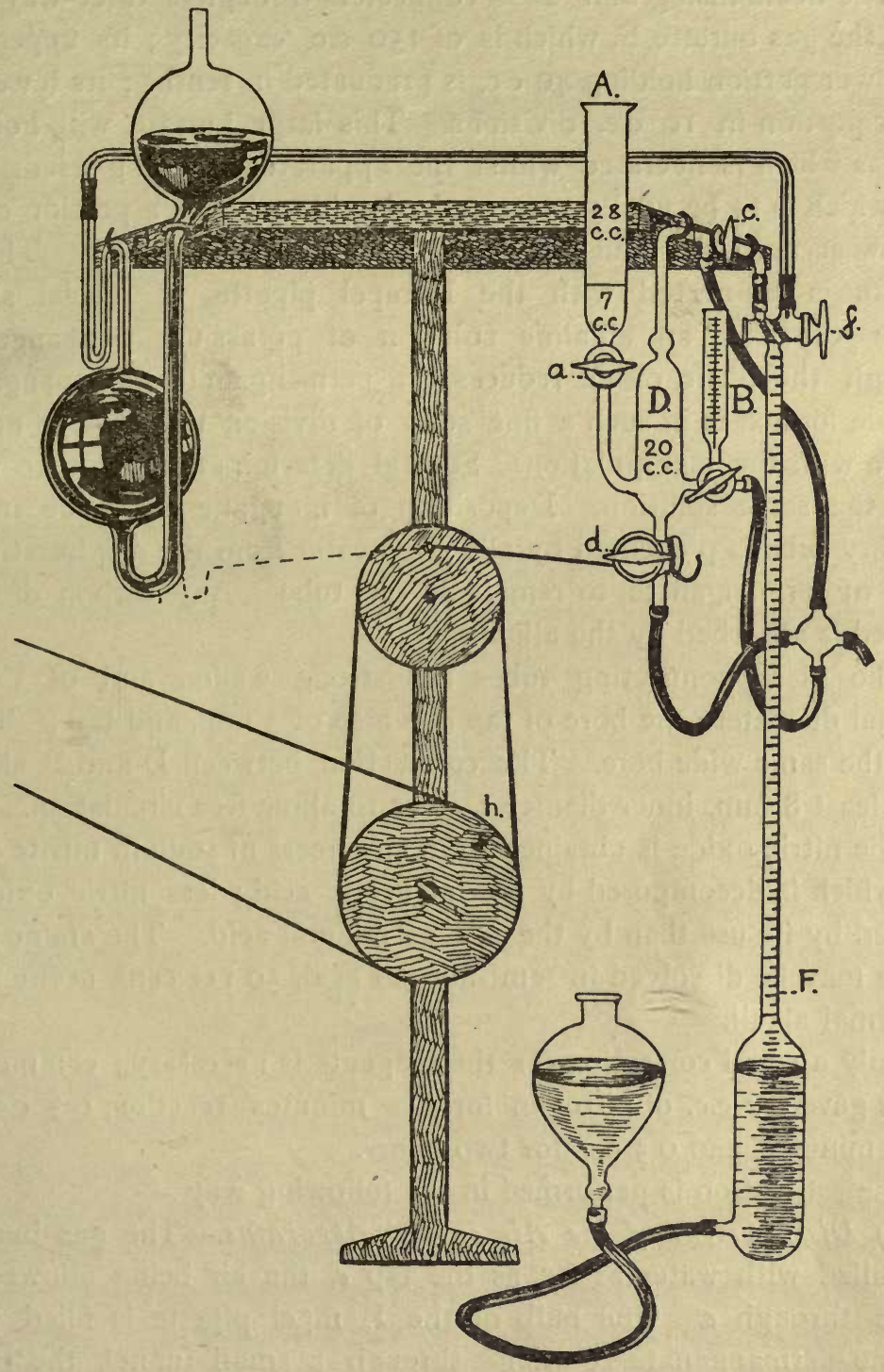

Fig. 3.

From Plimmer's Practical Organic and Biochemistry.

B, a ro c.c. burette for containing the solution of the amino substance.

A $\operatorname{tap} d$, for emptying the deaminising vessel $D$. 
There is above $\mathrm{D}$ a small bulb which keeps the reacting solution from splashing into the capillary.

The deaminising bulb $\mathrm{D}$ is connected through a three-way tap $c$ with the gas burette $\mathrm{F}$, which is of 150 c.c. capacity; its upper and narrower portion holding 40 c.c. is graduated in tenths; its lower and wider portion in Io c.c. divisions. This large burette will hold all the gas which is liberated whilst the apparatus is being used. The gas, which is to be finally measured, should only fill a portion of the narrow accurately graduated part. It is filled with water. The gas burette is connected with the Hempel pipette of special shape, which contains an alkaline solution of potassium permanganate. Though the nitric oxide reduces the permanganate, the manganese dioxide formed is in such a fine state of division that it does not interfere with the manipulation. Several determinations can be made with the same solution. Deposition of manganese dioxide in the capillary tube is prevented by allowing water from the gas burette, instead of permanganate, to remain in this tube. Any carbon dioxide evolved is absorbed by the alkali.

The glass connecting tubes are strong walled and of $3 \mathrm{~mm}$. internal diameter; the bore of tap $a$ is also of $3 \mathrm{~mm}$. and tap $d$ should have the same wide bore. The connection between $\mathrm{D}$ and $\mathrm{B}$ should be at least $8 \mathrm{~mm}$. inner diameter, so as to allow free circulation.

The nitric oxide is obtained from an excess of sodium nitrite solution which is decomposed by glacial acetic acid; less nitric oxide is evolved by its use than by the use of mineral acid. The amino substance may be dissolved in semi-normal acid, 50 per cent. acetic acid, or normal alkali.

Only a small correction for the reagents is necessary; commercial nitrite gave 0.2 c.c. of nitrogen for five minutes' reaction, 0.3 c.c. for thirty minutes, and 0.5 c.c. for two hours.

The estimation is performed in the following way :-

(I) Displacement of the Air in the Apparatus. - The gas burette $\mathrm{F}$ is filled with water as far as the tap $c$, the air being allowed to escape through $c$. One bulb of the Hempel pipette is filled with alkaline permanganate solution ${ }^{1}$ through a small funnel, the tap $f$ being arranged so that the air is displaced into the burette. The permanganate should just reach the tap, which is then closed in this direction and opened towards the $\operatorname{tap} c$. The air in the burette is driven out through $c$ so that water again fills the burette as far as

${ }^{1} 50$ gram $\mathrm{KMnO}_{4}+25$ gram $\mathrm{KOH}$ per 1000 c.c. 
the tap $c$, which is turned so as to shut off this part of the apparatus and to be in connection with $\mathrm{D}$ and the exit tube.

7 c.c. of glacial acetic acid are put into $A$ and run into D; 30 c.c. of the sodium nitrite solution ${ }^{1}$ are placed in $\mathrm{A}$ and also run into $\mathrm{D}$. Sufficient should be used so that excess stands in A above the tap.

The remaining air in the apparatus and that dissolved in the nitrous acid solution is removed by closing $c$ by a quarter turn, leaving $a$ open and shaking D. Rapid evolution of nitric oxide occurs which gathers in $\mathrm{D}$ and forces ro-r 5 c.c. of solution back into $\mathrm{A}$. The cock $c$ is now again opened and the nitric oxide, together with the air swept out of the solution, is forced out of $\mathrm{D}$ by liquid from $\mathrm{A}$ through $c$. This process is repeated twice to ensure removal of all the air.

By closing $c$ and shaking D a gas space of about 20 c.c. is now made to make room for the amino solution from $B$.

Tap $a$ is closed and tap $c$ is opened to connect D and F. These manipulations require about two minutes.

(2) Decomposition of the Amino Substance.-Io c.c. or less of the solution to be analysed is put into the graduated tube $B$; any excess can be run off. The desired volume is run into D. The burette $B$ need not be graduated and the desired volume can be introduced with a pipette into $\mathrm{B}$, run into $\mathrm{D}$, and $\mathrm{B}$ washed with a little water, which is also run into $D$. The evolution of nitrogen commences immediately, and D is thoroughly shaken for three to five minutes to complete the evolution of the gas. Only in a few cases is longer shaking necessary.

The evolved gas passes into the burette $\mathrm{F}$; the residual gas in the bulb is driven into $\mathrm{F}$ by opening the tap $a$ and letting liquid run from A into $\mathrm{D}$ as far as the tap $c$.

(3) Absorption of Nitric Oxide and Measurement of the Nitrogen.The tap of the burette $F$ is turned to connect it with the Hempel pipette and the gas is driven from $F$ into the Hempel pipette by raising the levelling bulb. By shaking the gases with the permanganate the nitric oxide is absorbed. The residual nitrogen is run back into $F$, the permanganate filling the tubing as far as the $\operatorname{tap} f$. The volume of gas in $\mathrm{F}$ is then measured by bringing the surface of the liquid in the bulb even with the meniscus. Generally, one shaking with the fresh permanganate suffices to remove all the nitric oxide, but it is advisable to test if the absorption is complete by returning the gas to the Hempel pipette and again measuring. The weight of nitrogen corre-

\footnotetext{
${ }^{1} 30$ grams per 100 c.c.
} 
sponding to the volume of gas is calculated in the usual way; the results are divided by 2 (see equation, p. 85). The weight may be taken from the table compiled by Van Slyke and reproduced on p. I 36.

Each milligram of amino substance gives off from $1 \cdot 7-1 \cdot 9$ c.c. of nitrogen.

A correction should be made for the air- 0.2 c.c.- dissolved in 10 c.c. amino solution, i.e., allowing for the oxygen which combines with the nitric oxide forming peroxide and is absorbed by the permanganate, 0.16 c.c. must be deducted from the volume of gas. This correction is equivalent to $0.09 \mathrm{mgm}$. of amino nitrogen. No correction is necessary, if air-free water be used in preparing the amino solution.

If proteins or other solutions which may froth are to be analysed, a few drops of capryl alcohol are first introduced into $D$ through $B$, and capryl alcohol can be added subsequently from B. ${ }^{1}$

Except lysine, the natural amino acids all react quantitatively in five minutes: half an hour is required for this substance. Ammonia and methylamine require one and a half to two hours, purines and pyrimidines two to five hours, and urea eight hours. With these substances the apparatus is allowed to stand for the required time and then shaken for two minutes.

The completeness of the reaction may be tested by repeating the process and ascertaining if more gas is evolved.

Glycine and cystine evolve a larger volume of gas than the theoretical ; the factor 926 may be used in estimating cystine; 3 per cent. of the total volume of gas must be deducted for glycine.

\section{Micro Apparatus $i$.}

Van Slyke [1913, 1] described a smaller form of apparatus for use in the analysis of amino acids in blood, tissues, etc., in which only minute quantities are present. It may be advantageously used in these estimations instead of the larger form of apparatus. Its dimensions are:-

(I) The gas burette: 10 c.c., the upper part of $2 \mathrm{~mm}$. diameter measuring 2 c.c. and graduated in $\frac{\lambda}{50}$ c.c., the lower part wider and graduated in $\frac{1}{20}$ c.c.

A gas burette holding a total volume of 20 or 30 c.c. is better as frequently more than Io c.c. of nitric oxide are evolved.

This burette or its upper part should be enclosed in a water jacket, alcohol.

${ }^{1}$ In later forms of apparatus another tube is sealed to D for introducing the capryl 
since temperature variations of the atmosphere affect the small volumes of gas which have to be measured.

(2) The deaminising bulb: I I-I 2 c.c.

(3) The burette: 2 c.c.

The quantities of reagents required are Io c.c. of sodium nitrite solution and 2.5 c.c. of glacial acetic acid for which the correction for impurities amounts to $06-12$ c.c. It is not necessary to have a smaller Hempel pipette; with the micro apparatus the permanganate lasts for a considerable time.

The solution to be analysed may be introduced into the burette with a pipette and the burette is washed with six or seven drops of water.

The error in the estimation need not exceed $005 \mathrm{mgm}$. when 2 c.c. or less gas is measured; with more gas or mgm. Onefifth of the amount of solution required for the macro apparatus is used in the micro apparatus. Not only is there an advantage economically with reagents, but also the apparatus is less fragile.

$0.5 \mathrm{mgm}$. of amino acid can be analysed with an accuracy of I per cent. The analysis is slightly more rapid : at $15-20^{\circ}$ four minutes' shaking suffice, at $20-25^{\circ}$ three minutes, above $25^{\circ}$ two to two and a half minutes.

It is essential that the burettes be accurate and the stopcocks be tight. The burettes are tested by weighing the water they deliver; the stopcocks by submitting them to a pressure of a column of water one metre high.

The apparatus is cleaned with a mixture of potassium bichromate and sulphuric acid.

\section{Micro Apparatus ii.}

The size of apparatus can be reduced to one-half of the above, if the form of the gas burette be modified [Van Slyke, 1915, 2]. This is shown in fig. 4. The zeropoint, instead of being placed at the bottom of the stopcock, is located on a capillary

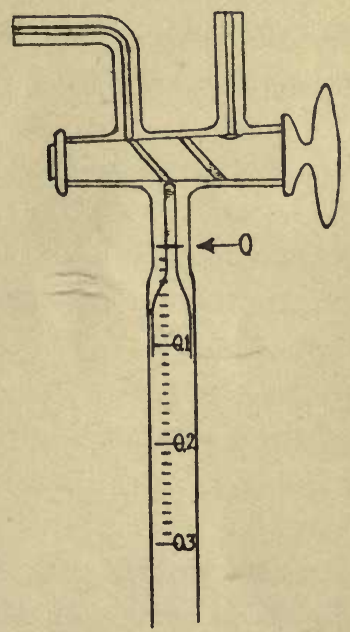

FIG. 4 .

After J. Biol. Chem., 19r5, 23, 408.

which extends for a few millimetres below the tap. It permits marking off the upper boundary of the gas volume with an error of 


\section{THE CHEMICAL CONSTITUTION OF THE PROTEINS}

less than oor c.c. The burette is of 3 c.c. capacity, and is graduated into 0.1 c.c. divisions about $\mathrm{I} \mathrm{mm}$. apart, so that by estimating tenths of a division gas volumes can be read to oor c.c. The burette must be carefully calibrated. I c.c. of amino solution is required for analysis.

The removal of air from the apparatus is more easily effected as follows :-

The apparatus is shaken once until sufficient nitric oxide is formed to force the liquid in the chamber down to the mark at which the reagent stands for introducing the amino solution. The tap $a$ is closed and $\operatorname{tap} c$ is turned so that the gases can escape at $c$. The vessel is then shaken rapidly for two minutes with the motor. The air is more completely removed by this procedure than by the other procedure. The deaminising bulb is then connected through $c$ with the gas burette.

Soft heavy-walled rubber tubing must be used for the connections. "Stethoscope" tubing with a wall 3 or $4 \mathrm{~mm}$. thick is very suitable. 


\section{Estimation of the Different Groups of Amino Acids.}

The estimation of the several groups of amino acids present in a protein is effected by the following series of operations:-

I. Hydrolysis. -3 grams of protein, or better 6 grams for duplicate analyses, are dissolved in 10 or 20 parts of 20 per cent. hydrochloric acid and boiled in a tared flask under a reflux condenser.

After six or eight hours the hydrolysis is stopped. Portions of I c.c. or 2 c.c. (enough to contain O.I gram of protein) are withdrawn with a pipette and diluted to Io c.c. In these portions the amount of amino nitrogen is determined, the reaction being allowed to proceed for five minutes standing and then for one minute with shaking. Under these conditions the same proportion of ammonia (I 5-20 per cent.) is decomposed in each determination.

The hydrolysis flask is weighed and the hydrolysis continued for another period of six or eight hours, when amino nitrogen is again determined.

Hydrolysis is continued until the amino nitrogen is constant.

The object of weighing is to ascertain if the solution has become concentrated by loss of vapour and to allow of a correction for a decrease of the volume.

2. Estimation of Total Nitrogen.-The products of hydrolysis are transferred to a measuring flask of 100 c.c. or 250 c.c. capacity. Total nitrogen is estimated by Kjeldahl's method in an aliquot portion containing 0.2 gram of protein. All the subsequent estimations are based upon this value.

3. Amide Nitrogen.-Since cystine is very easily decomposed by boiling with magnesia at $100^{\circ}$ the determination of ammonia must be carried out in vacuo at $40^{\circ}$, or at room temperature by the aeration method of Denis. ${ }^{1}$ The method of distilling in vacuo is to be preferred as the same apparatus is repeatedly employed in the other estimations.

The distillation in vacuo is performed in the apparatus shown in fig. 5 (p. 98), or in some arrangement by which the ammonia vapour passes into the standard acid.

The Claisen flask and receiver are of I litre capacity, the guard flask of 200 c.c.

The hydrolysed solution is placed in the double-necked flask and

${ }^{1}$ F. Biol. Chcm., 8, 427 .

PT. I. 
diluted to 200 c.c. ; 100 c.c. of alcohol are added to prevent frothing and then an excess of a 10 per cent. suspension of calcium hydrate, as shown by the turbidity and alkaline reaction of the solution. Air may be introduced through the stop-cock, if distillation starts too rapidly; the stop-cock serves to release the vacuum when the distillation is finished. The decinormal acid in both flasks is mixed and titrated with decinormal soda using alizarin sulphonate as indicator, which may be added previous to the distillation.

4. Humin Nitrogen.- The black colouring matter is absorbed by the lime, which is filtered off on a folded filter paper and washed with water until the washings are free from chlorides. The precipitate

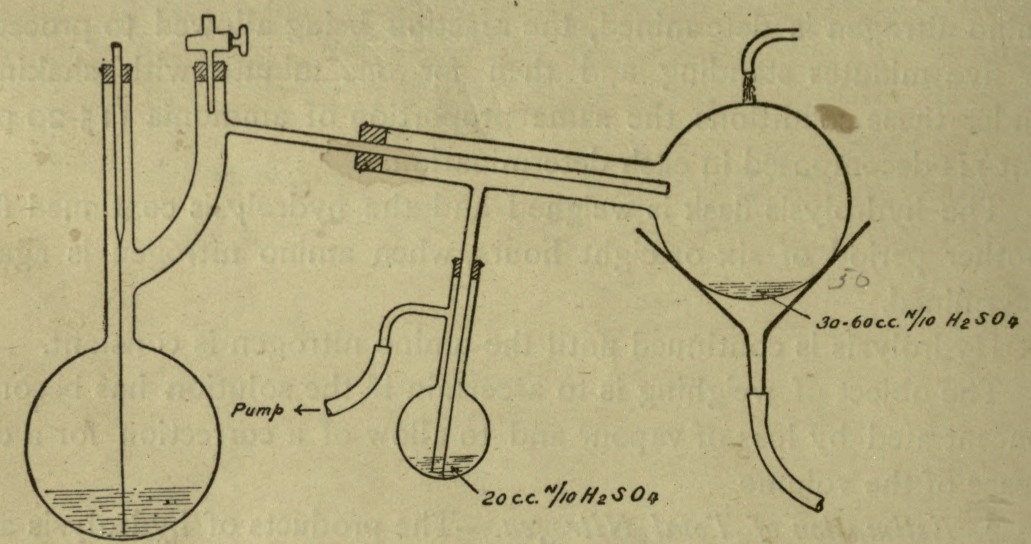

FIG. 5 .

From Biol. Chem., Igrr, ro, 21.

and paper are then submitted to Kjeldahl analysis, using 35 c.c. of sulphuric acid.

5. Precipitation and Washing of the Phosphotungstate PrecipitateThe filtrate from the humin nitrogen is neutralised with hydrochloric acid, returned to the vacuum distillation apparatus, and concentrated to about 100 c.c.

It is then washed into a 250 c.c. conical flask, and I 8 c.c. of concentrated hydrochloric acid and 15 grams of phosphotungstic acid ${ }^{1}$ in aqueous solution are added.

The entire solution is diluted to 200 c.c. with water and heated in a water-bath, until the precipitate has nearly, or quite, redissolved. On cooling, the phosphotungstates separate in a crystalline form.

${ }^{1}$ This should be purified by Winterstein's method by shaking its acid solution with ether; 'from the ethereal layer containing the substance the acid is recovered by recrystallisation. 
After standing for at least forty-eight hours they are filtered off and washed in the following manner:-

A 3-inch Buchner funnel is covered with a hardened filter paper of such a size that it fits against the bottom and side walls; the portion of the paper against the side walls is folded into about twenty plaits so that it fits snugly all round.

The precipitate is poured into this pocket and the mother liquor removed by suction and by pressing down the precipitate with a flattened rod.

The filtrate is returned to a beaker.

Washing is effected with IO-I 2 c.c. of a solution containing $2 \cdot 5$ grams of phosphotungstic acid and 3.5 grams of hydrochloric acid per IOO c.c. ; this is first used to dislodge the particles remaining in the flask; it is then poured upon the precipitate which is stirred up until all lumps are broken and until there is only a granular suspension. It is then sucked dry as before. The washing is repeated three to four times in this manner. Then the precipitate on the filter is washed five to ten times with the same solution from a wash bottle, commencing round the edges and sucking dry each time.

It frequently happens that the later washings run through somewhat turbid; these are filtered through a folded paper. All washings are combined with the main filtrate. The washing must be continued till the liquid is free from calcium; I c.c. of the filtrate when tested with oxalic acid in 3 per cent. sodium hydrate must give no turbidity even after standing for several minutes.

The filtration and washing may be effected equally well on a 2-inch Buchner funnel with a hardened filter paper pressed over the perforations in the usual manner, as was shown by Hartley [1914] and by Van Slyke [1915, I]. A steady and moderately strong suction is continued without interruption during the filtration and washing. The IO-I 5 c.c. of washing solution ${ }^{1}$ are poured upon the precipitate, which is stirred up with each portion. The washing is completed as soon as a few drops of the liquid on being allowed to flow upon a Io per cent. solution of sodium hydrate containing sodium oxalate and on gently shaking to bring the liquids in contact show no cloudiness even after standing for several minutes.

If there be any doubt as to the purity of the phosphotungstates they may be recrystallised by suspending in water and dissolving by adding sodium hydrate. The solution is acidified, heated, and the

${ }^{1}$ This should be cooled to $0^{\circ}$. 
bases thrown down by adding 15 c.c. of concentrated hydrochloric acid and 5 grams of phosphotungstic acid, the final volume being made up to 200 c.c. as in the original precipitation. Filtration and washing is carried out as above.

6. Treatment of the Phosphotungstate Precipitate.-The precipitate is removed with a spatula, as completely as possible, to a beaker of over I litre capacity. The filter paper is then spread out on the bottom of a basin and washed with water made just alkaline with a few drops of 20 per cent. sodium hydrate. The small folded paper is similarly treated. The particles of precipitate are dissolved by the soda, and any granules remaining in the original flask are dissolved in the same way. The alkaline solutions and washings are poured into the beaker containing the main bulk of the precipitate. The whole is then carefully dissolved in soda by adding 50 per cent. alkali, drop by drop, with continual stirring. Phenolphthalein is added as indicator; as soon as the solution becomes red, addition of the alkali must be stopped; if the colour disappears, more alkali, but only to the excess of three or four drops, must be added. A red solution must finally result.

The solution is diluted to 800 c.c. and the phosphotungstic acid is removed by slowly adding, in portions of a few c.c., a 20 per cent. solution of barium chloride, until a test portion gives an immediate granular precipitate with neutral sodium sulphate solution. If the red colour disappears in the process two or three more drops of alkali are added. A large excess of barium chloride should be avoided.

The barium phosphotungstate is filtered off using the same funnel, paper and precautions as before, except that larger portions of wash water may be used. The final washing must give no reaction for chlorides.

The filtrate and washings are concentrated in vacuo, until they are reduced in volume to 50 c.c. The barium phosphotungstate, which separates out, is filtered off, and the filtrate and washings received in a 200 c.c. double-necked distilling flask; the volume is then again reduced and made up to 50 c.c. in a measuring flask.

Van Slyke [1915, I] found that the following procedure was preferab $^{\top} \Rightarrow$ the original as described above :-

The precipitate is removed from the filter by a spatula and by washing with water and transferred to a 500 c.c. separating funnel, using 200-300 c.c. of water. 5 or IO c.c. of concentrated hydrochloric acid are added, and the mixture shaken with about 100 c.c. of a 
mixture of equal parts of amyl alcohol and ether. Complete solution of the precipitate occurs after shaking for one or two minutes. Should an oil appear at the bottom more of the amyl alcohol-ether mixture is added until the whole of it floats upon the surface.

If the layers do not separate readily with a clear boundary between them, due to humin not having been completely absorbed by the calcium hydrate previously and to its precipitation by phosphotungstic acid, the whole solution without separation of the layers is passed through a Buchner funnel with suction. The clear filtrate readily separates into two layers. The aqueous portion is extracted with three successive portions of amyl alcohol-ether using a volume of mixture equal to one quarter of the aqueous solution. The combined amyl alcoholether extracts are shaken once with water, and this portion of water, after being shaken once or twice with fresh amyl alcohol-ether, is added to the aqueous solution. This contains the bases and should be free from phosphotungstic acid as shown by testing a few drops with baryta solution; a precipitate should not be formed. The solution is evaporated to dryness in vacuo to drive off the excess of hydrochloric acid and the residue dissolved and diluted to 50 c.c.

This procedure is more rapid than the older and has the advantage that no barium is present, which may cause bumping in estimating the arginine.

7. Estimation of Arginine. - Arginine is stated by Van Slyke [I9I I, 4] to be quantitatively decomposed by boiling with 50 per cent.

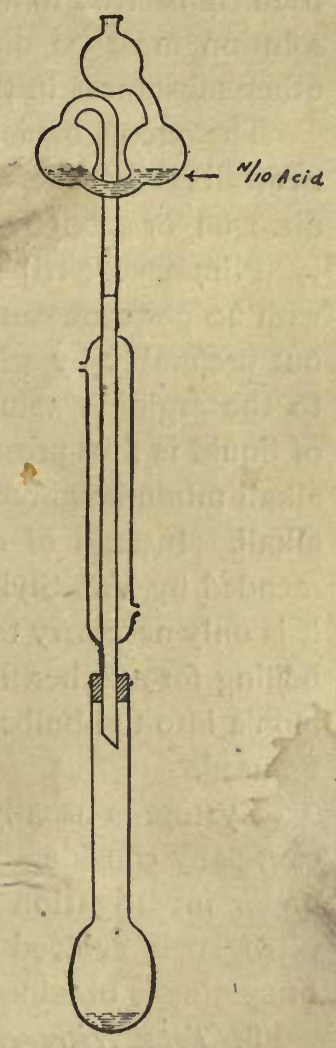

Fig. 6.

From Journ. Biol. Chem., Igrr, I0, 26. alkali with the loss of half of its nitrogen: Its estimation is performed before that of the total nitrogen contained in the solution.

25 c.c. of the solution are placed in the 200 c.c. flask of the apparatus shown in fig. 6.

The Folin bulbs are connected to the flask either by a ground glass joint, or by a heavy piece of rubber tubing. These bulbs contain 15 c.c. of decinormal acid, coloured with alizarin sulphonate. I 2.5 grams of solid potash and a piece of porous porcelain are added 
to the solution in the flask, and the solution is boiled gently for exactly six hours. Nearly all the evolved ammonia diffuses into the bulbs.

The bulbs are disconnected and 100 c.c. of water are poured through the condenser into the flask. The flask is connected with the condenser of a Kjeldahl distilling apparatus, and the remainder of the ammonia driven off and collected in the acid from the bulbs, which has been transferred to a suitable receiver. Not more than 100 c.c. of the solution must be distilled over as the strong potash may destroy the other substances in the solution.

The excess of acid in the receiver is titrated. Each c.c. of acid neutralised by the ammonia corresponds to 0.0028 gram argininenitrogen, or 0.0056 gram in the total solution.

Plimmer [1916] showed that arginine was decomposed by boiling with 20 per cent. caustic soda for six hours. ${ }^{1}$ The estimation is carried out preferably by adding an equal volume of 40 per cent. caustic soda to the arginine solution and boiling for six hours. A larger volume of liquid is thus present in the flask and the lower concentration of the alkali minimises breakage of the glass flasks through the action of the alkali. Instead of disconnecting the bulbs and distilling as recommended by Van Slyke so as to collect the remainder of the ammonia, it is only necessary to run the water out of the condenser and continue boiling for another fifteen to twenty minutes so as to drive the ammonia into the bulbs. 20 c.c. instead of 25 c.c. of the solution may be used.

Cystine is usually not present in sufficient amount in proteins to cause any considerable error in this determination, but if a keratin be under investigation a correction must be made; 18 per cent. of its nitrogen is evolved when it is boiled with alkali; the nitrogen figure of cystine is obtained later in the process.

8. Total Nitrogen of the Hexone Bases and Cystine.-The solution remaining from the arginine determination is transferred to a Kjeldahl flask of 500 c.c. ; 35 c.c. of sulphuric acid are added and 0.25 gram of copper sulphate. The nitrogen is then estimated in the usual way. This estimation can be performed in duplicate, if the solution be diluted to 100 or 200 c.c. and divided into two halves, each half being oxidised with 20 c.c. of sulphuric acid.

On account of persistent bumping from silica dissolved from the glass in the arginine estimation and consequent loss, Plimmer [1916]

${ }^{1}$ Histidine is decomposed to a slight extent by this treatment, but the error introduced is negligible. 
prefers to estimate the total nitrogen in another portion, 5 c.c., of the solution.

The sum of the number of c.c. of decinormal acid neutralised + the number of c.c. of decinormal acid previously neutralised in the arginine determination, multiplied by 0.0028 , gives the total nitrogen content.

9. Estimation of Cystine.-Cystine is estimated by determining 0 the total sulphur content by Denis' modification [1910, I] of Benedict's method [1909-10]. $\quad$ IO c.c. of the solution of hexone bases + cystine from operation (6) are placed in a porcelain dish of $7-10 \mathrm{~cm}$. diameter with 5 c.c. of a solution containing 25 grams copper nitrate, 25 grams sodium chloride, and 10 grams ammonium nitrate per 100 c.c. The mixture is evaporated to dryness on the water-bath and then gradually heated to redness, at which temperature it is maintained for ten minutes. The residue is dissolved in 10 c.c. of 10 per cent. hydrochloric acid and diluted to 150 c.c. Io c.c. of a 5 per cent. solution of barium chloride are slowly added to the boiling solution and the barium sulphate is filtered off and washed in the usual way. A correction must be made for the amount of sulphate in the reagents which should not exceed I. $5 \mathrm{mgm}$. barium sulphate.

I mgm. $\mathrm{BaSO}_{4}$ corresponds to $0.06 \mathrm{mgm}$. cystine nitrogen in the Io c.c. analysed, i.e., to $0.3 \mathrm{mgm}$. cystine nitrogen in the total solution of bases + cystine.

10. Estimation of Amino Nitrogen.-10 c.c. of the solution are usually used for this estimation (p. 89); I c.c. or 2 c.c. if the micro apparatus be used. The reaction may be allowed to proceed for half an hour at $20^{\circ}$ or longer at a lower temperature without shaking, or for five minutes with vigorous shaking; similarly for the blank determination for the reagents.

A correction must be made for cystine which gives 107 per cent. gas; as before it applies only to those proteins-keratins-which contain a large amount of cystine.

\section{Calculation of Histidine Value.}

Total nitrogen of bases minus total amino nitrogen gives the total non-amino nitrogen, D. This is contained in the arginine and histidine.

Since three-fourths of the arginine nitrogen and two-thirds of the histidine nitrogen are in this form, the total non-amino nitrogen minus 
three-fourths of the arginine nitrogen (found previously) represents twothirds of the histidine nitrogen. Hence

$$
\text { Histidine } \begin{aligned}
N & =\frac{3}{2}\left(\mathrm{D}-\frac{3}{4} \text { Arg. }\right) \\
& =1.5 \mathrm{D}-1.125 \text { Arg. }^{1}
\end{aligned}
$$

\section{Calculation of Lysine Value.}

Knowing the other values, that of lysine is found by difference:Lysine $\mathbf{N}=$ Total $\mathbf{N}-($ Arg. $\mathbf{N}+$ Cyst. $\mathbf{N}+$ Hist. $\mathbf{N})$.

I I. Determination of the Total Nitrogen of the Mono-amino Acids.To the combined filtrate and washings from the phosphotungstate precipitate 50 per cent. caustic soda is carefully added, until the solution becomes turbid by precipitation of lime and is just alkaline. Excess must be carefully avoided as the precipitate may then not completely dissolve in acetic acid, which is added to clear the solution when just alkaline. The acid solution is concentrated in vacuo until salt commences to crystallise out. The solution is then washed into a 150 c.c. measuring flask and diluted up to the mark.

Total nitrogen is estimated in 25 c.c. portions by Kjeldahl's method, using 35 c.c. of sulphuric acid, I 5 grams potassium sulphate and 0.25 grams of copper sulphate. The acid must be added carefully on account of the evolution of hydrochloric acid. The digestion must be continued for three hours after the solution has become clear.

12. Determination of the Amino Nitrogen of the Mono-amino Acids. -ro c.c. portions of the solution are used for this purpose and the time for the reaction with nitrous acid is six to ten minutes. Smaller portions are used with the micro apparatus.

The volume of nitrogen evolved by a given amount of amino nitrogen is 2.5 times the volume of decinormal acid neutralised, if the same amount is determined by the Kjeldahl method. Therefore, the portions of 25 c.c. and 10 c.c. used in these last estimations give results of similar accuracy.

13. Determination of the Nitrogen in the Mono-aminodicarboxylic Acids. - In estimating the nitrogen of the mono-aminodicarboxylic acids, ammonia, di-amino acids, glucosamine and organic acids must be absent from the solution; further, calcium salts must not be present.

Andersen and Roed-Müller [1915] therefore adopt a procedure differing from that of Van Slyke:I9I5, 3].

${ }^{1}$ In the original paper the formula $\mathrm{I} \cdot 667 \mathrm{D}-\mathrm{r} \cdot 125$ Arg. was given [Van Slyke, 
5 grams of protein, containing approximately $800 \mathrm{mgm}$. of nitrogen, are heated with $20-25$ parts of $3 \mathrm{~N}$ hydrochloric acid on a water-bath until there is complete or nearly complete solution, and then in an autoclave at $150^{\circ}$ for 1.5 hours which effects complete hydrolysis.

The solution is concentrated on the water-bath as much as possible, the residue dissolved in water, the solution filtered and made up to 250 c.c. The nitrogen retained in the filter paper, usually a negligible quantity, is estimated. Total nitrogen of the solution is determined in 5 c.c. and amide nitrogen in 20 c.c. by distilling in vacuo with ${ }_{5} \mathrm{~N}$ baryta dissolved in methyl alcohol (saturated baryta in methyl alcohol, if much ammonia be present).

200 c.c. are treated with saturated sodium carbonate solution, until the reaction of the solution is alkaline to turmeric paper, and evaporated to dryness in vacuo. The residue is dissolved in 100 c.c. of water and its reaction tested: if not alkaline, more sodium carbonate is added and the evaporation repeated; this must be continued until the reaction is alkaline. The residue is dissolved in 50 c.c. of water and neutralised with hydrochloric acid; 27 c.c. of concentrated hydrochloric acid and 25 grams of phosphotungstic acid are added; the solution is diluted to 300 c.c. and heated on a water-bath until the phosphotungstates have dissolved. After standing for forty-eight hours, the crystalline phosphotungstates are filtered off by suction on a hardened filter paper in an ordinary funnel. This method of filtration is preferred to that adopted by Van Slyke. The precipitate is washed ten times with I 5-20 c.c. of 2.5 per cent. phosphotungstic acid and 3.5 per cent. hydrochloric acid by stirring up with the wash solution and each time draining off completely. The precipitate is dissolved and the bases estimated as directed by Van Slyke.

The precipitate of barium phosphotungstate is dried in the air, and the nitrogen contained in it estimated. This is humin-nitrogen I., which is thrown down at this stage.

The filtrate is diluted to 1000 c.c., made distinctly red to phenolphthalein with alkali and barium chloride added to remove phosphotungstic acid; the solution is kept distinctly alkaline and not too small an excess of barium chloride is used. The barium phosphotungstate is filtered off and washed till free from chlorides. The nitrogen in the precipitate is estimated and forms humin nitrogen II.

The filtrate is neutralised, treated with an amount of hydrochloric acid equivalent to the total nitrogen, and evaporated in vacuo until salt 
crystallises out. 200 c.c. of alcohol are added, and after standing for one hour the salt is filtered off and washed with 80 per cent. alcohol. The salt is dissolved in water and the nitrogen estimated; usually very little nitrogen is contained in it, but if it be large in amount, the solution is acidified, evaporated, and treated with alcohol as described.

The alcoholic solution is evaporated in vacuo to dryness, dissolved in water and made up to 200 c.c.

Total nitrogen is determined in 5 c.c., and 25,30 , or 40 c.c., according to the amount of nitrogen, are neutralised with sodium hydroxide, diluted to 50 c.c., and used for the determination of amino nitrogen.

The mono-aminodicarboxylic acid nitrogen is determined by exactly neutralising 20 or 25 c.c. in a platinum basin to azolitmin paper ${ }^{1}$ and evaporated to dryness, the concentrated solution being stirred with a platinum wire if salts crystallise out, and ashed over a spirit burner. The ash is dissolved in not too great an excess of $0.2 \mathrm{~N}$ hydrochloric acid, washed into a conical Jena-glass flask, boiled over a flame for five to ten minutes, cooled and titrated with $0.2 \mathrm{~N}$ alkali with phenolphthalein as indicator. The difference between the amounts of acid and alkali is equivalent to the carboxyl groups of the mono-aminodicarboxylic acids and is expressed in terms of nitrogen by multiplying the figure in c.c. by $2 \cdot 8$.

14. Corrections for the Solubilities of the Phosphotungstates.Although the conditions of precipitation are not always the same, the variation is not sufficient to cause significant change in the solubilities of the phosphotungstates. When precipitated from a volume of 200 c.c. the following corrections should be added, and the sum of the figures for amino nitrogen and non-amino nitrogen subtracted from the figures for the mono-amino acids :-

\footnotetext{
${ }^{1}$ Henriques and Sörensen (Zeitschr.physiol. Chem., 64, 133) describe the preparation of sensitive litmus paper as follows :-

$0.5 \mathrm{gram}$ of powdered azolitmin is dissolved in 200 c.c. water +22.5 c.c. $\cdot 1 \mathrm{~N} \mathrm{NaOH}$ in a basin. 50 c.c. of alcohol are added after filtering. Strips of good, ash-less filter paper are drawn through the solution and dried by hanging on strings. The preparation takes about one hour. The paper must behave in the following way with Sörensen's phosphate solutions :-

To $3 \mathrm{sec}+7$ prim $\left(\mathrm{PH}_{\mathrm{H}}=6,47\right)$ slightly acid reaction.

To 5 sec 75 prim $\left(\mathrm{PH}_{1}=6,8 \mathrm{I}\right)$ neutral reaction.

To $7 \mathrm{sec}+3$ prim $\left(\mathrm{PH}^{\prime}=7 \cdot \mathrm{I} 7\right)$ slightly alkaline reaction.

The neutral point is chosen slightly more on the acid side $(=7 \cdot 07)$ on account of ammonium salts and amino acids.

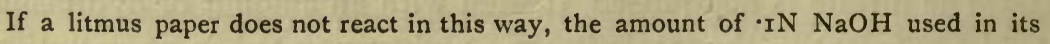
preparation must be altered accordingly.
} 


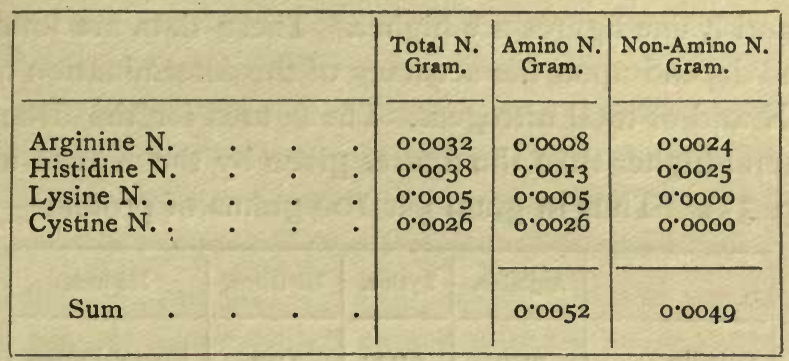

This long method was rigidly tested by Van Slyke upon pure amino acids singly, and when mixed together, and upon typical proteins. The accuracy of the method was borne out by the figures under the column of total nitrogen (p. I 32); usually, the nitrogen recovered was within I per cent. In the duplicate analyses of proteins the maximum and average differences were:-

\begin{tabular}{|l|c|c|c|c|c|c|c|c|}
\hline & $\begin{array}{c}\text { Amide } \\
\text { N. }\end{array}$ & $\begin{array}{c}\text { Humin } \\
\text { N. }\end{array}$ & $\begin{array}{c}\text { Cystine } \\
\text { N. }\end{array}$ & $\begin{array}{c}\text { Arginine } \\
\text { N. }\end{array}$ & $\begin{array}{c}\text { Histidine } \\
\text { N. }\end{array}$ & $\begin{array}{c}\text { Lysine } \\
\text { N. }\end{array}$ & $\begin{array}{c}\text { Mono-amino } \\
\text { N. }\end{array}$ & $\begin{array}{c}\text { Non-Amino } \\
\text { N. }\end{array}$ \\
\hline $\begin{array}{l}\text { Maximum } \\
\text { Difference } \\
\text { between } \\
\text { Duplicates. }\end{array}$ & 0.37 & 0.39 & 0.11 & $\mathbf{I . 2 7}$ & $\begin{array}{c}2.14 \\
0.93\end{array}$ & $\mathbf{I} 23$ & $\begin{array}{c}1.60 \\
0.60\end{array}$ & $\mathbf{I} 20$ \\
\hline $\begin{array}{l}\text { Average } \\
\text { Difference }\end{array}$ & 0.12 & 0.20 & 0.05 & 0.73 & 0.79 & 0.61 & 0.63 & 0.68 \\
\hline
\end{tabular}

The differences of $2 \cdot 14$ per cent. for the histidine (edestin) and $1 \cdot 60$ per cent. for the mono-amino nitrogen (hair) were more than twice any other deviations from the figures in the series. The highest average difference was 0.79 per cent. for histidine and the lowest 0.05 for cystine.

The correspondence between the figures and the actual amounts of amino acid isolated from the protein is fairly good. The high proline content of gelatin was well known, but the non-amino nitrogen content of 15 per cent. of the total nitrogen of this protein is very striking. Further, the large amount of lysine in hæmoglobin was unexpected; hæmoglobin has always been supposed to be composed chiefly of histidine.

Van Slyke [191 3, 2] published revised data for caseinogen. They differ considerably from his earlier data and may be partly accounted for by the use of the new apparatus for determining amino nitrogen. The data for gliadin by Osborne, Van Slyke, Leavenworth and Vinograd [1915] are in closer agreement with the older data of Van Slyke's; the 
histidine and lysine figures are higher. These data are found by difference and depend upon the accuracy of the determination of arginine, of amino $\mathrm{N}$ and of total nitrogen. The figures for the di-amino acids are in general higher than the figures given by the Kossel and Patten method (p. 55). Thus in gram per 100 grams of protein :-

\begin{tabular}{|c|c|c|c|c|}
\hline & Arginine. & Lysine. & Histidine. & Method. \\
\hline Gliadin & $\begin{array}{l}2 \cdot 70 \\
2 * 97\end{array}$ & $\begin{array}{l}0.13 \\
I \cdot 2 I\end{array}$ & $\begin{array}{l}\text { I*49 } \\
\text { 2. I9 }\end{array}$ & $\begin{array}{l}\text { Kossel-Patten } \\
\text { Van Slyke }\end{array}$ \\
\hline Lactalbumin & $\begin{array}{l}3.01 \\
3.47\end{array}$ & $\begin{array}{l}8.10 \\
9.89\end{array}$ & $\begin{array}{l}r \cdot 53 \\
2 \cdot 6 r\end{array}$ & $\begin{array}{l}\text { Kossel-Patten } \\
\text { Van Slyke }\end{array}$ \\
\hline
\end{tabular}

Both methods give the same value for arginine, the value for lysine is higher and more accurate, while the value for histidine is more consistent by the Kossel-Patten method, These and other data are given on page 132 .

The method has been of service to Hartley [1914] in his study of the proteins of ox and horse serum. His results confirm the observations of previous writers that the albumin and globulin of serum exhibit well-marked differences in composition. Albumin contains more di-amino nitrogen than globulin, which is in agreement with the data by Hausmann [1899], Gümbel [1904], and Gibson [1912]. Albumin also contains more nitrogen as cystine than globulin, a fact which agrees with the data of Bywaters and Tasker [1913-14] who found that albumin contained about 2 per cent. of sulphur and 0.25 per cent. of carbohydrate, while globulin contained $\mathrm{I} \cdot 2$ per cent. of sulphur and $3 \cdot 2$ per cent. of carbohydrate. Globulin was also found to contain phosphorus while this element is absent from albumin. The chief difference found by Hartley was the presence of more lysine in albumin than in globulin. The chemical differences between these two proteins are against the supposition of Moll [1904, 1906] that albumin can be converted into globulin. There is so little difference between the globulins that the chemical composition supports Chick's suggestion [1914] that under certain conditions pseudo-globulin may undergo a process of denaturation and that a substance is formed which is very similar to euglobulin. This substance may be a mechanical complex formed by the interaction and mutual precipitation of the two colloids, pseudoglobulin and lipoid. The euglobin of serum is a protein-lipoid complex.

Crowther and Raistrick [1916] used the method for the analysis of the proteins of colostrum and milk and showed that the casein- 
ogen, lactalbumin and lactoglobulin in these secretions were identical. They found that colostrum in the earliest stages of secretion was very rich in protein (18-20 per cent. of the total secretion), that it contained 4-5 per cent. of caseinogen, $0 \cdot 7-I^{\circ} \cdot 5$ per cent. of lactalbumin, and 6-I 2 per cent. of lactoglobulin. They separated the globulin into pseudo- and eu-globulin and found these to be identical. They considered that euglobulin was a protein-lipoid complex as suggested by Chick (see above). Lactoglobulin gave analytical data so close to those given by serum-globulin [Hartley, 1914] that they were regarded as identical proteins. Lactalbumin differed greatly from serum albumin. The difference in chemical composition of the three proteins leaves no doubt that milk contains three distinct proteins. Their figures for caseinogen are very close to the figures determined by Van Slyke, only that for arginine being higher. The analysis of lactalbumin is similar to that by Osborne, Van Slyke, Leavenworth and Vinograd [19I5]. The high lysine content of lactalbumin is the most noticeable difference in the three proteins; caseinogen has the least amount of monoamino nitrogen and the greatest amount of non-amino nitrogen.

Drummond [1916] analysed a large number of normal human and chicken tissues for comparison with pathological human tissues with special reference to cancer. In general, the pathological tissues showed a higher content of the di-amino acids and they are attributed to the fact that these tissues all contain more nuclear material rather than to a specific difference of cancer tissue as believed by Kocher [I9I5]. The hexone base content of the various organs of man and other animals in health and disease has been determined by Wakeman [1905, 1, 2; 1908] by the Kossel-Patten method. No very marked differences were noticeable, but there was a slight lowering of the bases in the pathological conditions. In the human liver, the amount of arginine varied from 6.9 in the normal to 5.1 in the pathological, that of lysine from $6 \cdot 6$ to $4 \cdot 9$, and that of histidine from $2 \cdot 0$ to $x \cdot 7$; these figures are in terms of the total nitrogen of the dry substance, which was II.9 per cent. in the normal and varied from 10.8 to 12.9 in the diseased organ. For purposes of comparison of proteins this method of nitrogen distribution is thus of extreme value.

Analyses of various cattle food-stuffs have been made by Grindley, Joseph and Slater [1915], Grindley and Slater [1915], and by Nollau [1915]. The figures given by these workers are not always in agreement, but are accounted for by a slight difference in manipulation. Grindley and his co-workers hydrolysed the feeding-stuff and carried 
out the estimations in the resulting solution, whilst Nollau filtered the hydrolysed solution. In practically all cases the humin nitrogen value was found to be very high and is due to the effect of the presence of carbohydrate (see p. 65). In spite of the errors introduced in the analyses by the presence of carbohydrate, the authors consider that the data are of extreme value for judging the food-value of the food-stuffs, in respect of the constituent amino acids. The data are given on page 134. Marked differences are noticeable in the various food-stuffs.

The influence of the presence of carbohydrate upon the results of the analysis by the Van Slyke method has been investigated in the case of caseinogen by Hart and Sure [1916] and of fibrin by Gortner [1916]. Osborne, Van Slyke, Leavenworth and Vinograd [1915] hydrolysed lactalbumin under the same conditions.

Hart and Sure found that variations of the different figures occur to a great extent and that they differ with the nature of the carbohydrate. The changes in the data are especially apparent in the amount of di-amino acids or hexone bases. Loss of nitrogen occurs in the mono-amino acids in the presence of starch and xylan. It is not possible to correct the data. They concluded that the Van Slyke method was not applicable to the determination of the distribution of nitrogen in food-stuffs, not even for comparative figures that could be of any value. Such great variations were not observed by Osborne, Van Slyke, Leavenworth and Vinograd, nor by Gortner. These workers used a limited amount of carbohydrate, which never amounted to the large quantity present in the natural food-stuff in relation to the amount of protein. In all cases the most noticeable change in the data was in the humin nitrogen. Gortner agreed with Hart and Sure in the general conclusions and pointed out that this method of analysis of proteins was accurate only with pure proteins, a statement emphasised originally by Van Slyke. Considerations of this nature must also be applied to Drummond's data with tissues which contain other natural substances as well as proteins.

\section{Conclusion.}

The analytical data show that our methods of determining the composition of proteins are far from satisfactory. Some of the methods have been adapted too exclusively to the solution of one particular part of the whole protein ; co-ordination of methods should bring about a better knowledge. The introduction of any new method has always advanced the study of the chemistry of proteins, and the final solution will probably result from the employment of new methods. 
ANALYTICAL DATA

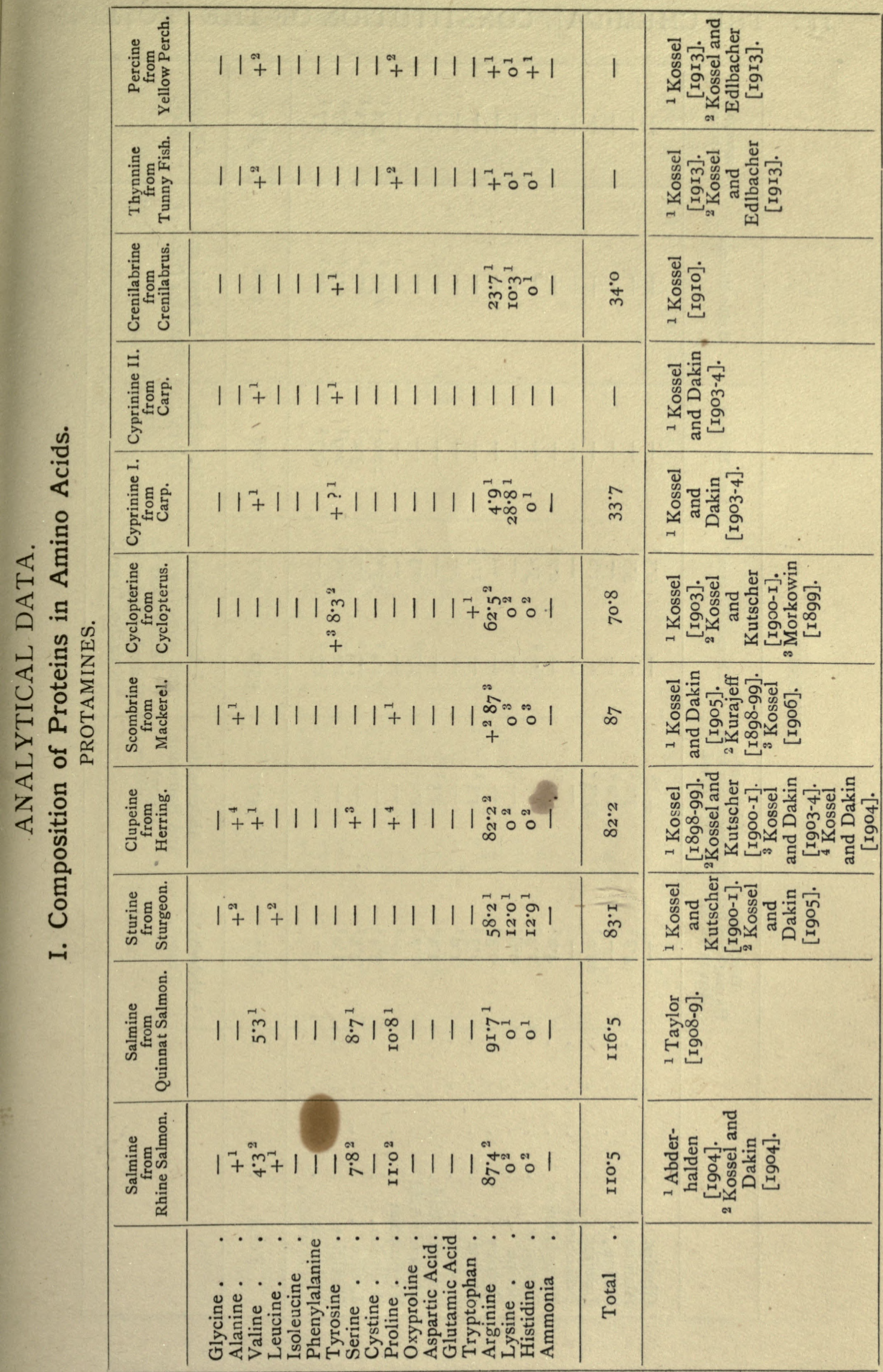


II2 THE CHEMICAL CONSTITUTION OF THE PROTEINS

\begin{tabular}{|c|c|c|c|}
\hline 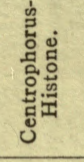 & 1111111111111||$_{\text {in }}^{+5}$ & $\stackrel{\hat{\infty}}{\tilde{m}}$ & 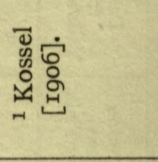 \\
\hline 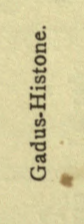 & $|1||||||||||| \mid \operatorname{inm}_{\text {in }}^{n}$ in & $\stackrel{\infty}{\dot{\leftrightarrow}}$ & 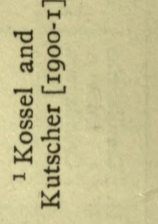 \\
\hline 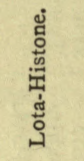 & 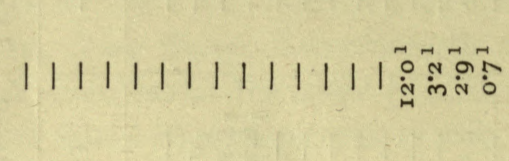 & 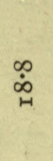 & 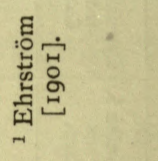 \\
\hline : & గnc & 菂 & \multirow{2}{*}{ 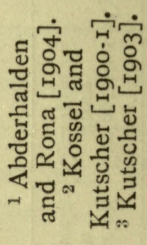 } \\
\hline$\stackrel{5}{E}$ & 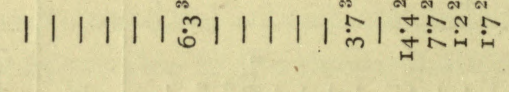 & in & \\
\hline 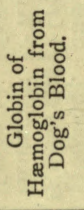 & 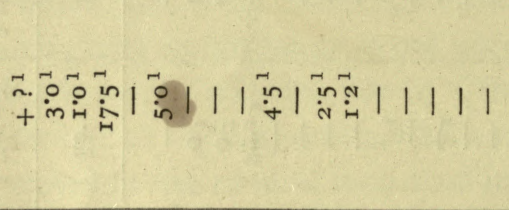 & $\hat{\dot{m}}$ & 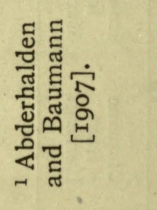 \\
\hline 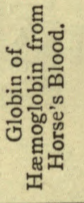 & 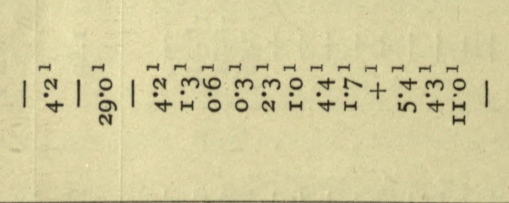 & $\hat{\sigma}$ & 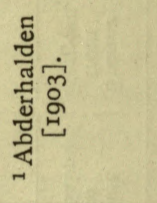 \\
\hline & $\begin{array}{c}\cdots \\
\ldots \ldots \\
\ldots \ldots\end{array} \ldots \ldots \ldots \ldots$ & . & \\
\hline
\end{tabular}




\begin{tabular}{|c|c|c|c|}
\hline 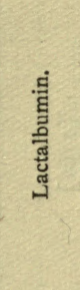 & 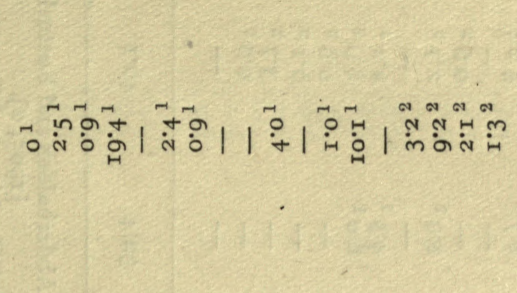 & in & 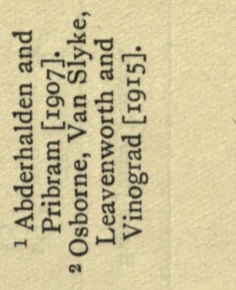 \\
\hline 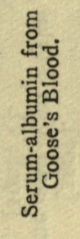 & 0||||$|\stackrel{\circ}{0}||||| \vec{n}|||| \mid$ & ب̈ㅜㅁ & 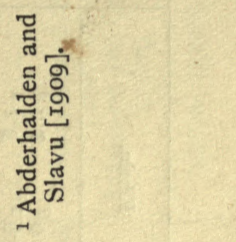 \\
\hline 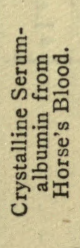 & 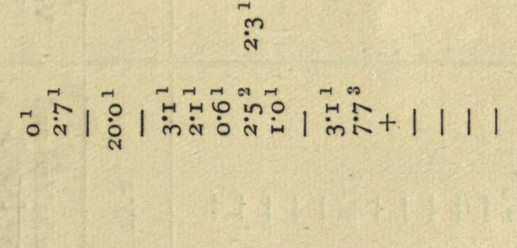 & \ั & 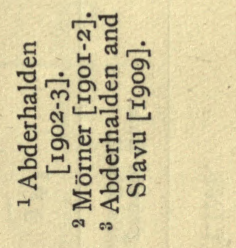 \\
\hline 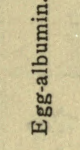 & 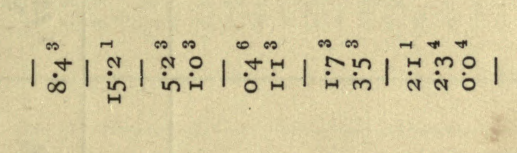 & $\ddot{\dot{q}}$ & 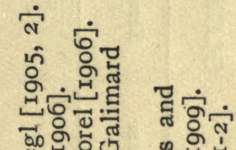 \\
\hline 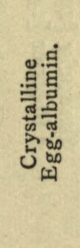 & 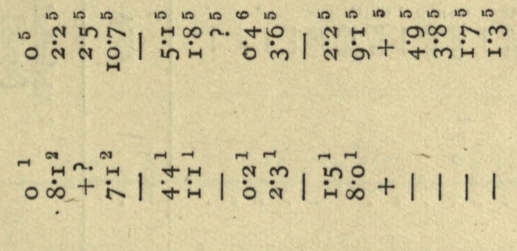 & $\ddot{m}$ & 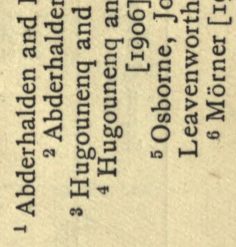 \\
\hline & 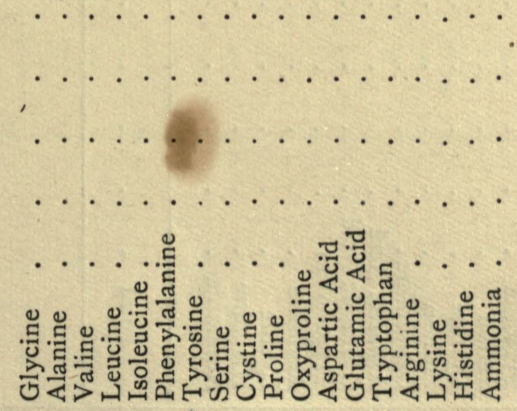 & 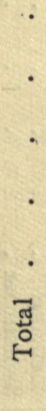 & \\
\hline
\end{tabular}

PT. I. 
I I4 THE CHEMICAL CONSTITUTION OF THE PROTEINS

\begin{tabular}{|c|c|c|c|}
\hline 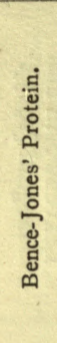 & 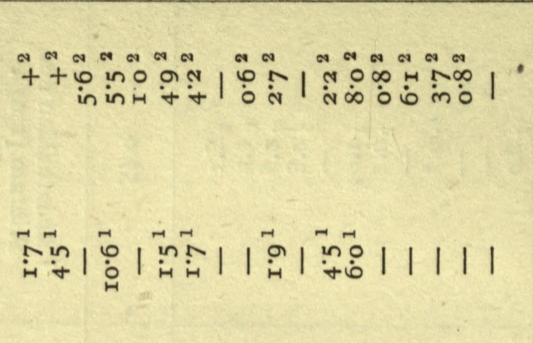 & iे & 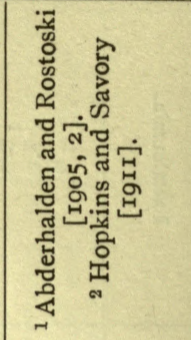 \\
\hline 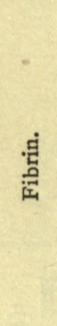 & 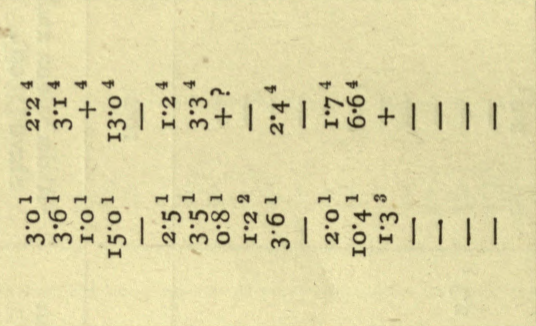 & $\begin{array}{l}n \\
m \\
m \\
\vdots \\
i \\
j\end{array}$ & 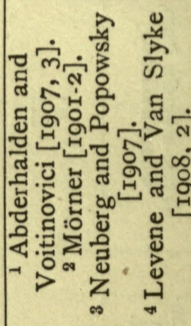 \\
\hline 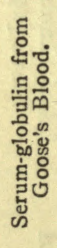 & 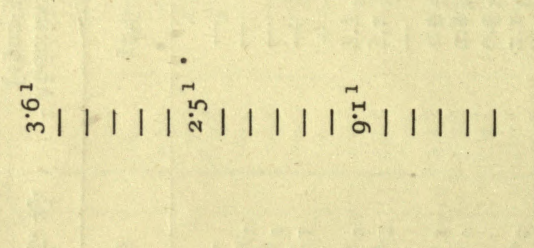 & in & 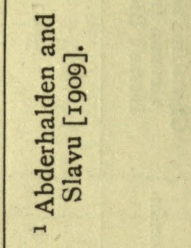 \\
\hline 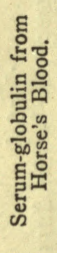 & 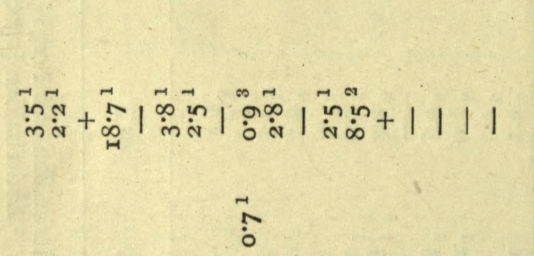 & in & 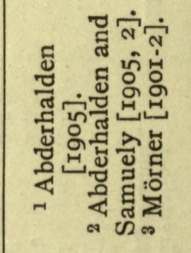 \\
\hline & 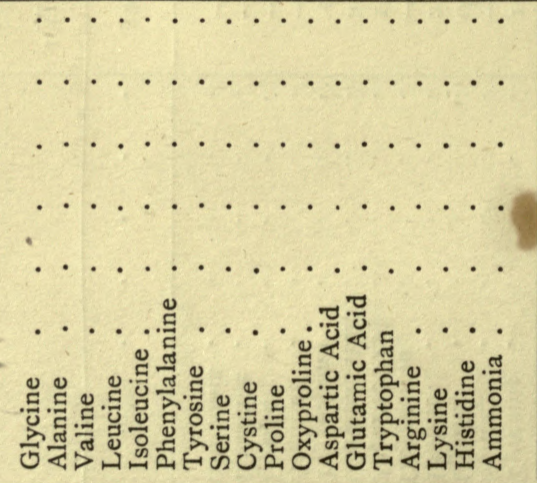 & 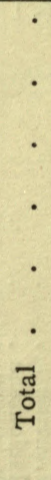 & $\omega$ \\
\hline
\end{tabular}




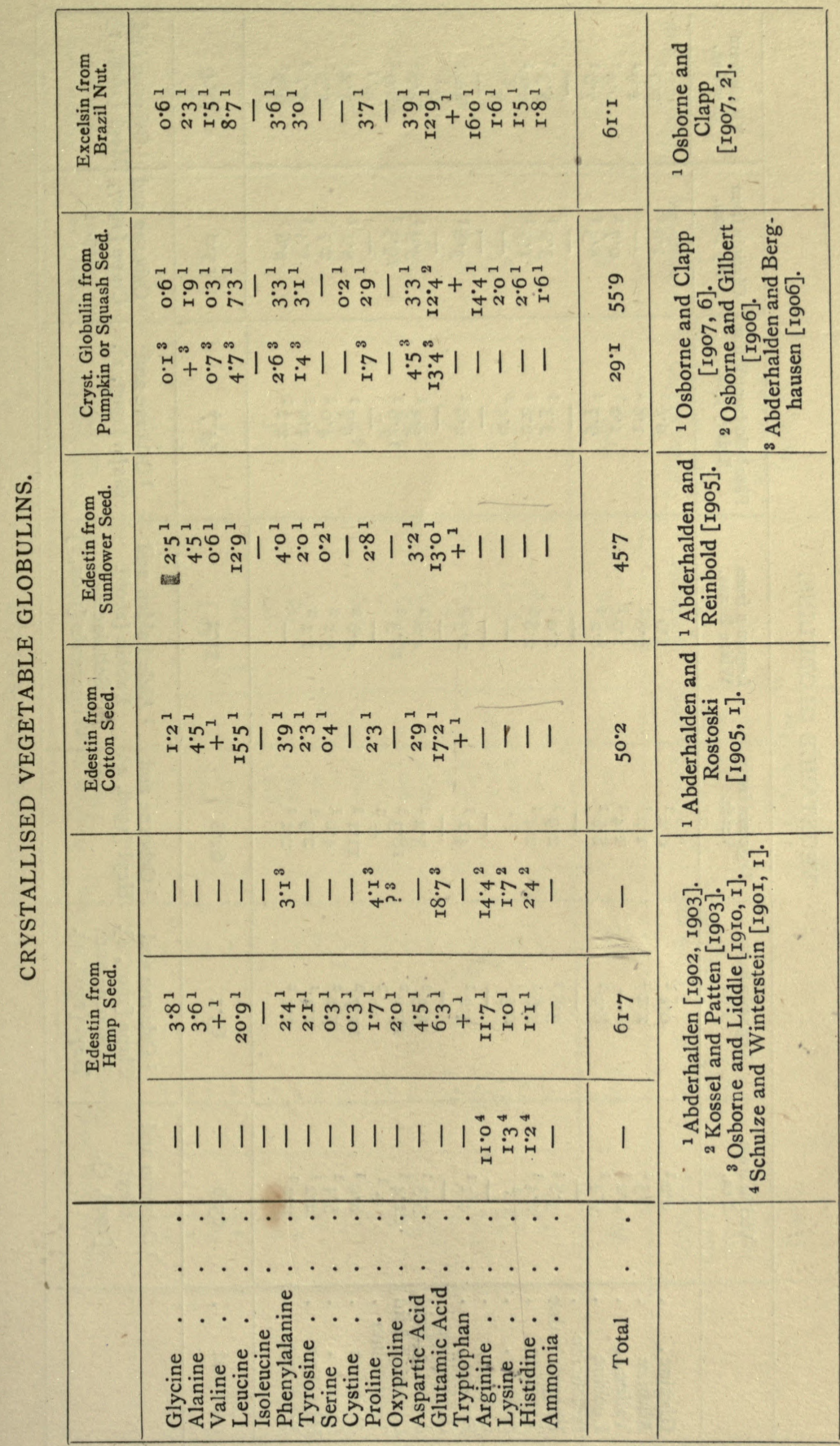


II6 THE CHEMICAL CONSTITUTION OF THE PROTEINS

\begin{tabular}{|c|c|c|c|}
\hline 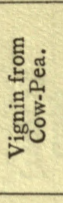 & 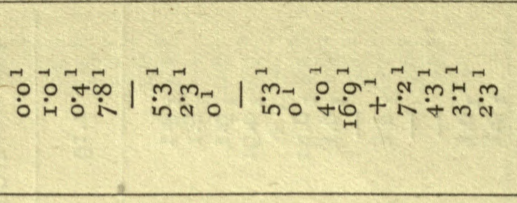 & i் & 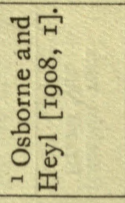 \\
\hline 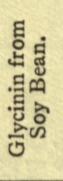 & 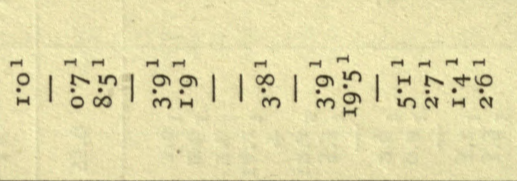 & in & 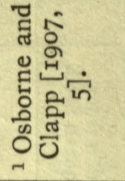 \\
\hline 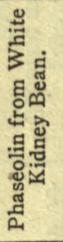 & 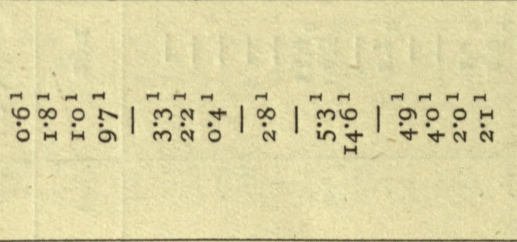 & iे & 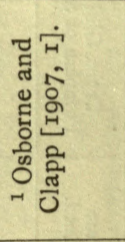 \\
\hline 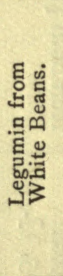 & 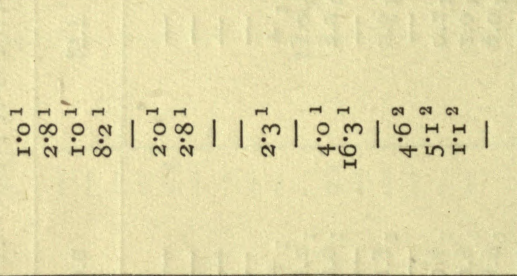 & $\underset{\text { in }}{\text { in }}$ & 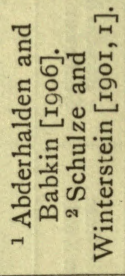 \\
\hline 竞 & 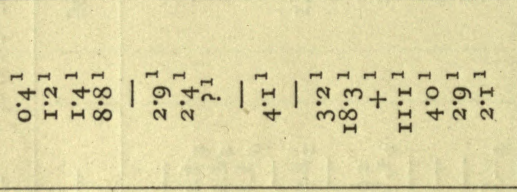 & $\begin{array}{l}\infty \\
\dot{\jmath} \\
0\end{array}$ & 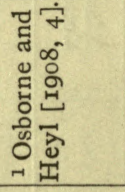 \\
\hline 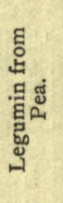 & 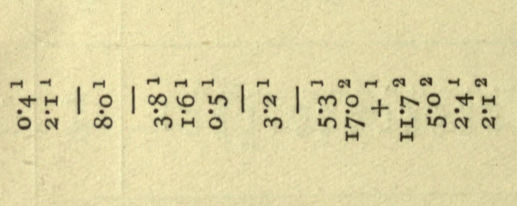 & $\stackrel{+}{\tilde{\sigma}}$ & 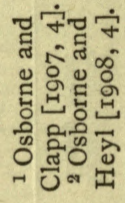 \\
\hline 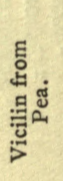 & 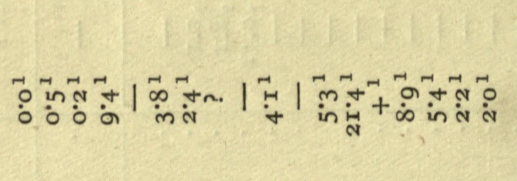 & $\begin{array}{l}0 \\
\text { in }\end{array}$ & 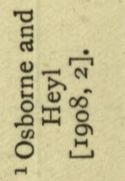 \\
\hline & 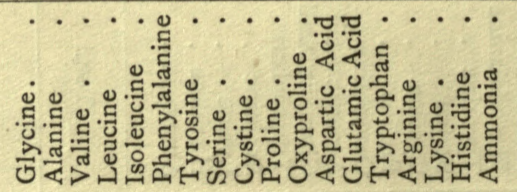 & 胥 & \\
\hline
\end{tabular}




\begin{tabular}{|c|c|c|c|}
\hline 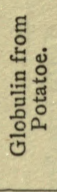 & 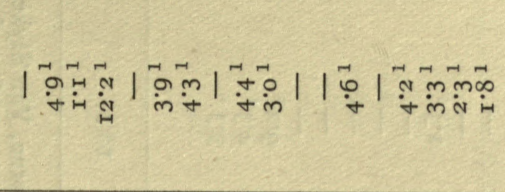 & $\dot{\text { in }}$ & 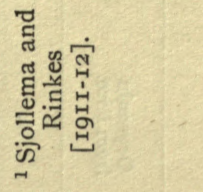 \\
\hline 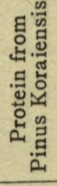 & 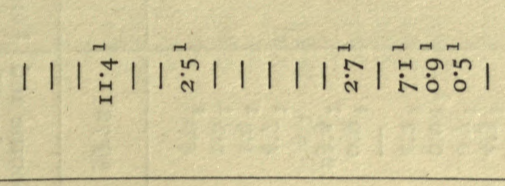 & in & 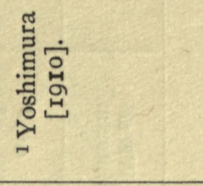 \\
\hline 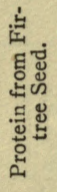 & 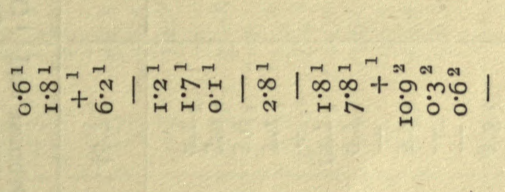 & 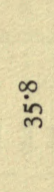 & 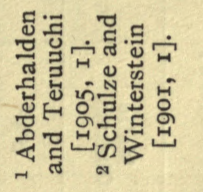 \\
\hline 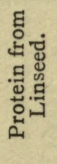 & $+\underbrace{+4 \hat{A}^{4}}$ & $\stackrel{\infty}{\dot{q}}$ & 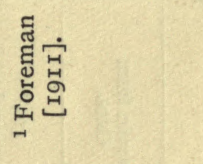 \\
\hline 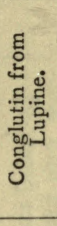 & 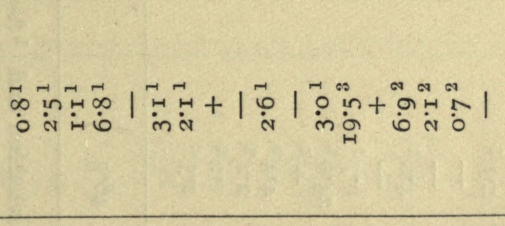 & $i_{i n}$ & 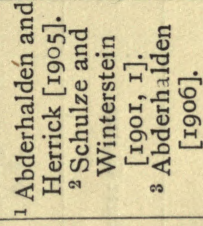 \\
\hline 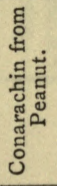 & ||||||||$\vec{H}||||+\underset{j}{\vec{j}} \overrightarrow{0} \underset{i}{0}|\vec{i}|$ & $\frac{n}{\text { on }}$ & 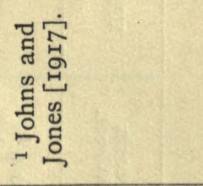 \\
\hline 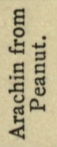 & 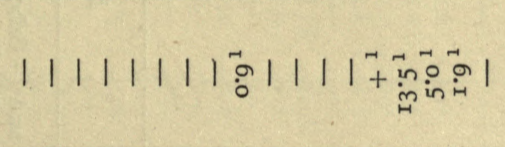 & $\stackrel{m}{\dot{\sim}}$ & 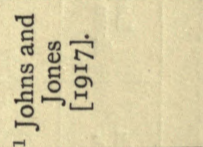 \\
\hline 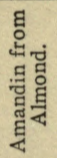 & ஸिं & i் & 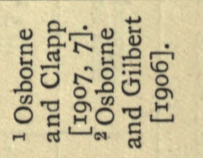 \\
\hline & $\ldots \ldots$ & • & \\
\hline
\end{tabular}


I 8 THE CHEMICAL CONSTITUTION OF THE PROTEINS

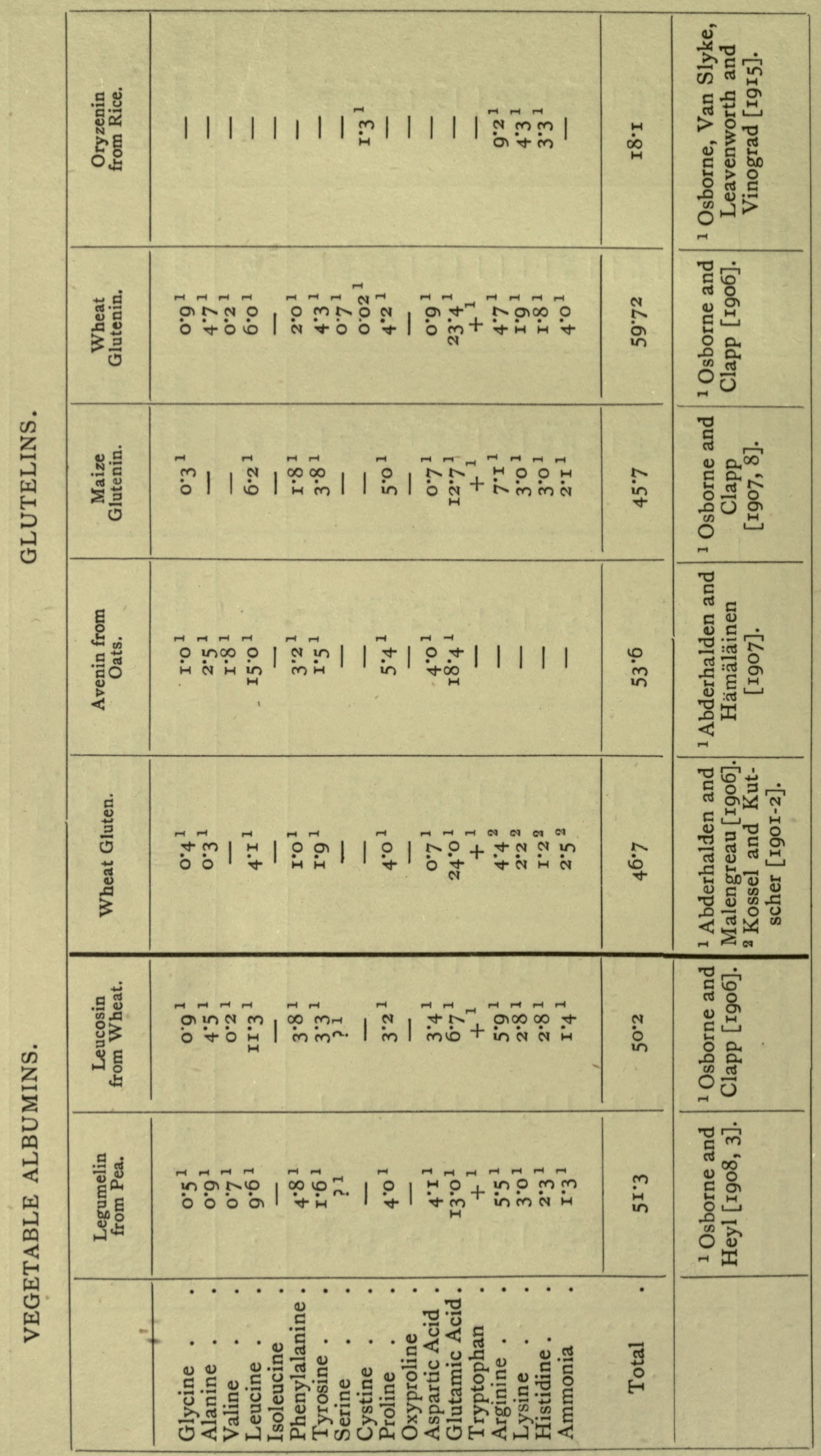




\begin{tabular}{|c|c|c|c|}
\hline & $11111111111111+\overrightarrow{0}$ & $\stackrel{i}{i}$ & 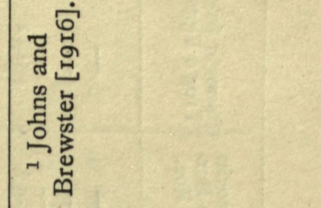 \\
\hline & 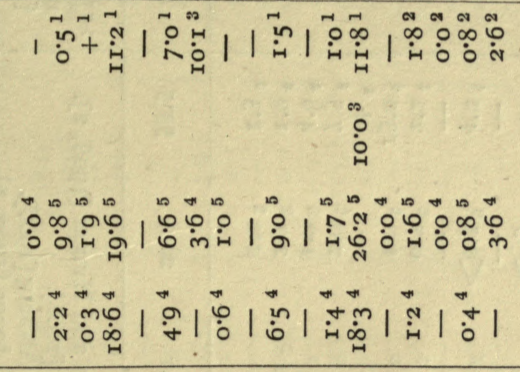 & के & 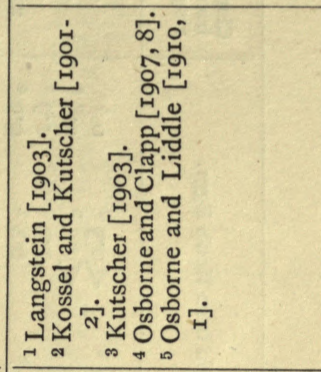 \\
\hline 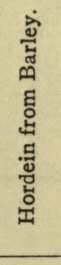 & 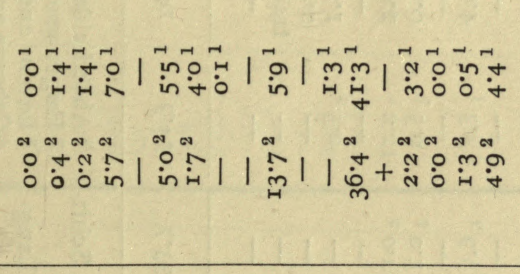 & 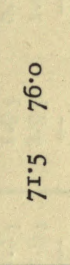 & 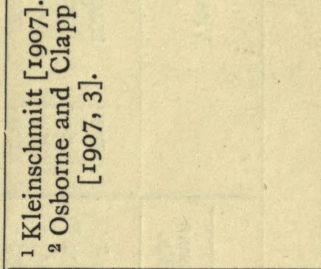 \\
\hline 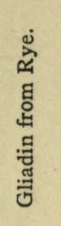 & $\vec{*}$ & $\stackrel{m}{\tilde{\sigma}}$ & 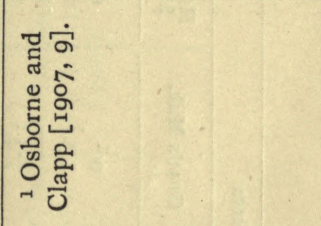 \\
\hline & 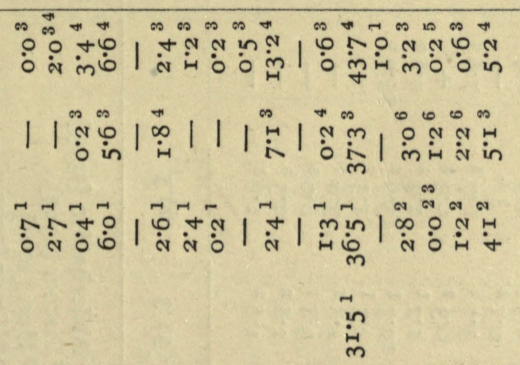 & i & 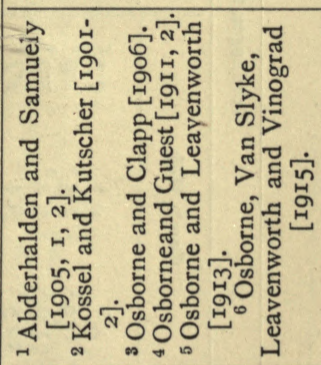 \\
\hline & 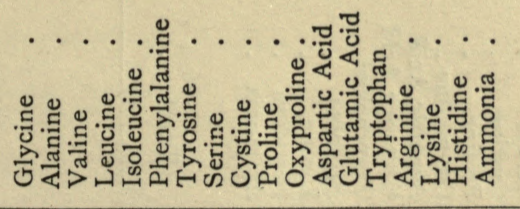 & $\underset{\leftarrow}{\stackrel{5}{5}}$ & \\
\hline
\end{tabular}




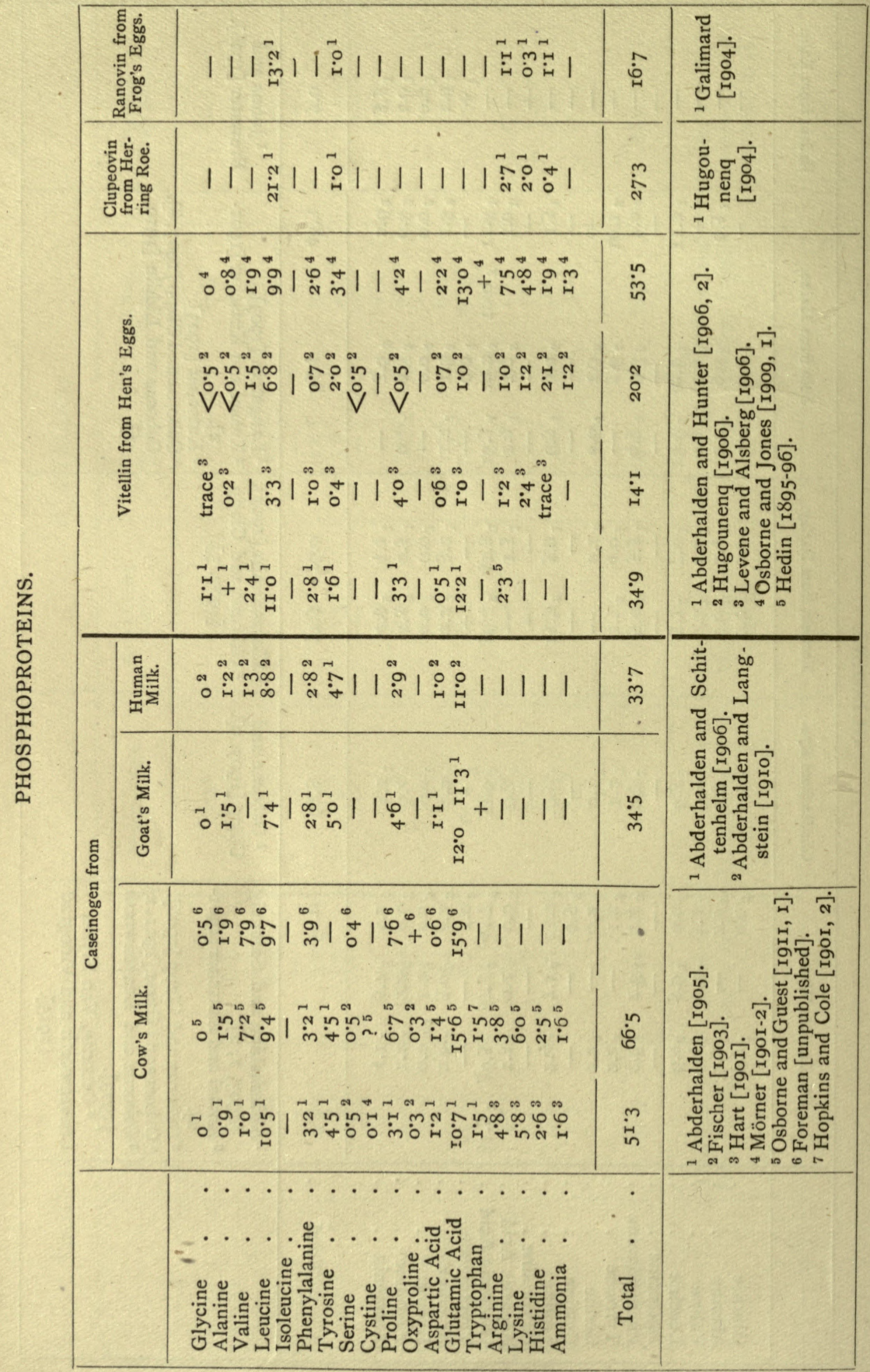




\begin{tabular}{|c|c|c|c|}
\hline 离 & 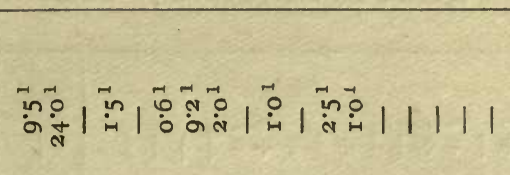 & $\underset{\text { in }}{\text { in }}$ & 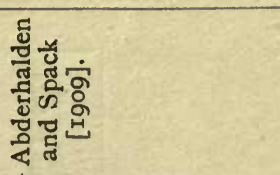 \\
\hline 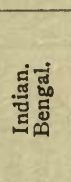 & 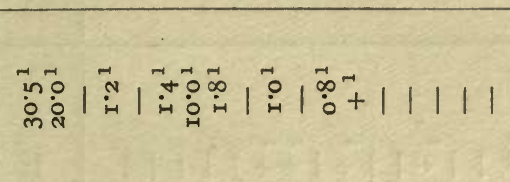 & $\hat{\dot{8}}$ & 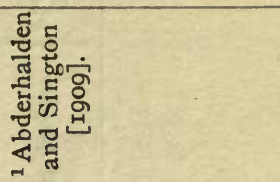 \\
\hline 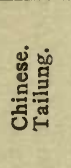 & 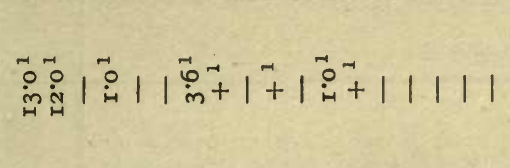 & ب̊ & 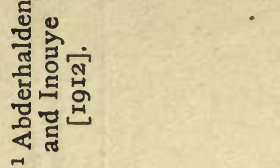 \\
\hline 逢: & 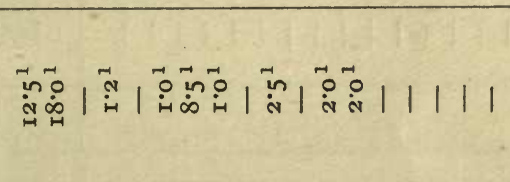 & 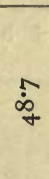 & 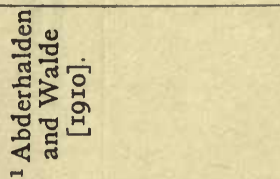 \\
\hline 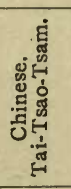 & 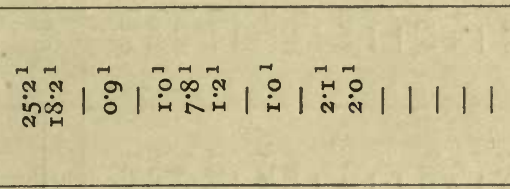 & i் & 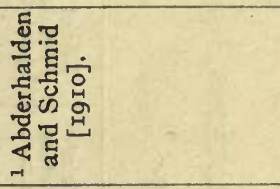 \\
\hline 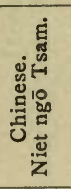 & 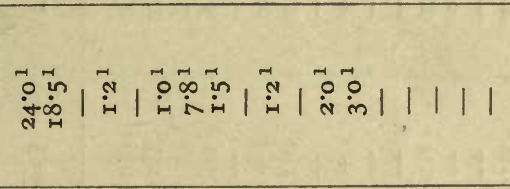 & $\begin{array}{l}\text { sै } \\
\dot{8}\end{array}$ & 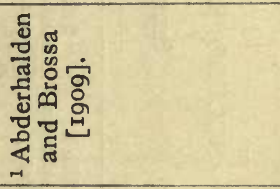 \\
\hline 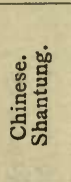 & 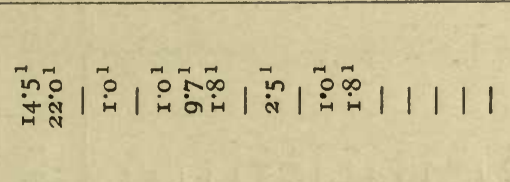 & $\begin{array}{l}m \\
\text { in }\end{array}$ & 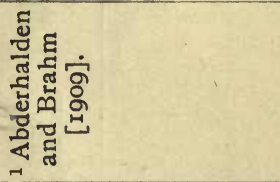 \\
\hline 要 & 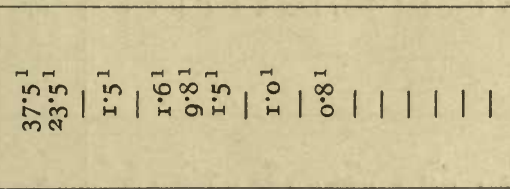 & $\stackrel{N}{N}$ & 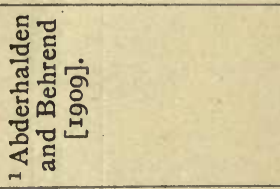 \\
\hline 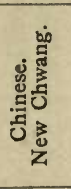 & 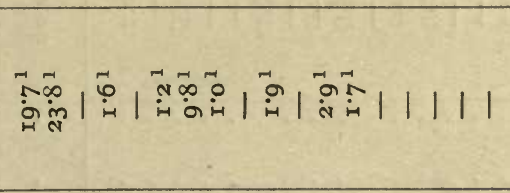 & 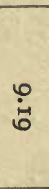 & 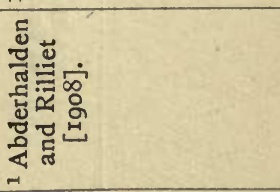 \\
\hline 运 & 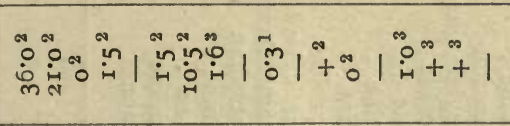 & $\ddot{\sim}$ & 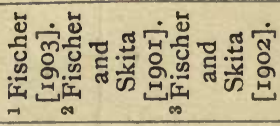 \\
\hline & 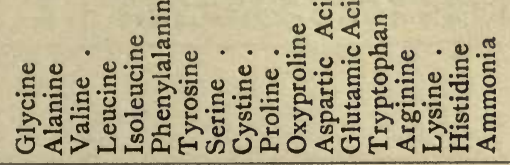 & 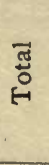 & \\
\hline
\end{tabular}




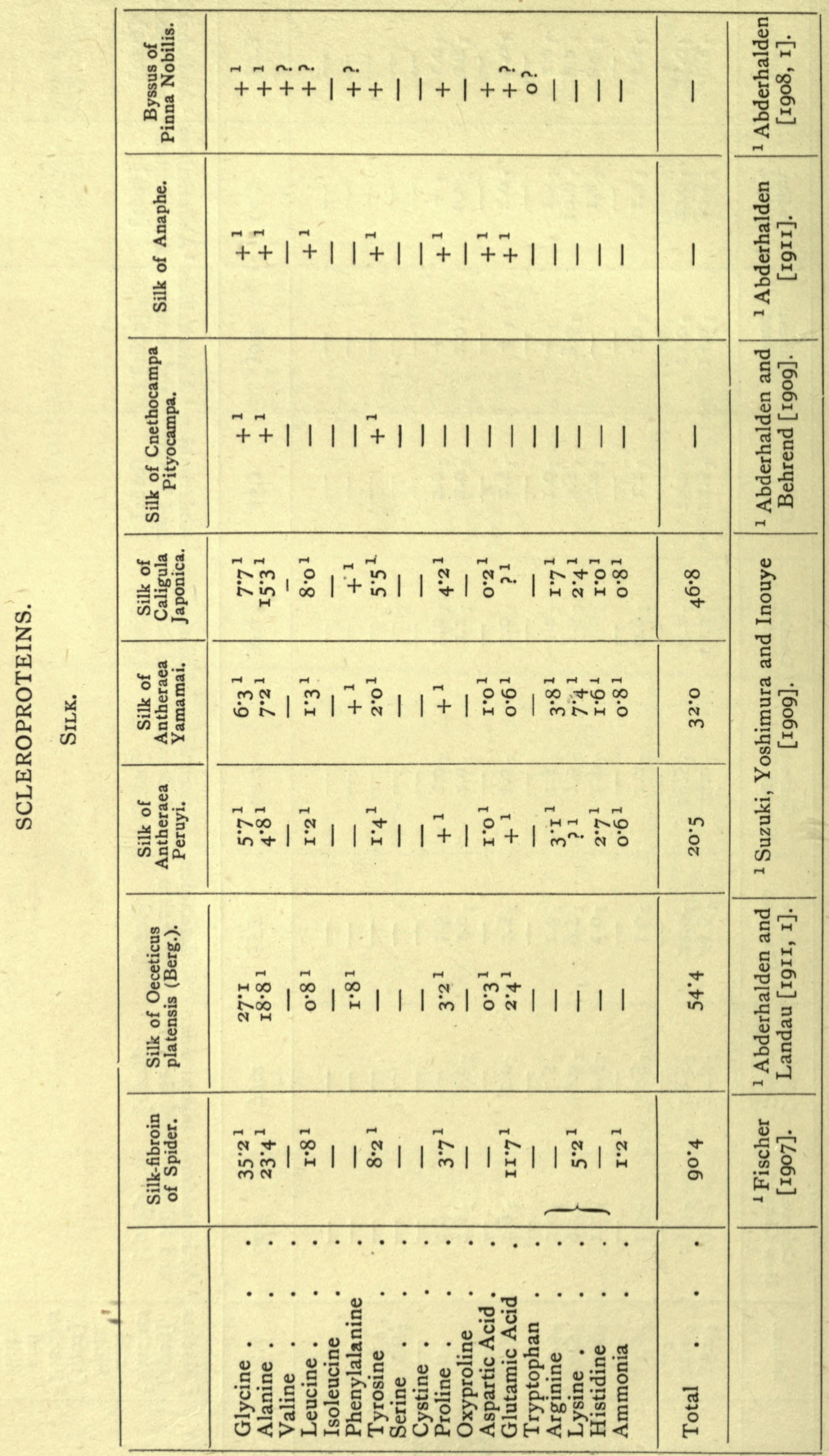


ANALYTICAL DATA

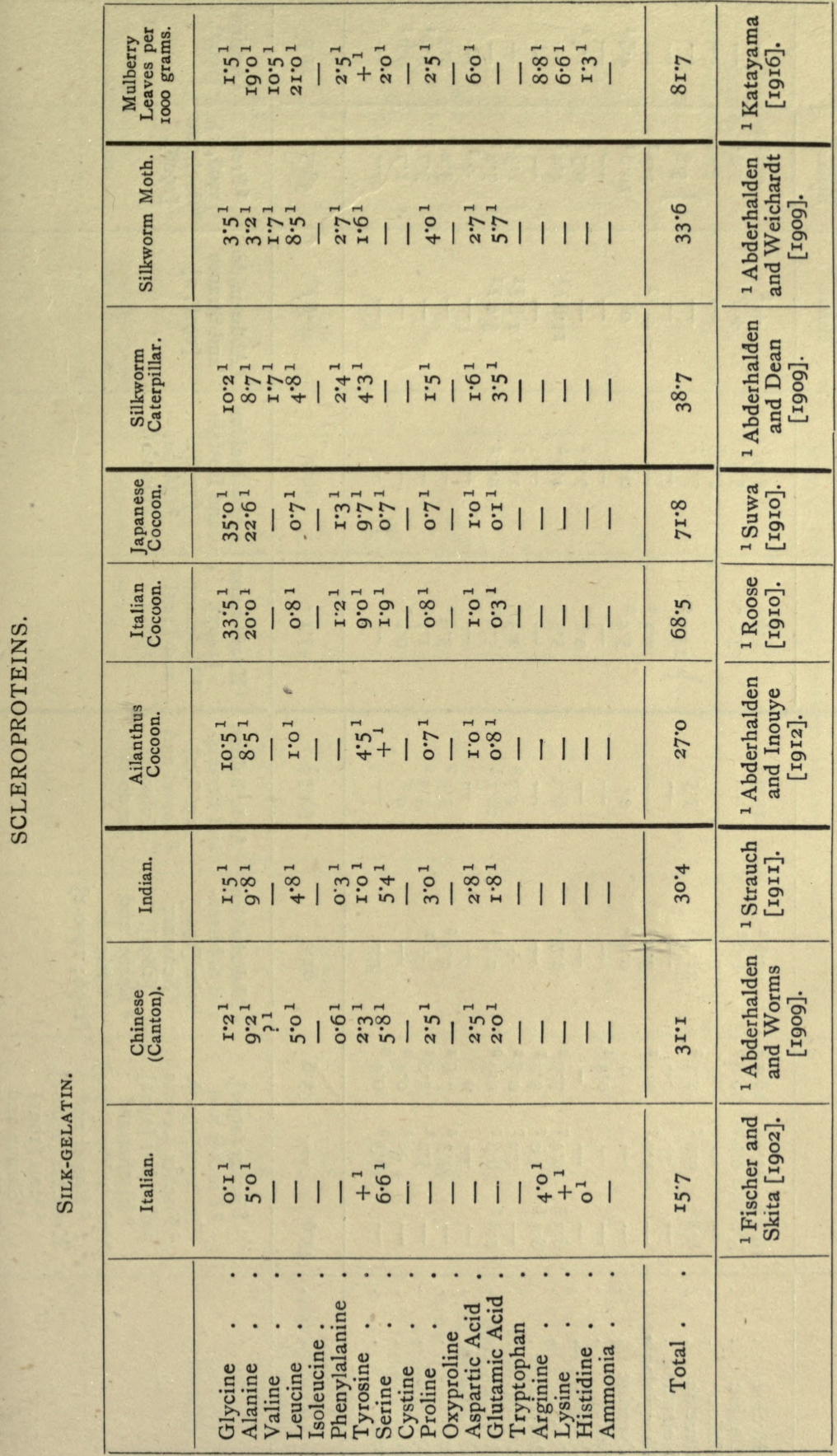




\section{THE CHEMICAL CONSTITUTION OF THE PROTEINS}

\begin{tabular}{|c|c|c|c|}
\hline 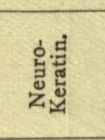 & 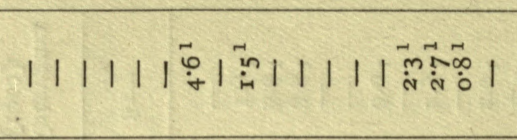 & $\dot{\dot{H}}$ & 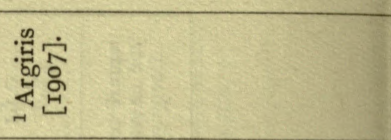 \\
\hline 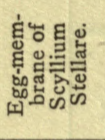 & 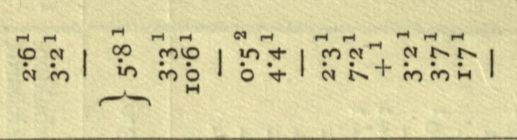 & $\underset{\dot{\phi}}{\dot{\phi}}$ & 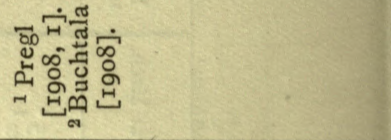 \\
\hline 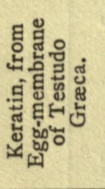 & 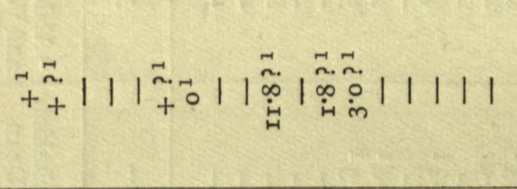 & 葛 & 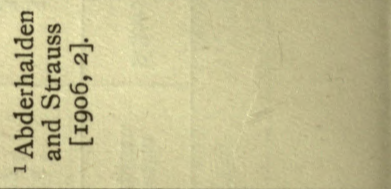 \\
\hline 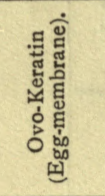 & 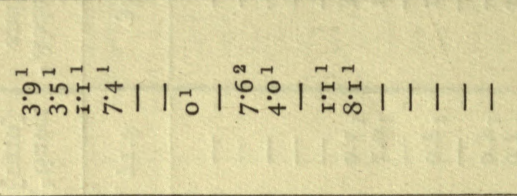 & $\hat{\dot{o}}$ & 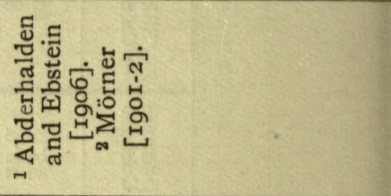 \\
\hline 砶 & 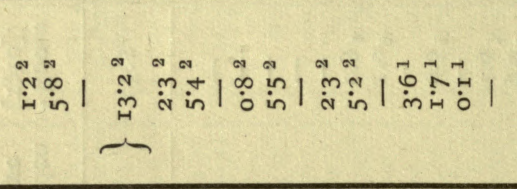 & i⿱ & 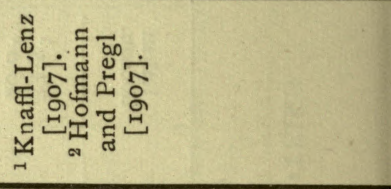 \\
\hline 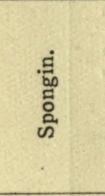 & 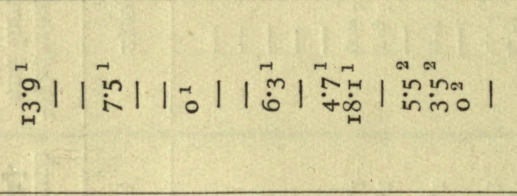 & in & 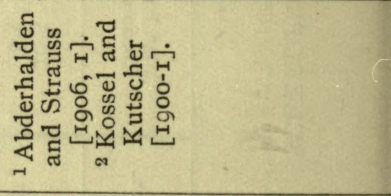 \\
\hline 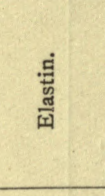 & 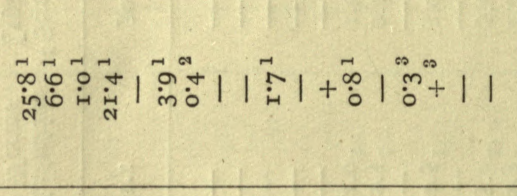 & : & 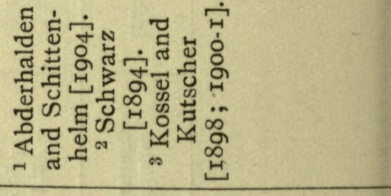 \\
\hline 意 & 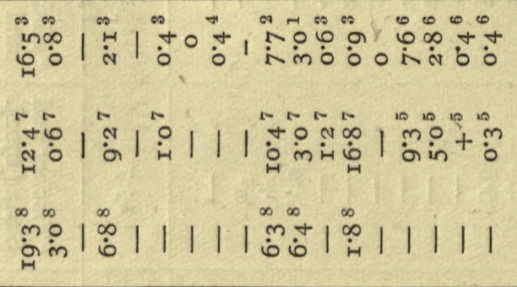 & $\begin{array}{l}\stackrel{\circ}{\%} \\
1 \\
\stackrel{\%}{\%}\end{array}$ & 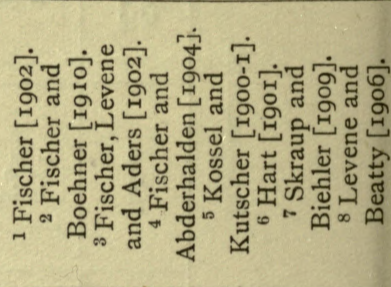 \\
\hline & $\therefore \ldots \ldots$ & . & \\
\hline
\end{tabular}




\begin{tabular}{|c|c|c|c|}
\hline 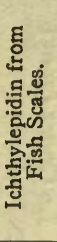 & 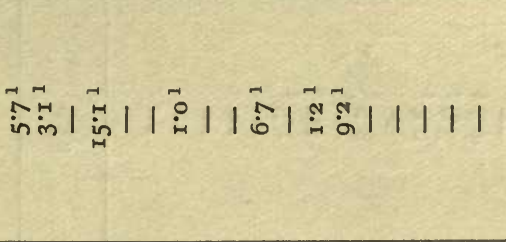 & $\stackrel{\text { ஸे }}{\text { ஸे }}$ & 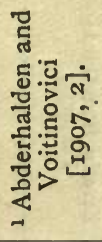 \\
\hline 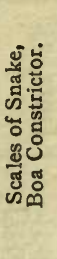 & 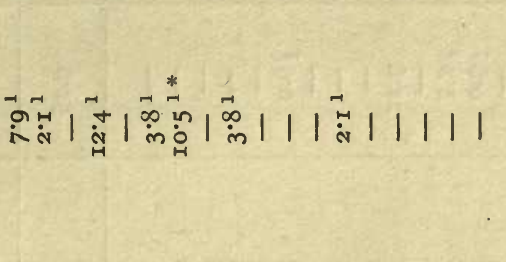 & $\begin{array}{l}\text { iे } \\
\dot{q}\end{array}$ & 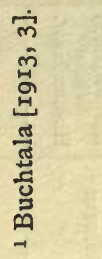 \\
\hline 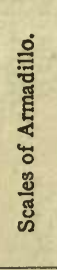 & mition & $\stackrel{\infty}{\dot{H}}$ & 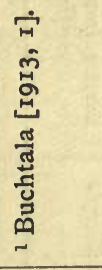 \\
\hline 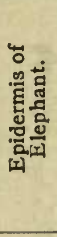 & 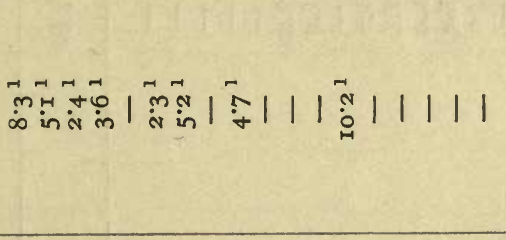 & $\stackrel{\infty}{\dot{H}}$ & 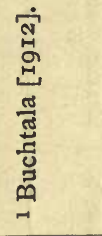 \\
\hline 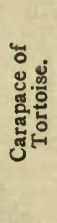 & 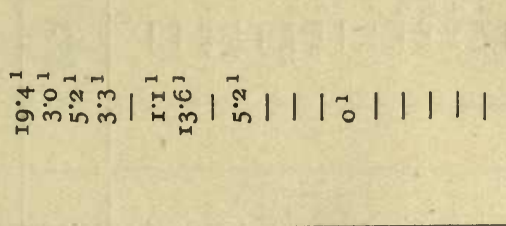 & $\begin{array}{l}\infty \\
\dot{0}\end{array}$ & 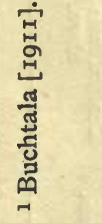 \\
\hline 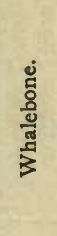 & 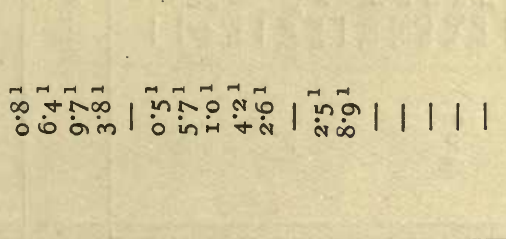 & $\ddot{\dot{q}}$ & 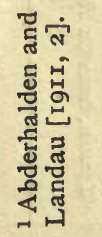 \\
\hline & $\cdots \cdots \cdots$ & :ึँّ & \\
\hline
\end{tabular}




\begin{tabular}{|c|c|c|c|}
\hline 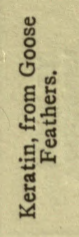 & 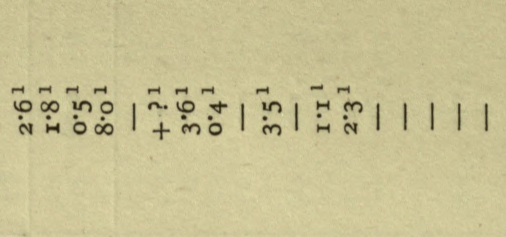 & $\stackrel{\infty}{\tilde{i}}$ & 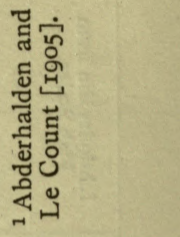 \\
\hline 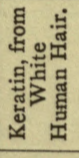 & 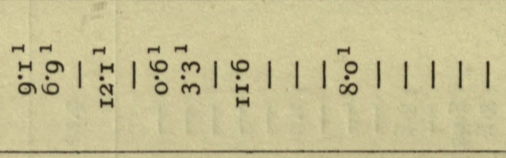 & फ் & 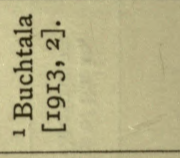 \\
\hline 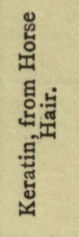 & 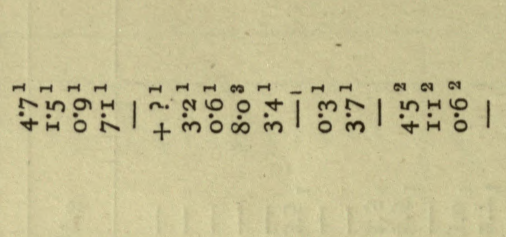 & ம் & 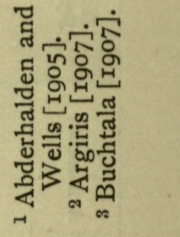 \\
\hline 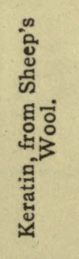 & 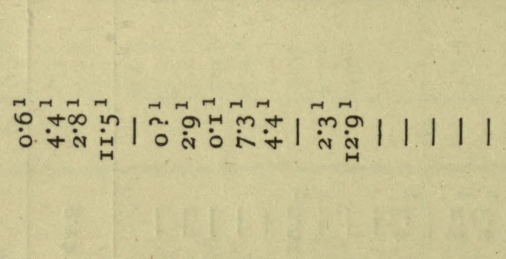 & $\stackrel{\text { N }}{\dot{q}}$ & 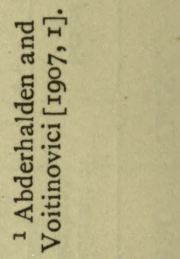 \\
\hline 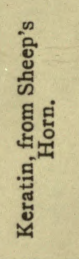 & 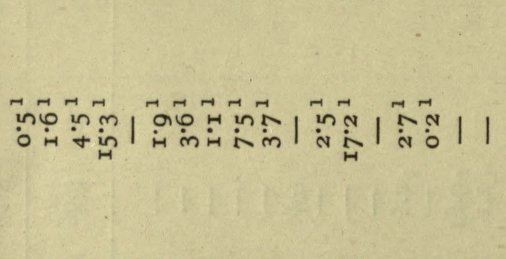 & $\stackrel{\mathscr{\delta}}{\sigma}^{m}$ & 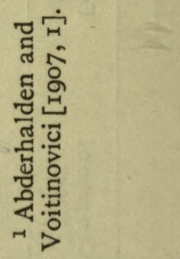 \\
\hline 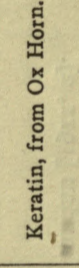 & 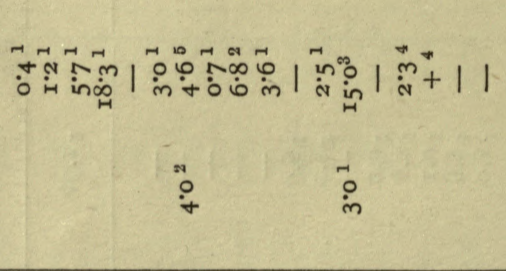 & ì & 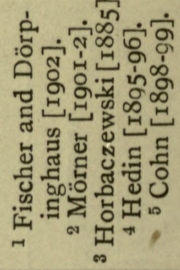 \\
\hline & 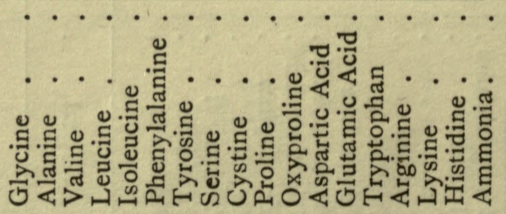 & స్ & \\
\hline
\end{tabular}




\begin{tabular}{|c|c|c|c|}
\hline 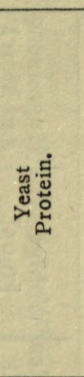 & 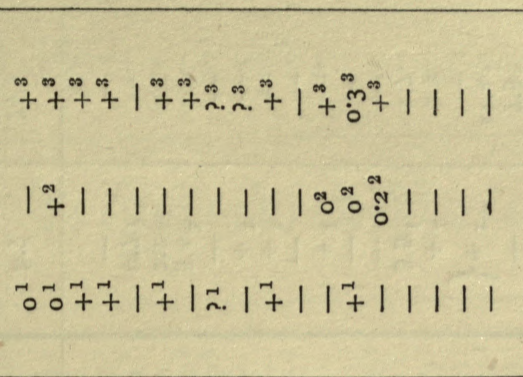 & 1 & 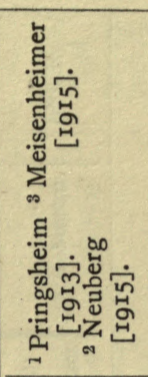 \\
\hline 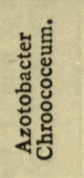 & 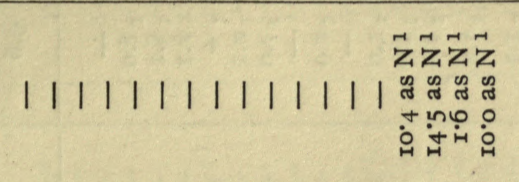 & 1 & 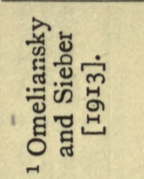 \\
\hline 离高 & 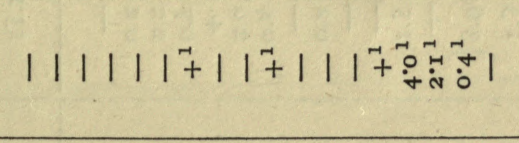 & $\stackrel{n}{0}$ & 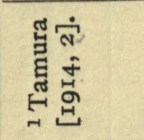 \\
\hline 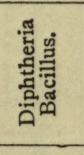 & 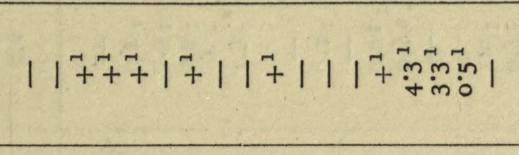 & $\dot{\infty}$ & 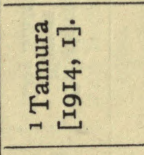 \\
\hline 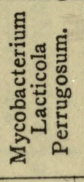 & 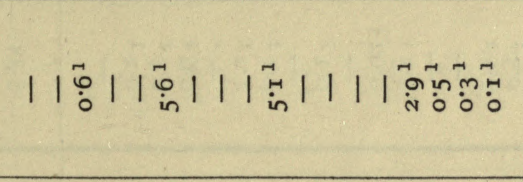 & in & 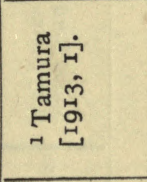 \\
\hline 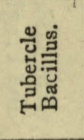 & 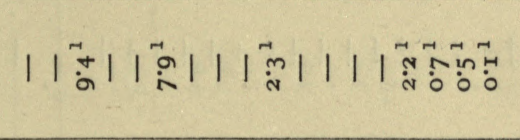 & $\ddot{\tilde{q}}$ & 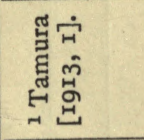 \\
\hline 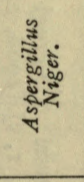 & $\mp+1 \mp 1111111 \mp+11111$ & 1 & 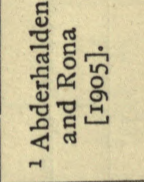 \\
\hline 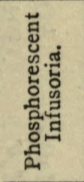 & 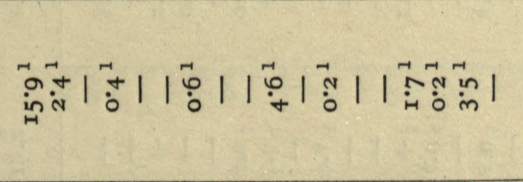 & $\ddot{\text { ๙े }}$ & 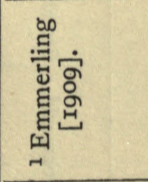 \\
\hline & 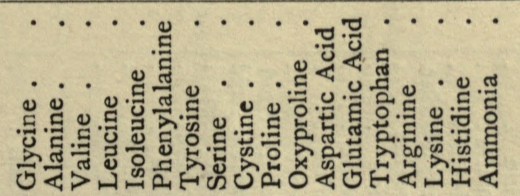 & त् & \\
\hline
\end{tabular}




\begin{tabular}{|c|c|c|c|}
\hline 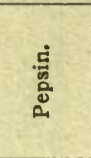 & 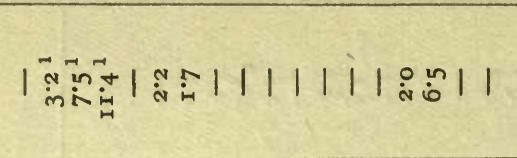 & $\stackrel{n}{\dot{m}}$ & 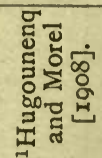 \\
\hline 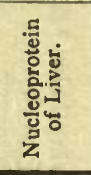 & 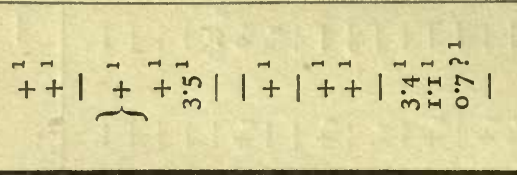 & $\hat{\infty}$ & 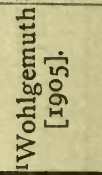 \\
\hline 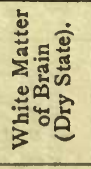 & 药得 & $\ddot{\circ}$ & 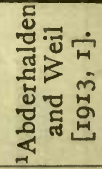 \\
\hline 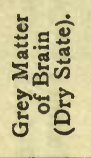 & 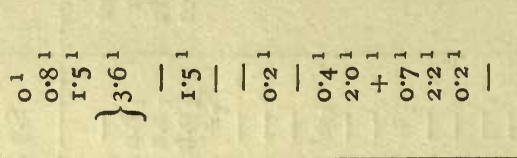 & $\stackrel{m}{m}$ & 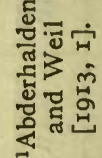 \\
\hline 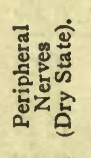 & - & $\dot{0}$ & 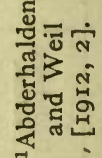 \\
\hline 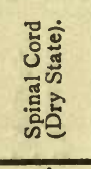 & 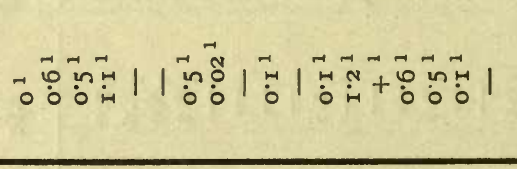 & 尚 & 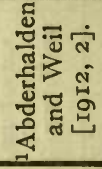 \\
\hline 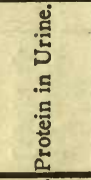 & $++1+1111111++11111$ & 1 & 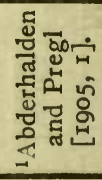 \\
\hline 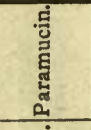 & 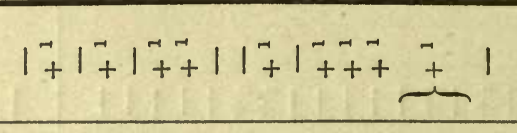 & 1 & 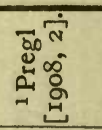 \\
\hline 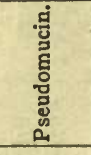 & 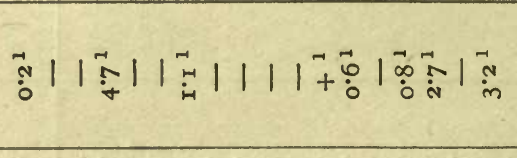 & $\stackrel{m}{\tilde{m}}$ & 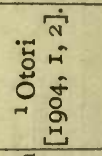 \\
\hline , & 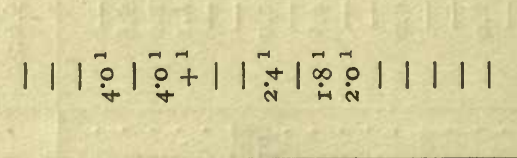 & $\stackrel{\text { du }}{\text { Not }}$ & 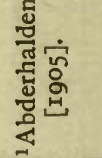 \\
\hline & 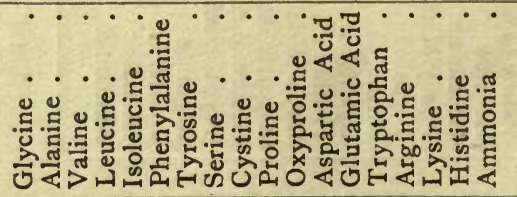 & . & \\
\hline
\end{tabular}




\begin{tabular}{|c|c|c|c|}
\hline 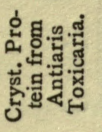 & 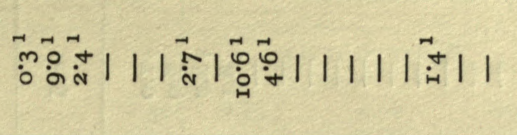 & $\underset{\text { di }}{\stackrel{0}{n}}$ & 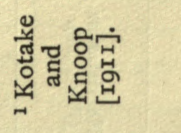 \\
\hline : & 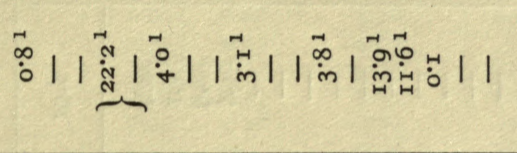 & ஸे & 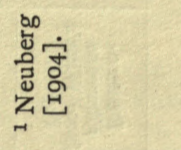 \\
\hline 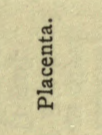 & 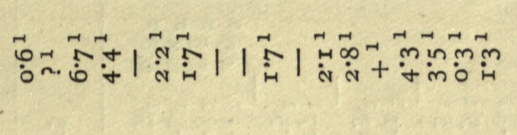 & $\underset{m}{\dot{m}}$ & 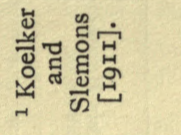 \\
\hline 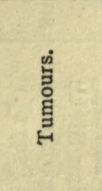 & 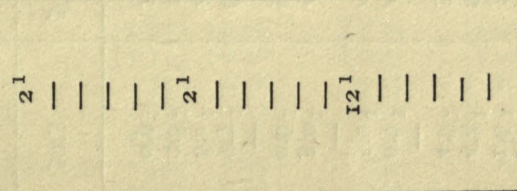 & 이 & 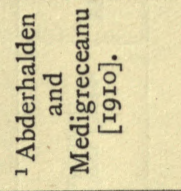 \\
\hline 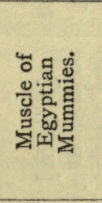 & 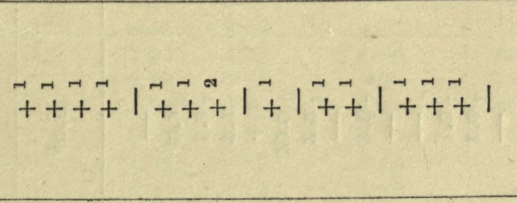 & 1 & 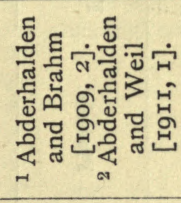 \\
\hline 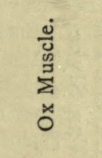 & ano & $\stackrel{n}{\hat{\sigma}}$ & 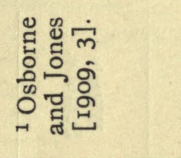 \\
\hline 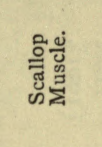 & 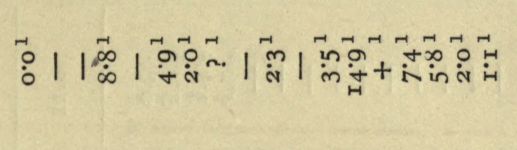 & in & 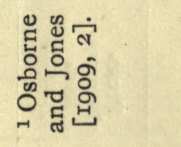 \\
\hline 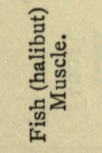 & 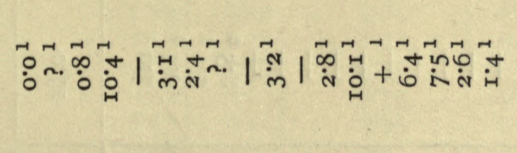 & $\hat{i}$ & 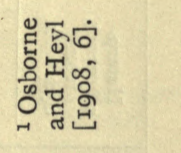 \\
\hline 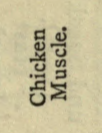 & 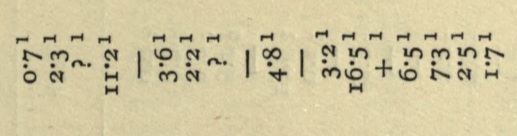 & î̃ & 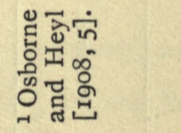 \\
\hline & 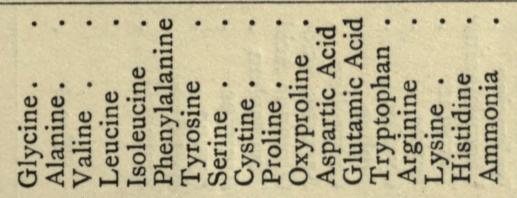 & • & \\
\hline
\end{tabular}

PT. I. 
I30 THE CHEMICAL CONSTITUTION OF THE PROTEINS

\begin{tabular}{|c|c|c|c|}
\hline 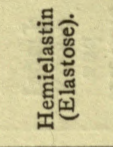 & |||||||||||||| कinin & in & 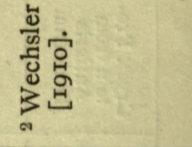 \\
\hline 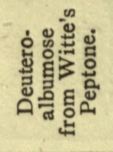 & 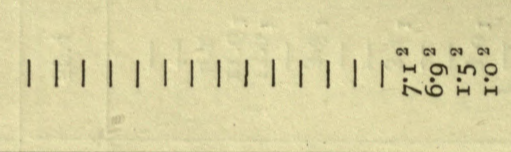 & $\dot{\varphi}_{\dot{H}}^{n}$ & 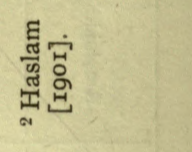 \\
\hline 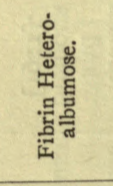 & omingina & $\dot{\text { in }}$ & 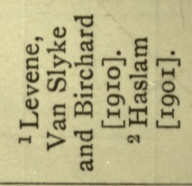 \\
\hline 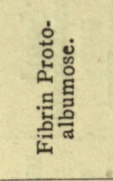 & 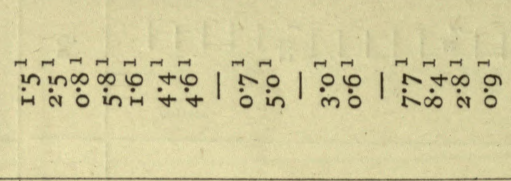 & $\dot{m}$ & 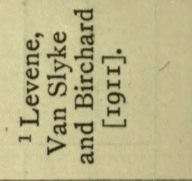 \\
\hline 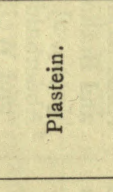 & 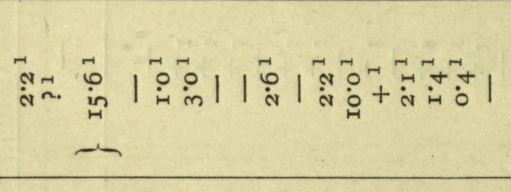 & in & 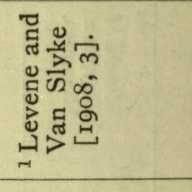 \\
\hline 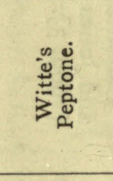 & 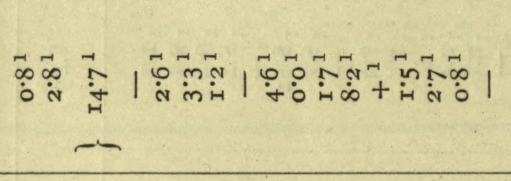 & $\stackrel{9}{\dot{j}}$ & 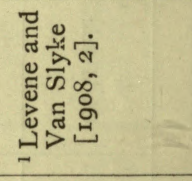 \\
\hline 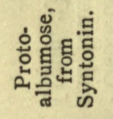 & 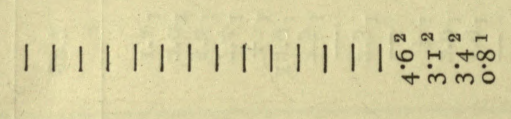 & $\stackrel{\leftrightarrow}{\dot{H}}$ & 莬䓌 \\
\hline 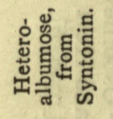 & $\left.||||||||||||||\right|_{\infty} ^{\infty}$ & $\stackrel{0}{i}_{H}^{\circ}$ & 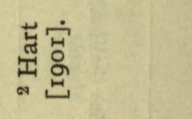 \\
\hline 这 & 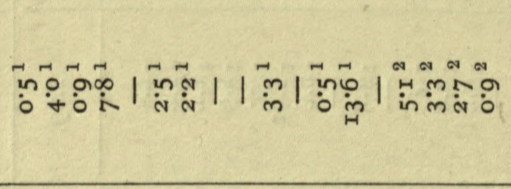 & $\stackrel{m}{\stackrel{f}{f}}$ & 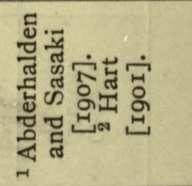 \\
\hline & 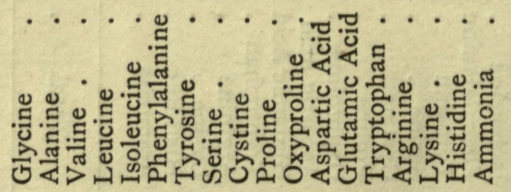 & . & \\
\hline
\end{tabular}


II. Composition of Proteins by Nitrogen Distribution in Three Groups.

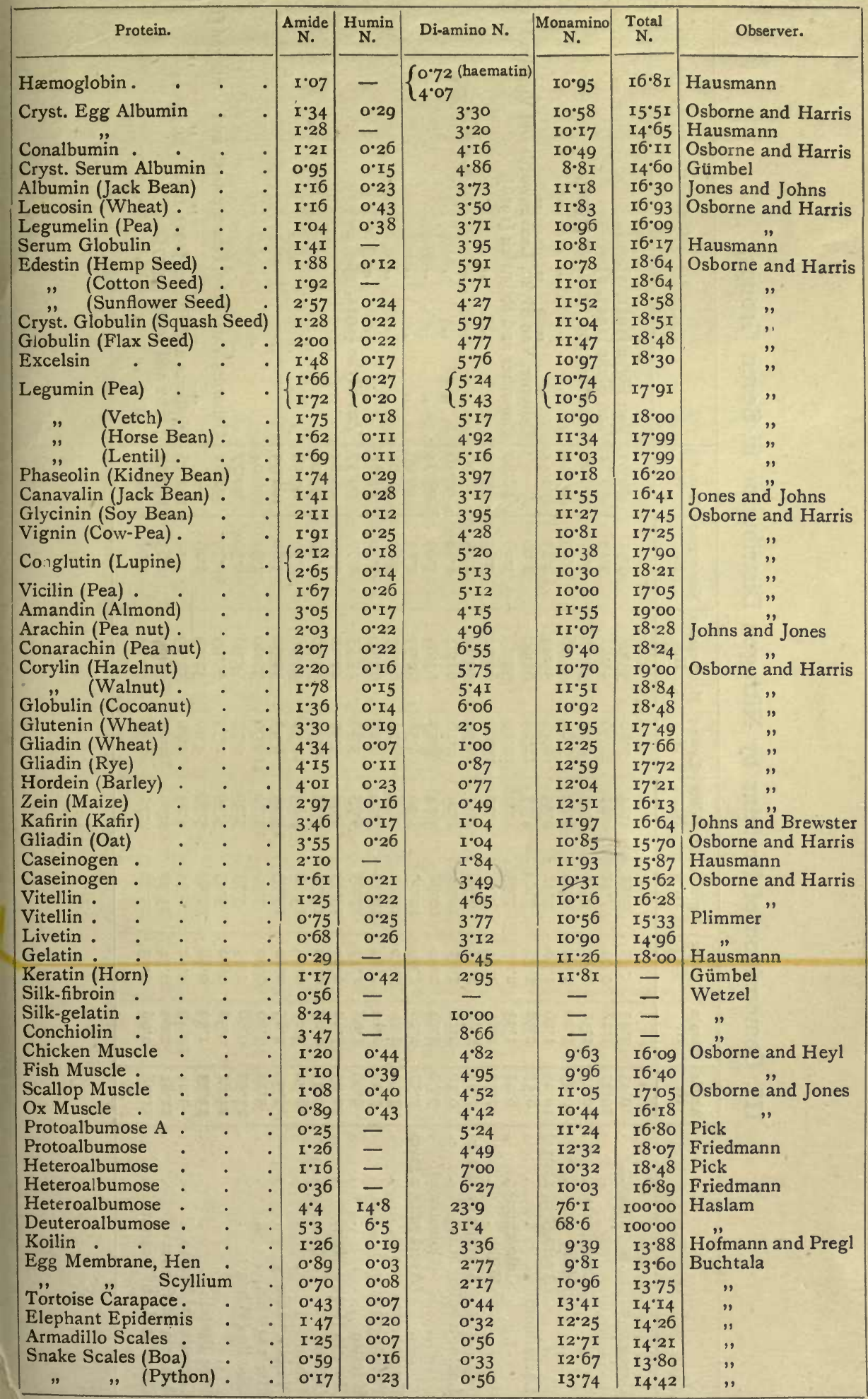




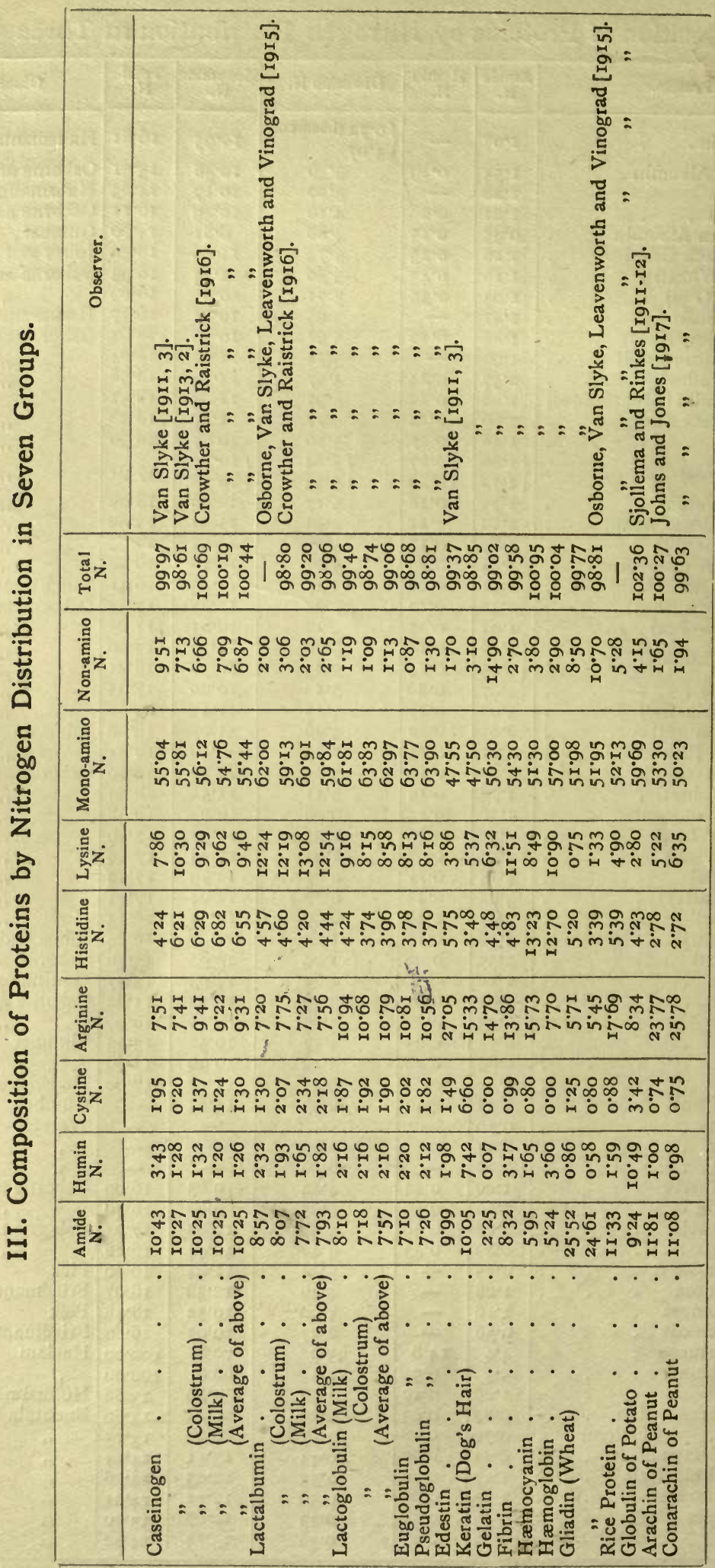




\begin{tabular}{|c|c|}
\hline 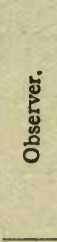 & 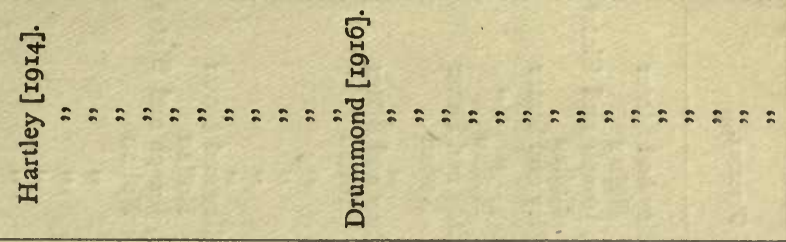 \\
\hline हुँ & 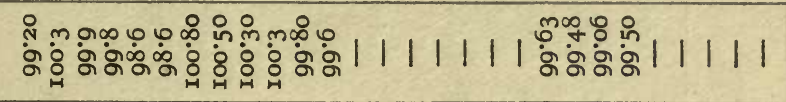 \\
\hline 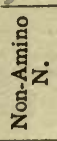 & 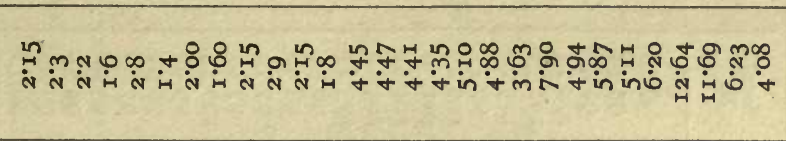 \\
\hline 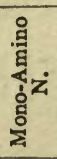 & 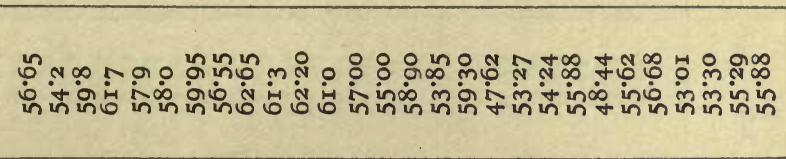 \\
\hline 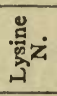 & 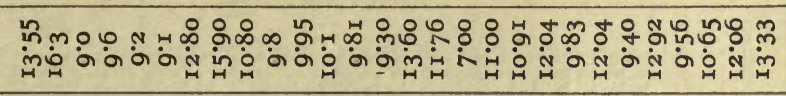 \\
\hline 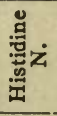 & 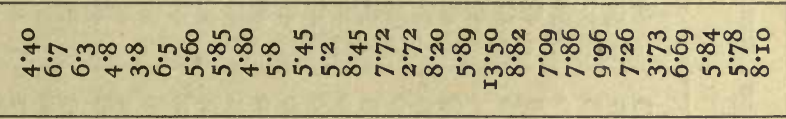 \\
\hline 运 & 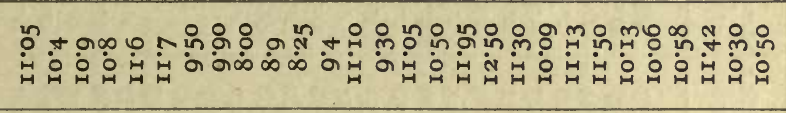 \\
\hline 芴 & 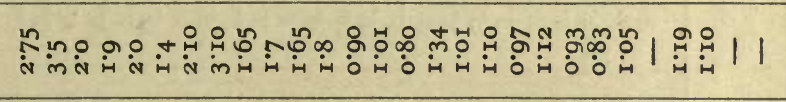 \\
\hline 至 & 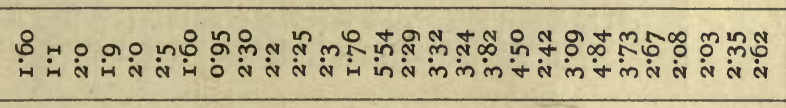 \\
\hline 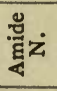 & 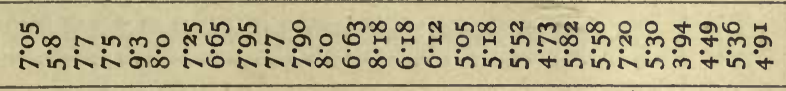 \\
\hline & $\begin{array}{c}\cdots \cdots \cdots \\
\cdots \cdots \cdots \\
\cdots \cdots \\
\cdots\end{array} \cdots \cdots$ \\
\hline
\end{tabular}


I34 THE CHEMICAL CONSTITUTION OF THE PROTEINS

\begin{tabular}{|c|c|}
\hline $\begin{array}{l}\dot{j} \\
\text { 岂 } \\
\text { on } \\
0\end{array}$ & 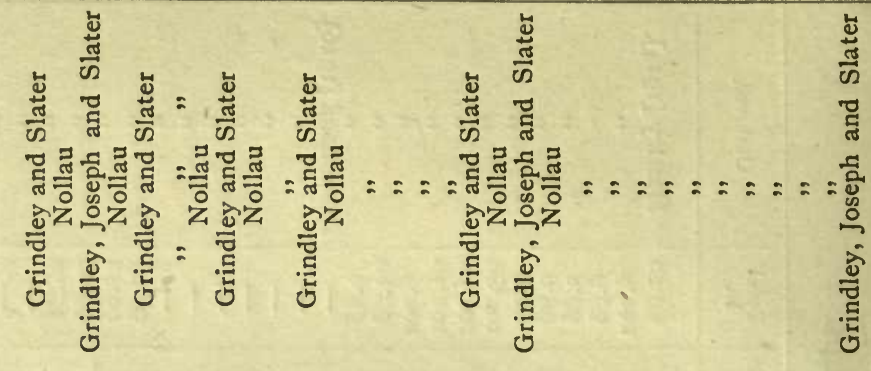 \\
\hline 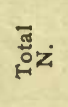 & 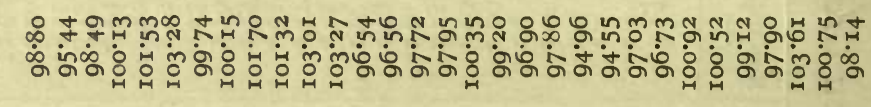 \\
\hline 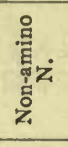 & 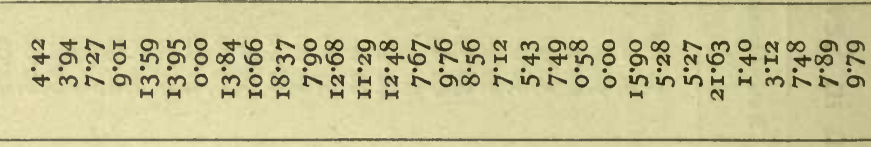 \\
\hline 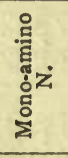 & 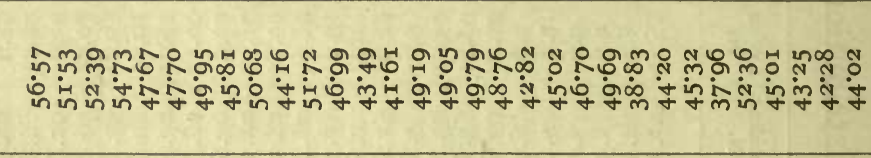 \\
\hline 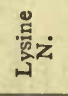 & 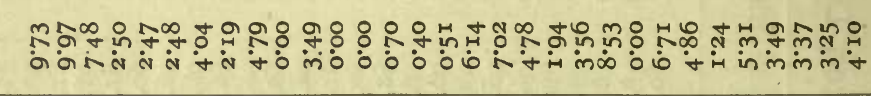 \\
\hline 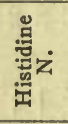 & 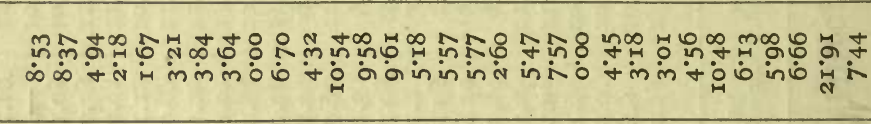 \\
\hline 营 & 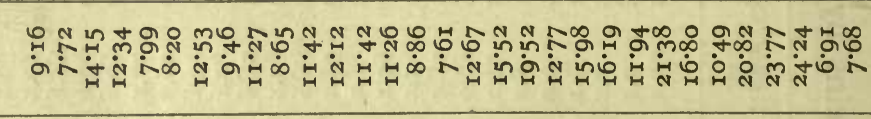 \\
\hline 营 & 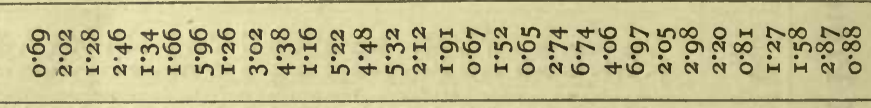 \\
\hline 富安 & 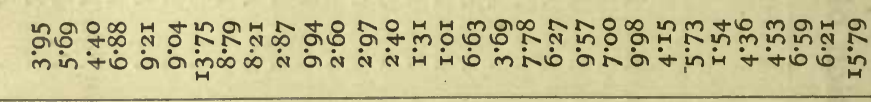 \\
\hline$\ddot{g}$ & 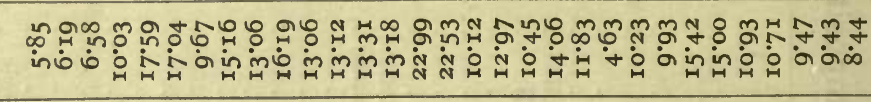 \\
\hline & 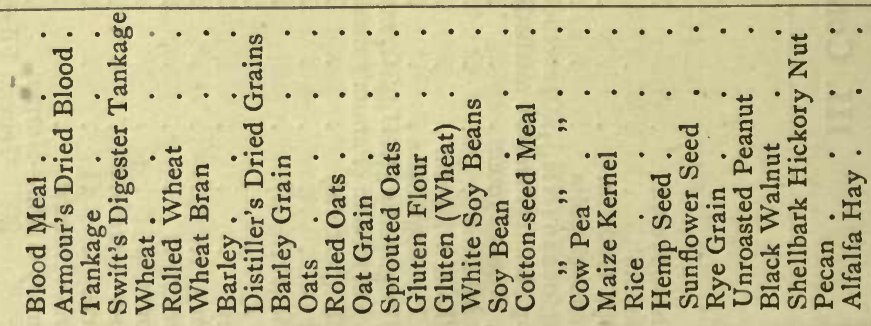 \\
\hline
\end{tabular}




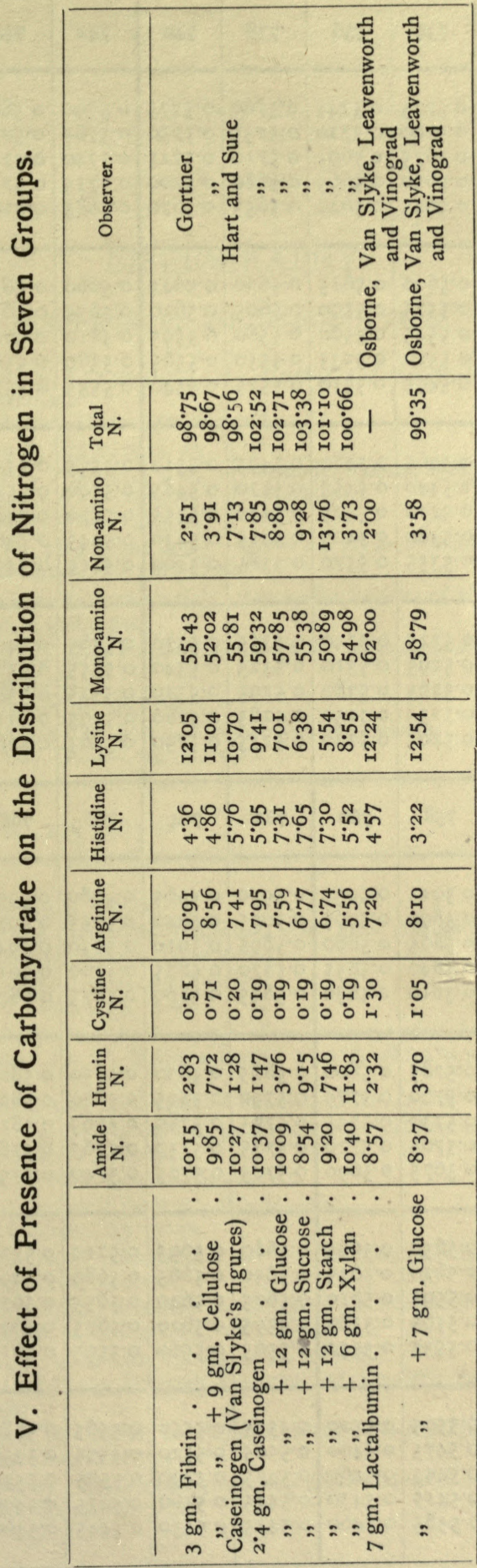


TABLE OF MILLIGRAMS OF AMINO NITROGEN CORRESPONDING TO I c.c. OF NITROGEN GAS AT $11^{\circ}-30^{\circ}$ C.; 728-772 mm. PRESSURE.

\begin{tabular}{|c|c|c|c|c|c|c|c|c|c|c|c|c|}
\hline$b$ & 728 & 730 & 732 & 734 & 736 & 738 & 740 & 742 & 744 & 746 & 748 & 750 \\
\hline $\begin{array}{l}11^{\circ} \\
12^{\circ} \\
13^{\circ} \\
14^{\circ} \\
15^{\circ}\end{array}$ & $\begin{array}{l}0.5680 \\
0.5655 \\
0.5630 \\
0.5605 \\
0.5580\end{array}$ & $\begin{array}{l}0.5695 \\
0.5670 \\
0.5645 \\
0.5620 \\
0.5595\end{array}$ & $\begin{array}{l}0.5510 \\
0.5685 \\
0.5660 \\
0.5635 \\
0.5610\end{array}$ & $\begin{array}{l}0.5725 \\
0.5700 \\
0.5675 \\
0.5650 \\
0.5625\end{array}$ & $\begin{array}{l}0.5745 \\
0.5720 \\
0.5695 \\
0.5665 \\
0.5640\end{array}$ & $\begin{array}{l}0.5760 \\
0.5735 \\
0.5710 \\
0.5680 \\
0.5655\end{array}$ & $\begin{array}{l}0.5775 \\
0.5750 \\
0.5725 \\
0.5700 \\
0.5670\end{array}$ & $\begin{array}{l}0.5790 \\
0.5765 \\
0.5740 \\
0.5715 \\
0.5685\end{array}$ & $\begin{array}{l}0.5805 \\
0.5780 \\
0.5755 \\
0.5730 \\
0.5705\end{array}$ & $\begin{array}{l}0.5820 \\
0.5795 \\
0.5770 \\
0.5745 \\
0.5720\end{array}$ & $\begin{array}{l}0.5840 \\
0.5815 \\
0.5785 \\
0.5760 \\
0.5735\end{array}$ & $\begin{array}{l}0.5855 \\
0.5830 \\
0.5805 \\
0.5775 \\
0.5750\end{array}$ \\
\hline $\begin{array}{l}16^{\circ} \\
17^{\circ} \\
18^{\circ} \\
19^{\circ} \\
20^{\circ}\end{array}$ & $\begin{array}{l}0.5555 \\
0.5525 \\
0.5500 \\
0.5475 \\
0.5445\end{array}$ & $\begin{array}{l}0.5570 \\
0.5540 \\
0.5515 \\
0.5490 \\
0.5460\end{array}$ & $\begin{array}{l}0.5585 \\
0.5555 \\
0.5530 \\
0.5505 \\
0.5475\end{array}$ & $\begin{array}{l}0.5600 \\
0.5575 \\
0.5545 \\
0.5520 \\
0.5495\end{array}$ & $\begin{array}{l}0.5615 \\
0.5590 \\
0.5560 \\
0.5535 \\
0.5510\end{array}$ & $\begin{array}{l}0.5630 \\
0.5605 \\
0.5580 \\
0.5550 \\
0.5525\end{array}$ & $\begin{array}{l}0.5645 \\
0.5620 \\
0.5595 \\
0.5565 \\
0.5540\end{array}$ & $\begin{array}{l}0.5660 \\
0.5635 \\
0.5610 \\
0.5580 \\
0.55555\end{array}$ & $\begin{array}{l}0.5675 \\
0.5650 \\
0.5625 \\
0.5595 \\
0.5570\end{array}$ & $\begin{array}{l}0.5690 \\
0.5665 \\
0.5640 \\
0.5610 \\
0.5585\end{array}$ & $\begin{array}{l}0.5710 \\
0.5680 \\
0.5655 \\
0.5630 \\
0.5600\end{array}$ & $\begin{array}{l}0.5725 \\
0.5695 \\
0.5670 \\
0.5645 \\
0.5615\end{array}$ \\
\hline $\begin{array}{l}21^{\circ} \\
22^{\circ} \\
23^{\circ} \\
24^{\circ} \\
25^{\circ}\end{array}$ & $\begin{array}{l}0.5420 \\
0.5395 \\
0.5365 \\
0.5335 \\
0.5310\end{array}$ & $\begin{array}{l}0.5435 \\
0.5410 \\
0.5380 \\
0.5350 \\
0.5325\end{array}$ & $\begin{array}{l}0.5450 \\
0.5425 \\
0.5395 \\
0.5365 \\
0.5340\end{array}$ & $\begin{array}{l}0.5465 \\
0.5440 \\
0.5410 \\
0.5380 \\
0.5355\end{array}$ & $\begin{array}{l}0.5480 \\
0.5455 \\
0.5425 \\
0.5400 \\
0.5370\end{array}$ & $\begin{array}{l}0.5495 \\
0.5470 \\
0.5440 \\
0.5415 \\
0.5385\end{array}$ & $\begin{array}{l}0.5510 \\
0.5485 \\
0.5455 \\
0.5430 \\
0.5400\end{array}$ & $\begin{array}{l}0.5525 \\
0.5500 \\
0.5470 \\
0.5445 \\
0.5415\end{array}$ & $\begin{array}{l}0.5540 \\
0.5515 \\
0.5485 \\
0.5460 \\
0.5430\end{array}$ & $\begin{array}{l}0.5555 \\
0.5530 \\
0.5500 \\
0.5475 \\
0.5445\end{array}$ & $\begin{array}{l}0.5575 \\
0.5545 \\
0.5515 \\
0.5490 \\
0.5460\end{array}$ & $\begin{array}{l}0.5590 \\
0.5560 \\
0.5530 \\
0.5505 \\
0.5475\end{array}$ \\
\hline $\begin{array}{l}26^{\circ} \\
27^{\circ} \\
28^{\circ} \\
29^{\circ} \\
30^{\circ}\end{array}$ & $\begin{array}{l}0.5260 \\
0.5250 \\
0.5220 \\
0.5195 \\
0.5160\end{array}$ & $\begin{array}{l}0.5295 \\
0.5265 \\
0.5235 \\
0.5210 \\
0.5175\end{array}$ & $\begin{array}{l}0.5310 \\
0.5280 \\
0.5250 \\
0.5220 \\
0.5190\end{array}$ & $\begin{array}{l}0.5325 \\
0.5295 \\
0.5265 \\
0.5235 \\
0.5205\end{array}$ & $\begin{array}{l}0.5340 \\
0.5310 \\
0.5280 \\
0.5250 \\
0.5220\end{array}$ & $\begin{array}{l}0.5355 \\
0.5325 \\
0.5295 \\
0.5265 \\
0.5235\end{array}$ & $\begin{array}{l}0.5370 \\
0.5340 \\
0.5310 \\
0.5280 \\
0.5250\end{array}$ & $\begin{array}{l}0.5365 \\
0.5355 \\
0.5325 \\
0.5295 \\
0.5265\end{array}$ & $\begin{array}{l}0.5400 \\
0.5370 \\
0.5340 \\
0.5310 \\
0.5280\end{array}$ & $\begin{array}{l}0.5415 \\
0.5385 \\
0.5355 \\
0.5325 \\
0.5295\end{array}$ & $\begin{array}{l}0.5430 \\
0.5400 \\
0.5370 \\
0.5340 \\
0.5310\end{array}$ & $\begin{array}{l}0.5445 \\
0.5415 \\
0.5385 \\
0.5355 \\
0.5325\end{array}$ \\
\hline$t$ & 752 & 754 & 756 & 758 & 760 & 762 & 764 & 766 & 768 & 770 & $77^{2}$ & \\
\hline $\begin{array}{l}11^{\circ} \\
12^{\circ} \\
13^{\circ} \\
14^{\circ} \\
15^{\circ}\end{array}$ & $\begin{array}{l}0.5870 \\
0.5845 \\
0.5820 \\
0.5790 \\
0.5765\end{array}$ & $\begin{array}{l}0.5885 \\
0.5860 \\
0.5835 \\
0.5805 \\
0.5765\end{array}$ & $\begin{array}{l}0.5900 \\
0.5875 \\
0.5850 \\
0.5825 \\
0.5795\end{array}$ & $\begin{array}{l}0.5915 \\
0.5890 \\
0.5865 \\
0.5840 \\
0.5810\end{array}$ & $\begin{array}{l}0.5935 \\
0.5905 \\
0.5880 \\
0.5855 \\
0.5830\end{array}$ & $\begin{array}{l}0.5950 \\
0.5925 \\
0.5895 \\
0.5870 \\
0.5845\end{array}$ & $\begin{array}{l}0.5965 \\
0.5940 \\
0.5910 \\
0.5885 \\
0.5860\end{array}$ & $\begin{array}{l}0.5980 \\
0.5955 \\
0.5930 \\
0.5900 \\
0.5875\end{array}$ & $\begin{array}{l}0.5995 \\
0.5970 \\
0.5945 \\
0.5915 \\
0.5890\end{array}$ & $\begin{array}{l}0.6010 \\
0.5985 \\
0.5960 \\
0.5935 \\
0.5905\end{array}$ & $\begin{array}{l}0.6030 \\
0.6000 \\
0.5975 \\
0.5950 \\
0.5920\end{array}$ & \\
\hline $\begin{array}{l}16^{\circ} \\
17^{\circ} \\
18^{\circ} \\
19^{\circ} \\
20^{\circ}\end{array}$ & $\mid \begin{array}{l}0.5740 \\
0.5710 \\
0.5685 \\
0.5660 \\
0.5630\end{array}$ & $\begin{array}{l}0.5755 \\
0.5730 \\
0.5700 \\
0.5675 \\
0.5645\end{array}$ & $\begin{array}{l}0.5770 \\
0.5745 \\
0.5715 \\
0.5690 \\
0.5660\end{array}$ & $\begin{array}{l}0.5785 \\
0.5760 \\
0.5730 \\
0.5705 \\
0.5675\end{array}$ & $\begin{array}{l}0.5800 \\
0.5775 \\
0.5745 \\
0.5720 \\
0.5690\end{array}$ & $\begin{array}{l}0.5815 \\
0.5790 \\
0.5765 \\
0.5735 \\
0.5705\end{array}$ & $\begin{array}{l}0.5830 \\
0.5805 \\
0.5780 \\
0.5750 \\
0.5725\end{array}$ & $\begin{array}{l}0.5850 \\
0.5820 \\
0.5795 \\
0.5765 \\
0.5740\end{array}$ & $\begin{array}{l}0.5865 \\
0.5825 \\
0.5810 \\
0.5780 \\
0.5755\end{array}$ & $\begin{array}{l}0.5880 \\
0.5850 \\
0.5825 \\
0.5795 \\
0.5770\end{array}$ & $\begin{array}{l}0.5895 \\
0.5865 \\
0.5840 \\
0.5810 \\
0.5785\end{array}$ & \\
\hline $\begin{array}{l}21^{\circ} \\
22^{\circ} \\
23^{\circ} \\
24^{\circ} \\
25^{\circ}\end{array}$ & $\begin{array}{l}0.5605 \\
0.5575 \\
0.5545 \\
0.5520 \\
0.5490\end{array}$ & $\begin{array}{l}0.5620 \\
0.5590 \\
0.5560 \\
0.5535 \\
0.5505\end{array}$ & $\begin{array}{l}0.5635 \\
0.5605 \\
0.5575 \\
0.5550 \\
0.5520\end{array}$ & $\begin{array}{l}0.5650 \\
0.5620 \\
0.5595 \\
0.5565 \\
0.5535\end{array}$ & $\begin{array}{l}0.5665 \\
0.5635 \\
0.5610 \\
0.5580 \\
0.5550\end{array}$ & $\begin{array}{l}0.5680 \\
0.5650 \\
0.5625 \\
0.5595 \\
0.5565\end{array}$ & $\begin{array}{l}0.5695 \\
0.5665 \\
0.5640 \\
0.5610 \\
0.5580\end{array}$ & $\begin{array}{l}0.5710 \\
0.5680 \\
0.5655 \\
0.5625 \\
0.5595\end{array}$ & $\begin{array}{l}0.5725 \\
0.5695 \\
0.5670 \\
0.5640 \\
0.5610\end{array}$ & $\begin{array}{l}0.5740 \\
0.5715 \\
0.5685 \\
0.5655 \\
0.5625\end{array}$ & $\begin{array}{l}0.5755 \\
0.5730 \\
0.5700 \\
0.5670 \\
0.5640\end{array}$ & \\
\hline $\begin{array}{l}26^{\circ} \\
27^{\circ} \\
28^{\circ} \\
29^{\circ} \\
30^{\circ}\end{array}$ & $\begin{array}{l}0.5460 \\
0.5430 \\
0.5400 \\
0.5370 \\
0.5340\end{array}$ & $\begin{array}{l}0.5475 \\
0.5445 \\
0.5415 \\
0.5385 \\
0.5355\end{array}$ & $\begin{array}{l}0.5490 \\
0.5460 \\
0.5430 \\
0.5400 \\
0.5370\end{array}$ & $\begin{array}{l}0.5505 \\
0.5475 \\
0.5445 \\
0.5415 \\
0.5385\end{array}$ & $\begin{array}{l}0.5520 \\
0.5490 \\
0.5460 \\
0.5430 \\
0.5400\end{array}$ & $\begin{array}{l}0.5535 \\
0.5505 \\
0.5475 \\
0.5445 \\
0.5415\end{array}$ & $\begin{array}{l}0.5550 \\
0.5520 \\
0.5490 \\
0.5460 \\
0.5430\end{array}$ & $\begin{array}{l}0.5565 \\
0.5535 \\
0.5505 \\
0.5475 \\
0.5445\end{array}$ & $\begin{array}{l}0.5580 \\
0.5550 \\
0.5520 \\
0.5490 \\
0.5460\end{array}$ & $\begin{array}{l}0.5595 \\
0.5565 \\
0.5535 \\
0.5505 \\
0.5475\end{array}$ & $\begin{array}{l}0.5610 \\
0.5580 \\
0.5550 \\
0.5520 \\
0.5490\end{array}$ & \\
\hline
\end{tabular}

Reprinted from Van Slyke's paper, "The Quantitative Determination of Amino Groups. II.," J. Biol. Chem., 1912, 12, 275. 


\section{BIBLIOGRAPHY.}

\section{REFERENCES TO INTRODUCTION.}

ABDERHALDEn, E., Und M. KeMPE [1907, I]. Beitrag zur Kenntnis des Tryptophans und einiger seiner Derivate.

Zeitschr. physiol. Chem., 52, 207-218.

AbDerhalden, E., UND A. WeIl [IgI2, 2].

ABDERHALDEN, E., UND A. WeIl [IgI3, I]. See under Results of Hydrolysis. B. Various AbDeRhalden, E., UND A. Weil [I9I3, 2].

Abderhalden, E., UNd A. Wril [1913, 3]. $\int$ Proteins.

Adensamrr, A., und Ph. Horrnes [1905]. Ueber die Hydrolyse des Eiereiweisses. Monatsh. f. Chem., 26, I217-1230.

Fischer, E., Und E. AbDerhalden [Ig04]. See under Results of Hydrolysis. B. Phosphoproteins, Caseinogen.

Foreman, F. W. [1913, 2]. Die Prolinfraktion bei der Hydrolyse des Caseins. Isolierung von Aminobuttersäure.

Biochem. Zeitschr., 56, r-10.

Funk, C. [IgIr]. Synthesis of dl-3:4-Dihydroxyphenylalanine. J. Chem. Soc. Trans., 99, 554-557.

Galimard, J., L. Lacomme et A. Morel [Ig06]. Sur la vraie nature des glucoproteines- $\alpha$ de M. Lepierre.

Compt. rend., I43, 298-300.

Gortner, R. A. [IgIr]. A New Decomposition Product of Keratin which gives Millon's Reaction.

J. Biol. Chem., 9, 355-357.

Guggenheim, M. [19r3]. Dioxyphenylalanin, eine neue Aminosäure aus Vicia Faba. Zeitschr. physiol. Chem., 88, 276-284.

Heckel, F. [1908]. Ueber Leucin aus Kasein. Monatsh. f. Chem., 29, I5-2I.

Hugouneng, L., et A. Morel [1906, 1907]. Sur la nature véritable des leucéines et glucoproteines obtenues par P. Schützenberger dans le dédoublement des matières protéiques.

Compt. rend., I42, I426-1428; Bull. Soc. Chim. [4], I, I54-164.

LEPIERRE, C. [1903]. Les Glucoproteines comme nouveaux milieux de culture chimiquement définis pour l'étude des microbes.

J. Physiol. et Path. general, 5, 323-330.

Samec, M. [rgo8]. Ueber des Leucin aus Nackenband. Monatsh. f. Chem., 29, 55-58.

SchÜTZENBERGER, P. [1875]. Recherches sur les matières albuminoides. Compt. rend., 80, 232-236.

Schützenberger, P. [1879]. Mémoire sur les Matières Albuminoides. Ann. de Chim. et de Phys. [5], I6, 289-4I9.

Skraup, $Z_{\mathrm{D}}$. H. [1904]. Ueber die Hydrolyse des Kaseins.

Ber., 37, I596-1597; Monatsh. f. Chem., 25, 633-656; Zeitschr. physiol. Chem., 42, $274-296$.

Skraup, ZD. H. [1905, I]. Ueber die Hydrolyse der Eiweissstoffe. II. Die Gelatine. Monatsh. f. Chem., 26, 243-264.

Skraup, $Z_{D}$. H. [1905, 2]. Berichtigung über die Diaminosäuren aus Casein und Gelatin. Monatsh. f. Chem., 26, 683 . 


\section{I38 THE CHEMICAL CONSTITUTION OF THE PROTEINS}

SKRAUP, $Z_{D}$. H., Und R. WitT [Ig07]. Über die Einwirkung von Bromlauge auf Casein. Monatsh. f. Chem., 28, 605-624.

Stephen, H., ANd C. Weizmann [19r4]. Synthesis of dl-Tyrosine and dl-3:4-dioxyphenylalanine.

J. Chem. Soc. Trans., 105, Ir52-Ir 55 .

Thudichum, J. L. W. [19or]. Die Chemische Konstitution des Gehirus des Menschen und der Tiere.

Franz Pietzcker, Tübingen.

Torquati, T. [1913, I]. Ueber die Gegenwart einer stickstoffhaltigen Substanz in den Keimlingen von Vicia Faba.

Arch. Farmacol, sperim., 15, 213-223 ; Chem. Centr., Igr3, II, 517-518.

Torquati, T. [1913, 2]. Ueber die Gegenwart einer stickstoffhaltigen Substanz in der grünen Hülse von Vicia Faba.

Arch. Farmacol. sperim., I5, 308-3I2 ; Chem. Centr., I913, II, 5 I8.

Wohlgemuth, J. [1904, I905]. See under Results of Hydrolysis. B. Various Proteins. 


\section{REFERENCES TO HYDROLYSIS.}

Abderhalden, E., und C. Brahm [Igog]. See under Results of Hydrolysis. B. Silk.

AbdrRhalden, E., und C. Funk [1907]. Beitrag zur Kenntniss der beim Kochen von Casein mit 25-prozentiger Schwefelsäure und mit starker Salzsäure entstehenden Spaltungsprodukte.

Zeitschr. physiol. Chem., 53, r9-30.

ABDeRhalden, E., und R. HANSLIAN [IgI2]. Ueber die Verwendbarkeit der Estermethode zum Nachweis von Monoaminosäuren neben Polypeptiden.

Zeitschr. physiol. Chem., 77, 285-288.

Abderhalden, E., F. Medigreceanu und L. Pincussohn [I909]. Vergleichende Hydrolyse von Seide durch kochende Salzsäure, 25-prozentiger Schwefelsäure, 25-prozentiger Natronlauge und heiss gesättigte Barytlösung.

Zeitschr. physiol. Chem., 6I, 205-209.

Coнn, R. [1896-97]. Ueber die quantitative Eiweissspaltung durch Salzsäure. I.

Z eitschr. physiol. Chem., 22, I53-175.

CонN, R. [1898-99]. Ueber eine quantitative Eiweissspaltung durch Salzsäure. II. Zeitschr. physiol. Chem., 26, 395-410.

Fischer, E., UND E. ABDRRHALDEN [I903, I]. Ueber die Verdaung einiger Eiweisskörper durch Pankreasfermente.

Zeitschr. physiol. Chem., 39, 81-94.

FischeR, E., UND E. ABDERHALDEN [1903, 2]. Ueber die Verdaunng einiger Eiweisskörper durch Pepsinsalzsäure und Pankreasfermente.

Zeitschr. physiol. Chem., 40, 2I5-2I9.

Henriques, V., und J. K. GjaldbäK [rgro]. Ueber quantitative Bestimmung der im Proteine oder in dessen Abbauprodukten vorhandenen Peptidbindungen.

Z eitschr. physiol. Chem., 67, 8-27.

HERZIG, J., UND K. LANDSTEINER [IgI4]. Ueber die Einwirkung von alkoholischen Salzsäure auf Eiweissstoffe.

Biochem. Z eitschr., 67, 334-337.

Hlasiwetz, H., und J. Habermann [187r]. Ueber die Proteinstoffe. I.

Ann. d. Chem., I59, 304-333.

Hlasiwetz, H., und J. Habermann [1873]. Ueber die Proteinstoffe. II. Ann. d. Chem., 169, I50-166.

Hugouneng, L., Et A. Morel [rgo8]. Contribution à l'étude de la constitution des matières protéiques. Nouvelle methode d'hydrolyse à l'acide fuorhydrique.

Compt. rend., I46, r29I-I293; Bull. Soc. Chim. [4], 3, IrI46-II5I ; J. Pharm. Chim. [6], 28, 486-493.

Hugouneno, L., ET A. Morel [rgog, r]. Contribution à l'étude de la constitution des matières protéiques par l'action de l'acide fluorhydrique. Obtention de peptides naturelles definies. Compt. rend., 148, 236-238.

Hugouneno, L., ET A. MOREL [I909, 2]. L'hydrolyse fuorhydrique des matières protéiques : nouveaux resultats.

Compt. rend., $149,4 \mathrm{r}-43$.

Osborne, T. B., AND H. H. GUest [IgII]. See under Results of 'Hydrolysis. B. Caseinogen.

Osborne, T. B., And D. Breese Jones [19io, 3]. See under Results of Hydrolysis. A.

Pfannl, M. [19ro]. Ueber den Verlauf der Hydrolyse von Proteinen mit wässeriger oder mit alkoholischer Salzsäure.

Monatsh. f. Chem., 3r, 8r-85.

Pribram, B. O. [Igri]. Ueber die Anwendbarkeit der Estermethode bei Stoffwechselversuchen.

Zeitschr. physiol. Chem., 7I, 472-478. 


\section{I4O THE CHEMICAL CONSTITUTION OF THE PROTEINS}

Skraup, ZD. H., und W. Türk [rgog]. Notiz über die Hydrolyse von Casein mit Salzsäure und Schwefelsäure.

Monatsh. f. Chem., 30, 287-288.

Sörensen, S. P. L. [1907]. Enzymstudien.

Biochem. Zeitschr., 7, 45-10r.

Sörensen, S. P. L., Und H. JeSSEn-HAnsen [1907]. Ueber die Ausführung der Formoltitrierung in stark farbigen Flüssigkeiten.

Biochem. Zeitschr., 7, 407-420.

Van Slyke, D. D. [Igrr, 4]. See under References to Analysis of Proteins by Distribution of the Nitrogen.

VAN SlyKe, D. D. [19r2, 2]. The Conditions for Complete Hydrolysis of Proteins. J. Biol. Chem., 12, 295-299.

Weizmann, C., And G. S. Agashe [1913]. Hydrolysis of Proteins with an Alcoholic Solution of Hydrogen Chloride.

Biochem. J., 7, 437-440. 


\section{REFERENCES TO ISOLATION AND ESTIMATION OF TYROSINE.}

ABDERHALDEN, E. [IgI2]. Notiz zur Darstellung und quantitativen Bestimmung von Tyrosin und Glutaminsäure.

Zeitschr. physiol. Chem., 77, 75-76.

ABDerhalden, E. [I9r3]. Nachtrag zu: Der Gehalt der Proteine an l-Tyrosin und die Genauigkcit der Bestimmung dieser Aminosäure. Zeitschr. physiol. Chem.; 85, 9 r.

Abderhalden, E., und D. Fuchs [Igr3]. Über den Gehalt der Proteine an l-Tyrosin und die Genauigkeit der Bestimmung dieser Aminosāure.

Zeitschr. physiol. Chem., 83, 468-473.

AbDerhalden, E., und L. Langstein [Igro]. See under References to Results of Hydrolysis. B. Phosphoproteins. Caseinogen.

Abderhalden, E., UND Y. TeRUUChi [1906]. Notiz zur Darstellung von Tyrosin aus Seide.

Zeitschr. physiol. Chem., 48, 528-529.

Brown, A. J., And E. T. Millar [1906]. The Liberation of Tyrosine during Tryptic Pro. teolysis.

J. Chem. Soc. Trans., 89, I45-I55.

Folin, O., AND W. Denis [Igr2, I]. On Phosphotungstic-phosphomolybdic Compounds as Color Reagents. J. Biol. Chem., 12, 239-243.

Folin, O., And W. Denis [IgI2, 2]. Tyrosine in Proteins as Determined by a New Colorimetric Method.

J. Biol. Chem., 12, 245-25r.

Folin, O., And W. Denis [Igr3]. On the Tyrosine Content of Proteins. A Reply to $A b$. derhalden and Fuchs.

J. Biol. Chem., I4, 457-458.

Habermann, J., UND R. EhRENFELD [1902]. Eine quantitative Methode zur Trennung des Leucins und Tyrosins. Zeitschr. physiol. Chem., 37, I8-28.

LeVene, P. A., AND D. D. van Slyke [1908, 2]. Hydrolyse von Wittepeptone. Biochem. Zeitschr., I3, 440-457.

Levene, P. A., And D. D. van Slyke [rgro]. Note on Insoluble Lead Salts of Amino Acids. J. Biol. Chem., 8, 235-286.

Marshall, E. K. jun. [Igr3]. On the Preparation of Tyrosine. J. Biol. Chem., I5, 85-86.

Millar, J. H. [Ig03]. A New Method for the Direct Estimation of Tyrosine in Mixtures of Amides and Amino Acids.

Trans. Guinness Research Laboratory, I, Part I, 40-44.

Osborne, T. B., ANd S. H. Clapp $[1907,8]$. See under Results of Hydrolysis. B. Gliadins.

Osborne, T. B., and H. H. Guest [Igrr]. Hydrolysis of Casein. J. Biol. Chem., 9, 333-353.

Plimmer, R. H. A., And E. C. EAves [19r3]. The Estimation of Tyrosine in Proteins by Bromination.

Biochem. J., 7, 297-3 I0.

Totani, G. [19r6]. Feeding Experiments with a Dietary in which Tyrosine is Reduced to a Minimum.

Biochem. J., I0, 382-398. 


\section{I42 THE CHEMICAL CONSTITUTION OF THE PROTEINS}

\section{REFERENCES TO ISOLATION AND ESTIMATION OF CYSTINE.}

Abderhalden, E. [1903]. See under References to Results of Hydrolysis. B. Histones. Abderhalden, E., Und F. Pregl $[1905,2]$. See under References to Results of Hydrolysis. B. Albumins.

EmbDen, G. [I900]. Ueber den Nachweis von Cystin und Cystein unter den Spaltungsprodukten der Eiweisskörper. Zeitschr. physiol. Chem., 32, 94-103.

Folin, O. [rgro]. On the Preparation of Cystine.

J. Biol. Chem., 8, 9-10.

Friedmann, E. [IgO2]. Beiträge zur Kenntniss der physiologischen Beziehungen der Schwefelhaltigen Eiweissabkömmlinge. I. Ueber die Konstitution des Cystins. Beitr. chem. Physiol. Path., 3, I-46.

Hopkins, F. G., and H. Savory [IgII]. See under Results of Hydrolysis. B. Globulins. Mörner, K. A. H. [Igor-2]. Zur Kenntniss der Bindung des Schwefels in den Proteinstoffen.

Zeitschr. physiol. Chem., 34, 207-338.

Osborne, T. B., and S. H. Clapp [I906]. See under Results of Hydrolysis. B. The Vegetable Proteins. Albumins.

Osborne, T. B, and S. H. Clapp $[1907,6]$. See under Results of Hydrolysis. B. The Vegetable Proteins. Globulins (crystallised).

Plimmer, R. H. A. [rgr3]. The Separation of Cystine and Tyrosine.

Biochem. J., 7, 3II-3I7.

Winterstein, E. [Igor]. Ueber eine Methode zur Abschcidung der organischen Basen aus den Phosphorwolframsäureniederschlägen und über das Verhalten des Cystins gegen Phosphorwolframsäure.

Zeitschr. physiol. Chem., 34, I53-I56. 


\section{REFERENCES TO ISOLATION AND ESTIMATION OF TRYPTOPHAN.}

Abderhalden, E., und M. Kempe [1907, I]. Beitrag zur Kenntnis des Tryptophans und einiger seiner Derivate.

Zeitschr. physiol. Chem., 52, 207-218.

FASAL, H. [1912]. Ueber eine colorimetrische Methode zur quantitativen Tryptophanbestimmung und über den Tryptophangehalt der Horngebilde und anderer Eiweisskörper. Biochem. Zeitschr., 44, 392-40r.

FASAL, H. [1913]. Ueber den Tryptophangehalt normaler und pathologischer Hautgebilde und maligner Tumoren.

Biochem. Z eitschr., 55, 88-95.

HerzFeld, E. [I913, I]. Ueber Indolbildung bei der alkalischen Hydrolyse der Eiweisskörper.

Biochem. Zeitschr., 56, 82-94.

HERZFELD, E. [1913, 2]. Ueber eine quantitative Tryptophanbestimmungsmethode. Biochem. Z eitschr., 56, 258-266.

Homer, A. [IgI5]. A Method for the Estimation of the Tryptophane Content of Proteins, Involving the Use of Baryta as a Hydrolyzing Agent. J. Biol. Chem., 22, 369-389.

Hopkins, F. G., AND S. W. Cole [Igor, 2]. A Contribution to the Chemistry of Proteids. I. A Preliminary Study of a Hitherto Undescribed Product of Tryptic Digestion. J. Physiol., 27, 418-428.

KURCHIN, E. [19I4]. Tryptophanbestimmungen in normalen und pathologischen Nieren. Biochem. Zeitschr., 65, 45 I-459.

LEVene, P. A., AND C. A. Rouiller [1906-7]. On the Quantitative Estimation of Tryptophan in Protein Cleavage Products.

J. Biol Chem., 2, 48I-484.

LeVene, P. A., Und C. A. RouIller [1907]. Ueber die Tryptophangruppe im Proteinmolekiil.

Biochem. Zeitschr., 4, 322-327.

NeUBERG, C., UND N. PopowsKy [1907]. Ueber Indolaminopropionsäure und ihre Halogenverbindungen (Tryptophanreaktion).

Biochem. Zeitschr., 2, 357-382.

SANDERS, J. A., AND C. E. May [1912-13]. A Method for the Determination of Tryptophan Derived from Prctein.

Biochem. Bull., 2, 373-378. 


\section{REFERENCES TO ISOLATION AND ESTIMATION OF THE OTHER MONO- AMINO ACIDS.}

Abderhalden, E. [Igro]. Allgemeine Technik und Isolierung der Monoaminosäuren Handbuch der biochemischen Arbeitsmethoden. Band II, 470-497.

Abderhalden, E. [1912]. Notiz zur Darstellung und quantitativen Bestimmung von Tyrosin und Glutaminsäure. Zeitschr. physiol. Chem., 77, 75-76.

Abderhalden, E., und K. Kautzsch [1912]. Nachweis des 1 -Prolins als primäres Spaltprodukt der Proteine.

Zeitschr. physiol. Chem., 78, 96-I I 4.

Abderhalden, E., und A. Weil [IgI2, 3]. Ueber die bei der Isolierung der Monoaminosäuren mit Hilfe der Estermethode entstehende Verluste III. Infreiheitsetzung der Ester mit Bleihydroxyd.

Zeitschr. physiol. Chem., 81, 226-227.

EHRLICH, F. [1904]. Ueber das natürliche Isomere des Leucins. I. Ber. Deutsch. Chem. Ges., 37, 1809-1840.

Fischer, E. [Igor]. Ueber die Hydrolyse des Caseins durch Salzsäure. Zeitschr. physiol. Chem., 33, I5I-I76.

Fischer, E. [1902]. Notizen. II. Quantitative Bestimmung des Glycocolls. Zeitschr. physiol. Chem., 35, 229-230.

Fischer, E., und C. Harries [rgo2]. Ueber Vacuumdestillation. Ber. Deutsch. Chem. Ges., 35, 2158-2163.

Foreman, F. W. [1913, I, and unpublished]. Studies in Protein Hydrolysis. J. Agric. Sci., 4, 43I-434.

Foreman, F. W. [rgr4, r]. Quantitative Estimation of Aspartic and Glutaminic Acids in the Products of Protein Hydrolysis.

Biochem. J., 8, 463-480.

Habermann, J. [1875]. Zur Kenntniss der Glutaminsäure. Ann. der Chem., I79, 248-256.

Hlasiwetz, H., und J. Habermann [1873]. Ueber die Proteinstoffe. II. Ann. der Chem., 169, 150-166.

Kutscher, $\mathrm{F}_{\mathrm{R}}$ [1903]. Beiträge zur Kenntniss der Eiweisskörper. II. Zeitschr. physiol. Chem., 38, Irr-I34.

Levene, P. A. [1905]. See under References to Results of Hydrolysis. B. Derivatives of Proteins.

Levene, P. A. [rgo6]. Glycocoll Picrate. J. Biol. Chem., I, 4I3-4I4.

Levene, P. A., And D. D. van Slyke [1908, r]. Zur Methodik der Destillation der Aminosäurenestern mittels der Geryk-Pumpe. Biochem. Zeitschr., 10, 214.

Lenvene, P. A., And D. D. van Slyke $[1908,2]$. See under References to Results of Hydrolysis. B. Derivatives of Proteins.

Levene, P. A., ANd D. D. van Slyke [1909, r]. The Leucin Fraction of Proteins. J. Biol. Chem., 6, 391-418.

Levene, P. A., And D. D. van Slyke [1909, 2]. The Leucin Fraction in Casein and Edestin.

J. Biol. Chem., 6, 4rg-430.

LeVene, P. A., and D. D. van Slyke [19ro]. Note on Insoluble Lead Salts of Amino Acids.

J. Biol. Chem., 8, 285-286.

Levene, P. A., and D. D. van Slyke [19r2]. The Composition and Properties of Glycocoll Picrate and the Separation of Glycocoll from Alanine.

J. Biol. Chem., 12, 285-294. 
Levene, P. A., And D. D. van Slyke [19r3]. The Separation of d-Alanine and d-Valine. J. Biol. Chem., r6, ro3-120.

Osborne, T. B., And R. D. Gilbert [1906]. The Proportion of Glutaminic Acid Yielded by Various Vegetable Proteins, when Decomposed by Boiling with Hydrochloric Acid. Amer. J. Physiol., 15, 333-356.

Osborne, T. B., And D. Breese Jones [1910, 2]. Some Modifications of the Method in Use for Determining the Quantity of Mono-amino Acids Yielded by Proteins when Hydrolyzed with Acids.

Amer. J. Physiol., 26, 212-228.

Osborne, T. B., And L. M. Lidde [IgJo, 2]. The Separation and Estimation of Aspartic and Glutaminic Acids.

Amer. J. Physiol., 26, 420-425.

Pribram, B. O. [Igro]. Ueber eine Modification bei der Fischer'chen Estermethode. Monatsh. f. Chem., 3I, 5I-54.

Siegfried, M. [18gr]. Zur Kenntniss der Spaltungsprodukte der Eiweisskörper. Ber. Deutsch. chem. Ges., 24, 418-432.

Van Slyke, D. D. [IgIr, 3]. Quantitative Determination of Prolin Obtained by the Ester Method in Protein Hydrolysis. Prolin Content of Casein. J. Biol. Chem., 9, 205-207.

ZeLinsky, N., A. ANNENKoff Und J. Kulikoff [IgIr]. Ueber ein einfaches und bequemes Verfahrung zur Darstellung der freien Ester der Aminosäuren. Zeitschr. physiol. Chem., 7, 459-470. 


\section{REFERENCES TO ISOLATION AND ESTIMATION OF THE DI-AMINO ACIDS}

Kossel, A., UND FR. KUTSCher [Igoo-I]. Beiträge zur Kenntniss der Eiweisskörper. Zeitschr. physiol. Chem., 3r, I65-214.

Kossel, A., und A. J. Patten [I903]. Zur Analyse der Hexonbasen.

Zeitschr. physiol. Chem., 38, 39-45.

Kossel, A, und H. Pringle [1906]. Ueber Protamine und Histone. Methode der quantitativen Spaltung des Histopeptons.

Zeitschr. physiol. Chem., 49, 318-321.

Osborne, T. B., C. S. Leavenworth and C. A. Brautlecht [1908]. The Different Forms of Nitrogen in Proteins.

Amer. J. Physiol., 23, 180-200.

Steudel, H. [1903]. Das Verhalten der Hexonbasen zur Pikrolonsäure. Z eitschr. physiol. Chem., 37, 219-220.

Steudel, H. [Igro]. Isolierung von Histidin, Lysin und Arginin.

Handbuch der bio-chemischen Arbeitsmethoden von E. Abderhalden, Band II, 498-509.

Schulze, E., Und E. Winterstein [1902]. Ueber die Trennung des Phenylalanins von anderen Aminosäuren. Zeitschr. physiol. Chem., 35, 210-220.

WEIss, F. [1907]. Untersuchungen über die Bildung des Lachsprotamins. Zeitschr. physiol. Chem., 52, I07-120.

WeIss, M., UND N. SSOBOLEW [1913]. Ueber ein colorimetrisches Verfahren zur quantitativen Bestimmung des Histidins.

Biochem. Zeitschr., 58, II9-I29. 


\section{REFERENCES TO RESULTS OF HYDROLYSIS. A.}

AbDeRhalden, E. [IgIo]. Beitrag zur Kenntnis der bei den totalen Hydrolyse von Proteinen auftretenden Aminosäuren.

Zeitschr. physiol. Chem., 68, 477-486.

ABdeRhalden, E., UND K. KAUTZSCH [I9I2]. Nachweis des l-Prolins als primäres Spalt. produkt der Proteine.

Zeitschr. physiol. Chem., 78, 96-II4.

ABderhalden, E., und A. WeIl [IgII, 2]. Ueber die bei der Isolierung der Monoaminosäuren mit Hilfe der Estermethode entstehenden Verluste. I.

Zeitschr. physiol. Chem., 74, 445-471.

Abderhalden, E., Und A. Weil [1912, I]. Ueber die bei der Isolierung der Monoamino. säuren mit Hilfe der Estermethode entstehenden Verluste. II. Zeitschr. physiol. Chem., 77, 59-74.

ANdersen, A. C., UND R. Roed-MülleR [I9I5]. Zur Kenntniss der Eiweisskörper. II. Die Verbindung von Ammoniak in die Eiweisskörper.

Biochem. Zeitschr., 70, 442-463.

Engeland, R. [1909]. Ueber Hydrolyse von Casein und den Nachweis der dabei entstandenen Monoaminosäuren.

Ber. Deutsch. chem. Ges., 42, 2962-2969.

ENGELAND, R. [Igro]. Ueber erschöpfende Methylierung einiger Aminosäuren.

Ber. Deutsch. chem. Ges., 43, 2662-2664.

Engeland, R. [IgI4]. Ueber den Nachweis von Monoaminosäuren. Zeitschr. f. Biol., 63, 470-476.

Gortner, R. A. [19r6]. The Origin of the Humin Formed by the Acid Hydrolysis of Proteins. II. Hydrolysis in the Presence of Carbohydrates and of Aldehydes. J. Biol. Chem., 26, 177-204.

Gortnkr, R. A., And M. J. Blish [I9I5]. On the Origin of the Humin Formed by the Acid Hydrolysis of Proteins.

J. Amer. Chem. Soc., 37, ז630-1636.

Grindley, H. S., AND M. E. Slater [I9I5]. See under References to Distribution of Nitrogen in Proteins.

Henriques, V., UND J. K. GJaldbäK [rgro]. Ueber quantitative Bestimmung der im Proteine oder in dessen Abbauprodukten vorhandenen Peptidbindungen. Zeitschr. physiol. Chem., 67, 8-27.

Matllard, L. C. [IgI2]. Action des acides aminés sur les sucres; formation des mélanoidines par voie methodique.

Compt. rend., 154, 66-68.

MaIllard, L. C. [1913]. Origin des bases cycliques du goudron de houille.

Compt. rend., I5I, 850-852.

MaILLARD, L. C. [1916]. Sur la formation des bases pyridiques à partir des albuminoides. Compt. rend., 162, 757-758.

Osrorne, T. B., And D. Breese Jones [Igro, I]. Some Points in the Analysis of Proteins. J. Biol. Chem., 7, Proc., viii-ix.

Osborne, T. B., and D. Breese Jones [rgio, 3]. A Consideration of the Sources of Loss in Analysing the Products of Protein Hydrolysis. Amer. J. Physiol., 26, 305-328.

Osborne, T. B., C. S. Leavenworth and C. A. Brautlecht [1908]. The Different Forms of Nitrogen in Proteins. Amer. J. Physiol., 23, 180-200.

Pictet, A., вт T. Q. Chou [Igr6]. Sur la formation de bases pyridiques et isoquinoléiques à partir de la caséine.

Compt. rend., 162, 127-129. 


\section{I48 THE CHEMICAL CONSTITUTION OF THE PROTEINS}

Piтtom, W. W. P. [1914]. Studies in Protein Hydrolysis.

Biochem. J., 8, r57-r69.

Roxas, M. L. [19r6]. The Reaction between Amino Acids and Carbohydrates as a Probable Cause of Humin Formation.

J. Biol. Chem., 27, 7 1-93.

SAmuely, F. [1902]. Über die aus Eiweiss hervorgehenden Melanine.

Beitr. chem. Physiol. Path., 2, 355-388.

SkRAup, Zd. H., und E. v. HARDT-STremayr [Ig08]. Ueber den sogenannten Amidstickstoff der Proteine. Monatsh. f. Chem., 29, 255-262.

VAN Slyke, D. D. [1912, 2]. The Conditigns for Complete Hydrolysis of Proteins. J. Biol. Chem., 12, 295-299. 
REFERENCES TO RESULTS OF HYDROLYSIS. B.

\section{Protamines.}

Abderhalden, E. [1904]. Die Monoaminosäuren des Salmins.

Zeitschr. physiol. Chem., 4I, 55-58.

Dezani, S. [1908]. Protein Bases of the Sperm and Ovaries of the Tunny Fish and their Products of Hydrolysis.

Giorn. R. Accad. Med. Torino, 14 ; J. Chem. Soc. Abs., rgog, ii. r63-164.

Kossel, A. [1896-97]. Ueber die basischen Stoffe des Zellkerns.

Zeitschr. physiol. Chem., 22, 176-187.

Kosser, A. [1898]. Ueber die Constitution der einfachsten Eiweissstoffe.

Zeitschr. physiol. Chem., 25, 165-189.

Kosser, A. [1898-99]. Weitere Mittheilungen über die Protamine.

Zeitschr. physiol. Chem., 26, 588-592.

Kossel, A. [1903]. Sur les Protamines et la Constitution des Matières Albuminoides. Bull. Soc. Chim. [iii], 29, Conference faite le $30 \mathrm{Mai}$.

Kosser, A. [1903-4]. Zur Kenntnis des Salmins. Zeitschr. physiol. Chem., 40, 3rr-315.

Kossel, A. [1905]. Einige Bemerkungen über die Bildung der Protanine im Tierkorper. Zeitschr. physiol. Chem., 44, 347-352.

Kossel, A. [1906]. Ueber das Scombrin. Zeitschr. physiol. Chem., 49, 3 ro-3rr.

Kossel, A. [19ro]. Zur Chemie der Protamine. Zeitschr. physiol. Chem., 69, 138-142.

Kossel, A. [19r3]. Witere Mitteilungen über die Proteine der Fischspermien Zeitschr. physiol. Chem., 88, 163-185.

Kossel, A., Und H. D. Dakin [1903-4]. Beiträge zum System der einfachsten Eiweisskörper. Zeitschr. physiol. Chem., 40, 565-57 r.

Kossel, A., Und H. D. DakIN [1904]. Ueber Salmin und Clupein.

Zeitschr. physiol. Chem., 4r, 407-4r5.

Kossel, A., und H. D. Dakin [I905]. Weitere Beiträge zum System der einfachsten Eiweisskörper.

Zeitschr. physiol. Chem., 44, 342-346.

Kossel, A., UND F. EdLbacher [1913]. Ueber einige Spaltungsprodukte des Thynnins und Percins.

Zeitschr. physiol. Chem., 88, r86-189.

Kossel, A., UND Fr. Kutscher [1900-1]. Beiträge zur Kenntniss der Eiweisskörper. Zeitschr. physiol. Chem., 3I, r65-2I4.

Kurajeff, D. [1898-99]. Ueber das Protamin aus dem Spermatozoen der Makrele. Zeitschr. physiol. Chem., 26, 524-534.

Malenück, W. D. [1908]. Zur Chemie der Protamine.

Zeitschr. physiol. Chem., 57, 99-r12.

Miescher, FR. [1874]. Das Protamin, eine neue organische Basis aus dem Samenfäden des Rheinlachses.

Ber. Deutsch. Chem. Ges., 7, 376-379.

Morkowin, N. [1899]. Ein Beitrag zur Kenntniss der Protamine. Zeitschr. physiol. Chem., 28, 313-317.

Piccard, J. [1874]. Ueber Protamin, Guanin und Sarkin, als Bestandtheile des Lachsspermas.

Ber. Deuts:h. Chem. Ges., 7, I714-r7rg.

TAYLOR, A. E. [1908-9]. On the Composition and Derivation of Protamin. J. Biol. Chem., 5, 389-398.

UlPIANI, C. [1902]. Sulla base proteica dello sperma di tonno. Gaz. chim. ital., 32, ii, 215-234.

WeIss, F. [1907]. Untersuchungen über die Bildung des Lachsprotamins. Zeitschr. physiol. Chem., 52, 107-I20. 


\section{I5O THE CHEMICAL CONSTITUTION OF THE PROTEINS}

\section{Histones.}

Abderhalden, E. [1903]. Hydrolyse des Krystallisirten Oxyhaemoglobins aus Pferdeblut. Zeitschr. physiol. Chem., 37, 484-494.

Abderhalden, E., und L. Baumann [1907]. Die Monoaminosäuren des Krystallisierten Oxyhaemoglobins aus Hundeblut. Zeitschr. physiol. Chem., 5I, 397-403.

Abderhalden, E., und F. Medigreceanu [1909]. Beitrag zur Kenntnis des Oxyhaemoglobins verschiedener Tierarten. Zeitschr. physiol. Chem., 59, r65-r69.

Abderhalden, E., und P. Rona [1904]. Die Abbauprodukte des "Thymushistons". Zeitschr. physiol. Chem., 4I, 278-283.

BANG, I. [1899]. Studien über Histon. Zeitschr. physiol. Chem., 27, 463-486.

EHRSTRÖM, R. [Igor]. Ueber ein neues Histon aus Fischsperm 7. Zeitschr. physiol. Chem., 32, 350-354.

Fischer, E., Und E. AbDerhalden [1902]. Hydrolyse des Oxyhaemoglobins durch Salzsäure. Zeitschr. physiol. Chem., 36, 268-276.

Kossel, A. [1883-84]. Ueber einen peptonartigen Bestandtheil des Zellkerus. Zeitschr. physiol. Chem., 8, 511-5I5.

Kossel, A. [1906]. Ueber Protamine und Histone. Zeitschr. physiol. Chem., 49, 307.

Kossel, A., Und Fr. Kutscher [1900-I]. See under Protamines.

KUTSCHER, Fr. [1903]. Beiträge zur Kenntnis der Eiweisskörper. II. Zeitschr. physiol. Chem., 38, III-I34.

LiLienfeld, L. [1894]. Zur Chemie der Leucocyten. Zeitschr. physiol. Chem., 18, 473-486.

Matthews, A. [1897]. Zur Chemie der Spermatozoen. Zeitschr. physiol. Chem., 23, 399-4II.

Miescher, Fr. [I874]. Die Spermatozoen einiger Wiebelthiere.

Die Histochemischen und Physiologischen Arbeiten. Band I. F. C. W. Vogel, Leipzig, 1897 .

Pröscher, Fr. [1899]. Ein Beitrag zur Evforschung der Constitution des Eiweissmoleküls. Zeitschr. physiol. Chem., 27, II4-I22.

Schulz, Fr. N. [1898]. Der Eizeisskörper des Hämoglobins. Zeitschr. physiol. Chem., 24, 449-48r. 


\section{Albumins.}

ABderhalden, E. [1902-3]. Hydrolyse des Krystallisirten Serumalbumins aus Pferdeblut. Zeitschr. physiol. Chem., 37, 495-498.

Abderhalden, E. [1906]. Nachtrag. Zeitschr. physiol. Chem., 48, 5 I8.

Abderhalden, E., und A. Hunter [1906, r]. Vorläufige Mitteilung über den Gehalt der Eiweisskörper der Milch an Glykokoll. Zeitschr. physiol. Chem., 47, 404-406.

Abderhalden, E., und F. PREgL [1905, 2]. Die Monoaminosäuren des Krystallisierten Eieralbumins.

Zeitschr. physiol. Chem., 46, 24-30.

Abderhalden, E., und H. Pribram [1907]. Die Monoaminosäuren des Albumins aus Kuh. milch.

Zeitschr. physiol. Chem., 5I, 409-4I4.

Abderhalden, E., und A. Schittenhelm [1906]. See under Phosphoproteins. Caseinogen.

Abderhalden, E., und Slavu [rgog]. Vergleichende Untersuchung ïber den Gehalt der Serumeiweisskörper verschiedener Blutarten an Tyrosin, Glutaminsäure und an Glykokoll.

Zeitschr. physiol. Chem., 59, 247-248.

Chapman, H. G., And J. M. Petrie [I909]. The Hexone Bases from Egg-White.

J. Physiol., 39, 34I-345.

Hugouneno, L., et J. Galimard [1906]. Sur les acides diaminés dérivés de l'ovalbumine. Compt. rend., $143,242-243$.

HugounenQ, L., Et A. MoRel [1906]. See under References to Introduction.

Mörner, K. A. H. [IgoI-2]. Zur Kenntniss der Bindung des Schwefels in den Proteinstoffen.

Zeitschr. physiol. Chem., 34, 207-338.

Osborne, T. B., D. Breese Jones and C. S Leavenworth [Igog]. Hydrolysis of Cry. stallized Albumin from Hen's Egg.

Amer. J. Physiol., 24, 252-262.

Osborne, T. B., D. D. van Slyke, C. S. Leavenworth and M. Vinograd [Igr5]. Some Products of Hydrolysis of Gliadin, Lactalbumin and the Protein of the Rice Kernel. J. Biol. Chem., 22, 259-280.

\section{Globulins.}

Abderhalden, E. [1905]. Abbau und Aufbau der Eiweisskörper im tierischen Organismus. Hydrolyse des Serumglobulins.

$Z$ eitschr. physiol. Chem., 44, 17-52.

Abderhalden, E., und O. Rostoski [1905, 2]. Beitrag zur Kenntnis des Bence-Fones'chen Eiweisskörpers.

Zeitschr. physiol. Chem., 46, 125-r35.

Abderhalden, E., und F. Samuely [1905, 2]. Beitrag zur Frage nach der Assimilation des Nahrungseiweiss im tierischen Organismus.

Zeitschr. physiol. Chem., 46, 193-200.

Abderhalden, E., und Slavu [rgog]. See above, under Albumins.

ABderhalden, E., und A. Vorrinovicr [1907,3]. Weitere Beiträge zur Kenntnis der Zusammensetzung der Proteine. II. Hydrolyse des Blutfibrins.

Zeitschr. physiol. Chem., 52, 371-374.

Hopkins, F. G., And H. Savory [rgir]. A Study of Bence-Fones Protein, and of the Metabolism in Three Cases of Bence-Fones Proteinuria.

J. Physiol., 42, 189-250.

Levene, P. A., and D. D. Van Slyke [1908, 2]. Hydrolyse von Wittepeptone.

Biochem. Zeitschr., 13, 440-457.

Mörner, K. A. H. [Igor-2]. See above, under Albumins.

Neuberg, C., und N. Popowsky [1907]. See under References to Isolation and Estimation of Tryptophan. 


\title{
I52 THE CHEMICAL CONSTITUTION OF THE PROTEINS
}

\author{
The Vegetable Proteins.
}

Albumins.

Osborne, T. B., and S. H. Clapp [1906]. The Chemistry of the Protein Bodies of the Wheat Kernel. III. Hydrolysis of the Wheat Proteins.

Amer. J. Physiol., r7, 23 r-265.

Osborne, T. B., And F. W. Heyl $[\mathrm{Ig08,3]}$. Hydrolysis of Legumelin from the Pea. J. Biol. Chem., 5, 197-205.

Globulins (crystallised).

AbDerhalden, E. [1902]. Hydrolyse des Edestins.

Zeitschr. physiol. Chem., 37, 499-505.

Abderhalden, E. [1903]. Nachtrag zur Hydrolyse des Edestins.

Zeitschr. physiol. Chem., 40, 249-250.

Abderhalden, E., und O. Berghausen [rgo6]. Die Monoaminosäuren von aus Kürbissamen dargestelltem Krystallinischen Eiweiss.

Zeitschr. physiol. Chem., 49, 15-20.

Abderhalden, E., und B. Reinbold [1905]. Die Monoaminosäuren des "Edestins" aus Sonnenblumensamen und dessen Verhalten gegen Pankreasseft.

Zeitschr. physiol. Chem., 44, 284-293.

Abderhalden, E., und O. Rostoski [1905, I]. Die Monoaminosäuren des "Edestins" aus Baumwollsamen und dessen Verhalten gegen Magensaft.

Zeitschr. physiol. Chem., 44, 265-275.

Kossel, A., und A. J. Patten [1903]. Zur Analyse der Hexonbasen.

Zeitschr. physiol. Chem., 38, 39-45.

Osborne, T. B., and S. H. Clapp [1907, 2]. Hydrolysis of Excelsin. Amer. J. Physiol., I9, 53-6o.

Osborne, T. B., And S. H. ClapP $[1907,6]$. Hydrolysis of the Crystalline Globulin of the Squash Seed.

Amer. J. Physiol., I9, 475-48r.

Osborne, T. B., ANd R. D. Gilbert [1906]. See under Isolation and Estimation of the other Mono-amino Acids.

Osborne, T. B., AND L. M. Lidde [19ro, r]. Notes on the Analysis of Edestin and Zein. Amer. J. Physiol., 26, 295-304.

Schulze, E., und E. Winterstein [Igor, I]. Ueber die Ausbeute an Hexonbasen, die aus einigen pflanzlichen Eiweissstoffen $z$ u erhalten ist.

Zeitschr. physiol. Chem., 33, 547-573. 
GLoBULins (amorphous).

Abderhalden, E. [1906]. Anmerkung.

Zeitschr. physiol. Chem., 47,358 .

Abderhalden, E., UND B. Babkin [1906]. Die Monoaminosäuren des Legumins.

Zeitschr. physiol. Chem., 47, 354-358.

Abderhalden, E., und J. B. Herrick [1905]. Beitrag zur Kenntnis der Zusammensetzung des Conglutins aus Samen von Lupinus. Zeitschr. physiol. Chem., 45, 479-485.

Abderhalden, E., Und Y. TeruUchi [1905, I]. Die Zusammensetzung von aus Kiefernsamen dargestelltem Eiweiss.

Zeitschr. physiol. Chem., 45, 473-478.

Foreman, W. [rgrr]. Hydrolysis of the Protein of Linseed. J. Agric. Science, 3, 358-382.

Johns, C. O., AND D. B. Jones [rgr 7]. See under References to Analysis of Proteins by Distribution of Nitrogen.

Osborne, T. B., and S. H. Clapp [r907, r]. Hydrolysis of Phaseolin. Amer. J. Physiol., 18, 295-308.

Osborne, T. B., and S. H. Clapp $[1907,4]$. Hydrolysis of Legumin from the Pea. J. Biol. Chem., 3, 219-225.

Osborne, T. B., and S. H. Clapp [1907, 5]. Hydrolysis of Glycinin from the Soy Bean. Amer. J. Physiol., I9, 468-474.

Osborne, T. B., and S. H. Clapp $[\mathrm{rg07}, 7]$. Hydrolysis of Amandin from the Almond. Amer. J. Physiol., 20, 470-476.

Osborne, T. B., And F. W. Heyl [1908, I]. Hydrolysis of Vignin of the Cow-Pea (Vigna Sinensis).

Amer. J. Physiol., 22, 362-372.

Osborne, T. B., and F. W. Heyl [1908, 2]. Hydrolysis of Vicilin from the Pea (Pisum Sativum).

J. Biol. Chem., 5, 187-195.

Osborne, T. B., and F. W. Heyl [1908, 4]. Hydrolysis of Vetch Legumin. Amer. J. Physiol., 22, 423.432.

Schulze, E., und E. Winterstein [1gor, I]. Ueber die Ausbeute an Hexonbasen, die aus einigen pflanzlichen Eiweissstoffen zu erhalten ist.

Zeitschr. physiol. Chem., 33, 547-573.

Sjollema, B., und I. J. Rinkes [IgII-I2]. Die Hydrolyse des Kartoffeleiweisses. Zeitschr. physiol. Chem., 76, 369-384.

Yoshimura, K. [rgro]. Ueber das Eiweiss aus Samen von Pinus Koraienis Sieb. et Zucc. Zeitschr. Nahr. Genussm., I9, 257-260. 
Gliadins.

Abde Rhalden, E., und F. Samuely [1905, r]. Die Zusammensetzung des " Gliadins" des Weizenmehles.

Zeitschr. physiol. Chem., 44, 276-283.

AbDerhalden, E., und F. SAmuely [1905, 2]. Beitrag zur Frage nach der Assimilation des Nahrungseiweiss im tierischen Organismus.

Zeitschr. physiol. Chem., 46, 193-200.

Johns, C. O., AND J. F. BREwSter [IgI6]. See under References to Distribution of Nitrogen in Proteins.

KLeinschmitt, A. [1907]. Hydrolyse des Hordeins. Zeitschr. physiol. Chem., 54, II0-118.

Kossel, A., UND Fr. KUTSCher [Igot-2]. Beiträge zur Kenntniss der Eiweisskörper. I. Zeitschr. physiol. Chem., 31, r65-214.

Kutscher, F. [1903]. Beiträge zur Kenntniss der Eiweisskörper. II. Zeitschr. physiol. Chem., 38, II I-134.

LANGStein, L. [1903]. Hydrolyse des Zeins durch Salzsäure. Zeitschr. physiol. Chem., 37, 508-512.

Osborne, T. B., AND S. H. Clapp [1906]. See under Vegetable Albumins.

Osborne, T. B., AND S. H. Clapp [1907, 3]. Hydrolysis of Hordein. Amer. J. Physiol., 19, II7-124.

Osborne, T. B., ANd S. H. Clapp [1907, 8]. Hydrolysis of the Proteins of Maize, Zea Mays.

Amer. J. Physiol, 20, 477-493.

Osborne, T. B., AND S. H. Clapp [1907, 9]. The Hydrolysis of Gliadin from Rye. Amer. J. Physiol., 20, 494-499.

Osborne, T. B., And H. H. Guest [IgII, 2]. Analysis of the Products of Hydrolysis of Wheat Gliadin.

J. Biol. Chem., 9, 425-438.

Osborne, T. B., AND L. M. LiddLe [rgro, I]. See under Vegetable Globulins (crystallised).

Osborne, T. B., and C. S. Leavenworth [Igr3]. Do Gliadin and Zein Yield Lysine? J. Biol. Chem., 14, 481-488.

Osborne, T. B., D. D. Van Slyke, C. S. Leavenworth and M. Vinograd [Igi5]. Some Products of Hydrolysis of Gliadin, Lactalbumin and the Protein of the Rice Kernel. J. Biol. Chem., 22, 259-280.

Suzuki, U., K. Yoshimura and S. Fuji [rgog]. Proteins of Rice Seeds.

J. Coll. Agric., Tokyo, I, 77-88; J. Chem. Soc. Abs., I909, ii, 927.

\section{Glutelins.}

Abderhalden, E., und Y. HämäläInen [1907]. Die Monoaminosäuren des Avenins. Zeitschr. physiol. Chem., 52, 515-520.

Abderhalden, E., UNd F. Malengreau [1906]. Die Monoaminosäuren des Glutens. Zeiţschr. physiol. Chem., 48, 513-5I8.

Kossel, A., AND F. KUtscher [rgor-2]. See under Gliadins.

Osborne, T. B., And S. H. Clapp [1906]. See under Vegetable Albumins.

Osborne, T. B., and S. H. Clapp $\left[\mathrm{rgO}^{7}, 8\right]$. See under Gliadins.

Osborne, T. B., D. D. Van Slyke, C. S. Leavenworth and M. Vinograd [1915]. See under Gliadins. 


\section{PHOSPHOPROTEINS.}

\section{Caseinogen.}

ABderhalden, E. [1905]. Abbau und Aufbau der Eiweisskörper im tierischen Organismus. Zeitschr. physiol. Chem., 44, 17-52.

Abderhalden, E., Und A. Schittenhelm [1906]. Vergleichung der Zusammensetzung des Caseins aus Frauen-, Kuh- und Ziegenmilch. Zeitschr. physiol. Chem., 47, 458-465.

Abderhalden, E., und L. Langstein [rgro]. Vergleichende Untersuchung des Caseins aus Frauen- und Kuh milch. Zeitschr. physiol. Chem., 66, 8-г2.

Fischer, E. [Igor]. Ueber die Hydrolyse des Caseins durch Salzsäure. Z eitschr. physiol. Chem., 33, I5 I-I76.

Fischer, E. [1903]. Nachtrag zur Hydrolyse des Caseins und Seidenfibroimns durch Säuren.

Z eitschr. physiol. Chem., 39, I55-I58.

Fischer, E., UND E. ABDERH 4 LDEN [I904]. Notizen iiber Hydrolyse von Proteinstoffen.

I. Hydrolyse des Caseins (Diaminotrioxydodecansäure).

$Z$ eitschr. physiol. Chem., 42, 540-544.

Foreman, F. W. [unpublished]. Studies in Protein Hydrolysis.

HART, E. [rgor]. Ueber die quantitative Bestimmung der Spaltungsprodukte von Eiweisskörpern.

Zeitschr. physiol. Chem., 33, 347-362.

Mörner, K. A. H. [Igor-2]. Zur Kenntniss der Bindung des Schwefels in den Proteinstöffen.

Zeitschr. physiol. Chem., 34, 207-338.

Hopkins, F. G., AND S. W. Cole [rgor, 2]. A Contribution to the Chemistry of the Proteins. Part I. A Preliminary Study of a Hitherto Undescribed Product of Tryptic Digestion.

I. Physiol., 27, 4r8-428.

Osborne, T. B., And H. H. Guest [IgII, I]. Hydrolysis of Casein.

J. Biol. Chem., 9, 333-353.

Skraup, Zd. H. [r905]. Ueber den Gehalt des Caseins an Glykokoll und Alanin. Monatsh. f. Chem., 26, 1343-1349.

WeItzenböck, R. [1906]. Ueber das Vorkommen von Isoleucin im Kasein. Monatsh. f. Chem., 27, 83 I-837.

Vitellin, etc.

Abderhalden, E., und A. Hunter [1906, 2]. Hydrolyse des im Eigelb des Hühnereies enthaltenen Proteins ("Vitellin").

Zeitschr. physiol. Chem., 48, 505-512.

ABDERHALden, E., UND M. KEMPE [I907, 2]. Vergleichende Untersuchung über den Gehalt von befruchteten Hïhnereien in verschiedenen Entwicklungsperioden an Tyrosin, Glykokoll und an Glutaminsäure. Zeitschr. physiol. Chem., 53, 398-402.

Galimard, J. [1904]. Sur une albumine extraite des oenfs de grenouille. Compt. rend., I38, 1354-1355.

Hedin, S. G. [1895-96]. Ueber die Bildung von Arginin aus Proteinkörpern. Zeitschr. physiol. Chem., 2r, r55-r68.

Hugouneng, L. [1904]. Sur une albumine extraite des oeufs de poissons; chimie comparée des productions sexuelles dans la même expèce. Compt. rend., 138, ro62-1064.

HugounenQ, L. [1906]. Recherches sur la Vitelline. Ann. Chim. Phys., [8], 8, II5-139; Compt. rend., I42, I426-I428.

Levene, P. A., ANd C. L. Alsberg [Ig06]. The Cleavage Products of Vitellin. J. Biol. Chem., 2, r27-133.

Osborne, T. B., And D. BREESE Jones [Igog, r]. Hydrolysis of Vitellin from the Hen's Egg. Amer. J. Physiol., 24, 153-160. 


\title{
I56 THE CHEMICAL CONSTITUTION OF THE PROTEINS
}

\author{
SCLEROPROTEINS.
}

Silk.

Abderhalden, E. [1908, r]. Die Monoaminosäuren des "Byssus" von Pinna nobilis L. Zeitschr. physiol. Chem., 55, 236-240.

ABDeRHALDEn, E. [1908, 2]. Vergleichende Untersuchungen über die Zusammensetzung und den Aufbau verschiedener Seidenarten.

Zeitschr. physiol. Chem., 58, 334-336.

Abderhalden, E. [Igrr]. Weiterer Beitrag zur Kenntnis der Zusammensetzung verschiedener Seidenarten. XIII.

Zeitschr. physiol. Chem., 74, 427-428.

ABDERHALden, E., UND L. Behrend [1909]. Vergleichende Untersuchungen über die Zusammensetzung und den Aufbau verscheidener Seidenarten. II. Die Monoaminosäuren aus Canton-Seide.

Zeitschr. physiol. Chem., 59, 236-238.

AbDeRhalden, E., und C. BRAHM [1909]. Vergleichende Untersuchungen über die Zusammensetzung und den Aufbau verschiedener Seidenarten. III. Die Monoaminosäuren aus Shantung-Tussah-Seide.

Zeitschr. physiol. Chem., 6r, 256-258.

ABderhalden, E., und G. A. BRossa [1909]. Vergleichende Untersuchungen über die Zusammensetzung und den Aufbau verschiedener Seidenarten. V. Die Mono. aminosäuren aus "Niet-ngō Tsam" Seide (China).

Zeitschr. physiol. Chem., 62, 129-r30.

Abderhalden, E., und H. R. Dean [19og]. Studien über die Bildung der Seide.

Zeitschr. physiol. Chem., 59, I70-173.

Abderhalden, E., und R. Inouye [1912]. Weiterer Beitrag zur Kenntnis der Zusammensetzung verschiedener Seidenarten. XIV. Ergebnisse der totalen und partiellen Hydrolyse des Kokons des Ailanthusspinners und von Tailung-Seide.

Zeitschr. physiol. Chem., 80, I98-204.

Abderhalden, E., und B. Landau [IgrI, r]. Ueber die Zusammensetzung des Gespintes von Oeceticus platensis (Berg).

Zeitschr. physiol. Chem., 71, 443-448.

AbdeRhalden, E., und A. Rilliet [1908]. Vergleichende Untersuchungen über die Zusammensetzung und den Aufbau verschiedener Seidenarten. I. Die Monoaminosäuren der "New-Chwang-Seide."

Zeitschr. physiol. Chem., 58, 337-340.

ABderhalden, E., UND J. Schmid [IgIo]. Vergleichende Untersuchungen über die Zusam. mensetzung und den Aufbau verschiedener Seidenarten. VIII. Die Monoaninosäuren aus "Tai-Tsao-Tsam" Seide (China).

Zeitschr. physiol. Chem., 64, 460-46r.

ABDERHALDEN, E., UND J. Sington [1909]. Vergleichende Untersuchungen über die Zusammensetzung und den Aufbau verschiedener Seidenarten. IV. Die Monoaminosäuren aus Bengal-Seide.

Zeitschr. physiol. Chem., 6I, 259-260.

ABderhalden, E., und W. SPACK [I909]. Vergleichende Untersuchungen über die Zusam. mensetzung und den Aufbau verschiedener Seidenarten. VI. Die Monoaminosäuren aus Indischer-Tussah.

Zeitschr. physiol. Chem., 62, 131-132.

ABderhalden, E., und E. WALDE [19ro]. Vergleichende Untersuchungen über die Zusammensetzung und den Aufbau verschiedener Seidenarten. IX. Die Monoaminosäuren aus Chefoo-Seide.

Zeitschr. physiol. Chem., 64, 462-463.

Abderhalden, E., und W. Weichardt [Igog]. Die Monoaminosäuren des Körpers des Seidenspinners.

Zeitschr. physiol. Chem., 59, 174-176.

ABdrRhalden, E., und Worms [1909]. Vergleichende Untersuchungen über die Zusammensetzung und den Aufbau verschiedener Seidenarten. VII. Die Monoaminosäuren aus dom Leim der Canton-Seide.

Zeitschr. physiol. Chem., 62, I42-I44. 
Fischer, E. [I903]. Nachtrag Zur Hydrolyse des Caseins und Seidenfibroins durch Säuren. Zeitschr. physiol. Chem., 39, I55-158.

Fischer, E. [1907]. Uber Spinnenseide.

Zeitschr. physiol. Chem., 53, 126-r 39.

Fischer, E., UND A. Skita [rgor]. Ueber das Fibroin der Seide.

Zeitschr. physiol. Chem., 33, I77. 192.

Fischer, E., und A. Skita [I902]. Ueber des Fibroin und den Leim der Seide. Zeitschr. physiol. Chem., 35, 22 I-226.

Inouye, R. [19ro]. Experiments with Bombyx Mori. J. Coll. Agric. Tokyo, 2, 223-235; Chem. Centr., I9ro, II, Ir46.

Inouye, R. [rgr2]. Composition of the Silkworm at Different Stages of its Metamorphosis. J. Coll. Agric. Tokyo, 5, 67-79; Chem. Centr., r9r3, i, r296.

Katayma, Y. [19r6]. Nitrogen Compounds of Mulberry Leaves.

J. Chem. Soc. Abs., rgr6, i, 875 .

Pigorini, L. [I9I5]. Amino Acids and the Formation of Silk in the Larva of Bombyx Mori. Observations and Experiments with Amino-acetic Acid.

Arch. Farmacol. Sperim., 20, 225-258.

Chem. Centr., rgr6, I, r68-r69; J. Chem. Soc. Abs., rgr6, i, 525-526.

Roose, G. [rgro]. Vergleichende Untersuchungen über die Zusammensetzung und den Aufbau verschiedener Seidenarten. X. Die Monaminosäuren der Cocons der italienischen Seidenraupe.

Zeitschr. physiol. Chem., 68, 273-274.

STRAUCh, F. W. [IgII]. Vergleichende Untersuchungen über die Zusammensetzung und den Aufbau verschiedener Seidenarten. XII. Die Monaminosäuren aus der Leim der indischen Tussahseide.

Zeitschr. physiol. Chem., 7r, 365-366.

Suwa, A. [19ro]. Vergleichende Untersuchungen ïber die Zusammensetzung und den Aufbau verschiedener Seidenarten. XI. Die Monoaminosäuren der Cocons aus der Fapanischen Seide "Haruko".

Zeitschr. physiol. Chem., 68, 275-276.

Suzuki, U., K. Yoshimura and R. Inouye [rgog]. Hydrolysis of Wild Silk. J. Coll. Agric. Tokyo, r, 59-75 ; J. Chem. Soc. Abs., I9o9, i, 859-86o. 


\section{58 THE CHEMICAL CONSTITUTION OF THE PROTEINS}

Gelatin.

Fischer, E. [1902]. Ueber eine neue Aminosäure aus Leim.

Ber. Deutsch. chem. Ges., 35, 2660-2665.

Fischer, E., UND E. ABDeRhaLden [1904]. Notizen über Hydrolyse von Proteinstoffen.

II. Hydrolyse von Gelatine (Bildung von Serin).

$Z$ eitschr. physiol. Chem., 42, 540.544.

Fischer, E., und R. Boehner [rgro]. Bildung von Prolin bei der Hydrolyse von Gelatin mit Baryt.

Zeitschr. physiol. Chem., 65, I 18-123.

Fischer, E., P. A. LeVENe UND R. H. Aders [1902]. Ueber die Hydrolyse des Leims. Zeitschr. physiol. Chem., 35, 70-79.

HART, E. [Igor]. Ueber die quantitative Bestimmung der Spallungsprodukte von Eiweisskörpern.

Zeitschr. physiol. Chem., 33, 347-362.

Kossel, A., UND F. KUTSCher [1900-I]. Beiträge zur Kenntnis der Eiweisskörper. Z eitschr. physiol. Chem., 3I, I65-226.

Levene, P. A., Und W. A. Beatty [1906]. Analyse der Spaltungsprodukte der Gelatine. Zeitschr. physiol. Chem., 49, 252-26r.

SkRAUP, ZD. H., UND A. v. BIEHLER [I909]. Ueber die Zusammensetzung der Gelatine. Monatsh. f. Chem., 30, 467-48o.

Skraup, ZD. H., UNd F. Heckel [1905]. Ueber Gelatin. II. Monatsh. f. Chem., 26, 1351-1358.

\section{Elastin.}

Abderhalden, E., und A. Schittenhelm [1904]. Die Abbauprodukte des Elastins. Z eitschr. physiol. Chem., 4I, 293-298.

BrRGH, E. [1898]. Untersuchungen über die basischen Spaltungsprodukte des Elastins beim Kochen mit Salzsäure.

Zeitschr. physiol. Chem., 25, 337-343.

Hedin, S. G. [1898]. Einige Bemerkungen über die basischen Spaltungsprodukte des Elastins.

Zeitschr. physiol. Chem., 25, 344-349.

Horbaczrwski, J. [1885]. Ueber die durch Einwirkung von Salzsäure aus den Albuminoiden entstehenden Zersetzungsproducte. II.

Ber. der Kais. Akad. der Wiss. Math.-Nat. Classe, 92, II, 657-668.

Kossel, A., und F. Kutscher [1898]. Ueber die Bildung von Arginin aus Elastin. Zeitschr. physiol. Chem., 25, 55 I-552.

Kossel, A., UND F. KutScher [Igoo-I]. See under Spongin.

SchWARZ, H. [1894]. Untersuchungen über die chemische Beschaffenheit der elastischen Substanz der Aorta.

Zeitschr. physiol. Chem., 18, 487-507.

Spongin.

Abderhalden, E., und E. Strauss [rgo6, r]. Die Spaltprodukte des Spongins mit Säuren. Zeitschr. physiol. Chem., 48, 49-53.

Kossel, A., uńd F. Kutscher [I900-I]. Beiträge zur Kenntnis der Eiweisskörper. Zeitschr. physiol. Chem., 3I, I65-226. 


\section{Keratins.}

Abdrrhalden, E., und E. Ebstein [1906]. Die Monoaminosäuren der Schalenhaut des Hühnereies.

Zeitschr. physiol. Chem., 48, 530-534.

ABDerhalden, E., UND D. Fuchs [1908]. Der Gehalt verschiedener Keratinarten an Glutaminsäure. (Ein Beitrag zur Kenntnis der Keratinsubstanzen.)

Zeitschr. physiol. Chem., 57, 339-34I.

AbDerhalden, E., und B. Landau [IgIr, 2]. Zur Kenntnis der Monoaminosäuren der Barten des Nordwales.

Zeitschr. physiol. Chem., 7I, 455-465.

AbDerhalden, E., und E. R. Le Count [1905]. Die Monoaminosäuren des Kcratins aus Gänsefedern.

Zeitschr. physiol. Chem., 46, 40-46.

Abderhalden, E., und E. Strauss [1906, 2]. Die Monoaminosäuren des Keratins aus Eiern von Testudo Graeca.

Zeitschr. physiol. Chem., 48, 535-536.

ABDERHALDEN, E., UND A. VoITINovici [1907, I]. Hydrolyse des Keratins aus Horn und aus Wolle.

Zeitschr. physiol. Chem., 52, 348-367.

AbDerhalden, E., Und A. VoItinovici [1907, 2]. Weitere Beiträge zur Kenntnis der Zusammensetzung der Proteine. I. Hydrolyse des Ichthylepidins aus den Schuppen von Cyprinus Carpio (Karpfen).

Zeitschr. physiol. Chem., 52, 368-37r.

Abderhalden, E., und H. G. Wells [1905]. Die Monoaminosäuren des Keratins aus Pferdehaaren.

Zeitschr. physiol. Chem., 46, 3r-39.

ARgIRIs, A. [1907]. Zur Kenntnis des Neurokeratins.

Zeitschr. physiol. Chem., 54, 86-94.

Buchtala, H. [1907]. Ueber das Mengenverhältnis des Cystins in verschiedenen Hornsubstanzen.

Zeitschr. physiol. Chem., 52, 474-48r.

Buchtala, H. [Igo8]. Elementaranalyse der Eihäute von Scyllium stellare, Pristiurus melanostomis und Scyllium canicula und Verteilung des Stickstoffes in denselben. Zeitschr. physiol. Chem., 56, rr-17.

Buchtala, H. [I9II]. Ueber das Schildpati von Chelone imbricata. Zeitschr. physiol. Chem., 74, 212-220.

Buchtala, H. [rgr2]. Ueber das Keratin der Elefanten-Epidermis. Zeitschr. physiol. Chem., 78, 55-6r.

Buchtala, H. [1913, I]. Ueber das Keratin der Schuppen von Manis japonica (Schuppentier). Zeitschr. physiol. Chem., 85, 24r-245.

Buchtala, H. [1913, 2]. Ueber das Keratin der weissen Menschenhaare. Zeitschr. physiol. Chem., 85, 246-249.

Buchtala, H. [1913, 3]. Ueber das Keratin von Schlangenhäuten. (Boa constrictor und Python). Zeitschr. physiol. Chem., 85, 335-340.

Conn, R. [1898-99]. See under References to Hydrolysis.

Fischer, E., Und Th. Dörpinghaus [1902]. Hydrolyse des Horns. Zeitschr. physiol. Chem., 36, 462-477.

HEDIN, S. G. [1895]. Ueber ein neues Spaltungsproduct des Hornsubstanzes. Zeitschr. physiol. Chem., 20, r86-rg2.

Hedin, S. G. [1895-96]. Ueber die Bildung von Arginin aus Proteinkörper. Zeitschr. physiol. Chem., 21, 155-168.

Hofmann, K. B., Und F. PRegl [1907]. Ueber Koilin. Zeitschr. physiol. Chem., 52, 448-47 I.

HoRBACZkWSKI, J. [1885]. See above, under Elastin.

KNAFFL-Lenz, E. v. [Igo7]. Ueber die Diaminosäuren des Koilins. Zeitschr. physiol. Chem., 52, 472-473.

MÖRNER, K. A. H. [IgOI-2]. Zur Kenntniss der Bindung des Schwefels in der Proteinstoffen. Zeitschr. physiol. Chem., 34, 207-338.

PREGL, F. [Ig08, I]. Ueber die Eihäute von Scyllium stellare Günth. und ihre Abbauprodukte. Zeitschr. physiol. Chem., 56, I-Io. 


\section{VARIOUS PROTEINS.}

Abderhalden, E. [1905]. See under Phosphoproteins-Caseinogen.

Abderhalden, E., und C. BRahm [1909, 2]. Ueber den Gehalt der Muskelsubstanz ägypti. scher Mumien an Monoaminosäuren. I.

Zeitschr. physiol. Chem., 6r, 4r9-420.

Abderhalden, E., und F. Medigreceanu [rgro]. Beitrag zur Kenntnis der Bausteine der Zellen von Tumoren.

Zeitschr. physiol. Chem., 69, 66-7r.

Abderhalden, E., UNd F. PRegl [ $1905, \mathrm{r}]$. Ueber einem im normalen menschlichen Harn vorkommenden, schwer diaylsierbaren Eiweissabkömmling.

Zeitschr. physiol. Chem., 46, 19-23.

Abderhalden, E., und P. Rona [1905]. Die Zusammensetzung des "Eiweiss" von Aspergillus niger bei verschiedener Stickstoffquelle.

Zeitschr. physiol. Chem., 46, 179-186.

Abderhalden, E., und W. Völtz [1909]. Beitrag zur Kenntnis der Zusammensetzung und der Natur der Hüllen der Milchkügelchen.

Zeitschr. physiol. Chem., 59, 13-18.

Abderhalden, E., UNd A. WeIL [Igrr, r]. Ueber den Gehalt ägyptischer Mumien an Eiweiss und Eiweiss-Abbauprodukten.

Zeitschr. physiol. Chem., 72, 15-23.

AbDerhalden, E., UND A. WeIL [1912, 2]. Vergleichende Untersuchungen über den Gehalt der verschiedenen Bestandteile des Nervensystems an Aminosäuren. I. Die Aminosäuren der peripheren Nerven und der Leitungsbahnen des Rückenmarks (weisse Substanz).

Zeitschr. physiol. Chem., 8r, 207-225.

AbDeRhalden, E., UND A. WeIL [1913, $\mathrm{r}]$. Vergleichende Untersuchungen über den Gehalt der verschiedenen Bestandteile des Nervensystems an Aminosäuren. II. Die Aminosäuren der grauen und weissen Substanz des Gehirns.

Zeitschr. physiol. Chem., 83, 425-440.

ABderhalden, E., und A. Weil [1913, 2]. Ueber eine neue Aminosäure von der Zusammensetzung $\mathrm{C}_{6} \mathrm{H}_{13} \mathrm{NO}_{2}$, gewonnen bei der totalen Hydrolyse der Proteine aus Nervensubstanz.

Z eitschr. physiol. Chem., 84, 39-59.

Abderhalden, E., und A. WeIL [1913, 3]. Ueber die Identifizierung der aus Proteinen der Nervensubstanz gewonnenen Aminosäure von der Zusammensetzung $\mathrm{C}_{6} \mathrm{H}_{13} \mathrm{NO}_{2}$. II. Zeitschr. physiol. Chem., 88, 272-275.

Emmerling, O. [I9og]. Hydrolyse der Meerleuchtinfusiorien der Nordsee (Noctiluca miliaris).

Biochem. Zeitschr., 18, 372-374.

HugounenQ, L., Et A. Morel [Igo8]. Contribution à l'étude de la constitution des nucleoproteides. Recherches sur les constituants de la pepsine.

Compt. rend., I47, 212-2I4.

Koelker, A. H., And J. M. Slemons [rgri]. The Amino Acids in the Mature Human Placenta.

J. Biol. Chem., 9, 471-489.

Kotake, Y., UND F. KNOOP [rgrr]. Ueber einen krystallisiertan Eiweisskörper aus dem Milchsafte der Antiarias toxicaria.

Zeitsçhr. physiol. Chem., 75, 488-498.

Meisenheimer, J. [rgr5]. Die Stickstoffhaltigen Bestandteile der Hefe.

Woch. Brauerei, 32, 325-326; J. Chem. Soc. Abs., rgr6, i, 236.

Neuberg, C. [1904]. Ueber Amyloid.

Chem. Centr. r904, II, I576-1577.

Neuberg, C. [19r5]. Yeast Protein.

Woch. Brauerei 32, 317-320; J. Chem. Soc. Abs., rgr6, i., 5 13.

OMeliansky, W. L., und N. O. Sieber [1913]. Zur Frage nach der chemischen Zusammensetzung der Bakterienkörper des Azotobacter chroococcum.

Zeitschr. physiol. Chem., 88, 445-459. 
Osborne, T. B., And F. W. Heyl [rgo8, 5]. Hydrolysis of Chicken Meat. Amer. J. Physiol., 22, 433-439.

Osborne, T. B., ANd F. W. Heyl [1908, 6]. Hydrolysis of Fish Muscle. Amer. J. Physiol., 23, $8 \mathrm{r}-89$.

Osborne, T. B., And D. B. Jones [Igog, 2]. Hydrolysis of the Muscle of Scallop (Pecten irradians). Amer. J. Physiol., 24, r6r-r6g.

Osborne, T. B., AND D. B. Jones [19og, 3]. Hydrolysis of Ox muscle. Amer. J. Physiol., 24, 437-446.

Otori, J. [rgo4, r]. Die Spaltung des Pseudomucins durch starke siedende Säuren. I. Zeitschr. physiol. Chem., 42, 453-460.

Otori, J. [1904, 2]. Die Spaltung des Pseudomucins durch starke siedende Säuren. II. Zeitschr. physiol. Chem., 43, 74-85.

PREGL, F. [1908, 2]. Notiz über die Monoaminosäuren des Paramucins. Zeitschr. physiol. Chem., 58, 229-232.

Pringsheim, H. [Igr3]. Zur Totalhydrolyse der Hefeeiweisses. Woch. Brauerei, 30, 399-400 ; Chem. Centr., I9I3, II, r310.

TAmura, S. [rgr3, r]. Zur Chemie der Bakterien. I. Zeitschr. physiol. Chem., 87, 85-II4.

TAMURA, S. [1913, 2]. Zur Chemie der Bakterien. II. Zeitschr. physiol. Chem., 88, rgo-rg8.

Tamura, S. [IgI4, I]. Zur Chemie der Bakterien. III. Zeitschr. physiol. Chem., 89, 289-303.

TAMURA, S. [IgI4, 2]. Zur Chemie der Bakterien. V. Ueber die chemische Zusammensetzung eines Wasserbacillus.

Zeitschr. physiol. Chem., 90, 286-29o.

WohLgemuth, J. [1904]. Zur Hydrolyse des Leberproteids. Ber. Deutch. chem. Ges., 37, 4362-4364.

Wohlgemuth, J. [rgo5]. Ueber das Nucleoproteid der Leber. IV. Zeitschr. physiol. Chem., 44, 530-539. 


\section{Derivatives of Proteins.}

Abderhalden, E., und T. SASAKi [Ig07]. Die Monoaminosäuren des "Syntonins" aus Rindfleisch. Zeitschr. physiol. Chem., 51, 404-408.

HART, E. [Igor]. Ueber die quantitative Bestimmung der Spaltungsprodukte von Eizveisskörpern.

Zeitschr. physiol. Chem., 33, 347-362.

Haslam, H. C. [Igor]. Quantitative Bestimmung der Hexonbasen in Hetero-albumose und Pepton.

Zeitschr. physiol. Chem., 32, 54-58.

Dennstedt, M., und F. Hassler [1906]. Ueber den Abbau von Eiweiss. Zeitschr. physiol. Chem., 48, 489-504.

Gupta, N. [19og]. Ueber die Zusammensetzung der Produkte alkalischer Hydrolyse des Krystallisierten Ovalbumins. Monatsh. f. Chem., 30, 767-771.

LeVene, P. A. [1902-3]. Ueber die Spaltung der Gelatine. Zeitschr. physiol. Chem., 37, 8I-85.

LEVENe, P. A. [Igo4]. Ueber die Spaltung der Gelatine. II. Zeitschr. physiol. Chem., 4I, 8-I4.

Levene, P. A. [1905]. The Cleavage Products of Proteoses. J. Biol. Chem., I, 45-58.

Levene, P. A., und D. D. van Slyke [1908, 2]. Hydrolyse von Wittepeptone. Biochem. Zeitschr., 13, 440-457.

Levene, P. A., und D. D. van Slyke [1908, 3]. Ueber Plastein. Biochem. Zeitschr., 13, 458-474.

Levene, P. A., D. D. van Slyke and F. J. Birchard [19Io]. The Partial Hydrolysis of Proteins. II. On Fibrin-heteroalbumose. J. Biol. Chem., 8, 269-284.

Levene, P. A., D. D. VAN SlyKe ANd F. J. Birchard [IgIr]. The Partial Hydrolysis of Proteins. III. On Fibrin-protoalbumose.

J. Biol. Chem., ro, 57-71.

LAMPEL, H., UND $Z_{D}$. H. SKRAup [19og]. Über Hydrolyse des Serumglobulins durch Alkalien.

Monatsh. f. Chem., 30, 363.375.

SkRAup, ZD. H., UNd F. Hummelberger [1908]. Ueber einige Gelatosen. Monatsh. f. Chem., 29, 45I-469.

Skraup, $Z_{\text {D. }}$ H., und F. Hummelberger [Igog]. Ueber die Hydrolyse des Eiereiweisses mit Natronlange. Monatsh. f. Chem., 30, 125-146.

Skraup, $Z_{\text {D. }}$ H., und E. Krause [Igro, I]. Partielle Hydrolyse von Proteinen durch Schwefelsäure. Monatsh. f. Chem., 3r, 142-148.

SkRAup, $Z_{\mathrm{D}}$. H., und E. KRAUSe $[\mathrm{rg} \mathrm{I0}, 2]$. Ueber partielle Hydrolyse von Casein. Monatsh. f. Chem., 3I, I49-I64.

Skraup, Z D. H., UND R. Witt [Igo6]. Ueber Peptone aus Kasein. Monatsh. f. Chem., 27, 663-684.

SKRAUP, $Z_{\mathrm{D}}$. H., UND A. WöBER [Igog]. Ueber die partielle Hydrolyse von Edestin. Monatsh. f. Chem., 30, 289-3ro.

SKRAUP, ZD. H., UND R. Z WERGER [1905]. Zur Kenntnis der Kyrine. Monatsh. f. Chem., 26, I403-I4I4.

WeCHSLER, E. [19ro]. Zur Kenntnis des Hemielastins. Zeitschr. physiol. Chem., 67, 486-488. 


\section{REFERENCES TO ANALYSIS OF PROTEINS BY DISTRIBUTION OF NITROGEN.}

ANdersen, A. C., Und R. Roed-Müller [1915]. Zur Kenntniss der Eiweisskörper. III. $Z$ ur Bestimmung der Monoaminodicarbonsäuren.

Biochem. Zeitschr., 73, 326-339.

BENEDICT, S. R. [rgog-Io]. The Estimation of Total Sulphur in Urine. J. Biol. Chem., 6, 363-37r ; 8, 499-50r.

Brewster, J. F., AND C. L. Alsberg [IgI5]. Proc. Soc. Expt. Biol. Med. New York, 12, r92-193.

Brown, H. T. AND J. H. Millar [rgo3]. On the Sachsse-Kormann (Nitrous Acid) Method as Applied to the Determination of the Monoamino Acids and their Amides. Trans. Guinness Research Laboratory, I, 29-40.

Bywaters, H. W., AND D. G. C. TASker [1913-14]. On the Real Nature of the So-called Artificial Globulin. J. Physiol., 47, 149-158.

CHIск, H. [1914]. The Apparent Formation of Euglobulin from Pseudoglobulin and a Sug. gestion as to the Relationship between these Two Proteins in Serum. Biochem. J., 8, 404-420.

Chittranden, R. H., And A. C. Eustis [190o]. The Proportion of Basic Nitrogen yielded by Elastin on Decomposition with Hydrochloric Acid. Amer. J. Physiol., 3, Proc. xxxi.

Crowther, C., ANd H. Raistrick [rgr6]. A Comparative Study of the Proteins of the Colostrum and Milk of the Cow and their Relations to Serum Proteins. Biochem. J., I0, 434-452.

Denis, W. [rgro, r]. The Determination of Total Sulphur in Urine. J. Biol. Chem., 8, 40r-403.

Denrs, W. [Igro, 2]. The Determination of the Amid-Nitrogen in Proteins. J. Biol. Chem., 8, 427-435.

Drummond, J. C. [rgr6]. A Study of the Distribution of Nitrogen in the Proteins of Tumours and Normal Tissues. Biochem. J., 10, 473-494.

FrIedmann, E. [r899]. Ueber die Bindungsweise des Stickstoffs in primären Albumosen. Zeitschr. physiol. Chem., 29, 51-58.

Gibson, R. B. [19r2]. On the Nature of the So-called Artificial Globulin. J. Biol. Chem., 12, 6r-64.

Gortner, R. A. [rgr6]. The Origin of the Humin Formed by the Acid Hydrolysis of Pro. teins. II. Hydrolysis in the Presence of Carbohydrates and of Aldehydes. J. Biol.Chem., 26, 177-204.

Gortner, R. A., AND M. J. Blish [1915]. On the Origin of the Humin Formed by the Acid Hydrolysis of Proteins. J. Amer. Chem. Soc., 37, r630-1636.

Grindley, H. S., W. E. Joseph and M. E. Slater [19r5]. The Quantitative Determination of the Amino Acids of Feeding-Stuffs by the Van Slyke Method. J. Amer. Chem. Soc., 37, 1778-r78r.

Grindley, H. S., AND M. E. Slater [I9I5]. The Quantitative Determination of the Amino Acids of Feeding-Stuffs by the Van Slyke Method. II. J. Amer. Chem. Soc., 37, 2762-2769.

GüMBEL, T. [1904]. Ueber die Verteilung des Stickstoffs im Eiweissmolekül. Beitr. chem. Physiol. Path., 5, 297-3 r2.

HART, E. [IgOI]. Ueber die quantitative Bestimmung der Spaltungsprodukte von Eiweisskörpern.

Zeitschr. physiol. Chem., 33, 347-362.

HART, E. B., AND B. SURE [1916]. The Influence of Carbohydrates on the Accuracy of the Van Slyke Method in the Hydrolysis of Casein. I. Biol. Chem., 28, 241-249.

Hartley, P. [rgI4]. The Determination of the Composition of the Different Proteins of $O x$ and Horse Serum by the Method of Van Slyke. Brochem. J., 8, 54r-552. 


\section{I64 THE CHEMICAL CONSTITUTION OF THE PROTEINS}

Hausmann, W. [I899]. Ueber die Vertheilung des Stickstoffs im Eiweissmolekül. Zeitschr. physiol. Chem., 27, 95-ro8.

Hausmann, W. [Igoo]. Ueber die Vertheilung des Stickstoffs im Eiweissmolekiil. II. Zeitschr. physiol. Chem., 29, I36-I45.

Henderson, Y. [1899]. Zur Kenntniss des durch Säuren abspaltbaren Stickstoffes der Eiweisskörper. Zeitschr. physiol. Chem., 29, 47-50.

Johns, C. O., And J. F. Brewster [1916]. Kafirin, an Alcohol-Soluble Protein from Kafir, Andropogon Sorghum.

J. Biol. Chem., 28, 59-65.

Johns, C. O., And D. Breese Jones [rgr6.] The Proteins of the Peanut, Arachis Hypogaa. J. Biol. Chem., 28, 77-87.

Johns, C. O., And D. Breese Jones [IgI7]. The Proteins of the Peanut, Arachis Hypogaa. II. The Distribution of the Basic Nitrogen in the Globulins Arachin and Conarachin.

J. Biol. Chem., 30, 33-38.

Jones, D. Breese, And C. O. Johns [Igr6]. Some Proteins from the Fack Bean, Canavalia Ensiformis.

J. Biol. Chem., 28, 67-76.

KLeIN, D. [rgrr]. An Improved Apparatus for the Determination of Amino Groups. J. Biol. Chem., I0, 287-289.

Kocher, R. A. [rgr5]. The Hexone Bases of Malignant Tumours.

J. Biol. Chem., 22, 295-303.

Kutscher, Fr. [I9oo]. Ueber die Verwendung der Phosphorwolfrumsäure bei quantitativen Bestimmungen der Spaltungsprodukte des Eiweisses.

Zeitschr. physiol. Chem., 3I, 2I5-226.

MoLL, L. [1904, I906]. Ueber künstliche Umwandlung von Albumin in Globulin.

Beitr. chem. Physiol. Path., 4, 563-577; 7, 3 I I-3r2.

Nollau, E. H. [IgI5]. The Amino Acid Content of Certain Commercial Feeding-Stuffs and other Sources of Protein.

J. Biol. Chem., 2I, 6rr-6r4.

Osborne, T. B., And I. F. Harris [Ig03]. Nitrogen in Protein Bodies.

J. Amer. Chem. Soc., 25, 323-353.

Osborne, T. B., C. S. Leavenworth and C. A. Brautlecht [1908]. The Different Forms of Nitrogen in Proteins.

Amer. J. Physiol., 23, r80-200.

Osborne, T. B., D. D. van Slyke, C. S. Leavenworth and M. Vinograd [IgI5]. Some Products of Hydrolysis of Gliadin, Lactalbumin and the Protein of the Rice Kernel.

J. Biol. Chem., 22, 259-280.

Plimmer, R. H. A. [Igo8]. The Proteins of Egg-Yolk.

J, Chem. Soc., 93, I500-I506.

Plimmer, R. H. A. [rgr6]. The Analysis of Proteins. I. The Estimation of Arginine by Decomposition with Alkali.

Biochem. J., I0, Ir5-rig.

Rothera, C. 'H. [Ig04]. Zur Kenntniss der Stickstoffbindung im Eiweiss.

Beitr. chem. Physiol. Path., 5, 442-448.

Sachsse, R., und W. Kormann [1875]. Ueber eine Methode zur quantitativen Bestimmung einiger Amide mittels salpetriger Säure.

Landw. Versuchsstat., I7, 32I-328; Zeitschr. anal. Chem., I4, 380-383.

Schulze, E., und E. Winterstein [Igor, 2]. Ueber das Verhalten einiger Monoaminosäuren gegen Phosphorwolframsäure.

Zeitschr. physiol. Chem., 33, 574-578.

Sjollema, B., und I. J. Rinkes [IgII-I2]. See under Results of Hydrolysis. B. Vegetable Globulins. 
Van Slyke, D. D. [rgro, r]. A Method for the Determination of Amino Nitrogen and its Applications.

J. Biol. Chem., 7, Proc., xxxiv-xxxvi.

VAN Slyke, D. D. [1910, 2]. Eine Methode zur quantitativen Bestimmung der aliphatischen Aminogruppen; einige Anwendungen derselben in der Chemie der Proteine, des Harns und der Enzyme.

Ber. d. Deutsch. chem. Ges., 43, 3170-318r.

VAN Slyke, D. D. [IgrI, r]. Nachtrag zu meiner Mitteilung über die Bestimmung von Aminogruppen in Aminoverbindungen und im Harn, sowie über eine Methode zur Analyse von Proteinen.

Ber. Deutsch. chem. Ges., 44, r684-r692.

Van Slyke, D. D. [rgrr, 2]. A Method for the Quantitative Determination of Aliphatic Amino Groups. Applications to the Study of Proteolysis and Proteolytic Products. J. Biol. Chem., 9, 185-204.

VAn Slyke, D. D. [Igrr, 4]. The Analysis of Proteins by Determination of the Chemical Groups Characteristic of the Different Amino Acids. J. Biol. Chem., ro, I5-55.

Van Slyke, D. D. [IgI2, I]. The Quantitative Deternination of Aliphatic Amino Groups. II. J. Biol. Chem., r2, 275-284.

Van Slyke, D. D. [1913, r]. The Gasometric Determination of Aliphatic Amino-nitrogen in Minute Quantities.

J. Biol. Chem., I6, 121-124.

VAN Slyke, D. D. [1913, 2]. The Hexone Bases of Casein.

J. Biol. Chem., I6, 531-538.

VAN Slyke, D. D. [1915, I]. Improvements in the Method of Analysis of Proteins by Determination of the Chemical Groups Characteristic of the Different Amino Acids. J. Biol. Chem., 22, 28I-285.

Van Slyke, D. D. [1915, 2]. Note on the Micro-method for Gasometric Determination of Aliphatic Amino Nitrogen.

J. Biol. Chem., 23, 407-409.

Van Slyke, D. D. [I9I5, 3]. Analysis of Proteins by Determination of the Chemical Groups Characteristic of the Different Amino Acids. A Correction.

J. Biol. Chem., 23, 4Ir.

Wakeman, A. J. [1905, r]. Ueber die chemische Veränderung der Leber bei der Phosphorvergiftung.

Zeitschr. physiol. Chem., 44, 335-340.

Wakeman, A. J. [1905, 2]. Ueber die Verteilung des Stickstoffs in der Leber des Störs. Zeitschr. physiol. Chem., 44, 34r.

Wakeman, A. J. [1908]. Estimations of Arginin, Lysin and Histidin in Products of Hydrolysis of Various Animal Tissues.

J. Biol. Chem., 4, IIg-I47.

Wetzel, G. [19oo]. Die organischen Substanzen der Schaalen von Mytilus und Pinna. Zeitschr. physiol. Chem., 29, 386-410. 



\section{INDEX.}

Acid albumin, 2.

- amide groups, 4.

Adamkiewicz-Hopkins reaction, 28.

Alanine, $5,7,38,7 \mathrm{r}, 77,79,82,85,89$.

-, amount in proteins, III-I3O.

-, characterisation, $5 \mathrm{I}$.

-, constitution, 2.

-, ester, 38, 42, 5 I.

-, in humin formation, 65 .

-, isolation, $44,45,48-50$.

-, loss during analysis, $67,68,69$.

-, phosphotungstate, 48 .

-, separation from glycine, $5 \mathrm{I}$.

-, - - valine, 48-50.

Albumins, $x, 73,76$.

-, composition, II3.

-, tryptophan, $3 \mathrm{I}$.

-, vegetable, $\mathrm{I}, 74$.

-, - composition, II8.

,,$-- N$ distribution, I3 $1,132, I_{33}$.

Albumose, 2.

Aldehydes in humin formation, 66 .

Alfafa hay, $\mathrm{N}$ distribution, $\mathbf{I} 34$.

Alkali globulin, 2.

Amandin, $\mathrm{x}, 75$.

$\rightarrow$ composition, II7.

-, $\mathrm{N}$ distribution, $\mathrm{I}_{3} \mathrm{I}$.

-, tyrosine, 20, 23.

Amide nitrogen, $4,64,74,75,85,86$. See also Ammonia.

- -, analytical data, III-I30, I3I-I35.

- - estimation, $15,55-56,87-88,97-98$, I05.

Amino-acetic acid, 2.

Amino acid anhydrides, 54 .

Aminobutyric acid, 5.

Aminocaproic acid, 5 .

Aminoglutaric acid, 3 .

Aminoguanidinevalerianic acid, 3 .

Aminoisobutyric acid, 5.

Amino-isocaproic acid, 3 .

Amino-isovalerianic acid, 2.

Amino-methyl-ethyl propionic acid, 3 .

Amino nitrogen, 44, 64, 85 .

- - estimation, Sörensen's method, I2-I4. - - - Van Slyke's method, r2, 89-96,

Aminopropionic acid, 2.

Amino succinic acid, 3 .

Aminovalerianic acid, 71 .

Ammonia, 4, 64, 74, 75, 94.

-, amount in proteins, III-I30, I3I-I35.

_, estimation, $15,55-56,85,88,97-98$.
Amyloid, composition, I29.

Analysis, by $\mathrm{N}$ distribution, 85-110.

-, loss during, 63-69.

-, results, 63-84.

Analytical data, III-I35.

Anhydrides of amino acids, 54 .

Antiaris toxicaria, protein, 82.

- - - composition, I29.

Antipeptone, I4

Arachin, composition, II7.

-, $\mathrm{N}$ distribution, $\mathrm{I}_{3} \mathrm{r}, \mathrm{r}_{32}$.

Arginine, 70, 7x, 72, 73, 74, 75, 79, 81, 82, 83,85 , Iog.

一, amount in proteins, I08, III-I3o.

-, constitution, 3 .

-, estimation, $55,59,85$, IoI-I02, ro7, ro8.

-, in humin formation, 65 .

-, isolation, $55,56-57,59$.

-, nitrogen, 70,85 , 103.

- - analytical data, I32-r35.

- -, estimation, IOI-I02, I03.

- , separation from histidine, 55 .

Armadillo scales, 80.

- - composition, I25.

- - $\mathrm{N}$ distribution, $\mathrm{I} 3 \mathrm{I}$.

Asparagine, 74, 8g.

Aspartic acid, 82, 85, 86, 8 .

- $\rightarrow$ amount in proteins, III-I30.

- characterisation, 52 .

- -, constitution, 3 .

- - ester, $37,42,52,53$.

- - isolation, $34,35,52-53$.

- - loss during analysis, 67, 68, 69.

- -, separation from glutamic acid, 34 .

- - - - leucine, 53 .

Aspergillus niger, $8 \mathrm{r}$.

- -, composition, 127 .

Avenin, composition, II8.

Azolitmin paper, ro6.

Azotobacter, 8I.

-, composition, I27.

BACILLI, $8 \mathrm{I}$.

-, composition, 127.

Barley, $\mathbf{N}$ distribution, $\mathbf{I} 34$.

Bau-steine, 4.

Bence-Jones protein, 25, 73.

- - - composition, II4.

Benzaldehyde in humin formation, 66.

Betaine, 69.

Betaines of amino acids, 69 .

Blood corpuscles, histone, $\mathbf{I}, 72$.

-, dried, $\mathrm{N}$ distribution, $\mathrm{I} 34$.

- meal, $\mathrm{N}$ distribution, 134 . 
Body resistant to enzymes, I4.

Brain, protein, 5 .

- - composition, 128 .

Bread, tryptophan, 3 I.

Bromination of tryptophan, 22, 28, 32 .

- - tyrosine, 22-23.

Canavalin, $\mathrm{N}$ distribution, I3I.

Caproic acid, 5.

Carapace, tortoise, 77,80 .

- - composition, 125 .

Carbohydrate in proteins, 2, 6-7.

Carbohydrates in humin formation, $65-67$, Iro.

- in N distribution, Iro, $\mathrm{I}_{35}$.

Carcinoma, rog.

-, tryptophan, 29, 30 .

Caseanic acid, 5 .

Caseinic acid, 5 .

Casein-kyrin, 83.

Caseinogen, I, 5, 6, r2, I9, 2r, 33, 35, 44, 63, $64,65,69,76,81,83$, 107, ro9, rro.

-, composition, 86, $\mathbf{1 2 0}$.

-, derivatives, 83 .

-, N distribution, I3I, I32, 135 .

-, tryptophan, 27, 29, 30, 31, 32.

-, tyrosine, I9, $20,23$.

Caseoglutin, tryptophan, $3 \mathrm{I}$.

Caseoses, 2, 83.

Cattle foodstuffs, rog.

-, $\mathrm{N}$ distribution, $\mathrm{I}_{34}$.

Centrophorus-histone, composition, II 2.

Chicken muscle, 8 I.

- - composition, I29.

-, $\mathrm{N}$ distribution, I3I, I33.

Chromoproteins, $\mathbf{r}$.

Clupeine, $\mathrm{r}, 70,7 \mathrm{r}$.

-, composition, IIr.

Clupeovin, composition, I2O.

Collagen, $\mathrm{x}$.

Colorimetric estimation of histidine, 6I-62.

- - - tryptophan, 28-3r.'

- - tyrosine, 20-2I.

Colostrum proteins, ro8-ro9.

$-\ldots, \mathrm{N}$ distribution, $\mathrm{r}_{22}$.

Completion of hydrolysis, 12.

Composition, elementary, 2.

Composition of albumins, Ir3.

- - - vegetable, Ir8.

- - gliadins, rig.

- - globulins, Ir4.

- - , vegetable, II5-II7.

- - glutelins, Ir8.

- - histones, Ir2.

- - phosphoproteins, I2O.

- - protamines, III.

- - protein derivatives, Iзо.

- - scleroproteins, I2I-I26.

- various proteins, I27-1 30 .

Conalbumin, $\mathrm{x}$.

$\rightarrow, \mathrm{N}$ distribution, $\mathrm{r}$ Ir.

-, tyrosine, 20.

Conarachin, composition, II 7 .

-, N distribution, I3I, $\mathrm{I}_{32}$.

Conchiolin, N distribution, I3r.

Conglutin, $\mathrm{x}$.
Conglutin, composition, Ir7.

-, $\mathrm{N}$ distribution, $\mathrm{I3} \mathrm{r}$.

-, tryptophan, $3^{\text {I. }}$

-, tyrosine, 23.

Conjugated proteins, $\mathbf{I}$.

Corylin, $\mathrm{N}$ distribution, $\mathrm{I} 3 \mathrm{I}$.

$\longrightarrow$ tyrosine, 20.

Cotton-seed Meal, N distribution, 134 .

Cow-Pea Meal, N distribution, I34.

Crenilabrine, composition, III.

Cyclic bases, formation, 65,66 .

Cyclopterine, $\mathrm{r}, 7 \mathrm{r}$.

-, composition, Irr.

Cyprinine, $\mathbf{x}, \mathbf{7}$.

-, composition, Irr.

Cystine, $\mathrm{I}_{5}, \mathrm{I7}_{7}$ 27, 28, 79, 80, 82, 94, 97, 102, 108 .

-, amount in proteins, III-I3O.

-, constitution, 3 .

-, estimation, $24-26,85,103$.

- , in humin formation, 65 .

-, isolation, 24-26.

-, loss during analysis, 68-69.

-, nitrogen, 85 .

-, - , analytical data, I32-I35.

-, -, estimation, 102-I07.

-, separation from tyrosine, 25-26.

Derivatives of proteins, $2,82-84$.

- - , composition, $\mathbf{1}_{3}$.

- - $\mathrm{N}$ distribution, $\mathrm{I} 3 \mathrm{I}$.

Deutero-albumose, composition, 130 .

- $\rightarrow \mathrm{N}$ distribution, $\mathrm{I}_{3} \mathrm{I}$.

Diamino acids, $4,7,15,18,19,39,70,71$, $72,75,78,79,83$, 109, тго.

- - esters, 38 .

- -, estimation, 55-62, 85-86, 98-104, 108.

- -, isolation, 55-6r.

- -, list, 3 .

-, loss during analysis, 63 .

- - nitrogen, 85,86 , 108 .

- - , - analytical data, I3I.

- -, -, estimation, 88, 102.

-, origin in fish sperm, $7 \mathrm{I}$.

-

- - , separation, $55-62$.

Diamino-adipic acid, 5 .

Diaminocaproic acid, 3 .

Diamino-glutaric acid, 5 .

Diaminotrioxydodecanic acid, 5, 6, 63 .

Diazobenzenesulphonic acid reaction in histidine estimation, $6 \mathrm{r}-62$.

Dicysteine, 3.

Differentiation of proteins by $\mathrm{N}$ distribution, 85-riro.

Digestion of proteins, 4 .

Dihydroxy-diaminosuberic acid, 5 .

Dihydroxyphenylalanine, 6 .

Di-iodotyrosine, 6.

Dimethylaminobenzaldehyde in tryptophan estimation, 30-3I.

Dimethyl-glutamic acid, 69.

Diphtheria bacillus, $8 \mathrm{r}$.

- composition, 127 .

Distillation, in vacuo, fractional, 40-42. 
Distillation, in vacuo, loss during, 67. - residue, 54 .

Distillers' grains, $\mathbf{N}$ distribution, I34.

Distribution of nitrogen, 85-I Io.

_ _ , analytical data, I3I-135.

Di-thio-aminopropionic acid, 3.

Edestin, I, 74, ro7.

-, composition, 83 , II5.

-, N distribution, I3r, 132.

-, tryptophan, 29, 3I.

-, tyrosine, 20, 22, 23.

Egg-albumin, I, 5, 7, 64, 73, 84 .

-, composition, 83 , Ir3.

-, $\mathrm{N}$ distribution, $\mathrm{I} 3 \mathrm{I}$.

-, tryptophan, $3 \mathbf{I}$.

-, tyrosine, 20.

Egg-membrane, $\mathrm{I}, 24,80$.

-, composition, 124 .

-, N distribution, $\mathrm{I} 3 \mathrm{I}$.

Egg-white, 73.

Elastin, $\mathrm{I}, 5,79,80$.

-, composition, 124 .

-, tryptophan, 3 I.

Elastose, composition, Ізо.

Elementary composition, 2, 84 .

Elephant epidermis, 80.

- -, composition, 125 .

-, $\mathrm{N}$ distribution, I3I.

Engeland's methylation method, 44, 69.

Enzymes in hydrolysis, 9, 14, 15, 19, 22, 27, 30, 3I.

Epidermis, 8o.

-, elephant, composition, 125.

-, $\mathrm{N}$ distribution, $\mathrm{I} 3 \mathrm{I}$.

-, tryptophan, 29.

Ester method, 7, 33-54.

Esterification, 35-42.

-, loss during, 67 .

Esters, extraction, 37-40.

,-- , loss during, 67.

-, fractional distillation, 40-42.

-, reconversion into amino acids, 42, 52.

Estimation of units, 15-62, 97-107.

Euglobulin, ro8, rog.

- $\mathrm{N}$ distribution, $\mathrm{r}_{32}, \mathrm{r} 33$.

Excelsin, $x, 74$.

-, composition, Ir 5 .

-, $\mathrm{N}$ distribution, I3 $\mathrm{r}$.

-, tyrosine, 23.

Feathers, $1,80$.

-, composition, 126.

Fibrin, I, 72, 1 ro.

-, composition, II4.

-, N distribution, I32, 135 .

- , tryptophan, $3 \mathbf{I}$.

Fibrinogen, $x$.

Fibrinpeptone, 2.

Fir-tree seed, protein, composition, II7.

Fish muscle, 8r, 82.

- -, composition, I29.

-, $\mathrm{N}$ distribution, I3I.

Foodstuffs, cattle, rog-r ro.

Formaldehyde in humin formation, 65,66 .
Formalin titration method of Sörensen, I2-I4.

Fractional distillation in vacuo, 40-42.

Furfural in humin formation, 66 .

\section{Gadus-histone, $\mathbf{r}$.}

- - composition, II2.

Gelatin, I, 4, 5, 7, 2r, 36, 39, 79, 80, ro7.

-, composition, 124 .

-, $\mathrm{N}$ distribution, $\mathrm{I3I}, \mathrm{I} 32$.

-, non-amino $\mathrm{N}$, 107.

-, tyrosine, 20.

Gelatin-kyrin, 83 .

Gelatin peptone, 82-83.

Gelatoses, 82.

Gliadin, rye, 75 .

-, wheat, $x, 25,63,69,75,86,107,108$.

-, 一, cystine isolation, 25.

-, -, tyrosine, 20.

Gliadins, $\mathrm{I}, 74,75$.

-, composition, 86, I08, II9.

-, N distribution, $13 \mathrm{r}, \mathbf{I}_{32}$.

Globin, 2, 72.

-, composition, II2.

Globulins, $\mathrm{x}, 20,25,73$.

-, composition, II4.

-, N distribution, I3I, I32, I33.

-, tryptophan, 3 I.

-, tyrosine, 20, 23.

-, vegetable, $\mathrm{x}, 74-75,8 \mathrm{r}$.

-, -, composition, II5-II7.

-, -, N distribution, I3I, I32.

-, 一, tryptophan, $3 \mathbf{I}$.

Gi, - tyrosine, 20, 23.

Globulose, 2.

Glucoproteines, 7 .

Glucoproteins, 2, 7, 8r.

Glucosamine, 6-7.

Glutamic acid, $33,73,74,75,76,77,79,80$, $82,83,85,86,89$.

- -, amount in proteins, III-I30.

- -, characterisation, 53 .

- - constitution, 3 .

- -, ester, 37, 42, 52.

- - hydrochloride, 33,35 .

- -, in humin formation, 65.

- -, isolation, $33-35,53$.

- , loss during analysis, $67,68,69$.

- -, separation from aspartic acid, 34 .

- - - - leucine, 34,53 .

Glutamine, 74 .

Glutelins, $\mathbf{~}, 75$.

-, composition, II8.

-, tyrosine, 20.

Gluten, 75 .

一, composition, 118 .

-, flour, $\mathrm{N}$ distribution, 134 .

-, N distribution, $\mathrm{x} 34$.

-, tryptophan, $3 \mathrm{I}$.

Glutencasein, tryptophan, $3 \mathrm{I}$.

Glutenin, $x, 75$.

-, composition, II8.

-, $\mathrm{N}$ distribution, I3I.

- tyrosine, 20.

Glycine, $5,8,33,44,50,73,75,76,77,78$, $79,80,82,83,85,89,94$.

- , amount in proteins, III-I3O. 
Glycine, constitution, 2.

-, ester, $38,40,42$.

-, 一, hydrochloride, $36,38,5$ r.

-, estimation, 36-37.

-, in humin formation, 65.

-, isolation, $36,38,44,45$.

-, loss during analysis, 67, 68.

-, phosphotungstate, 48 .

- picrate, $5 \mathbf{I}$.

- , separation from alanine, $5 x$.

Glycinin, composition, I 6 .

-, N distribution, I3I.

- , tyrosine, 20, 23.

Glycocoll, see glycine.

Glycoleucine, 5 .

Glycyl-alanine, 2.

Goose feathers, 80.

Grey matter, brain, 128 .

Hemocyanin, N distribution, 132.

Hæmoglobin, I, 2, 72, ro7.

-, composition of globin, II2.

-, N distribution, $\mathrm{I} 3 \mathrm{I}, \mathrm{I} 32$.

Hair, I, 20, 24, 79, 80, I07.

-, composition, 126.

-, N distribution, I32.

-, tryptophan, 29.

-, tyrosine, 20.

Hemi-elastin, composition, $\mathbf{1} 30$.

Hemp seed, $\mathrm{N}$ distribution, $\mathrm{I}_{34}$.

Hetero-albumose, $8 \mathbf{8}$.

-, composition, I30.

-, N distribution, I3 $\mathrm{I}$.

Heterocyclic compounds, 3-4, 85 .

Hexone bases, I5, 63, 70, 83, 85, ro9, г го.

- -, total N, 88, I02.

- - separation, 55-62.

Hickory Nut, $\mathrm{N}$ distribution, I34.

Histidine, $4, \mathrm{I}_{5}, 65,70,7 \mathrm{I}, 72,73,74,75$, $79,82,83,85$, 102, го3, 104, 108.

一, amount in proteins, I08, III-I30.

-, constitution, 3 .

-, diazobenzene sulphonic acid reaction, $6 r-62$.

-, estimation, $55,5^{6-5^{8}}, 6 \mathrm{r}-62,85$.

-, in humin formation, 65 .

- , isolation, $55,56-58$.

-, nitrogen, 70,85 .

-, -, analytical data, I32-I35.

-, 一, estimation, I03-I04, I07.

-, separation from arginine, 55 .

Histones, r, 2, 7x, 72.

-, composition, Ir2.

Hordein, I, 75.

- composition, IIg.

-, N distribution, I3I.

-, tyrosine, 20.

Horn, I, 20, 24, 80 .

-, composition, 126 .

-, N distribution, I3I.

-, tryptophan, 29.

$\rightarrow$ tyrosine, 20.

Horse serum proteins, $\mathrm{N}$ distribution, 133.

Humin nitrogen, 98, I05, I Io.

- - analytical data, I3I-135.

_- estimation, $55-56,88,98$, I05, 107.
Humin nitrogen, formation, $9,64,65-67$.

Hydrolysis, 7, 9-14, 55, 63, 64, 97.

-, by alkalies, $\mathrm{II}$.

-, by baryta, 9,32 .

-, by enzymes, 9, I4, I5, I9, 22, 27, 30, $3 \mathrm{I}, 64$.

-, by hydrochloric acid, 9-10, II, I7, I8, $24,33,34,64,87,97$, ro5.

-, by hydrofluoric acid, II.

-, by sulphuric acid, 9 , II, I5, I7, I8, 33, 34,55 .

-, completion of, $12,64,97$.

-, loss during, $63-65$.

- , oxidation during, 84 .

Hydroxyaminopropionic acid, 3 .

Hydroxyaminosuberic acid, 5 .

Hydroxyaminosuccinic acid, 5 .

Hydroxydiaminosebacic acid, 5 .

Hydroxyphenylaminopropionic acid, 3.

Hydroxypyrrolidinecarboxylic acid, 3.

ICHTHULIN, $x, 76$.

-, composition, 120.

Ichthylepidin, composition, 125.

Imidazole-aminopropionic acid, 3 .

Indole, 30.

Indole-aminopropionic acid, 4.

Infusoria, phosphorescent, composition, 127.

Iodoform from spongin, 65 .

Isolation of units, I5-6r.

Isoleucine, $5,76,85$.

-, amount in proteins, 68 , III-I30.

- constitution, 3 .

一, isolation, 44-46, 47-48.

-, loss during analysis, 68.

-, separation from leucine, 47-48.

-, _ - valine, 45-46.

KAFIRIN, 75.

-, composition, IIg.

-, $\mathrm{N}$ distribution, $\mathrm{I} 3 \mathrm{r}$.

Keratins, I, 24, 79-80.

-, composition, $\mathbf{1 2 6 .}$

-, N distribution, I3I, 132 .

-, tryptophan, 29, 3 I.

Koilin, 80.

-, composition, I24.

,$- \mathrm{N}$ distribution, $\mathrm{I}_{3} \mathrm{r}$.

Kossel's method, 55-6r.

Kyrins, 83 .

LACTALbUMin, 73, I09, Iro.

-, composition, I08, II3.

-, N distribution, $\mathrm{I32}, \mathrm{I} 35$.

-, tryptophan, 29, 30, 31 .

-, tyrosine, 20.

Lactoglobulin, rog.

$\longrightarrow$ N distribution, 132 .

Legumelin, 74, 75 .

-, composition, Ir8.

-, N distribution, $\mathrm{I} 3 \mathrm{I}$.

Legumin, $I, 74,75$.

-, composition, I 6 .

- $\mathrm{N}$ distribution, $\mathrm{I} 3 \mathrm{r}$.

-, tryptophan, 31 .

-, tyrosine, 20, 23. 
Leuceines, 7.

Leucine, $5, \mathrm{r} 8,38,48,75,79,82,85,89$.

- , amount in proteins, 68, I I I-I30.

-, constitution, 3 .

-, fraction, 5 .

-, ester, 38, 42, 53.

-, in humin formation, 65 .

-, isolation, $44-46,47-48$.

-, loss during analysis, $67,68,69$.

-, separation from aspartic acid, 53.

-, - - glutamic acid, 34 .

-, - - isoleucine, 47-48.

-, - - tyrosine, 18 .

-, - - valine, $45-46$.

Leucininide, 54 .

Leucosin, 74 .

-, composition, II8.

-, $\mathrm{N}$ distribution, I3I.

Leucyl-glutamic acid, 2.

Linseed protein, 75 .

- - composition, II7.

Liver nucleoprotein, composition, 128.

Liver, protein, 5, 29.

-, N distribution, 133 .

-, tryptophan, 29.

Livetin, $\mathrm{N}$ distribution, $\mathbf{I} 3 \mathbf{I}$.

Loss during analysis, 63-69.

Lota-histone, $\mathrm{I}$.

-, composition, Ir2.

Lysalbic acid, 83,84 .

Lysine, $\mathrm{rg}, 70,7 \mathrm{r}, 73,74,75,8 \mathrm{r}, 82,83,85$, 94,107, 109.

-, amount in proteins, Io8, III-I30.

-, constitution, 3 .

-, estimation, $55,60-6 \mathrm{x}, 85$, I04.

-, in humin formation, 65 .

-, isolation, $55,56,60-6 \mathrm{r}$.

-, nitrogen, 85 .

-, _, analytical data, I32-I35.

-, -, estimation, I04, I07.

-, separation from arginine and histidine, 55,60 .

Maize-Glutelin, tyrosine, 20.

Maize-glutenin, composition, II8.

- kernel, $\mathrm{N}$ distribution, 134 .

Melanin, 24, 36, 55, 65-67. See Humin.

Membrane, fat particles of milk, $8 \mathrm{r}$.

Metaproteins, 2.

Methylamine, 94

Methylation method, Engeland, 44, 69.

Methylene compound of amino acids, I2.

Methylhygric acid, 69 .

Micro-organisms, $8 \mathrm{x}$.

-, composition, 127.

Milk, membrane of fat particles, $8 \mathrm{r}$.

-, proteins of, ro8-rog.

,,$-- \mathrm{N}$ distribution, $\mathbf{I} 32$.

$\rightarrow$ tryptophan, $3 \mathrm{I}$.

Mono-amino acids, $5,7, \mathbf{1 5}, 16,70,71,72,78$.

- - isolation, 33-54.

- -, list, 2-3.

_ - loss during analysis, 63-69, Iro.

— -, nitrogen, $70,85,86$, I04, Iog.

- - -, analytical data, I3I-I35.

_- - , estimation, 87-88, 104, I07.
Mono-amino dicarboxylic acids, estimation, 85-86, 104-106.

Mucin, 2, 8r.

Mulberry leaves, 78 .

- - composition, 123 .

Muscle, $1,81,82$.

-, composition, I29.

$\rightarrow, \mathrm{N}$ distribution, I3I, I33.

Mycobacterium, $8 \mathrm{r}$.

- , composition, 127.

Myosin, $\mathbf{I}$.

Myosinogen, $\mathbf{r}$.

NaIL, 8o.

-, tryptophan, 29.

Nervous tissue, protein, 5,82 .

- -, 一, composition, I28.

Neurokeratin, composition, 124 .

Nitrogen, amide, $4,64,74,75,85,86,94$.

,-- , analytical data, III-I30, I3 I-I35.

-, 一, estimation, $15,55-56,87-88,97-8$, I05.

- amino, $44,64,85$.

_, - estimation, Sörensen's method, I2I4.

_, _, _, Van Slyke's method, 89-96.

-, arginine, 70, 85, 103.

-, 一, analytical data, I32-135.

-, -, estimation, IOI-IO2, I03.

-, cystine, 85 .

-, - analytical data, I32-r35.

-, - , estimation, I02-103, I07.

-, diamino, 85, 86, 108.

-, -, analytical data, I3I.

,- -, estimation, 88 , 102.

-, distribution, 85-I Io.

,-- , analytical data, I3I-r35.

—, histidine, 70,85 .

-, 一, analytical data, I32-I35.

-, - -, estimation, 103-104, 107.

-, humin, 98, ro5, rro.

-, -, analytical data, I3I-I35.

-, - estimation, $55-56,88,98$, 105, 107.

-, lysine, 85 .

-, - , analytical data, r32-r35.

-, - estimation, 104,107 .

一, mono-amino, 70, 85, 86, ro4, rog.

-, - , analytical data, I3 I-I35.

-, - , estimation, 87-88, 104, 107.

-, non-amino, 85, 103, Iog.

-, -, analytical data, I3 I-I35.

-, - -, estimation, 103, 104, ro7.

-, total, 4 .

-, -, analytical data, I3I.

Nitrous acid, action of, 85 .

Non-amino nitrogen, 85 , ro3, rog.

- -, analytical data, I32-I35.

- - estimation, I03, I04, I07.

Norleucine, 5, 82 .

Nucleic acid, I, 2, 71, 72 .

Nucleoprotein, liver, composition, I28.

Nucleoproteins, I, 2.

OAT-GLIADIN, N distribution, I3r.

Oats, $\mathrm{N}$ distribution, $\mathrm{I}_{34}$.

Oryzenin, $\mathrm{r}, 75$. 
Oryzenin, composition, $\operatorname{Ir} 8$. ,$- \mathrm{N}$ distribution, $\mathrm{I}_{32}$.

Ovalbumin, see Egg-albumin. Ovokeratin, 78.

-, composition, I24.

Ovomucoid, 2, 20.

-, composition, 128 .

-, tyrosine, 20.

Oxidation during hydrolysis, 84 .

Ox muscle, 8r.

-, composition, I29.

,$- \mathrm{N}$ distribution, $\mathrm{I} 3 \mathrm{r}$.

Ox serum, proteins, $\mathrm{N}$ distribution, $\mathrm{I} 33$.

Oxyproline, 8, I5, 2I, 74, 79, 85 .

-, amount in proteins, III-I3O.

-, characterisation, 54 .

-, constitution, 3 .

-, isolation, 54 .

-, loss during analysis, 68.

Oxytryptophan, 6, 2 I.

\section{Paramucin, 8r.}

-, composition, I28.

Pathological tissues, Iog.

-, $\mathrm{N}$ distribution, $\mathrm{I} 33$.

Peanut, proteins, 75 .

,$- \mathrm{N}$ distribution, $\mathrm{I} 34$.

Pecan, $\mathrm{N}$ distribution, $\mathrm{I} 34$.

Pepsin, composition, I28.

Peptone Roche, tyrosine, 23.

Peptones, 2, 83 .

-, composition, 83 , rзo.

Percine, 70, $7 \mathbf{r}$.

-, composition, IIr.

Peripheral nerves, composition, 128.

Phaseolin, composition, Ir6.

-, N distribution, I3I.

-, tyrosine, 20.

Phenylalanine, $7, \mathrm{x} 4,52,73,79,80,81,82$, $83,85,86,89$.

-, amount in proteins, III-I3o.

-, characterisation, 52 .

-, constitution, 3 .

-, ester, 42, 52, 53 .

- in humin formation, 65 .

-, isolation, 52 .

- , loss during analysis, 69 .

Phenylaminopropionic acid, 3 .

Phosphoproteins, $\mathrm{x}, 2,76$.

-, composition, r2o.

,$- \mathrm{N}$ distribution, I3I, I32.

Phosphorescent infusoria, 8I.

- - composition, I27.

Phosphotungstic acid precipitation, r6, 25 $32,48,54,6 I, 87,88,98-99$.

Phosphotungstic-phosphomolybdic reagent for tyrosine estimation, 20.

Pinus Koraiensis protein, composition, II7.

Placenta, composition, I29.

Plastein, 84

-, composition, гзо.

Polypeptides, 2, 8, 82 .

Potato, globulin, composition, II7.

,,$-- \mathrm{N}$ distribution, $\mathrm{I}_{32}$.

Prolamines, 75 .
Proline, 8, I4, I5, 43, 45, 69, 7x, 75, 79, 82, 83,85, ro7.

-, amount in proteins, III-I3O.

-, characterisation, 43 .

-, constitution, 3 .

-, copper salt, 43 .

-, ester, 42.

-, estimation, 43-44.

$\rightarrow$, in humin formation, 65 .

-, isolation, 43 .

-, loss during analysis, 68, 69 .

Protalbic acid, 83, 84.

Protamine nucleus, $7 \mathrm{I}$.

Protamines, I, 2, 63, 70-71, 72 .

$\rightarrow$ composition, Irr.

-, $\mathrm{N}$ distribution, 70 .

Proteins, differentiation by $\mathrm{N}$ distribution, I3I-I35.

-, elementary composition, 2.

-, various, $8 \mathrm{I}-82$.

-, -, composition, IrI-r3o.

Proteoses, 2, 82-84.

-, composition, 130 .

-, N distribution, I3I.

Proto-albumose, 83 .

-, composition, rзo.

$\rightarrow \mathrm{N}$ distribution, $\mathrm{I} 3 \mathrm{I}$.

Pseudoglobulin, ro8, rog.

,$- \mathrm{N}$ distribution, I32, I33.

Pseudomucin, 8r.

- composition, I28.

Purines, 2, 72, 94 .

Pyridine, origin in coal tar, $65,66$.

Pyrimidines, 2, 94.

Pyrrolidine carboxylic acid, 3 .

Pyrrolidone carboxylic acid, 34, 35, 67.

RANOVIN, composition, I20.

Residue from ester distillation, 54 .

Resistant body to enzymes, $\mathrm{I}_{4}$.

Results of analysis, $63-84$.

Rice, $\mathrm{N}$ distribution, $\mathrm{r}_{34}$.

- protein, 75 .

- - composition, Ir8.

-, $\mathrm{N}$ distribution, $\mathrm{I} 32$.

Rye-gliadin, 75 .

- , composition, rI9.

- -, N distribution, I3I.

- grain, $\mathrm{N}$ distribution, $\mathrm{I}_{34}$.

Salmine, $\mathrm{r}, 4,70,7 \mathrm{r}$.

-, composition, III.

Sarcoma, tryptophan, 29.

Scales, armadillo, fish, snake, composition, 125.

,,,,$---- \mathrm{N}$ distribution, I3I.

Scallop muscle, $8 r$.

- -, composition, I29.

- , $\mathrm{N}$ distribution, $\mathrm{I} 3 \mathrm{I}$.

Scleroproteins, $x, 69,77-80$.

-, composition, I2I-r26.

-, N distribution, I3I-I32.

Scombrine, $\mathbf{I}$.

-, composition, Irr.

Separation of amino acids into groups, $x_{5}, 85$.

Serine, 7, 7r, 77, 79 . 
Serine, amount in proteins, IrI-rзo.

-, characterisation, 53-54.

-, constitution, 3 .

-, ester, 42,52 .

-, isolation, 53-54.

-, loss during analysis, 68, 69 .

Serum-albumin, $x, 7,73$, ro8, rog.

一, composition, II3. $_{3}$.

-, N distribution, I08, I3I, I32.

Serum-globulin, I, 73, r08, rog.

-, composition, 83 , II4.

$\longrightarrow \mathrm{N}$ distribution, $108, \mathrm{I} 3 \mathbf{1}, \mathrm{r}_{32}$.

-, proteins, 108.

,,$-- \mathrm{N}$ distribution, $\mathrm{I} 33$.

Silk, 77-79.

-, composition, 122, I23.

Silk-fibroin, $1,63,77$.

-, composition, I2I, I22.

-, N distribution, I3 $\mathrm{r}$.

-, tyrosine, 23.

Silk-gelatin, $\mathrm{x}, 77,79$.

-, composition, I23.

-, N distribution, I3r.

Snake scales, 80 .

- - composition, I25.

- - $\mathrm{N}$ distribution, I3I.

Sörensen's titration method with formalin, I2-14.

Soy beans, N distribution, I34.

Spiders' silk-fibroin, 63 .

-, composition, I22.

Spinal cord, composition, 128.

Spongin, 69, 79.

-, composition, I24.

Squash seed globulin, composition, Ir5.

- - - cystine isolation, 25.

_ _, N distribution, I3I.

- - tryptophan, 3r.

_ - - tyrosine, $20,23$.

Sturine, $\mathbf{x}, 70,71$.

-, composition, III.

Sulphur in hydrolysis, 65 .

Sunflower seed, N distribution, I34.

Synthesis, 8.

Syntonin, 82 .

-, composition, Iзо.

TANKaGE, $\mathbf{N}$ distribution, I34.

Tetrapeptide, 2 .

Thymus-histone, $\mathbf{x}, 72$.

-, composition, Ir2.

Thynnine, composition, III.

Tissues, rog.

-, N distribution, $\mathrm{r} 33$.

Tortoise carapace, $77,80$.

- -, composition, r25.

- $\mathrm{N}$ distribution, $\mathbf{r} 3 \mathbf{r}$.

Total nitrogen, 4 .

-, analytical data, I3I.

Trimethyl-alanine, 69 .

Trimethyl-leucine, 69 .

Trimethyl-phenylalanine, 69 .

Trimethyl-valine, 69.

Tryptophan, 6, I5, 21, 22, 23, 7 I, 75, 79, 85, 86.

_, amount in proteins, $\operatorname{rrr-r3o.~}$
Tryptophan, bromination, 22, 28, 32.

-, constitution, 4 .

-, estimation, 27-32.

-, in humin formation, 65.

-, isolation, 27.

-, loss during analysis, 68,69 .

-, nitrogen, 85 .

-, separation from cystine, 27.

-, - - tyrosine, 27.

Tubercle bacilli, $8 \mathrm{r}$.

- - composition, 127.

Tumours, $8 \mathrm{r}$, rog.

-, composition, r29.

-, N distribution, $\mathrm{I} 33$.

Tyroleucine, 7 .

Tyrosine, 6, 8, I5, 24, 27, 28, 32, 35, 39, 6r, $71,73,75,76,77,78,79,80,82,83$, $85,86,89$.

-, amount in proteins, III-I3O.

-, - - - , by bromination method, 23.

-, - - - - colorimetric method, 20.

-, constitution, 3 .

-, ester, 26, 38 .

-, estimation, bromination method, 22-23.

-, - colorimetric method, 20-2I.

,-- , gravimetric method, I7-I8.

-, in humin formation, 65 .

-, isolation, I7-I9.

- , loss during analysis, 68.

-, separation from cystine, 25-26.

-, - - leucine, I8.

URAMIDO groups, 64.

Urea, 94 .

Urine protein, composition, $\mathbf{1 2 8 .}$

VALBRIANIC acid, 5 .

Valine, r8, 7r, 75, 85 .

-, amount in proteins, III-130.

-, characterisation, 46 .

-, constitution, 2.

-, ester, 42, 43 .

-, isolation, $44,45-46,48-50$.

-, loss during analysis, 68,69 .

-, phosphotungstate, $4^{8}$.

-, separation from alanine, $4^{8-50}$.

-, - - - leucine and isoleucine, 45-46.

Van Slyke's amino nitrogen method, I2, 44, $64,89-96$.

-, N distribution method, $85,97-108$.

Various proteins, $8 \mathrm{I}-82$.

- - composition, 127-r3o.

Vegetable albumins, $x, 74$.

- - composition, Ir8.

,$- \mathrm{N}$ distribution, $\mathrm{I} 3 \mathrm{I}$.

- globulins, r, 74-75, 81.

- -, composition, Ir5-II7.

- - $\mathrm{N}$ distribution, $\mathrm{I}_{3} \mathrm{I}$.

- - tyrosine, 20, 23.

- proteins, $33,74-75,8 \mathrm{r}$.

- composition, Ir5-IIg.

Vicilin, 74 .

-, composition, I 16.

-, $\mathrm{N}$ distribution, $\mathrm{r} 3 \mathrm{I}$.

Vignin, 69, 74 .

-, composition, Ir6. 
Vignin, $\mathrm{N}$ distribution, $\mathrm{I}_{3} \mathrm{r}$.

-, tyrosine, 20, 23.

Vitellin, $\mathbf{x}, 76$.

-, composition, I20.

-, N distribution, $\mathrm{r} 3 \mathrm{r}$.

-, tyrosine, 20.

WaLNUT, N distribution, 134 .

Water bacillus, $8 \mathrm{r}$.

-, composition, 127 .

Whalebone, 80.

-, composition, I25.

Wheat, bran, $\mathrm{N}$ distribution, $\mathrm{I} 34$.

,$- \mathrm{N}$ distribution, $\mathrm{I}_{34}$.

Wheat-gliadin, $\mathrm{x}, 63,69,75$, ro 7 .

-, composition, 86, 108, II9.

-, cystine isolation, 25.

-, $\mathrm{N}$ distribution, $\mathbf{1 3 2}$.

-, tyrosine, 20.

Wheat-gluten, 75 .

-, composition, II8.

-, N distribution, I3I. $^{2}$
Wheat-gluten, tryptophan, 3 I.

Wheat-glutenin, $\mathrm{x}, 75$.

-, composition, Ir8.

,$- \mathrm{N}$ distribution, $\mathrm{I} 3 \mathrm{I}$.

-, tyrosine, 20.

White matter, brain, composition, $\mathbf{r 2 8}$.

Witte's peptone, $8_{3}, 84$.

- -, composition, 130.

$\overline{-}-$, tryptophan, $3 \mathrm{r}$.

Wool, 6, 2o, 8 .

-, composition, $\mathbf{r} 26$.

-, cystine, 24.

-, tryptophan, 29.

-, tyrosine, 20, 24 .

YEAST protein, $8 \mathrm{r}$.

- - composition, 127 .

$Z_{\text {EIN, I, I9, 2I, 65 } 69,75 .}$

-, composition, 86, II9.

-, $\mathrm{N}$ distribution, $\mathrm{I} 3 \mathrm{I}$.

-, tyrosine, 20. 







THIS BOOK IS DUE ON THE LAST DATE STAMPED BELOW

AN INITIAL FINE OF 25 CENTS WILL BE ASSESSED FOR FAILURE TO RETURN THIS BOOK ON THE DATE DUE. THE PENALTY WILL INCREASE TO 50 CENTS ON THE FOURTH DAY AND TO \$1.00 ON THE SEVENTH DAY OVERDUE.

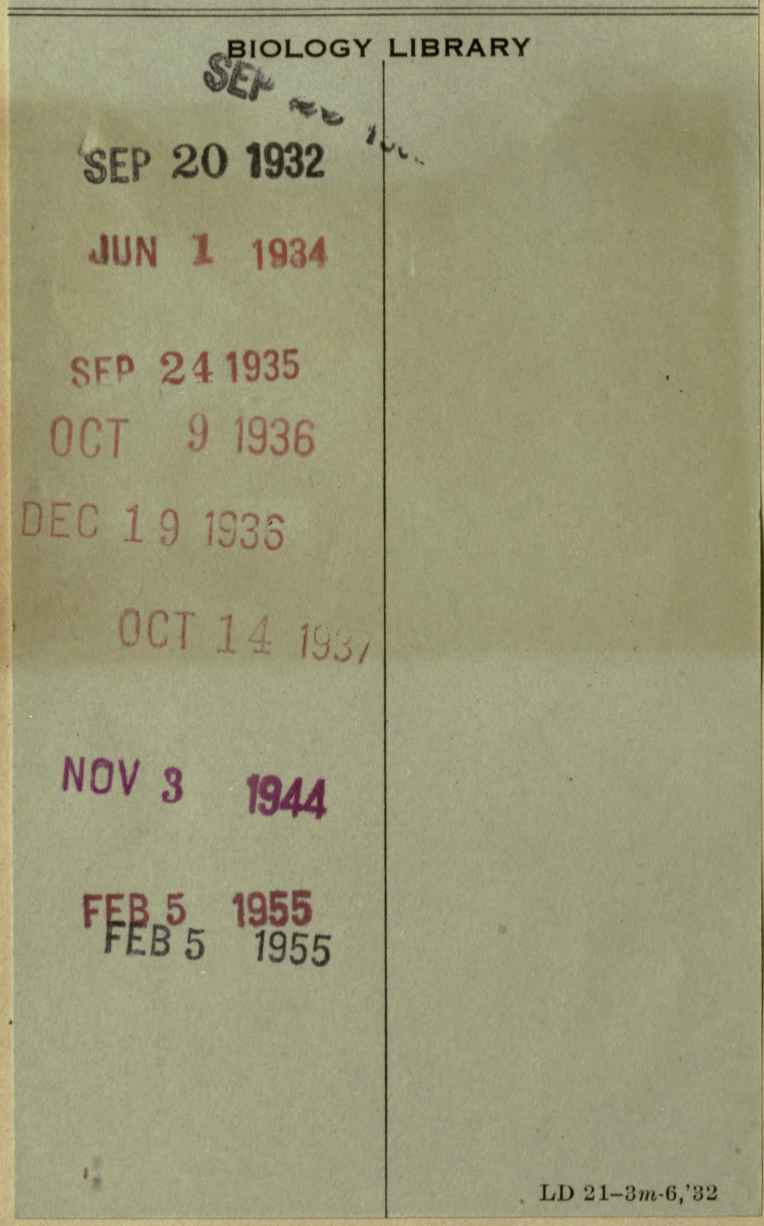




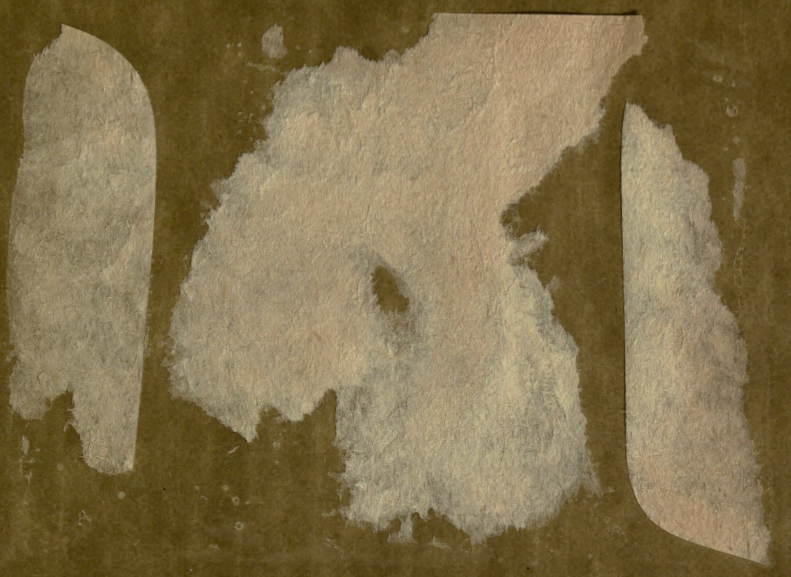


